\title{
Buying Thebes: Promoting a Cultural Commonwealth in Contemporary Anglophone Adaptations of Greek Tragedy
}

Phillip Zapkin

Follow this and additional works at: https://researchrepository.wvu.edu/etd

\section{Recommended Citation}

Zapkin, Phillip, "Buying Thebes: Promoting a Cultural Commonwealth in Contemporary Anglophone Adaptations of Greek Tragedy" (2017). Graduate Theses, Dissertations, and Problem Reports. 7027. https://researchrepository.wvu.edu/etd/7027

This Dissertation is protected by copyright and/or related rights. It has been brought to you by the The Research Repository @ WVU with permission from the rights-holder(s). You are free to use this Dissertation in any way that is permitted by the copyright and related rights legislation that applies to your use. For other uses you must obtain permission from the rights-holder(s) directly, unless additional rights are indicated by a Creative Commons license in the record and/ or on the work itself. This Dissertation has been accepted for inclusion in WVU Graduate Theses, Dissertations, and Problem Reports collection by an authorized administrator of The Research Repository @ WVU.

For more information, please contact researchrepository@mail.wvu.edu. 


\title{
Buying Thebes: \\ Promoting a Cultural Commonwealth in Contemporary Anglophone Adaptations of Greek Tragedy
}

\author{
Phillip Zapkin
}

Dissertation submitted to the

Eberly College of Arts and Sciences

at West Virginia University

in partial fulfillment of the requirements for the degree of

Doctor of Philosophy in

English Literature

Ryan Claycomb, Ph.D., Chair

Lisa Weihman, Ph.D.

Kathleen Ryan, Ph.D.

Dennis Allen, Ph.D.

Emily Klein, Ph.D.

Department of English

Morgantown, West Virginia

2017

Keywords: Adaptation, Drama, Theatre, Cosmopolitanism, Commonwealth, Greek Tragedy

Copyright 2017 Phillip Zapkin 


\section{Abstract \\ Buying Thebes: Promoting a Cultural Commonwealth in Contemporary Anglophone Adaptations of Greek Tragedy}

\section{Phillip Zapkin}

This project argues that theatrical adaptations of Greek tragedy exemplify the functioning of a cosmopolitan cultural commonwealth. Dramatists like Christine Evans, Colin Teevan, David Greig, Marina Carr, Femi Osofisan, Moira Buffini, and Yael Farber enact intercultural collaborations to reshape material from a cultural common and make that material meaningful for contemporary audiences. This collaborative ethos of drawing from shared source material undermines the logic of neoliberal late capitalism, which is premised on property ownership and individualist competition. "Buying Thebes" contributes to adaptation studies scholarship by theorizing a political economy of adaptation, combining both a formal reading of adaptation as an aesthetic practice and a political reading of adaptation as a form of resistance.

Drawing an ethical center from Kwame Anthony Appiah's work on cosmopolitanism and Michael Hardt and Antonio Negri's theory of the common, I argue that Attic tragedy forms a cultural commonwealth from which dramatists the world over can rework, reimagine, and restage materials to build new worlds through the arts. Neoliberalism imposes an economized market logic on all social and cultural interactions, which erodes possibilities for rounded humanity, democracy, and social justice. However, contemporary adapters resist these attacks both with overtly anti-capitalist content and through the aesthetic structures of adaptation and performance. Chapter I begins to theorize adaptation as a collaborative form. Chapter II traces resistance to the reduction of human beings to homo oeconomicus. Chapter III examines resistance to the erosion of democracy and a non-marketized public sphere. Chapter IV argues against the global inequality reproduced in economic (neo)colonialism. Chapter V claims Yael Farber's Molora exemplifies the hybrid cosmopolitanism that characterizes all adaptation. And finally, the Conclusion brings together the arguments from each chapter to demonstrate how theatrical adaptation performs a cosmopolitan cultural commonwealth in defiance of neoliberal political economy. 


\section{Acknowledgments}

I would like to first thank my committee members for their support, encouragement, advice, and feedback, without which this project would not have been completed. Above all, I'd like to thank Ryan Claycomb, without whom my entire academic life would probably be a shambles. Over the past six years, I could not have asked for a better mentor. I would also like to thank Katy Ryan, Lisa Weihman, and Emily Klein for their valuable chapter feedback. In addition, I appreciate the numerous discussions I've had with Dennis Allen about philosophy, theory, and psychoanalysis. Thanks to Ryan, Katy, Lisa, and Dennis for their graduate classes, which have helped shape my thinking, writing, and teaching.

Additionally, thanks for the financial support from West Virginia University and the English Department, which helped make the completion of this project possible. In particular, I am grateful for the fellowship support. Further, I would like to thank Graley Herren, editor of Text \& Presentation, for publishing an essay on David Greig based on an early draft of Chapter III; and Elizabeth Bradburn, editor of Comparative Drama, for publishing a forthcoming article on Christine Evans' Trojan Barbie and Femi Osofisan's Women of Owu.

Personally, I would like to thank my family for their support. In particular, Andi Stout, with whom I've talked, argued, and thought through much of the political economy, psychoanalysis, and other ideas here. Without our discussions/arguments, this project would not be what it is. I'd also like to thank my mother and father, Sandy and Mike Zapkin, who always supported me in my educational endeavors, and my sister, Molly, who got the siblings' share of the scientific talent and left me more of the humanities talent. 


\section{Table of Contents}

\section{Introduction}

Buying Thebes: Political Economy, Theatre, and Culture under Neoliberalism 1

McTheatre: Neoliberalism on Stage $\quad 6$

Reshaping the Human and the Social: Neoliberal Ideology at Work 10

Staging Resistance to Neoliberal Hegemony 19

\section{Chapter I}

Adaptation: Shared Cultural Myths $\quad 28$

What is Adaptation? $\quad 32$

Faithful Infidelity $\quad 44$

Why the Greeks in the $20^{\text {th }}$ and $21^{\text {st }}$ Centuries?

Global Greeks? $\quad 56$

$\begin{array}{ll}\text { The Political Economy of Adaptation } & 61\end{array}$

\section{Chapter II}

Homo Oeconomicus: Marketized People and Culture 68

Rebuilding Barbie: Bare Life and Modern Art after Troy $\quad 74$

Korinthiazomai: Colin Teevan's Alcmaeon in Corinth, the Commodification of Social

Processes, and Jouissance $\quad 92$

\section{Chapter III}

Polis No More: Atomized Consumers and the Dissolution of Common Modes of Being 109

The Communal Crisis as Crisis of Individualism in David Greig's Oedipus the

Visionary

Marina Carr's By the Bog of Cats and the Politics of Space and Family in Neoliberal

Ireland

\section{Chapter IV}

Economic (Neo)Colonialism: Disaster Capitalism Makes Globalization Go Round 150

Economic Anti-Colonialism: Protest in Two Femi Osofisan Plays 154

The God of Profit: Nation Building and Global Economics in Moira Buffini's Welcome

to Thebes

Politics of Disavowal: Neoliberal Rhetoric and Results

\section{Chapter V}

Ubuntu: Building a Better World Together

\section{Conclusion}




\section{Introduction}

\section{Buying Thebes: Political Economy, Theatre, and Culture under Neoliberalism}

In the sitting room of an American CEO's swanky home, Theseus and Theramenes discuss the collapse of the Russian economy after its transition to capitalism. When Theramenes questions the possibility of a pure market economy, Theseus replies that the problems facing the former Soviet state in the mid-90s are entirely the Russians' fault: "How're we supposed to prop them up when they've sold their whole damn system to the black market?” (Maguire 11). Taking a traditional neoliberal line, Theseus obscures the inherent connection between free market orthodoxy and the predatory stripping of Russian assets through privatization following the fall of the Soviet government. ${ }^{1}$

The conversation might seem slightly incongruous, given that Theseus and Theramenes are characters from Jean Racine’s 1677 play Phèdre. But in 1995 Matthew Maguire adapted it specifically for the context of the roaring nineties, drawing on contemporary themes like the links between sexuality, power, and finance, the ruthlessness of stock-trader and CEO international financial culture, affluenza, and exploitation. ${ }^{2}$ Of course, just as Maguire adapted his play for the 1995 premier at New York's Here Theatre, Racine had adapted his version for the $17^{\text {th }}$ century French court, drawing on Seneca's Roman tragedy, which in turn drew from Euripides' $5^{\text {th }}$ century BCE Athenian tragedy Hippolytus. A play like Maguire's Phaedra, with its series of sources and adaptive predecessors leading back to antiquity, challenges a romantic illusion of the literary genius/genuine/genesis - that tripartite linguistic structure suggesting

\footnotetext{
${ }^{1}$ For more on the economic impact of Russia's neoliberal experiment, see Harvey's A Brief History of Neoliberalism. For more on the economic, cultural, and human impact, see Klein.

${ }^{2}$ In his adaptation, Maguire changed many of the characters' names. He calls Theseus Thomas, and Theramenes becomes Angus. I have chosen to open with the names from Racine's play to emphasize the contrast made possible by temporal juxtaposition in adaptation.
} 
authentic and original creativity. Instead, this chain of intertexts and influences indicates the fundamental communality of artistic creation and literary authorship (or, perhaps more accurately, co-authorship). Maguire drew from the works of others to respond to his own political economic and cultural context, as did the authors/theatre practitioners he drew from. This process of shared creative development, and the reworking of material to find or produce new meanings in new contexts poses an existential threat to the kind of greedy, ruthless capitalistic culture of ownership that Maguire satirizes in his version of Phaedra.

As we shall discover over the course of this project, the fundamentally communal and collaborative natures of adaptation and theatrical production can open spaces to resist neoliberal capitalism, modeling instead a social organization grounded in a cosmopolitan cultural commonwealth. By reproducing the world-defining project of ancient Greek theatre for contemporary audiences, adaptations of Attic tragedy offer possibilities of remaking a world currently dominated by neoliberal ideological hegemony.

$$
* * *
$$

I want to start with a summary and brief history of neoliberalism, a gloss that will develop through the course of this project. Essentially, neoliberalism is a comprehensive political economic philosophy privileging free market capitalism as the primary guarantor of individual freedom, and conceptualizing society, culture, and the individual in economized market terms. The degree to which this is a political economic philosophy as opposed to a cultural philosophy is contested by theorists. On the one hand, David Harvey writes, "Neoliberalism is in the first instance a theory of political economic practices that proposes that human well-being can best be advanced by liberating individual entrepreneurial freedoms and skills within an institutional framework characterized by strong private property rights, free markets, and free trade" 
(Neoliberalism 2). On the other hand, Lisa Duggan, writing about the cultural politics of neoliberalism, explains, "the New Deal consensus was dismantled in the creation of a new vision of national and world order, a vision of competition, inequality, market 'discipline,' public austerity, and 'law and order"' (x). To understand its wide and pervasive impact we must see neoliberalism principally as an ideology. I mean by this, we must see it as metanarrative for understanding the world through market logic. Wendy Brown calls neoliberalism "a normative order of reason developed over three decades into a widely and deeply disseminated governing rationality, neoliberalism transmogrifies every human domain and endeavor, along with humans themselves, according to a specific image of the economic" (9-10). Ultimately, neoliberalism reshapes the human subject into homo oeconomicus — the economic human-by envisioning all human interactions as guided exclusively by market principles, and it reshapes societies by enforcing laissez faire capitalism through a top down imposition of force, based in a faith that the free market ultimately provides the most just, free, and equal society possible when left without interference.

Neoliberalism emerged out of the mid- $20^{\text {th }}$ century economic crisis, the most dramatic results of which were the Great Depression and the rise of totalitarianism. The 1930s and 40s saw a flurry of new economic theories, as economists struggled to make sense of the Depression and its consequences. One of the most influential voices was that of Austrian economist Friedrich Hayek. Hayek was a staunch opponent of central planning, which he identifies as the key element threatening individual freedom under both Nazism/fascism and socialism. ${ }^{3}$ His central argument is that liberal capitalism is the best system for ensuring individual liberty: "We

\footnotetext{
${ }^{3}$ One major weakness of Hayek's work is that he treats socialism as monolithic, and understands it almost exclusively in terms of Stalinism (83). In fact, socialism incorporates a wide variety of political economic systems, including democratic socialism, anarcho-socialism, and syndicalism, all of which are anti-authoritarian.
} 
have progressively abandoned that freedom in economic affairs without which personal and political freedom has never existed in the past" (67). While he recognizes the need for some regulation (87), his work imagines an economic market free of coercion of any sort (86). ${ }^{4}$

The major competing voice to emerge during this time was the British economist John Maynard Keynes, who argues that economies should attempt to produce high employment rates with high wages to stimulate economic cycles, even if that employment occasionally requires governments to undertake civic projects financed with public debt. Keynes claims, "For a man who has been long unemployed some measure of labour, instead of involving disutility, may have a positive utility. If this is accepted, the above reasoning shows how 'wasteful' loan expenditure may nevertheless enrich the community on balance" (56-57). Essentially, what Keynes envisions is a system wherein governments can kick start flagging economies by providing a temporary boost in employment, which provides more money with which consumers can buy products, as opposed to an austerity approach (favored by neoliberals) in which governments cut spending, thereby increasing unemployment and decreasing the number of consumers with reliable incomes who buy products. From the WWII years through the 1970s, Keynes' ideas shaped Western economic policy, producing the post-war economic boom, while Hayek's theories were maintained only by a fairly small number of academics. ${ }^{5}$

\footnotetext{
${ }^{4}$ Neoliberalism often relies on technocratic theories imagining an ideal economy, rather than acknowledging the messy contradictions of real world economics. One problem with the neoliberal theorization of the free market's non-coercive economy is that it requires a major condition to be met, one which is almost never actually met in practice: "both parties to an economic transaction benefit from it, provided the transaction is bilaterally voluntary and informed" (Friedman 13, original emphasis). Neoliberal theory obscures the actual workings of economic exchange, in which power is almost never balanced equally between the parties involved. The actual functioning of competition is not to generate freedom from coercion, but to remove that coercive force from the hands of the government to the hands of big capitalists. This is the unacknowledged violence inherent in neoliberal political economics, because it envisions capitalist competition as a natural brake upon itself and upon the tendency toward accumulation.

${ }^{5}$ A third important voice from the mid-century was Karl Polanyi, whose work didn't garner the attention that Hayek or Keynes did at the time. Polanyi argues principally against Hayek's theory that a market system promotes personal freedom, using historical examples (Hayek and his neoliberal disciples rarely look to history for evidence, preferring technocratic theory) to show how economic liberalism was a massively destructive force
} 
Neoliberalism languished as a largely ignored theory until the 1970s economic downturn cast doubt on the viability of the Keynesian system, at which point Milton Friedman emerged as perhaps the most prominent economic theorist of the day, promoting a reinvigorated neoliberalism. Like Hayek, his mentor, Friedman asserted that liberal capitalism would ensure political and individual liberty, but Friedman abandoned much of the nuance of Hayek's work in favor of a more fundamentalist laissez faire capitalism. Friedman argues, "Political freedom means the absence of coercion of a man by his fellow men... By removing the organization of economic activity from the control of political authority, the market eliminates this source of coercive power. It enables economic strength to be a check to political power rather than a reinforcement" (15). ${ }^{6}$ Despite Friedman's assertion that economic liberalism decreases coercive government authority, the overwhelming majority of neoliberal reforms around the world have been coerced, eroding democracy, social welfare, and public control of economies. Friedman's ideas appealed to Margaret Thatcher in the UK and Ronald Reagan in the US, both of whom used governmental authority to enforce market liberalization, destroy worker's rights, and erode social programs developed during the Keynesian era. In the 1990s, neoliberalism got a facelift with Bill Clinton's New Democrats and Tony Blair's New Labour, both of whom kept neoliberalism's economic values and technocratic orientation but dropped the overt militarism

\footnotetext{
attacking both the human/social and nature, and only through collectivism were nations like Britain able to survive the upheaval of the Industrial Revolution. Given how prescient his critiques of economic liberalism were, Polanyi's work is gaining increasing attention as more and more economists and scholars acknowledge flaws in neoliberalism.

${ }^{6}$ McGowan points out an interesting contradiction inherent in Hayek and Friedman's faith in the link between free markets and individual liberty; namely, that the nature of the market actually limits our choice for employment, production, or consumption. Because, in theory, the market will only support products and jobs for which there is a social need sufficient to induce consumers to pay, there are a limited number of jobs or products one could produce within a market economy. Hayek explains how social/economic utility serves as a guide for employment: "What is more important is that if we want to leave [workers] the choice, if they are to be able to judge what they ought to do, they must be given some readily intelligible yardstick by which to measure the social importance of the different occupations" (151). As McGowan points out, this utilitarian emphasis on doing the work that is social necessary functions as a form of coercion: "The magic of the market will direct us to the proper, socially necessary line of work. Despite Hayek's insistence that only capitalism ensures our absolute liberty, here he describes its brake on that liberty as a virtue" (Capitalism and Desire 122).
} 
and nationalism of the Reagan-Thatcher years. Despite these changes, the economic order of the day remained the same: free markets, erode the social safety net, and free trade.

\section{McTheatre: Neoliberalism on Stage}

Before exploring these effects of neoliberalism in more depth, I want to quickly discuss the position of theatre under neoliberal regimes. This is, after all, a project focused on how drama and theatre respond to and fare under neoliberalism. One of the most significant theatre trends under neoliberalism is the rise of what's called McTheatre, which is a globalized, bigmoney approach to production that eliminates (as much as possible) the influence of individual theatre artists. Shows like Cats or The Lion King must be bought. ${ }^{7}$ But unlike traditional theatre where a company pays for the rights to produce a script in their own way, McTheatre involves buying the entirety of the production and performing it in exactly the same way it has been performed elsewhere (Rebellato 41). ${ }^{8}$ One effect of this is the erosion of aesthetic individuality in favor of standardization. One attraction of theatre during the age of mechanical reproduction has been the unique personality of every performance-it's a truism of theatre that even the same company doing the same show will give a different performance every night—but McTheatre tries, as much as possible, to eliminate the agency and the artistic choice of the performers, providing instead a pre-packaged product.

A second crucial effect of McTheatre is economic. Because producers are not merely buying scripts and scores, but buying the entire experience, the costs for these shows are

\footnotetext{
${ }^{7}$ It's interesting how many of these major productions are adaptations. A partial list includes Cats, The Phantom of the Opera, The Lion King, Les Miserables, and Beauty and the Beast.

${ }^{8}$ Rebellato explains, "When you buy the rights to put on Phantom of the Opera, you're not given a score and a script and told to get on with it; you buy the original production: sets, costumes, direction, lighting, the poster, and all the merchandise. This means that all productions of The Phantom of the Opera are, to a very significant extent, identical" (41).
} 
exorbitant. ${ }^{9}$ According to Dan Rebellato, in many cases these shows do not make a profit at the box office; instead, they are meant to sell the extensive merchandise lines that go with themshirts, posters, hats, souvenir programs, DVDs, CDs, mugs, glasses, buttons, etc. (48). This is theatre as advertising, where the production runs at a loss because it earns money for the parent company selling related products. As Rebellato puts it, "What McTheatre demonstrates is the ruthless inventiveness of global capitalism for transforming everything into a way of making money" (48). Of course, money is a dominant concern in the (notoriously impoverished) world of theatre. Ric Knowles points out that Western theatre can be divided between commercialincluding those which put on McTheatre productions-and not-for-profit theatres, with distinct funding schemes. For profit theatres run on an overtly capitalist model, in which "the theatrical event is explicitly constructed as a product of an entertainment industry. Producers finance productions and/or raise funds from investors in hopes of mounting long-running shows to large audiences paying high prices - 'market value' - for entertainment" $(54) .{ }^{10}$ In other words, commercial theatres make no bones about their position within a capitalist economy, putting on expensive shows and charging the highest ticket prices they think people will reasonably pay. ${ }^{11}$

\footnotetext{
${ }^{9}$ Further, because of the price for producers, ticket prices are extremely high, which financially limits access the theatre, reinforcing links between theatre and class privilege.

${ }^{10}$ Boyle argues that theatre's embodiment of a capitalist mode of production is based not on the creation of a long-lasting commodity (because performance is ephemeral), but in the social relations of production. He explains that when performers perform for an audience, the social relations are unproductive (in the capitalist sense) because the audience consumes the performance for its use value as entertainment; however, in the social relations between theatrical laborers and a theatrical entrepreneur, theatre becomes a productive site of capitalist exchange because the entrepreneur invests capital, which is supplemented by the productive labor of workers (i.e., actors, stage hands, promoters, etc.) and then resold as a commodity for an audience (16). In other words, in the social relations between theatre laborers and an investor, theatre embodies a capitalist mode of production because the capitalist captures the surplus value of labor in order to realize profit.

${ }^{11}$ Knowles also argues that to succeed in this commercialized world, theatrical productions are largely stripped of any social, political, or economic critique they might originally have incorporated. Rent was originally a brutal critique of capitalism and the communal indifference it breeds, but in order to succeed on Broadway the show needed to undergo "a process of commodification, and the appropriation of the world of its characters as objects of a voyeuristic or consumeristic gaze was only solidified by its Broadway and tour packaging" (55). Because commercial theatres aim to provide entertainment in its most basic form, "commercial production is virtually prohibitive of extensive radical or social critique" (54).
} 
On the other hand, not-for-profit theatre "relies on public funding, private donations, and box-office receipts to pay its bills" (55-56). This funding scheme is beneficial because not-forprofit theatres are not limited to producing the pure entertainment productions commercial theatres rely on to make money. Because funds come from a mix of public and private sources, as well as box office returns, not-for-profit theatres may be comparatively free to take on experimental, radical, or critical shows in the name of aesthetic, social, or cultural value. ${ }^{12}$ While not-for-profit theatres have comparatively more freedom to show risky productions, neoliberalism poses a major threat to arts funding because a free market ideology largely opposes public/government funding for the arts. In Fair Play, Jen Harvie analyzes a 2011 pamphlet entitled Supporting Growth in the Arts Economy, published by the Arts Council England (ACE). She argues that this pamphlet directly encourages artists in the UK to behave more like entrepreneurs to make up for declining arts budgets. Harvie explains that thinking of art as commercial will have three major detrimental effects: it will de-prioritize artistic production itself, threaten collaboration and artistic communities, and reduce the artist from a rounded human being to homo oeconomicus (72-73). Under neoliberal austerity, with its erosion of public funds and privatization of government functions, money allotted to the arts regularly declines, but particularly when the art/theatre in question is perceived to be critical of existing power structures. ${ }^{13}$ Comparably, private donors may be reluctant to support some overtly critical

\footnotetext{
${ }^{12}$ Many of the plays discussed in this study were produced at not-for-profit theatres_-London's National Theatre, university theatres, small regional theatres, etc.

${ }^{13}$ Austerity is at the heart of neoliberal practice, which is why contemporary politicians in the US, the UK, and Europe, as well as financial organizations like the IMF and World Bank are so enamored of the mantra that nations must live within their means. Arguments against social programs and a social safety net—made by politicians ranging from conservatives to libertarians to center-left technocrats - consistently present austerity and budget cuts as the solution to national debts and struggling economies. For examples of this austerity drive, we need only look at the 2010 imposition of austerity measures on Greece by the European Union and IMF ("Greece's Austerity") which brought IMF austerity conditions - commonly imposed in the global south-home to Europe; or to the long campaign by Republicans and some Democrats in the US to abolish social programs like the Affordable Care Act, and to defund programs like Medicare, Medicaid, and Social Security.
} 
performances, and private donors always have the option to stop patronizing a theatre or company if they object to the content of the performances. In these ways, the uncertain status of funding actually can play a role in limiting the potential scope of critical and experimental performance that not-for-profit theatres can produce.

However, because of their mixed funding sources and (generally) more stable government arts grants, not-for-profit theatres do have more opportunities to produce critical, experimental, or controversial plays and performances than their commercial counterparts, including plays that critique the exploitative and anti-democratic world that neoliberal politics has built. This project examines ways in which contemporary dramatists adapt Greek tragedy to protest, critique, and resist tenets of neoliberalism. ${ }^{14}$ Of course, theatre has an inherently expository cultural role, reflecting for audiences the nature of the world in which they find themselves. ${ }^{15}$ Alain Badiou calls theatre the "art of the declaration of the state (of affairs)," and claims that it reflects the conditions that prompted the creation of the theatrical event $(37$, original emphasis). ${ }^{16}$ If this is true - that theatre holds as it were the mirror up to the entirety of culture - then it is an excellent medium for exploring the problematic effects of neoliberal ideology in the world. While there are many troubling elements of late capitalism, this study is

\footnotetext{
${ }^{14}$ I think adaptations of Greek tragedy exemplify current resistance to neoliberalism, for reasons that will be explored more thoroughly in this Introduction, in Chapter I, and throughout the project. However, I also contend that adaptation and theatre as forms can promote a collaborative worldview that threatens late capitalism.

15 This was true in ancient Athens, in which theatre was intricately interconnected with and reflective of a comprehensive culture. Walton describes "theatre as a medium for the exploration of the world via the parable of myth... The structure of Greek tragedy was informed by the whole visual culture of the times, as well as by the ways in which Athenians of the fifth century BC lived, loved, thought, felt and died" (x).

${ }^{16}$ Badiou writes, "Unable to show the revolution, caught in the habit of the State, is theatre not the only art to establish a certain visibility of the State? The only art to show the State? What does the theatre talk about if not the state of the State, the state of society, the state of the revolution, the state of consciousness relative to the State, to society, to the revolution, to politics?" (36, original emphasis). We must note that Badiou has only a specific kind of theatre in mind here-what he calls the theatrical event. He claims that under certain conditions "it is possible that we come upon the process of a truth, of an elucidation whose spectacle would be the event...Because under these conditions, theatre makes it known to you that you will not be able innocently to remain in your place" (23, original emphasis).
} 
focused on four of the most important ways in which neoliberalism reshapes what it means to be human: 1) the creation of a society of enjoyment, with an ideological imperative to enjoy oneself above all else, 2) the application of market logic to individuals and publics, 3) the erosion of communities and the potential for democracy, and 4) economic (neo)colonialism through a globalized economy.

\section{Reshaping the Human and the Social: Neoliberal Ideology at Work}

One of the most comprehensive psychological effects of neoliberal capitalism is the creation of a society oriented toward enjoyment, rather than requiring subjects to renounce their desires. This cultural shift has reshaped the role of desire and pleasure in ways that isolate the individual and compromise the social fabric. Todd McGowan theorizes "a dramatic change in the way the social order is constituted: rather than being tied together through a shared sacrifice, subjects exist side by side in their isolated enclaves of enjoyment" (End of Dissatisfaction 2). When the social imperative becomes to enjoy, rather than to limit enjoyment, individuals become increasingly atomized as they pursue private jouissance and abandon commitments to the social which require giving up private enjoyment. ${ }^{17}$ When "private enjoyment becomes of paramount importance...the importance of the social order as a whole seems to recede" (End of Dissatisfaction 3). The twin problems McGowan identifies in this shift are that it threatens both individual enjoyment (paradoxically) and the social itself (directly). When the imperative is to enjoy, enjoyment becomes impossible because the relentless pursuit of hidden enjoyment "does not expose the enjoyment; on the contrary, it destroys it" (End of Dissatisfaction 79). In other

\footnotetext{
${ }^{17}$ Perhaps the most important contemporary example of this is human-driven climate change. The world is threatened with catastrophe, driven in large part by human consumption of resources and continual disposal of waste products, especially from the global north. Despite a scientific consensus about the causes and probable effects of climate change, global north societies continue to consume resources and produce waste products, driven by a capitalist ideology that pushes us to embrace jouissance rather than curb our enjoyment for the benefit of society.
} 
words, when commanded to pursue enjoyment, the problem becomes the impossibility of ever enjoying enough, enjoying as much as the fantasmatic Other who is believed to have full access to jouissance. But the imperative to enjoy also compromises society because the preservation of society depends on renunciation, while enjoyment thinks only of the moment. ${ }^{18}$ In the neoliberal period, the brake of social prohibition is being largely eliminated. Rather than conceptualizing the social as a force organizing people in a collective sacrifice of enjoyment (which paradoxically allows enjoyment to exist), global capitalism isolates individuals pursuing selfish desires and reshapes human subjectivity as pathological narcissism (End of Dissaisfaction 34). ${ }^{19}$ Under late capitalism, society, community, democracy, and a shared public erode as neoliberalism reshapes the subject as atomized individual consumer and human capital, called homo oeconomicus.

${ }^{18}$ As McGowan says, "Whereas the self-perpetuation of the social order depends on conservation of resources, calculation of possibilities, and allowances for the future, enjoyment occurs without any consideration of how it will be sustained, without any fear of using itself up" (End of Dissatisfaction 13). Obviously this doesn't mean that all pleasure must be rejected, but that historically there has been a social imperative to ensure sustainability. One paradox of neoliberalism (at least in the global north) is the fantasy that scarcity ceases to existwe are surrounded by advertising and media training us to consume, to buy, and to enjoy, the result of which is that the US has become the most wasteful society in world history and we teeter on the brink of ecological disaster due to human consumption. Simultaneously, however, the entire logic of capitalism is underpinned by the belief in scarcity and the competition for resources that drives the capitalist mode of production (Capitalism and Desire 197).

${ }^{19}$ The evolution of pathological narcissism as the dominant contemporary subjectivity is deeply rooted in neoliberal materialism and marketization. Pathological narcissism thrives on an ethic of social detachment: "The narcissistic subject knows only the 'rules of the (social) game' enabling him to manipulate others; social relations constitute for him a playing field in which he assumes 'roles,' not proper symbolic mandates; he stays clear of any kind of binding commitment that would imply a proper symbolic identification. He is a radical conformist who paradoxically experiences himself as an outlaw" (Žižek, Looking Awry 102-103, original emphasis). This social detachment manifests in the psychological compulsion to pursue individual enjoyment - that is, the obscene law of the superego. McGowan explains how pathological narcissism refigures the subjective experience of duty: "Unlike the autonomous individual of liberal capitalism and the organization man of monopoly capitalism, the pathological narcissist does not envision duty as devotion to an ego-ideal. In the epoch of global capitalism...duty is transformed into a duty to enjoy, which is precisely the commandment of the superego" (End of Dissatisfaction 34). Pathological narcissism as a psychological result of neoliberal capitalism has entered common parlance through the portmanteau affluenza. James describes affluenza as a disease spreading across the English speaking world, wherein people increasingly "define their lives through earnings, possessions, appearances and celebrity, and those things are making them miserable because they impede the meeting of our fundamental needs" (xvi). Pathological narcissism is one way through which neoliberalism threatens both individual and social health. 
Neoliberalism seeks to reduce all available models of selfhood to homo oeconomicus. Foucault recognized the biopolitical implications of the neoliberal worldview as early as his 1978-79 lectures at the Collège de France, though he was thinking at the very beginning of the neoliberal reformation. In his tenth lecture, on 21 March 1979, Foucault claimed "American neoliberalism still involves, in fact, the generalization of the economic form of the market. It involves generalizing it throughout the social body and including the whole of the social system not usually conducted through or sanctioned by monetary exchanges" (243). Even in its nascent form, Foucault recognizes the importance of a universalized market mentality for the political aims of neoliberalism. In order to function, neoliberal ideology must be wide reaching and deeply penetrating, because it attempts to overwrite traditions of political, socio-cultural, religious, and aesthetic world views, reconceptualizing culture solely through a market ethos.

Neoliberal attempts to reshape culture as a whole begin on the ground level with the individual, as neoliberal theory and propaganda reformulate not just traditional capitalists but workers as capitalists. Foucault explains that neoliberal capitalism does not properly have a theory of labor, but "a conception of capital-ability which, according to diverse variables, receives a certain income that is a wage, an income-wage, so that the worker himself appears as a sort of enterprise for himself" (225). The abolition of a theory of labor is consistent with neoliberal rhetoric, which necessarily denies the fundamentally exploitative nature of capitalism, arguing instead that labor is paid based on the value of its service and is fully capable of enforcing economic fairness without access to collective bargaining or unionization. ${ }^{20}$ Friedman equates productive output with material input—he argues that what has been invested in a

\footnotetext{
${ }^{20}$ Friedman envisions an economic world in which there are so many employment options that it becomes inconceivable for an employer to exploit any employee because the worker can simply find a new job (14-15). He also ties wage value and living standards directly to productivity, ignoring the real world economic role capitalists play in depressing and fixing wages in the quest for profit.
} 
worker (training, capital, land, etc.) correlates directly to the wage and standard of living that worker can expect. ${ }^{21}$ This is precisely neoliberal theory's reformulation of homo oeconomicus, which posits: “Homo oeconomicus is an entrepreneur, an entrepreneur of himself” (Foucault 226). ${ }^{22}$ Quite unlike Marx's alienated laborer who sells his productive power in exchange for bare sustenance, neoliberals like Friedman see laborers as embryonic capitalists who can augment the value of their labor through self-investment.

The construction of individual subjects as enterprises/entrepreneurs contributes to neoliberalism's foundational attempts to remake society as a whole. Foucault notes, “An economy made up of enterprise-units, a society made up of enterprise-units, is at once the principle of decipherment linked to liberalism and its programming for the rationalization of a society and an economy" (225). This atomizing entrepreneurialism alters the individual relationship to society under neoliberalism. Polanyi argues that imposing the market model on society threatens the very existence of human subjects and nature, both of which are stripped of their socio-cultural protections when abandoned to the market (76). ${ }^{23}$ One need not search long for evidence of the neoliberal commitment to individualism. Perhaps the most famous articulation of this principle comes from Margaret Thatcher in her declaration that "There is no

${ }^{21}$ Friedman writes, "If the Japanese worker has a lower standard of living than the American, it is because he is less productive on the average than the American, given the training he has, the amount of capital and land and so on that he has to work with" (72, my emphasis). The contemporary adjunct crisis in US higher education belies this logic, as adjuncts invest years and thousands of dollars in specialized training and preparation, only to find a market that does not even offer a living wage in many cases.

${ }^{22}$ This is, according to Foucault, a different form of homo oeconomicus than that conceived in classical economics, where homo oeconomicus is seen as a figure of exchange, trading goods/commodities to meet specific needs (225).

${ }^{23}$ Polanyi explains, "Robbed of the protective covering of cultural institutions, human beings would perish from the effects of social exposure; they would die as the victims of acute social dislocation through vice, perversion, crime, and starvation. Nature would be reduced to its elements, neighborhoods and landscapes defiled, rivers polluted, military safety jeopardized, the power to produce food and raw materials destroyed" (76). In Capitalism: A Love Story, Roy describes in moving prose these detrimental results in contemporary India: "the poltergeists of dead rivers, dry wells, bald mountains, and denuded forests; the ghosts of 250,000 debt-ridden farmers who have killed themselves, and of the 800 million who have been impoverished and dispossessed" (8). 
such thing as society. There are only individual men and women... and their families" (qtd. in W. Brown 100). Mrs. Thatcher's sentiment is almost an exact echo of Milton Friedman's claim that "As liberals, we take freedom of the individual, or perhaps the family, as our ultimate goal in judging social arrangements" (12). Neoliberalism's ideological devotion to capitalist competition requires it privilege the individual, because all interaction figures as competition between atomized buyers or sellers. Friedman describes his ideal economic structure as "a number of independent households — a collection of Robinson Crusoes, as it were" (13). ${ }^{24}$

Wendy Brown extends Foucault's and Polanyi's analysis of the cultural work of neoliberalism, with the benefit of seeing how neoliberalism has unfolded up to 2015 . In an important, fundamental passage, Brown writes:

To speak of the relentless and ubiquitous economization of all features of life by neoliberalism is thus not to claim that neoliberalism literally marketizes all spheres, even as such marketization is certainly one important effect of neoliberalism. Rather, the point is that neoliberal rationality disseminates the model of the market to all domains and activities - even where money is not at issue - and configures human beings exhaustively as market actors, always, only, and everywhere as homo oeconomicus. (31, original emphasis)

She suggests, in other words, that a market mindset becomes the prevailing way of looking at the world under neoliberalism, and that this worldview has redefined every facet of culture. Markets are not limited, in other words, to financial exchanges - money is not the only market factor. Instead, the human becomes a commodity measured not just in monetary wealth or the economic value of labor power, but instead a commodity capable of (and compelled to) invest in the self throughout all aspects of life, from happiness/psychological health, to labor capacity, to

\footnotetext{
${ }^{24}$ While the self-sufficiency and bartering Friedman describes hearken back to Aristotle's description of the foundation of economics in the home (Politics $1257^{\mathrm{a}} 19-42$ ), it is hard to conceptualize such independence in a complex capitalist economy where household self-sufficiency is virtually impossible for most people (in advanced capitalism economics has lost its root in the oikos, which was its original Greek orientation).
} 
knowledge. This is why the self-help genre emerges with such stunning force contemporaneously with the rise of neoliberal capitalism—self-help is at its core an investment in the self. However, even those who don't read or use self-help books or programs remain interpolated within a marketized cultural space, a space which reconfigures the very nature of work, politics, culture, aesthetics, and so on. This individualization and atomization of human capital forecloses possibilities for collective, democratic action by isolating individuals.

Both Hayek and Friedman express anti-democratic sentiments, preferring to uphold the economic freedom of the individual and characterizing democracy and collective action as oppressive. Hayek is not overtly anti-democratic, but he characterizes the individualist position: "individuals should be allowed, within defined limits, to follow their own values and preferences rather than somebody else's; that within these spheres the individual's system of ends should be supreme and not subject to any dictation by others" $(102) .{ }^{25}$ While enshrining individual freedom is in many ways admirable, when coupled with a libertarian constriction of the functions of government to a bare minimum, it represents a rejection of collective or democratic action that might shield human beings, society, or nature from the ravages of the market. ${ }^{26}$

The institutional spaces facilitating vibrant and popular democracy have been attacked by neoliberalism, largely through the ideologically driven process of privatization. Duggan explains privatization as "the transfer of wealth and decision-making from public, more-or-less

\footnotetext{
${ }^{25}$ Hayek takes $18^{\text {th }}$ and $19^{\text {th }}$ century Liberal philosophers at their word, that capitalism brought individuals freedom; however, in practice Liberalism secured rights and privileges for bourgeois men at the expense of workers, women, slaves, etc.

${ }^{26}$ Polanyi argues that collective action was the only way Britain survived the Industrial Revolution with its attendant social devastation, and that the history of Liberal culture has involved a direct confrontation pitting laissez faire markets endangering society and nature against social self-defense mechanisms. He writes that a market based society "could not exist for any length of time without annihilating the human and natural substance of society; it would have physically destroyed man and transformed his surroundings into a wilderness. Inevitably, society took measures to protect itself, but whatever measures it took impaired the self-regulation of the market, disorganized industrial life, and thus endangered society in yet another way" (3-4).
} 
accountable decision-making bodies to individual or corporate, unaccountable hands.

Neoliberals...go further than this, though, in advocating that many ostensibly public services and functions also be placed in private profit-making hands" (12). Neoliberal philosophy allocates little room for government ownership of any service, except the most basic services for defending a nation from military invasion and enforcing voluntarily entered contracts. ${ }^{27}$

Privatization is, however, a major challenge to democracy because private authority removes decision making power from publicly accountable institutions to private, unaccountable organizations (Chomsky 132). Putting control of services like public transportation, education, health care, communications, and prisons into private hands drives up costs for individual users, fees which might be minimal or non-existent under public ownership.

Privatization decreases open and shared public spaces that once offered possibilities for communal interaction and collective discussion, which Robert McChesney identifies as a crucial structure supporting democracy. ${ }^{28}$ Theorists like Duggan, Brown, and Chomsky all argue that democratic, public mindsets are deliberately attacked under neoliberalism to consolidate control and reshape human subjectivity as homo oeconomicus. The thesis of Brown's Undoing the Demos is, in fact, that by imposing an economic worldview, neoliberalism limits possibilities for democracy by turning subjects into human capital rather than citizens:

${ }^{27}$ With the massive expansion of private military contractors, particularly during the US led Iraq War under George W. Bush, neoliberal governments have even begun moving to privatize responsibilities like national defense. The rise of privately owned for-profit prisons shows a similar trend in law enforcement. The military and judiciary have, however, remained among the least privatized realms of Western society.

${ }^{28}$ Putnam's thoroughly researched study Bowling Alone provides a strong case that Americans have become increasingly disconnected since the 1970s, arguing that baby boomers, Gen-Xers, and millennials have less social capital and are less civically engaged in almost all realms of collective life than the generations that came of age from the 1930s-early 1960s. The main problem he identifies with declining social capital and connectivity is the erosion of networks of general reciprocity, which he characterizes as, "I'll do this for you without expecting anything specific back from you, in the confident expectation that someone else will do something for me down the road" (21). While this attitude characterized an older generation (and still characterizes that aging group according to Putnam's research), generations with declining social capital increasingly fragment into individuals. And as Putnam notes, "A society of many virtuous but isolated individuals is not necessarily rich in social capital" (19). As individualism rises, public engagement declines along with the norms of reciprocity that build strong communities. 
democracy itself has been radically transformed by the dissemination of neoliberal rationality to every sphere, including politics and law. Thus, distinctly political meanings of 'equality,' 'autonomy,' and 'freedom' are giving way to economic valences of these terms, and the distinctive value of popular sovereignty is receding as governance through expertise, market metrics, and best practices replaces justice-framed considerations over who we are, what we should be or become, what we should do or not do as a people. (177, original emphasis)

In other words, neoliberal governance and rationality - the power of ideological apparatuses to reshape the common-sense terrain of our lives without exerting direct influence (117) — eliminate traditional democratic values and questions about issues like justice, equality, fairness, and freedom. These questions are replaced with economized questions of value. For Brown this is a crucial shift because it reshapes the psychological terrain of the human, undermining homo politicus in favor of homo oeconomicus, who has no collective values and no ethical basis for resisting processes of subordination, oppression, and exclusion. Further, as the economy becomes more and more globalized, neoliberalism expands its reach around the world, utilizing International Financial Organizations (IFOs) and political pressure to promote free markets and free trade that extort resources from the developing nations of the global south on behalf of the financial centers of the global north. ${ }^{29}$

The economic basis of (neo)colonialism is a process Harvey terms accumulation by dispossession, a key technique for securing the global north's hegemony. He links accumulation by dispossession to the new global financial scheme: "above all we have to look at the speculative raiding carried out by hedge funds and other major institutions of finance capital as the cutting edge of accumulation by dispossession in recent times" (“"New' Imperialism” 75). ${ }^{30}$

${ }^{29}$ IFOs-IMF, World Bank, WTO, etc. - are crucial for exporting neoliberal ideology around the globe.

${ }^{30}$ Harvey takes the specific example of the late 1990s Southeast Asian credit crisis, which seriously compromised the world economy and nearly collapsed several national economies as a result of targeted financial speculation from the West: "By creating a liquidity crisis throughout South East Asia, the hedge funds forced profitable businesses into bankruptcy. These businesses could be purchased at fire-sale prices by surplus capitals in the core countries" (“"New' Imperialism” 75). 
Two reasons it has proven so difficult for anti-globalization and anti-neoliberal forces to resist accumulation by dispossession are because it is often carried out 1) using legal systems to manipulate ostensibly compromised economies, and 2) in fragmented, disconnected pieces. The forces of economic dispossession utilize the carrot of international aid money and the stick of IMF and World Bank regulation to coerce struggling economies into adopting neoliberal policies, often to the detriment of their own people. Harvey explains, "As new institutional arrangements come to define the rules of world trade...developmental states find themselves increasingly drawn into the neoliberal fold" (Neoliberalism 72). Because IFOs tie economic aid to neoliberal inflected internal reforms, the charade of legality is maintained over many actions that are in reality little more than boldfaced theft. ${ }^{31}$

However, just because accumulation by dispossession looks random does not mean it isn't systematic and purposeful. In The Shock Doctrine, Naomi Klein theorizes a three phase process of disaster capitalism, which she defines as "orchestrated raids on the public sphere in the wake of catastrophic events, combined with the treatment of disasters as exciting market opportunities" (6). For Klein, the structure of disaster capitalism proceeds in three phases: first, a political or cultural shock, which might be a coup, a natural disaster, an economic crisis, etc. Second, economic shock therapy, featuring rapid privatization of as many public resources as possible, the elimination of trade barriers, and the cutting or outright elimination of public services and welfare. These policies may be imposed by a dictatorial government influenced by Chicago School economics or through coercive IFOs. Finally, when the economic shock inevitably breeds popular resistance, comes the physical shock of widespread torture,

\footnotetext{
${ }^{31}$ Further, because neoliberal dispossession "is fragmented and particular-a privatization here, an environmental degradation there, a financial crisis of indebtedness somewhere else...It is hard to oppose all of this specificity and particularity" (Harvey, Neoliberalism 178).
} 
imprisonment, "disappearances," and increasing militarization of the police and armed forces.

Klein traces this three shock pattern from its original imposition under the military dictators of the southern cone in 1970s Latin America, through the 2003 Iraq invasion, the tsunami that devastated Sri Lanka in 2004, and Hurricane Katrina in 2005. On the one hand, disaster capitalism produces fabulous wealth for a handful of people, but the vast majority of the affected population finds themselves destitute. ${ }^{32}$ While a tiny elite enjoy massive increases in their wealth and lifestyles, the majority of the world's population sinks into poverty, violence, and repression.

\section{Staging Resistance to Neoliberal Hegemony}

Despite neoliberalism's extensive and comprehensive campaign to rewrite subjectivity and limit bases for ideological dissent, many continue to resist the ethical embrace of free markets as a universal model for social and personal life. One important bastion of resistance has been the theatre-despite the economic success of McTheatre-which has gamely clung to an ethic of political and cultural resistance. Again, theatre has a long tradition, theorized overtly in the $20^{\text {th }}$ century, of resisting authority, opening up new ways of seeing the world, and encouraging spectators to question hegemonic power structures. Thinkers like Augusto Boal in Theatre of the Oppressed, Alain Badiou in Rhapsody for the Theatre, and Bertolt Brecht have all asserted theatre's radical revolutionary potential. In considering adaptation's potential to resist a dominant ideology, Brecht is particularly useful because he identifies critical distance as a useful tool for prompting inquiry and self-reflection in an audience. ${ }^{33}$ Brecht writes, "if we play works

\footnotetext{
${ }^{32}$ Using a nautical metaphor, Klein writes that national economies "do, eventually, stabilize, but that new equilibrium is achieved by throwing millions of people overboard: public sector workers, small-business owners, subsistence farmers, trade unionists. The ugly secret of 'stabilization' is that the vast majority never climb back aboard. They end up in slums, now home to 1 billion people; they end up in brothels or in cargo ship containers" (350).

${ }^{33}$ By contrast, Boal is critical of the Aristotelian tragic structure as a form that pacifies and therefore represses potentially revolutionary anger. He writes, "Aristotle formulated a very powerful purgative system, the objective of which is to eliminate all that is not commonly accepted, including the revolution, before it takes place"
} 
dealing with our own time as though they were historical, then perhaps the circumstances under which he himself [the audience member] acts will strike him as equally odd; and this is where the critical attitude begins" (190). In other words, the discontinuity between the historical—or in this case, adapted — situation and the audience's own context diminish their identification with the characters. Instead, Brecht argues that audience members will ponder what they would do in the context and circumstances staged, and through this self-reflexive inquiry will become critically aware of their own ideologically conditioned behavior.

With Greek tragedy it is not necessarily clear how much audiences actually experience alienation, given the canonical and foundational place these plays hold at the ostensible origin point of Western culture. However, this canonical authority does provide a benefit for resisting neoliberalism. While, as many critics point out, the notion that the Greeks represent the genesis of Western civilization is largely a myth, the myth nonetheless exerts a great deal of power over how Westerners receive Hellenic drama. ${ }^{34}$ Greek drama has a vast amount of cultural capital, and when contemporary dramatists utilize these plays for their own political/social ends, the adaptation brings along a portion of that cultural capital, thereby authorizing the adaptation (and its critique) by association. ${ }^{35}$ This means that in utilizing Attic myth and tragedy as subject material, playwrights can imbue their work with a pre-existing legitimacy.

(47). To the extent that $5^{\text {th }}$ century BCE Attic tragedy is Aristotelian-or to the extent that contemporary adaptations are - this is an important caution to keep in mind.

${ }^{34}$ Notably, Bernal and other Afroclassicists challenge the notion that classical Greece was itself an origin point, arguing that Hellenistic culture drew heavily from African and Near Eastern influences. Laera, in Reaching Athens, also confronts the myth of a cultural continuity between ancient Greece and the contemporary West, specifically as it relates to performances and adaptations of Greek drama.

35 This can be a complex reflexive process, especially when the adaptation attacks the very cultural power invested in the 'classics,' challenging the dominant position of Greek culture in the Western mind. For instancewe'll see this briefly in Chapter I-in how Sarah Kane's Phaedra's Love attacks the ostensible rule that violence happens off stage in Greek tragedy. 
Part of this legitimacy is grounded in the notion of the Greeks as the origins of a democratic civic culture, which many classicists argue remains reflected in tragedy. The role of ritual and performance in Greek life is well documented, as are the deep interconnections between performance and Athenian civic and political life. Tragedy as such almost certainly originated during the $6^{\text {th }}$ century BCE tyranny of Peisistratos, but it came to be deeply entwined with the democratic elements of Athenian life by the $5^{\text {th }}$ century. Margherita Laera explains that pro-democratic forces in the late $6^{\text {th }}$ century utilized drama to disburse democratic ideals: "the particular synergy, which was undeniably established between the 'democratic' system and dramatic performances, emerged more clearly when political leaders, such as Themistocles and Pericles, often acting as sponsors of the chorus through the institution of the koregia, sought to promote 'democratic' values through tragedy, reinforcing their agenda by promoting the idea of Athens as a 'democratic' community" (Reaching Athens 215). In other words, democrats used tragic performances to popularize the idea of democracy. Ian Storey and Arlene Allan explain that leaders like Perikles and Themistokles promoted the new system of government through plays that performed fundamental democratic values: "Particularly notable in this regard are the twin principles of isonomia ('equality before the law') and parrhesia ('freedom to speak') on which democracy was founded, as they are represented in the tragedies" (70-71). So because characters were able to express their opinions, values, ethics, and positions- tragic drama being almost inconceivable without this freedom — and more or less viewed as equals before the lawwith Aiskhulos' The Eumenides being probably the most obvious example ${ }^{36}$ - the foundational

\footnotetext{
${ }^{36}$ In spelling Greek dramatists' and characters' names I have attempted to transliterate the Greek originals, rather than using the more common Latinized terms - my own small act of fidelity. Therefore, I use Aiskhulos in preference over Aeschylus and Sophokles rather than Sophocles. However, in discussing specific adaptations or translations, I defer to the spelling used by that author. So, in quoting from the Paul Roche translation of The Oresteia, I would use Clytemnestra, rather than Klytaimnestra, for example.
} 
principles of Athenian democracy were promoted through the civic rituals of the City Dionysia and other dramatic festivals.

At the same time, tragedies replicated structures already central to Athenian life, and so tragedy and civic engagement in the polis were mutually reinforcing cultural institutions. The agonistic structure of much Attic tragedy mirrored the public institutions of an Athens struggling to define how its democracy would be constituted and how citizens would take active roles in a polis. Greek life centered around competition, and the ethical contests at the heart of tragic drama reflect the same rhetorical techniques and debate styles citizens would have been familiar with from the ekklesia (the citizens' assembly) and the agora (the marketplace, which was the center of public life). ${ }^{37}$ These were spaces of debate, where one's ability to convince fellow citizens determined policy, guilt or innocence, and praise or censure. These processes of democratic life seem to have influenced and shaped drama during the $5^{\text {th }}$ century BCE: "many of the structural aspects of tragic and comic drama would seem to owe their form to preexisting institutions of the polis - its law courts, assemblies, and councils" (Storey and Allan 67). These public institutions relied on different speakers laying out alternative policies, cases, and points of view in the hope of convincing the assembled citizens to vote for a particular proposition or verdict. This rhetorical approach has parallels in much extant tragedy, where different characters put forward competing ethical positions and debate them - the most famously agonistic structure probably being in Antigone, where the titular character and Kreon represent competing notions of how the state should be run, the role of law, and the relationship between law and the divine.

${ }^{37}$ Habermas notes the centrality of the agora as a space and of speech as a political tool in the constitution of an Athenian public sphere: "The public life, bios politikos, went on in the market place (agora), but of course this did not mean that it occurred necessarily only in this specific locale. The public sphere was constituted by discussion (lexis), which could also assume the forms of consultation and of sitting in the court of law, as well as in common action (praxis)" (3). 
With drama being staged at major civic/religious festivals honoring the god Dionysos, these plays made up an important part of Greek public or visual culture.

Public or collective culture has come under attack under neoliberalism's reign, but theatre preserves a public sphere offering the possibility to critically interrogate, discuss, and argue over pressing issues. Michael Warner explains that "A public seems to be self-organized by discourse but in fact requires preexisting forms and channels of circulation. It appears to be open to indefinite strangers but in fact selects participants by criteria of shared social space (though not necessarily territorial space), habitus, topical concerns, intergeneric references, and circulating intelligible forms" (106). In other words, a public coheres when groups of strangers are organized through some kind of dialogic channel into a relatively coherent group organized around mutual concerns. By its collective nature, by its ability to orient strangers around a central concern, and by its use of a shared discursive foundation, theatre inherently constructs a public sphere. ${ }^{38}$ By bringing together audience members and addressing them through the medium of performance, theatre builds publics. And by their very nature, publics are collective; they orient individuals toward one another and construct social bonds (however temporary and weak). Contemporary theatre probably produces weaker publics than its Greek predecessor, but these communal spaces of discourse still represent possible spaces of resistance to the atomization and individualism of neoliberalism.

Further, adaptation as such represents a potential form of resistance to capitalist property ownership. As we've already begun to see with Maguire's Phaedra, the question of textual ownership and individual copyright is fraught in the case of adaptations. While Maguire owns

\footnotetext{
${ }^{38}$ One benefit theatre has over other art forms as a tool for resisting neoliberal atomization is precisely that performance engages us in a shared public space. So while the readers of a novel or viewers of a painting may share an intellectual/aesthetic.virtual public space, being together in a theatre with live performers and live audience members trains us to share communal spaces more than most other art.
} 
the copyright to his particular version, the play is, nonetheless, a version of Racine's play (which is a version of Seneca's, which is a version of Euripides', which was drawn from a common body of stories). So legally Maguire owns his play, but the intellectual work of writing it remains dependent on these predecessors. We might even pose the question: how much of Phaedra is Maguire's, as opposed to Racine's, or Seneca's, or Euripides'? If the question of textual ownership is troubled by the multi-authored status of adaptations, this may reflect larger instabilities in the concept and ethical underpinning of property ownership as such. Intellectual property rights are a pillar of capitalism (especially in the digital age), and by raising questions about the legitimacy of intellectual property ownership, as opposed to a shared commonwealth of knowledge, cultural codes, myths, etc. from which artists can draw, adaptation may existentially jeopardize capitalism.

Individual ownership of intellectual or artistic works is even more uncertain in theatre, which is inherently a communal activity. Theatre requires the collaborative work of actors, a director, tech people, and props and costume people, not to mention the labor involved in promotion, securing funding, preparing programs, ushering, etc. Additionally, a play requires an audience to participate by showing up and watching. To stage a play requires people to work together toward a shared goal. Despite a tradition of identifying a production by director (or more rarely by a famous lead actor), no one person can take credit for the show. The practice of theatre requires a group effort, which can undermine both neoliberal notions of private ownership and individualism. Performing a show and relying on members of a community opens up space to imagine an alternative kind of society, opposed to the one posited as natural and inevitable by neoliberalism. Rather than filtering all social relations through the logic of the market and fundamentally distrusting others (who must, under neoliberal logic, figure as a threat 
to one's own property, and therefore both one's value and enjoyment), theatre may enact a model of a community working together for the greater good. This kind of communal approach to intellectual and artistic production can inspire alternatives to the marketization of individuals, the erosion of democratic publics, the upward redistribution of wealth, and the exploitative economic globalization that are the hallmarks of neoliberalism.

$$
* * *
$$

These negative effects of neoliberal capitalism provide the basis for my work throughout this project. This project is, principally, a literary analysis of a variety of contemporary Anglophone adaptations of Greek tragedies in the context of neoliberal culture. The global range of these authors-English, Scottish, Irish, Nigerian, South African, and Australian — suggests how globally comprehensive are the effects of neoliberal capitalism, though these effects vary in different places and contexts. My argument is informed by various theoretical disciplines, including political economics (generally from a Marxist view), adaptation theory, reception studies, psychoanalysis, and postcolonialism. Although my project is grounded in literary analysis, I also incorporate performance theory, generally considering how elements like sets, costuming, dance, and ritual contribute to particular productions' critiques of neoliberal late capitalism. The project's structure largely follows the major neoliberal trends this introductory section has begun theorizing.

The first chapter sets the stage for seeing theatrical adaptation as an important contemporary genre. Utilizing Hippolytos adaptations as an example, Chapter I discusses some major issues at the forefront of adaptation theory, defining adaptation, and posing the problem of intellectual ownership in a collaborative medium. This chapter also discusses why it matters that contemporary dramatists adapt Attic tragedy: why do the Greeks remain relevant? how do they 
reflect into current Anglophone cultures? who has cultural ownership of Greek heritage? This chapter provides an important backdrop for the arguments developing over the course of the project by proposing the theory of faithful infidelity, in which contemporary dramatists maintain fidelity to the politico-cultural world making project of Greek tragedy, rather than the more traditional and limited notion of naïve fidelity as reproducing content, stories, characters, etc.

The body of the project — Chapters II, III, and IV—-focuses on the trends of neoliberalism that have already been briefly discussed. Chapter II argues that Christine Evans' Trojan Barbie and Colin Teevan's Alcmaeon in Corinth critique the reduction of the human, relationships, and social institutions to the logic of the market. Evans draws attention to the problematic conflation between the human and the commodity within late capitalist biopoitical regimes. Teevan explores the breakdown of social order and norms under the society of enjoyment, when the pursuit of jouissance triumphs over social responsibility. Building on the implications of this, Chapter III looks at the problem of a declining public sphere and the erosion of democratic potential in David Greig's Oedipus the Visionary and Marina Carr's By the Bog of Cats. Greig's adaptation, set in South Africa, contrasts the individual isolation of Sophokles' Oedipus against the potential for a communal renunciation of violence in favor of unity. Carr's play exposes how the atomizing effects of neoliberalism's political, cultural, and financial politics further isolates and disenfranchises people already susceptible to socio-cultural violence, including women and ethnic minorities. Chapter IV takes a more global lens, with plays that look at the role of economic (neo)colonialism: Femi Osofisan's Tegonni: An African Antigone and Women of Owu, and Moira Buffini's Welcome to Thebes. The two Osofisan plays demonstrate a shift in the Nigerian dramatist's worldview, from a traditionally postcolonial Tegonni in 1994 to a more cosmopolitan engagement with global politics in Women of Owu in 2004. Buffini's play is 
perhaps the most directly concerned with economics in my entire project, as she explores the role of economic power in shaping or dominating policy decision in developing countries.

This project culminates in Chapter $\mathrm{V}$ and the Conclusion, which argue that these adaptations propose an alternative to neoliberal ideology: specifically, a cosmopolitan commonwealth based on shared cultural experiences and communality. In Chapter V, I discuss Yael Farber's Molora, an adaptation of Aiskhulos' Oresteia. Farber filters Aiskhulos' play through the structure of South Africa's Truth and Reconciliation Commission, but her version of the TRC ultimately defers to the community, represented by the chorus, to create peace. The Conclusion includes brief discussions of the plays analyzed in Chapters II, III, IV, and V, exploring ways in which these plays evoke a cosmopolitan commonwealth. These final sections also return to issues raised in Chapter I, to assert that both adaptation and theatre may inherently evoke a cosmopolitan commonwealth by exemplifying an ethical and open engagement with the world, and resisting the neoliberal ethic of private ownership and consumer atomization.

Although this project deals with some of the most exploitative and dehumanizing ideological trends since the end of the Second World War, ultimately this is a hopeful project. We have ample evidence of greed, inhumanity, and isolation. But there is reason to hope for a better future grounded in a cosmopolitan collective, a future more open to difference and dedicated to supporting each other, rather than dedicated to the cutthroat ethics of greed-is-good consumerism. The plays this study discusses, while they may be dark and pessimistic at times, are, I argue, positive gestures toward a better future. 


\section{Chapter I}

\section{Adaptation: Shared Cultural Myths}

In Reaching Athens: Community, Democracy and Other Mythologies in Adaptations of Greek Tragedy, Margherita Laera argues persuasively for the central roles of myth making and transmission as cultural forces shaping identities. She writes, "myth empties reality of the material, cultural and historical conditions which enabled it, turning complex and contradictory processes into essences, universalisms and hierarchies ready to be consumed. Myth is thus an ideological device which 'interpellates' subjects and enables mechanisms of identification, in order to produce a certain image of reality and support a given power system" (17). In other words, mythologies structure the horizon of possibilities for identity, socio-cultural norms, and ideals, often in the service of existing power structures within a society. She claims that performing Greek tragedy, either in adaptation or translation evokes cultural mythologies of ancient Hellas - as birthplace of philosophy, theatre, democracy, etc. ${ }^{39}$ However, according to Laera, these performances often reinforce the status quo by identifying contemporary Western liberal democracies as the inheritors of Athenian tradition. ${ }^{40}$ My study traces a more pervasive critical element in adaptations of Attic tragedies, arguing that many contemporary performances do in fact confront the ways in which cultural myths are used to prop up a neoliberal status quo. This first chapter defines the terms through which I conceptualize adaptation, as well as introducing the important work of cultural resistance performed by adaptations of Greek tragedy in our current globalized moment. Dramatists and audiences around the world receive Attic

${ }^{39}$ Bernal is among the most famous critics of this origin myth. His work on Afro-classicism is discussed more in Chapter IV. Further, Settis argues that how the 'classical' has figured in Western cultural consciousness has changed dramatically across various parts of Europe and across time.

${ }^{40}$ Though she does acknowledge, "I believe, however, that it is possible to critique these mythologies through performance, though sadly this is not often the case in contemporary productions" (Reaching Athens 3 ). 
tragedies in different ways and with different cultural emphasis, and these various forms of reception shape the immediate political/social aims to which adapters put this source material.

Terms like adaptation and appropriation are much contested in the spheres of adaptation theory, with some critics arguing for broad understandings and others proposing narrow definitions. Basically, I support a broad approach to theorizing adaptation: an adaptation is a text that devotes substantial attention to directly and purposefully reworking a previous text. This definition will develop over the course of this chapter and the project as a whole, but I will briefly explain some of the key terms now. By text, I mean any work of art or performance, though in this study I focus principally on theatrical adaptations with available print play texts. An adaptation must devote substantial attention to revising a previous text, which precludes passing allusions or references. The reworking should be direct and purposeful to achieve the status of adaptation, as opposed to just an influence. ${ }^{41}$ And finally, an adaptation must rework $a$ previous text. This reworking may include anything from linguistic translation, changing setting or costumes (which may be regarded as minor changes), up to rewriting a play's ending, reenvisioning characters, ascribing new motives, or creating a new plot line (or other major changes). This definition is purposefully broad and inclusive, which I find more useful for literary analysis than minute distinctions. ${ }^{42}$

Because it requires the reworking of source texts — generally texts with a high degree of cultural currency, visibility, and recognizability - adaptation is often dismissed as derivative or parasitic. In A Theory of Adaptation, Linda Hutcheon points out the irony of this dismissal. In a

${ }^{41}$ For instance, J.P. Clark-Bekederemo's Song of a Goat is influenced by the structure and themes of Greek tragedy but is not a direct adaptation of a specific play.

${ }^{42}$ I think a broad definition better allows us to read adaptations for political or cultural implications, as opposed to arguing small scale differences between types of intertextuality. I find more value in how a text creates meaning in the world than in the question of whether it's a burlesque, a travesty, a parody, or an appropriation. 
section entitled "Familiarity and Contempt," she provides a catalogue of dismissals, rejections, and derisions of adaptation as a form; the charges range from simplification, to a kind of sexual perversity, to Virginia Woolf's claim that film (or perhaps adaptation more generally?) is parasitical (2-4). ${ }^{43}$ The paradox, however, is that despite the continuing negative evaluationsand what lover of the written word has not uttered the immortal cry, "The book was better" after a disappointing silver screen experience-adaptations continue to flourish. As Hutcheon writes, "If adaptations are, by this definition, such inferior and secondary creations, why then are they so omnipresent in our culture and, indeed, increasing steadily in numbers?" (4). Hutcheon cites the pleasure of recognition as a principal driving force behind adaptation, but I suggest that adaptation remains central to human artistic activity because returning to culturally significant texts allows us to renegotiate their meanings - and therefore their implications for the kind of worlds we want to live in - through ritual and artistic re-negotiation. However, in adaptation this process of re-negotiation is always divided between a cultural loyalty to the hypotext and a desire to re-make the adapted text in defiance of the culturally authorized version.

Euripides’ 428 BCE play Hippolytos is agonistically structured between polar opposites of austere purity and incestuous lust, which may evoke the tension in adaptation studies pitting the devotion to an original (most directly embodied in fidelity criticism) against an ostensibly illegitimate usurpation of a literary/theatrical text (giving rise to charges of vampirism). ${ }^{44}$ The play tells of Hippolytos, the puritanically chaste son of king Theseus, and his stepmother

\footnotetext{
${ }^{43}$ Leitch takes up a similar concern in his essay "Vampire Adaptation," in which he notes, "one of the hoariest clichés in the field is that adaptations act like vampires in sucking the life out of the passive, helpless progenitor texts who enable their existence, often unwittingly or unwillingly, but are powerless to control their excesses" (5).

${ }^{44}$ This tension characterizes contemporary adaptation theory, which maintains strong influences from the Romantic faith in and value of artistic "originality" and "genius." Many non-Western cultural contexts and Western culture prior to around 1785 valued an artist's ability to re-present culturally authorized narratives, characters, and texts in new and unique ways without demanding an absolute originality.
} 
Phaedra, who is doomed by Aphrodite to love her stepson. After Phaedra's nurse discovers that her mistress' wasting illness results from her love of Hippolytos, the nurse reveals Phaedra's desire after making Hippolytos swear that he will not tell anyone the secret. Hippolytos is outraged by the incestuous desire, and Phaedra kills herself to preserve her honor. However, when Theseus returns he finds a note from Phaedra accusing Hippolytos of attempting to rape her. In his rage, Theseus banishes his son and calls on his own father, the sea god Poseidon, to kill the boy. Following Hippolytos' departure, a messenger arrives bearing news of his grisly fate, but Theseus' celebration is cut short by Artemis, the goddess of chastity whom Hippolytos worshipped. Artemis reveals the entire plot to Theseus, including Hippolytos' innocence and Aphrodite's role in turning Phaedra's heart. The play ends with the broken body of Hippolytos brought on stage, where he forgives his father before dying.

Apart from the thematic conflict between incestuous desire and austere purity (i.e., parasitism versus fidelity) ${ }^{45}$, Hippolytos has had unusually strong afterlives through adaptation. ${ }^{46}$ Through the medieval and Renaissance period, the most commonly known version of the myth

45 This ostensible distinction between the pure original and the debased adaptation is rooted in an ethical evaluation, which continues to haunt adaptation studies with the assumed power of fidelity criticism and its implied literary hierarchies. The parasitism so often associated with adaptation stands, in this model, as the obscene and debased counter-part to the holy purity of the original text. This is, of course, one of the myths that contemporary adaptation studies confronts - repeatedly and at length - and the fact that so many theorists of adaptation feel it necessary to deny or denounce the secondary, derivative, or debased status of adaptation shows us just how much power these perceived ethical hierarchies still hold. Needless to say, I don't subscribe to either the notion that original are properly original in the Romantic sense of unique works of a genius, nor to the notion that adaptations are not in themselves unique and innovative works.

${ }^{46}$ All Attic tragedies are versions of Greek mythological stories, and therefore already adaptations, but the extant version of Euripides' Hippolytos is noteworthy because it is one of the few recorded instances of a Greek tragedian returning to the same subject matter. The extant play, properly called Hippolytos Stephanephoros (which might be translated as Hippolytos the Garland Bearer) is a revised version of Euripides' earlier Hippolytos Kalyptomenos (or, Hippolytos Veiled). McDermott explains, "The Hippolytus that has survived as a classic for over two millennia was one of Euripides' two dramatic presentations of Phaedra's love for her stepson and its disastrous results. The surviving play (called either 'Stephanias' or 'Stephanephoros,' to distinguish it from the lost 'Kalyptomenos') is, by the testimony of the hypothesis, the later of the two, produced in 428 B.C.E....it has reasonably (and all but universally) been inferred that the original production of the play had met with such public disfavor that the author was stung to the extraordinary course of presenting a "correction"' (239). We also know of a lost Phaedra by Sophokles that may have shaped the Stephanephoros (246). 
was preserved in the Roman dramatist Seneca's Phaedra. However, contemporary adapters often turn to Jean Racine's 1677 Phèdre rather than to either the Euripides or the Seneca. Racine's version reimagined the myth: shifting Phaedra's guilt to her nurse Cnone, providing Hippolytus with a love interest in Aricia, and focusing more directly on dynastic politics. These changes were in keeping with the taste and fashion of classical French theatre. Racine's play has inspired adaptations ranging from Ted Hughes' free verse or Edwin Morgan's Scots translations, to Tony Harrison's version set in British colonial India. Euripides' version has produced its own adaptations, however, including Timberlake Wertenbaker's free verse translation, Eugene O’Neill's Desire Under the Elms set in rural New England, and H.D.'s starkly Modernist and cerebral Hippolytus Temporizes. These are all examples of what Graham Ley calls secondary adaptation, which involves a theatrical adaptation of an earlier drama ("Discursive Embodiment" 206 and "Cultural Adaptation" 28-29). ${ }^{47}$ Unlike transmedial adaptation—primary adaptation, in Ley's terms - secondary adaptation more directly renegotiates the cultural position and authority of its hypotext. ${ }^{48}$ Throughout the course of this chapter, I shall return to some of these adaptations (as well as others) to illustrate the complexities of adaptation as a form.

\section{What is Adaptation?}

Adaptation is one of the oldest and most pervasive approaches to literature/performance. Aristotle's Poetics - the earliest extant treatise on tragedy in the Western tradition — actually suggests that playwrights should draw from a shared stock of material, taking existing mythology and presenting it in new and innovative ways: "one must not aim at a rigid adherence to the

\footnotetext{
${ }^{47}$ Or a novel adapted from another novel, or a film from another film, etc.

${ }^{48} \mathrm{We}$ will see this in more detail throughout the project. Ley writes, "In the contemporary period of theatre, secondary adaptation is a sophisticated aesthetic weapon, registering what we tend to call an interrogation of a text, finding a vehicle for an intervention, or setting out terms for an adjustment to contemporary dramaturgy. It is recurrent and omnipresent, but each particular case would repay close analysis, since what is at work is more than repertoire recycling, and regularly betrays - largely because a commissioned theatrical adaptation is institutionally embedded - an interesting nexus of aesthetic attitudes and aspirations" ("Discursive Embodiment” 207).
} 
traditional stories on which tragedies are based. It would be absurd, in fact, to do so, as even the known stories are only known to a few, though they are a delight none the less to all" $\left(1451^{\mathrm{b}} .24-\right.$ 26). ${ }^{49}$ What he means here is that while the best tragedies focus on the same broad story linesthe great tragic houses of Atreus, Laius, etc.- - the tragedian must present the material in a way that differs from existing versions. ${ }^{50}$ This has, in fact, been the dominant mode of artistic production in various performance traditions, including European (at least until the Romantic era), African, Indian, and Japanese drama. Ley points out that these theatrical canons draw heavily from culturally constitutive mythologies, often religious: Greco-Roman drama drawing from Homeric myth, medieval European drama building from the Bible, much Sanskrit drama inspired by Hindu holy texts like the Mahabharata, while the noh play Atsumori comes from the epic Tale of the Heike (“Cultural Adaptation” 28). There is a long history of artists combining

${ }^{49}$ This repetition of a canon of myth narratives produces what Bourdieu calls the 'field of cultural production,' which he argues provides both a conservative and revisionary function: "The literary or artistic field is a field of forces, but it is also a field of struggles tending to transform or conserve this field of forces" ( 30 , original emphasis). He argues that each phase of a culture's literary/artistic development subsumes and negates the phase before it, moving through a genealogy of rebellion against the prior generation's predominant artistic mode. One consequence of this dialectic of negation is that "returns to past styles (frequent in painting) are never 'the same thing', since they are separated from what they return to by negative reference to something which was itself the negation of it" (60, original emphasis). In other words, the reproduction of a previous style or narrative through adaptation is inherently the production of a new artistic work in a new context because the adaptation is a product of a culture that has returned, as a negation, to a previous style that was itself negated by an intermediary artistic generation.

${ }^{50}$ Similarly, in 19 BCE, the Roman poet and critic Horace exhorted tragedians in Rome to represent the same myth cycles in new and innovative ways, writing, "with some few precautions, you may set / Your private mark on public chattels yet" (74). However, he also cautioned that Roman playwrights should avoid being "bound too closely to the Grecian muse" (74). In other words, by the Roman period-remember that the Romans were deeply inspired by Greek aesthetics, mythology, and theatre - Horace instructs Roman dramatists working with Greek mythological cycles to establish a balance between original interpretations and the revision of existing material. Centuries later, TS Eliot advocates a similar balance, a similar relationship between original and traditional material in his essay "Tradition and the Individual Talent." Eliot argued against the pervasive notion that a poet (or artist in general) should be judged based on the originality of their work, or by the portions of the work that least resemble any other artist. Instead, Eliot argues that, "if we approach a poet without this prejudice we shall often find not only the best, but the most individual parts of his work may be those in which the dead poets, his ancestors, assert their immortality most vigorously" (499). Or, as he puts it, the best artistic works demonstrate a knowledge of the past's continuity in the present and acceptance of the interconnectedness of originality and tradition (499). 
traditional material in new ways, but in the latter half of the $20^{\text {th }}$ century-largely with the emergence of film studies - adaptation studies took on its contemporary disciplinary contours.

Few other fields within literary criticism devote as much ink to self-definition as adaptation studies. Virtually every book on adaptation studies includes a section defining adaptation and distinguishing it from related concepts like appropriation, intertextuality, or parody. ${ }^{51}$ While acknowledging this genre convention, I still want to spend a brief amount of space explaining adaptation. Linda Hutcheon and Julie Sanders have probably done as much as any two thinkers to provide adaptation studies with a common language and theoretical framework. Hutcheon's 2006 A Theory of Adaptation (revised in 2013) was a landmark work in establishing disciplinary coherence among adaptation theorists. Hutcheon locates adaptation within a large scale cultural framework, looking at various methods of transcultural, transhistorical, transpolitical, and transmedial adaptation, as well as providing over-arching thoughts on issues like the cultural and monetary economics of adaptation. Hutcheon's basic definition is: "Adaptation is repetition, but repetition without replication" (7). What this means is that adaptation in some way rewrites/reperforms a prior text, but does so with critical distance. She asserts that this distance - and we can preliminarily suggest this as the difference between an adaptation and a translation, though the distinction is a troubled one $\mathrm{e}^{52}$ - allows the adaptation to

51 The prevalence of these definitional impulses are one reason adaptation studies has struggled to develop a complex theoretical framework in the way that many other critical disciplines have. In his book on Parody, Denith argues that scholars often fail to tell us anything about the substance of the field because they get bogged down in detailed distinctions over definitions that don't affect how we read or interpret the text at hand (6-7). Genette's Palimpsests, for instance, is a weighty tome devoted to establishing a catalogue of minute distinctions between different models of intertextuality. The book is compendious (and challenging for readers not intimately familiar with the classic French literature from which Genette draws many of his examples). But, as Denith argues, its devotion to detail has two major drawbacks: 1) Genette's painstaking definitional work won't ultimately set the terms through which either scholars or laypeople talk about intertextuality, and 2) these distinctions tell us nothing about the context, history, or purpose of the intertextual relationships (Denith 14). As Elliott puts it, "If the field continues to lack a presiding poetics, it is more because scholars cannot agree upon one rather than because one has not been propounded" ("Theorizing" 22).

52 With innermedial adaptation (in this case adapting a Greek tragedy for the contemporary stage), the more closely one approximates the adapted text the closer one is to translation rather than adaptation. However, the 
stand as its own work of art. However, this is not to say that the relationship with the previous text can be ignored: "Although adaptations are also aesthetic objects in their own right, it is only as inherently double- or multilaminated works that they can be theorized as adaptations" (6, original emphasis). In other words, Hutcheon asserts that adaptations must establish some degree of distance from the adapted text, but that we as readers/viewers must be aware of the hypotext in order to understand that critical distance.

In Adaptation and Appropriation, Sanders takes a more definitional approach, proposing the two broad titular categories as related methods of intertextuality. Essentially the difference Sanders suggests is one of distance: adaptations are closer to the adapted texts than appropriations, while appropriations develop a more critical relationship. She explains that an adaptation "constitutes a more sustained engagement with a single text or source than the more glancing act of allusion or quotation, even citation, allows. Beyond that, appropriation carries out the same sustained engagement as adaptation but frequently adopts a posture of critique, even assault" (4). This is fundamentally a distinction based on the perceived ideological/aesthetic distance between the hypotext and the hypertext. For Sanders, adaptation signals some kind of transposition without a critical re-envisioning, while appropriators take material for their own distinct purposes. She explains that adaptations are "reinterpretations of established texts in new

dividing line between these two intertextual forms is not always immediately apparent. When most people think of translation they probably think of what both Bassnett, and Raw and Gurr characterize as pedagogical translation. Bassnett explains that in teaching second languages, instructors generally understand translation as having two goals: conveying the surface meaning of the source text, and conveying the linguistic/literary structures as much as possible from one language to the other (11-12). Raw and Gurr similarly describe what they call the 'transfer model,' which asks translators to "find the closest possible equivalents in the target text: in other words, to remain 'faithful' to the target text" (164). However, some translation theorists assert a much more expansive and creative role for translators than merely conveying a source's words from one language to another. Whereas the Western tradition imagines the translator as invisible (Venuti being one of the most important proponents of the translator's invisibility), Bassnett champions what she identifies as non-European explanations of the translator's role: "a redefinition of the terminology of faithfulness and equivalence, the importance of highlighting the visibility of the translator and a shift of emphasis that views translation as an act of creative rewriting" (6). Bassnett advocates seeing translators as co-creators of an artistic text, rejecting the notion that translation is secondary or purely mimetic. 
generic contexts or perhaps with relocations of an 'original' or sourcetext's cultural and/or temporal setting, which may or may not involve a generic shift" (19). In other words, adaptation involves processes like medial shifts, changes in historical/geographic setting, linguistic/dialect or stylistic changes. However, appropriation involves a much more distanced relationship: "appropriation frequently involves a more decisive journey away from the informing source into a wholly new cultural product and domain" (26). One limitation of this distinction between adaptation and appropriation is in the assumption that something like a transhistorical shift can be done without establishing an effective critical distance. But the textual fluidity created by, at the very least, changes in reception context may mean that any rewriting (and, as we shall see, perhaps any re-performance) is inherently distanced.

Kamilla Elliott invokes textual fluidity and the multi-dimensional nature of contemporary adaptation as a counterpoint to fidelity criticism, which tends to reduce the adaptive process to a singular reproductive relationship. ${ }^{53}$ Notions like fluidity, dialogue, and dialectical exchange loom large in how contemporary adaptation theorists conceptualize the discipline. Adaptation is inherently heteroglossic, with multiple authorial voices, points of view, and languages at work within a singular text. This polyvocality is crucial to the politics of adaptation because it puts different voices into the same artistic space, which opens possibilities for cosmopolitan cultural interaction (which will be discussed in more detail later in this chapter and in chapter V). Heteroglossia is a concept developed by Mikhail Bakhtin to describe the multiple voices and perspectives at work in the novel: "a diversity of social speech types (sometimes even diversity of languages) and a diversity of individual voices, artistically organized" (262). The polyvocality

\footnotetext{
${ }^{53}$ She writes, "changes to the source text hold more scholarly value than fidelity because they convey more information about adapting contexts and processes of adaptation" ("Adaptation of Adaptation" 149, original emphasis).
} 
Bakhtin describes manifests in adaptation as the echoing or haunting of the adaptation by a hypotext - the layering of voices from a previous version of a play. Hutcheon claims that adaptations are "haunted at all times by their adapted texts. If we know that prior text, we always feel its presence shadowing the one we are experiencing directly" (6).

To take an example of this echoing, Ted Hughes' translation of Phèdre replaces the stately alexandrines of Racine with a sleeker twentieth century style free verse. However, for those familiar with classical French drama the longer and more regular lines of Racine haunt Hughes' shorter lines. Take for example, Hippolytus' opening stanza in Racine (translated by Rawlings):

Le dessein en est pris: je pars, cher Théramène, Et quitte le séjour de l'aimable Trézène. Dans le doute mortel dont je suis agité, Je commence à rougir de mon oisiveté. Depuis plus de six mois éloigné de mon père, J'ignore le destin d'une tête si chère;

J'ignore jusqu'aux lieux qui le peuvent cacher. (26)

My mind's made up. I go, Theramenes:

I can no longer stay in beautiful

Trozene. In mortal doubt I waver; grow

Ashamed of idleness. Six months and more

My father has been gone! I do not know

What has become of that beloved head:

Nor even where upon the earth he hides. (27)

Racine's verse is written in the long twelve syllable lines characteristic of French classical

drama, as opposed to the more varied lines of Hughes' contemporary free verse:

I have made my decision.

It is six months now

And there hasn't been one word of my father.

Somebody somewhere knows what's happened to him.

Life here in Troezen is extremely pleasant

But I can't hang around doing nothing

With this uncertainty. My idleness makes me sweat.

I must find my father. (3) 
In contrast to the classical regularity of Racine's alexandrines, Hughes both opens and closes this speech with shorter, punchier declarative sentences. Although the content of the speeches remains roughly the same, the style of Racine's Hippolytus is decidedly different from Hughes' style. Racine's lines have formal musicality, they suggest a regular rhythm for the actor's speech. On the other hand, Hughes' conversational free verse echoes the sounds of everyday speech. Again, however, the courtly style of the hypotext remains as an echo for viewers/readers who remember the conventions of classical French theatre and Phèdre. Memory is particularly important in drama because, as Carlson argues, theatre relies for its meaning making strategies on audiences' ability to read and derive meanings from different performances of the same text(s). He writes, "Among all literary forms it is the drama preeminently that has always been centrally concerned not simply with the telling of stories but with the retelling of stories already known to its public" (17).

Further, the very practices of theatre are heteroglossic, requiring a communal effort wherein a variety of voices and participants collaborate to create a unified artistic work. Not only playwrights, directors, and actors work together, but entire theatre companies including tech people, designers, front of house staff, ushers, etc. Even a one person show requires an infrastructure of support, an infrastructure of people who contribute their various talents and skills to the success of the performance. Beyond those directly involved in creating a theatrical production are the communities and institutions whose efforts are necessary to support performances. While most contemporary theatre does not engage as many people as the massive festivals at which ancient Athenian drama was performed, theatre today remains a much more communal experience than most other art forms - something we witness in a space shared with other spectators, where our reactions can influence how the actors perform their parts. 
Scholars take up the question of intertextual relations in different ways, characterizing the adaptive process according to different models, but one element most theorists emphasize is the reciprocal relationship between the hypo- and hypertext. In other words, the process of adaptation is not unidirectional or teleological, because an adaptation actually alters how we experience the adapted text(s). Hutcheon writes, "we often come to see the prior adapted work very differently as we compare it to the result of the adapter's creative and interpretive act" (121). ${ }^{54}$ Many contemporary adapters use their revisions to challenge the cultural role/authority of Greek tragedy, which underpins many Imperialist/racist conceptions of Western cultural superiority. This dual relationship is especially important to theorists working on African adaptations of Greek tragedy, who frequently emphasize the ways in which African adapters critique the cultural role of the Greeks/classics in narratives of Euro-American superiority. In an essay on West African adaptations of Greek drama, Budelmann asserts, "Studying the reception of ancient Greek and Roman literature should always be a two-way process. After looking at the engagement of the new plays with the ancient plays, it is now time to see whether the new plays can point us back to the ancient plays" (139). Astrid Van Weyenberg is more explicit: "the adaptations direct attention to Greek texts and contexts, as well as to the cultural tradition of which Greek tragedy has come to form a canonical part" (xii). In other words, our experience of an adaptation will inherently change the context from which we experience the adapted text. Adaptation is not teleological in the sense that a certain text is created and then in the future a new work adapts that text. Rather adaptation is multifaceted: there is a teleological component,

\footnotetext{
${ }^{54}$ In advocating a dialogic approach to adaptation, Bruhn makes a similar argument for seeing a reciprocal relationship between adapted texts and adaptations. He explains that adaptation "ought to be regarded as a two-way process instead of a form of one-way transport... we should study both the source and result of the adaptation as two texts, infinitely changing positions, taking turns being sources for each other in the ongoing work of the reception in the adaptational process" (73, original emphasis).
} 
but there is also an anti-chronological element as the adaptation reflects back upon the adapted text to challenge its assumptions, ideology, and place within the canon.

In some cases, adaptations draw attention to their own anti-teleological nature. For instance, in Marina Carr's Phaedra Backwards (which premiered at the McCarter Theatre in Princeton, NJ, in October 2011) the plot of Phèdre is run both backward-beginning after Hippolytus' death — and in a modernized setting. This play is interesting, not only for the reversed order of the plot, but because temporality and causality are central thematic concerns. In particular, Phaedra is concerned with how the past asserts itself in the present. In the first scene she tells Theseus, "Last night was the cause of tonight as tonight will spawn tomorrow and all your tomorrows until the..." (79). These are prescient words, because as the play continues Phaedra becomes increasingly haunted by her family's past_culminating in an attack during scene 8 by the spirits of Pasiphae, Ariadne, Minos, and the Minotaur, during which they beat, hang, and bite chunks out of Phaedra. Phaedra is, in this scene, literally consumed by the ghosts of her past, which come to determine her future. The final image of the play conflates Phaedra's past and present/future, as the Minotaur slain by Theseus before Phaedra's marriage becomes Poseidon's sea bull who kills Hippolytus - the stage directions read, "Enter the Minotaur carrying Hippolytus, both dripping from the sea" (124). The temporal play in this version evokes the recursive and reflexive teleology of adaptation itself: spawned by, reproducing, and challenging the past.

John Bryant proposes a geneticist approach to adaptation, identifying what he calls fluid texts. The genetic approach to fluid texts takes a work to be inherently located within its broad cultural context and through all versions of a text. ${ }^{55}$ Conceptualizing adaptations as fluid texts

\footnotetext{
${ }^{55}$ Bryant writes, “if we see the writing process as progressing beyond the originating author's work, stretching back in time to sources that precede the work and forward from the moment of publication across genres
} 
requires us to see them as part of a lineage, stretching back to source text(s) and forward to future incarnations. With plays, this collection of past and future incarnations is more expansive than for novels or poetry because various productions can also play important roles in how we understand a text. For instance, Erika Fischer-Lichte's Dionysus Resurrected and Helene Foley's Reimagining Greek Tragedy on the American Stage both trace important performance histories of Greek tragedy. However, adaptation theorists differ over whether or not individual performances of plays qualify as adaptations. Would a particular production of Euripides' Hippolytos count as an adaptation (as opposed to a play like Phaedra Backwards)? Of course, any production of a play on any given night will differ from every other production, and every run of a show will differ drastically from every other company's production.

Many adaptation theorists believe that performance does constitute adaptation through the physical embodiment of one potential enactment of a play. Hutcheon and Laera both assert that adaptation is a broad enough term to incorporate all performances. Laera states directly that adaptation "also covers the work of directors and their mise en scène, that of actors in performance and rehearsals, that of translators in transferring a text from one language to another, and that of audiences in co-authoring and responding to a piece" (Introduction 2). Hutcheon makes a similar point, reminding us that a play script offers fairly few guidelines "about such matters as the gestures, expressions, and tones of voice," which are worked out by individual actors and directors (39). ${ }^{56}$ On the other hand, Ley argues that the term adaptation

and media; and if we see creativity as both an individual and social process involving moments of solitary inspiration but also collaboration with readers; then we can conceive of a 'version' of geneticism at its fullest, one that embraces the social text in its broadest material incarnations, and in particular texts in revision, or what I call the fluid text. A fluid text is any work that exists in multiple versions in which the primary cause of those versions is some form of revision" (47-48, original emphasis).

${ }^{56}$ Fischlin and Fortier are more cautious, writing, "Writ large, adaptation includes almost any act of alteration performed upon specific cultural works of the past and dovetails with a general process of cultural recreation" (4). However, they follow this broad definition by noting that the plays contained in Adaptations of Shakespeare involve more substantial rewritings of the Bard's works, rather than just unique performances. 
loses critical meaning when expanded to include what he calls "realizations" of a script (“Cultural Adaptation" 30). He contends that from a performance studies perspective, every discrete performance is assumed to be different — that a performance of Hippolytos at London's National Theatre would naturally differ from a performance at a Cape Town high school. ${ }^{57}$

As with most of the terminological disputes characterizing adaptation studies, I am not convinced that this difference of opinion tells us much one way or the other about either a particular performance or how we should react to a play. However, it is important that we remain aware of performance histories and practices because contemporary adaptations-either rewritings or radically unique stagings — respond to, complicate, and build upon repertoires of performance style. Diana Taylor tells us that repertoires play a key role in simultaneously preserving embodied knowledges and allowing those knowledges to change and adapt to new socio-cultural needs and conditions. On the one hand, Taylor says, "Embodied expression has participated and will probably continue to participate in the transmission of social knowledge, memory, and identity" (Archive and the Repertoire 16). However, unlike the material artifacts and records that make up a cultural archive, the repertoire allows for growth and change (Archive and the Repertoire 20). The notion of the repertoire as a performed and living repository of cultural knowledge and forms is important when considering the social/civic function of theatre and performance — unlike most other forms of art, which are regularly enjoyed alone, theatre and performance are often viewed in groups. ${ }^{58}$ Without the presence of spectators and performers, the repertoire degrades because transmission is personal: "The repertoire requires presence: people participate in the production and reproduction of knowledge by 'being there,' being a part

\footnotetext{
${ }^{57}$ At the outside, Ley is willing to concede that "except in extreme examples, we might think that this kind of adjustment lies at the slighter end of adaptation" ("Cultural Adaptation" 30).

58 Though again, contemporary black box, proscenium arch, and even major national theatres rarely intend/do bring together as many spectators and performers as the Greek festivals.
} 
of the transmission" (Archive and the Repertoire 20). These repertoires of performance offer one way of making and comprehending meaning across the multitude of versions of a particular play, whether those be enactments, adaptations, or realizations.

Seeing adaptations within a continuum of versions helps understand the relationships between multiple complex texts. For instance, the intertextuality of Sarah Kane's Phaedra's Love becomes more complex when regarded as a fluid text connecting to both Seneca's Phaedra and Euripides' Hippolytos. According to Kane, her play was an adaptation of the Seneca version, and she told an interviewer that she hadn't read the Euripides (Laera, Reaching Athens 172). She also claimed that she chose to rewrite Hippolytos because "everything happens offstage" in Attic tragedy (qtd. in Laera, Reaching Athens 171). Certainly, the Senecan tragedy is more overtly gory than the Euripidean hypotext, but Laera argues that Phaedra's Love is "closer to the Greek text than one might initially expect" from an author who claims not to have read the Attic version (Reaching Athens 172) ${ }^{59}$ Kane's In-Yer-Face version of the play borrows elements from both the Roman and the Greek version, but ultimately represents a very contemporary theatrical experiment in visibility and the limits of staging. Her project in Phaedra's Love was ultimately an experiment in the reception of an ancient play, because as she told interviewer Nils Tabert, "I thought you can subvert the convention of everything happening off-stage and have it on-stage and see how that works" (qtd. in Laera Reaching Athens 175). In other words, the play challenges the (ostensible) conventions and limitations of Greek tragedy and proposes a new cultural mode for these stories in the late $20^{\text {th }} / 21^{\text {st }}$ century. ${ }^{60}$ However, between Phaedra's Love

${ }^{59}$ Laera explains, "In Seneca and Racine, Phaedra kills herself onstage at the end of the play, unlike in Kane and Euripides. Kane also adopts Euripides' scheme of a suicide in the middle of the play with a note accusing Hippolytus of rape, an element which can only be found in Euripides. What seems to have influenced Kane most strongly, however, is Seneca's final dismemberment of Hippolytus' body" (Reaching Athens 172).

${ }^{60}$ Laera argues persuasively that the long understood rule about violence and death taking place off stage in Greek tragedy is actually a myth based in part on scholarly impositions of Christian morality onto the Athenians. 
and the Euripides and Seneca hypotexts we can see complex relationships and influences working in both directions: Euripides and Seneca inspire Kane, and Kane asks us to rethink the limits of visibility implied or established in the earlier dramas. Though, as Laera suggests, Kane may not get as far from the Greek hypotext as she imagines.

\section{Faithful Infidelity}

The question of distance is central to adaptation theory and usually manifests in discussions of fidelity criticism. In brief, fidelity criticism assumes that a hypertext should seek to reproduce its hypotext as exactly as possible. The irony of fidelity criticism is that adaptation theorists seem to spend more space denouncing it than has actually been devoted to fidelity studies themselves. ${ }^{61}$ Unlike page-to-screen adaptations (the general domain of fidelity discussions), there is little imperative for a theatrical adaptation of an Hellenic tragedy to follow its source material precisely because secondary adaptation depends for its effect on not merely being a version of the original text. ${ }^{62}$ However, I want to take up the idea of fidelity in a new way, because I feel we can put fidelity to good theoretical use (at least in the context of adaptations of Greek tragedy). I propose an ethic of "faithful infidelity."

What do I mean by this? Faithful infidelity is the act of political adaptation, not in the sense of accurately re-presenting/re-producing a source text, but in fidelity to reproducing (what we imagine to be) the political project and critical aspirations of Attic dramatists. While the Greeks used tragedy to imagine and promote a limited form of democracy, our ultimate goal

\footnotetext{
She shows that the preference for reporting violence rather than displaying it was more likely a logistical and performative decision based on the economy of actors and the limitations of staging realistic violence.

${ }^{61}$ Virtually every contemporary scholar working on adaptation distances themselves from fidelity criticism, so much so that Elliott dismisses the rejection of fidelity criticism as a faux innovation substituting for critical insight in undertheorized adaptation studies works. She claims, "scholars who have read prior work know that fidelity has always been robustly challenged in adaptation studies" ("Theorizing" 24, original emphasis).

62 This is, of course, complicated by two important debates: whether or not a particular production can be an adaptation, and the degree to which we should distinguish between translations and adaptations.
} 
should be to contribute to a cosmopolitan commonwealth of cultural forms helping to remake a more just world. The idea that adaptations engage in a world-building project similar to their Greek source texts is, I think, particularly important in terms of how we should view adaptions, and how we should understand their political potential. Rather than the naïve and myopic demands of old school fidelity criticism, I argue for embracing a new fidelity criticism based on loyalty to a (contemporary understanding of) the political spirit of Greek tragedy, rather than trying to reproduce or replicate these plays on a content level. Greek drama, through its strategies of political and cultural formation, provide opportunities for contemporary dramatists, theatre practitioners, and audiences to establish liberatory relationships with the ideals of the plays. To an extent, this potential is evidenced by the fact that Attic drama has been picked up as source texts for adaptation by dramatists all over the world, but more fundamentally, because Greek tragedies engage in a world-building project, they offer the cultural and artistic space to re-make worlds in more just and equitable forms.

If we accept that a fundamental characteristic of Greek tragedy is the use of a shared mythological canon refashioned/re-presented as commentary on contemporary political or cultural situations with the underlying goal of providing a ritualistic foundation to maintain cultural stability, then this is a project modern adaptations are ideally suited to continue. ${ }^{63}$ Many adaptations engage in multi-tiered critiques: on a content level with direct political commentary, on the level of microsigns with hybrid cultural forms, and contesting modes of cultural transmission by challenging oedipal models of cultural authority. However, even as adaptations

${ }^{63}$ I think adaptation as a form inherently offers this liberatory potential, and it need not necessarily be limited of Attic tragedy. I would make the same argument about many adaptations of Shakespeare, or Ibsen, or Chekov. However, I do think that, given the status of the ancient Greeks in contemporary cultural history as signifiers for democracy, philosophy, theatre, the arts, etc. adaptations of Greek tragedy exemplify the cosmopolitan potential of adaptation perhaps more directly than adaptations of many other works. 
critique and contest cultural spaces, the technique through which these critiques are performed remains the same: a shared set of cultural images/myths/ideas deployed in unique and purposeful ways as the material of social commentary. In other words, even as some adaptations trouble cultural authority on the level of microsigns and modes of cultural transmission/reproduction, adaptation builds upon and participates in a commonwealth of shared knowledge. Adapters capitalize on pre-existing impressions of source texts, which of course assumes that the text(s) being adapted are recognizable enough that audiences will know and engage with them. And again, because textual transmission is fluid rather than teleological, adapters combine many traditions, performance styles, and approaches, thereby situating the Attic play as one component of a complex and multifaceted cosmopolitan performance.

The use of these multiple traditions, performances, styles, sources, intertexts, and adapted works constructs and strengthens a shared commonwealth of style, content, ideas, and images, which becomes increasingly capable of remaking the world through fidelity to the ideals of justice, co-existence, and openness. This, I think, is the political project of faithful infidelity: to forgo any pretense that adaptations must be limited translations and focus instead on the potential to reshape unjust political, economic, and social arrangements by building and participating in a shared culture that is global in its ability to draw on symbols, images, styles, narratives, and performances, but local in its applications of this shared commonwealth to specific political, social or cultural situations. In other words, we can (re)build a more just global, hybrid community through a shared commonwealth which manifests locally. And each application of the shared global culture enhances the store and value of this commonwealth. Rather than viewing Greek culture, literature, and drama as the exclusive cultural property of the West, the political project of faithful infidelity within a commonwealth encourages us to see Greek drama 
(along with all other cultural forms) as part of a global culture that provides a basis for reconstructing an ever more socially just global world.

As we shall see in more detail in chapter $\mathrm{V}$ and the Conclusion, this process of building a global culture is both ethically important and practically challenging. One problem, often identified by critics studying intercultural theatre, is the risk of global north theatre practitioners appropriating (in the sense of stealing illegitimately, though as we shall see this concept is more complicated than it initially seems) global south performance cultures or rituals, and simultaneously asserting, in the old imperialist fashion, that Attic tragedy continues to be a distinctly Western cultural force. However, the process of adaptation, particularly by blending sources - including Greek tragedy with other cultural myths and styles - can open new ways of conceptualizing a shared world and seeing other people and cultures as legitimate. In promoting a style of cosmopolitanism that encourages us to converse with strangers, Kwame Anthony Appiah writes, "evaluating stories together is one of the central human ways of learning to align our responses to the world. And that alignment of responses is, in turn, one of the ways we maintain the social fabric, the texture of our relationships" (29). The challenge, of course, becomes to realign our responses not merely by our own cultural stories but on a global scale. ${ }^{64}$ Adaptation, particularly intercultural adaptation, allows cultures or individuals to change how it/they align(s) behind cultural stories.

${ }^{64}$ Hardt and Negri argue that a universal right to education is necessary to promote a genuine democracy of the multitude and the global right to collective self-rule: "Everyone needs access to a basic education, of course, and a series of basic social and technical knowledges and skills. These are some of the prerequisites necessary for any political participation. Armed with these basic elements everyone will not be the same, of course, but will be able to participate equally in the collective management of society" (Commonwealth 381). 


\section{Why the Greeks in the $20^{\text {th }}$ and $21^{\text {st }}$ Centuries?}

The Introduction provided a brief introduction to why $5^{\text {th }}$ century BCE Athenian tragedy has so thoroughly engaged the interest of late $20^{\text {th }}$ and early $21^{\text {st }}$ century dramatists and audiences, but this section will provide a more comprehensive explanation. ${ }^{65}$ One of the most important reasons Attic tragedy remains influential is because of its ritual world-defining role. I argue that adaptations of Greek tragedy seek to promote a new, more ethical world, and this premise undergirds evocations of the common: that through ritual and performance Attic tragedy helped build a new democratic polis, and adaptations can serve a comparable generative function. Barbara Goff and Michael Simpson assert the necessity of performatively establishing cultural foundations through repeated ritual:

Both these ancient and these modern plays are preoccupied by the paradox of the foundational moments that they represent: since these foundations of social institutions cannot be built on anything, because they are absolute beginnings, they must be ritually refounded so that they will cumulatively come to be founded on themselves. To be new, liminal events they must, paradoxically, be repeated. (19)

Performance and ritual have been systematically theorized as socially transformative forces, capable of both preserving and reshaping cultures. Victor Turner provides a foundational theory of the world-building potential of ritual, arguing for the power of liminal rites of passage to facilitate change. He claims that during rituals or rites of passage "there has to be an interfacial region or, to change the metaphor, an interval, however brief, of margin or limen, when the past is momentarily negated, suspended, or abrogated, and the future has not yet begun, an instant of

\footnotetext{
${ }^{65}$ Interest in the Greeks has to do with contemporary trends in classical reception. As Hardwick explains, reception studies focuses on how people within a given cultural context understand and ideologically deploy images of and texts from Greek and Roman cultures (and for some scholars, other classical civilizations): "interest has focused on ways in which some aspects were selected and used ('appropriated') in order to give value and status to subsequent cultures and societies and to inspire new creative work" (3). This process of reception is neither neutral nor objective, but is deeply contoured by the preoccupations and needs of particular societies. In The Future of the 'Classical', Settis traces a kind of genealogy of classical reception, demonstrating how profoundly cultural and ideological deployments of Greco-Roman antiquity have changed through the history of Western culture.
} 
pure potentiality when everything, as it were, trembles in the balance" (44, original emphasis). In other words, by passing through three distinct ritualized phases-separation, transition, and incorporation (24-25) — cultural elements, norms and truths can be reorganized and coalesce in new, sometimes radically different, forms. The radical transformation made possible by liminal performances allowed democratic Athenians to promote an imagined democratic polis, proposed as an alternative to all previously existing governmental forms.

But what kind of social institutions did Athenian tragedy suggest? These plays functioned as ideological state apparatuses, utilized by pro-democratic aristocrats like Perikles and Themistokles to promote democratic values like the equality of citizens before the law and freedom of speech. ${ }^{66}$ Performing these values publicly helped establish them as cultural norms in the Athenian polis. Goff and Simpson characterize this as "the Athenian polis interrogating itself, and its radical democracy, by testing itself democratically against its Theban antithesis" (19-20). Through the liminal experience of Athenian tragedy — which was, as we must remember, culturally situated within a religious festival—Athenian culture could be reformed. However, the ideals of the Athenian democrats as well as those we now identify with the classics may reflect profound differences from the evidence provided by history. Laera argues that many modern beliefs about Greek culture are not supported by the historical record, and that modern theatrical performances of Attic tragedy conservatively shore up neoliberal representative democracy and Christian-influenced Western sensibilities.

${ }^{66}$ While tragedy certainly represented other values and ideas - human fatedness, the power of the gods, etc. - and Athenian culture had any number of repressive elements in practice, I believe, with Hall (the relevant passage will be quoted below) that tragedy allowed Athenians to imagine a more open and truly democratic polis than their political reality allowed. And for our contemporary liberatory projects, this ability to imagine possibilities beyond our current boundaries opens the possibility to move beyond the limits of late capitalism. 
While Laera's argument is well developed and supported, I identify different trends in contemporary adaptations of Greek tragedy, namely the redeployment of certain Greek values (whether or not those values reflected the reality of Greek daily life) to protest contemporary structures of inequality and exploitation in the name of cosmopolitan cultural ideals. For instance, two principle values evoked by the plays examined here are civic engagement within a community and democratic political organization. Attic theatre reflected both of these values, though as Laera reminds us these were often espoused and contested values more than the practical reality of $5^{\text {th }}$ century Athenian life. ${ }^{67}$

Politically, Athens in the $5^{\text {th }}$ and $4^{\text {th }}$ centuries BCE was a democracy, but this democracy looked very different from contemporary liberal/representative democracies like the ones in the UK or US. Two of the major differences were: 1) Athenian democracy had a very limited scope of citizenship, including only free-born males, and 2) political decisions were made through direct democratic interaction rather than representatives. Women, slaves, and foreigners were all excluded from the political life of Athens, though they played necessary social roles in keeping Athenian society functioning. ${ }^{68}$ If the stratification of society and the political disenfranchisement of as much as three quarters of the city-state's population were the negative elements of Attic democracy, its advantage over contemporary democratic frameworks was direct democracy. ${ }^{69}$ Rather than voting for representatives who make decisions on behalf of their

\footnotetext{
${ }^{67}$ Of course, for much of the era of Attic tragedy, Athens found itself threatened by enemies like the Persians or the Spartans, so these democratic values were continually threatened and tested by invasion and conflict.

${ }^{68}$ As Arendt puts it, "this equality of the political realm has very little in common with our concept of equality: it meant to live among and to have to deal only with one's peers, and it presupposed the existence of 'unequals' who, as a matter of fact, were always the majority of the population in a city-state" (32). While contemporary society, especially under neoliberalism, is riven by class differences, at least in theory citizenship is a right freely available to everyone. In practice contemporary liberal democracies continue to rely on an underclass for their daily functioning, but on an ideological level this dependency is elided.

${ }^{69} \mathrm{My}$ point in drawing these comparisons is precisely that each system has undemocratic shortcomings that should be resisted. However, I believe it is possible to imagine (and implement) a democratic system combining the
} 
constituencies, in Athens citizens attended the ekklesia (the public assembly) where issues were debated, court cases were heard, and voting took place. ${ }^{70}$ In the ekklesia, speakers trained in rhetoric advocated or opposed policies, and citizens voted by putting a colored pebble into large counting jars, a white pebble for yes or a black pebble for no. Direct voting combined with the drawing of lots to assign many civic responsibilities, thereby distributing political authority/responsibility (fairly evenly) among citizens rather than concentrating power in the hands of professional politicians. ${ }^{71}$ For Laera, the differences between Athenian and contemporary democracy constitute a problem because, she argues, contemporary performances of Attic tragedy ideologically reinforce the cultural notion that Athens was an origin point for Western (i.e., democratic) culture, and legitimize contemporary democratic structures through an idealized evocation of classical Athens.

In contrast to Laera's position, I think contemporary adaptations often evoke ideals of political equality and civically-engaged citizenship present in democratic Athens, even if the reality failed to live up to those ideals. Although some-like Plato-denounced democracy as ineffective mob rule governed by selfishness and desire, other Athenians were strident defenders of democratic ideals. In his Politics, Aristotle links freedom and equality (for citizens) as the great virtues of democracy: "from the type of justice that is agreed to be democratic, which consists in everyone having numerical equality, comes what is held to be most of all a democracy and a rule by the people, since equality consists in the poor neither ruling more than

best elements of both systems - the (nearly) universal suffrage of modern nation-states with the direct participation of the Athenian polis - while trying to limit or eliminate the disadvantages.

${ }^{70}$ In principle, every citizen could attend, though work or geographic distance from the city probably made it difficult for poorer citizens to attend as often as their aristocratic compatriots.

${ }^{71}$ Plato, an outspoken opponent of democracy, referred condescendingly to this process of drawing lots in Book VIII of the Republic. He describes a morally bankrupt young man - a stand in for democracy — who allows himself to be ruled by whatever idea temporarily holds sway over him: "And so he lives, always surrendering rule over himself to whichever desire comes along, as if it were chosen by lot. And when that is satisfied, he surrenders the rule to another, not disdaining any but satisfying them all equally" (561 ${ }^{\mathrm{b}}$, my emphasis). 
the rich nor being alone in authority, but in all ruling equally on the basis of numerical equality" $\left(1318^{\mathrm{a}} .3-8\right) .^{72}$ If the equality of citizens within a political framework is a fundamental goal of democracy, then it becomes possible to utilize the democratic echoes within Attic tragedy to advocate for greater democracy today. Those echoes neither inherently reinforce contemporary liberal democratic power structures nor limit us to the realities of Hellas.

We need not be limited by the historical shortcomings of $5^{\text {th }}$ and $4^{\text {th }}$ century Athenian life, but we can redeploy these classical texts in our own context to revive ideals of equality and direct democracy, while simultaneously denouncing the gendered, economic, and nativist exclusions of Athenian (and contemporary) political life. Theatre provides aesthetic tools through which we can reimagine - and thus begin the work of reforming - the worlds in which we find ourselves. In contrast to the relatively limited scope of Athenian democracy in practice, on the stage Athenians could imagine vastly expanded political possibilities and democratic openness - In "The Sociology of Athenian Tragedy," Edith Hall argues, "Greek tragedy does its thinking in a form which is vastly more politically advanced than the society which produced Greek tragedy. The human imagination has always been capable of creating egalitarian models of society even when they are inconceivable in practice" (125). It is for this reason that Hellenic tragedy offers such a fertile terrain for imagining a world commonwealth, a multitude of global citizens whose productive capacity exceeds traditional modes of production, and whose creativity undoes the restrictive structures of neoliberal capitalism. The egalitarian and democratic political thinking Hall identifies was deeply imbued in the fabric of Attic drama.

\footnotetext{
72 In contrast to Plato's denunciation of the rule of desire in democracy, Aristotle defines both citizenship and the polis through responsibility and cooperation. He writes, "someone who is eligible to participate in deliberative and judicial office is a citizen in this city-state, and that a city-state, simply speaking, is a multitude of such people" $\left(1275^{\mathrm{b}} .17-19\right)$. In other words, what defines a citizen is responsibility to the state, and what defines the state is the conglomeration of citizens, therefore, the fundamental assumption of the polis is the mutually constitutive relationship between the individual and the collective; without the collective individual citizenship is meaningless, and without individual citizens the collective of the polis is incomprehensible.
} 
For classical Athens, theatre was much more than a mode of entertainment-it was a mode of participatory democracy. Both the materiality of the theatre as a physical space, and the structure of tragic performances mirrored Athenian democratic ideals. Physically, the theatre where the City Dionysia took place was a central location commanding a view of Dionysos' shrine and one's fellow citizens. The purpose of this location was that "spectators would be conscious of far more than the performance unfolding below - of the city and country around them and of their very existence as spectators" (Storey and Allan 3). As both a physical and cultural space, theatre positioned Athenians alongside other citizens in a public, civic ritual. Additionally, the large number of spectators and the collective power of their emotional reactions to the religious ritual and the aesthetic experience of the plays would have a powerful ability to establish a collective ethos, an ethos that lent itself to a democratic worldview. ${ }^{73}$ On the one hand, $5^{\text {th }}$ century BCE Athenian theatre was a profoundly civic experience. Plays were performed at religious festivals — principally the City Dionysia and the Lenaea—where citizens gathered to honor the god Dionysos, patron of drama. These festivals included massive numbers of participants, "at least 2,500-3,000 male citizens were directly involved as participants in the processions, ceremonies, rites, or dramatic competitions constituting the festival" (Zarrilli et al 62). Further, wealthy citizens had a duty to financially contribute to the polis and one popular method was as a "khoregos (literally, 'chorus leader'), who covered preparation, costume and rehearsal expenses on behalf of the city, in return for social prestige and political influence" (Laera, Reaching Athens 66). In this sense, the Dionysia, Lenaea, and other festivals were

${ }^{73}$ Typical estimates of how many spectators saw the plays at the City Dionysia range from 14,000 to 20,000. Plato claimed that 30,000 people saw some performances, but the archeological evidence from surviving theatres suggests this is an over-estimation. Obviously smaller local theatres in cities outside Athens held less people, but audience scale was still much larger than a typical black box theatre or even most modern national theatres. 
directly citizens' festivals. Citizens provided the financial backing, citizens performed, and citizens attended. ${ }^{74}$ The scale of civic engagement with the festivals promoted the kind of communal and mutually responsible ethos that underpinned democratic Athens.

Theatre-going was, in fact, a specifically democratic ritual. In his analysis of Athenian audiences, Goldhill claims, "to be in an audience is above all to play the role of democratic citizen" (54, original emphasis). Goldhill writes extensively about the close ties between Athenian audiences and the polis as such, arguing that the two entities were virtually identical. The democratic nature of the audience mirrored the collective character of the chorus. The tragic chorus was a communal character, made up of numerous dancers - numbers for various performances and rituals varied from twelve to one hundred ${ }^{75}$ - who collectively responded to events and offered wisdom. To a certain extent, the chorus represented a democratic citizenry, which was meant to guide the audience's response to the conflicts in the play. ${ }^{76}$ As Laera puts it, "Through melody and choreography, the chorus stood at the symbolic centre of the collective religious ritual, the City Dionysia, mirroring the audience and symbolically incorporating it into the show" (Reaching Athens 66). Because of the collective civic component of these religious/theatrical festivals, attendance was regarded as a duty of citizenship (Goldhill 67). Further, the massive number of spectators and participants would have forged bonds between those who shared the experience of being in the crowd together. David Wiles asserts that Greek

\footnotetext{
${ }^{74}$ Classicists debate exactly how many and what types of non-citizens were allowed to attend the festivals. One of the fiercest conflicts is whether or not women (apart from select priestesses) were present for the Dionysia.

75 Part of the reason there's such a wide gap in the number of Chorus members is that different performance types required different size Choruses: "For the choral dithyrambs alone each of ten tribes organized 50 boys under 18 and 50 men (aged 20-30) - a total of 1,000. The three days of tragedies utilized between 36 and 45 young men (at first 12 and later 15 in each chorus) and nine mature men (each playing three speaking roles)" (Zarrilli et al 62).

${ }^{76}$ Laera expands on links between the Chorus and various democratic collectives, writing, "The tragic chorus...established a connection between the spectators gathered at the theatre and the heroes of mythology; it now articulates correspondences between itself and contemporary audiences, while also pointing to its half-mythical, half-historical counterpart performed by the demos of Athenian democracy" (Reaching Athens 4).
} 
theatre was a viscerally collective experience. ${ }^{77}$ To witness a performance at the Dionysia or Lenaea would mean to experience the performances - at least to a certain extent—as part of the crowd, as opposed to individually. Fischer-Lichte argues that this is always a component of drama, which has an inherent mutual impact. She claims, "within a performance or any other kind of communal gathering as well as in society as a whole the idea of an autonomous subject is delusive. Our actions in such situations are always co-determined by others" (Dionysus Resurrected 41). To a certain extent, then, spectatorship in a communal space like the theatreparticularly on the scale and with the visual interconnectedness of the City Dionysia-trains a citizen for the experience of equality and collectivity in a democratic polis.

Theatre's role in training citizens for democracy was also woven into the fabric of the plays, through an agonistic structure that evoked the rhetorical conflicts of the ekklesia and the agora. According to Hegel, the agonistic structure of Attic tragedy pits one character's constitutive ethical system again an oppositional ethical system in a struggle that finally resolves itself with the conclusion of the play (324-325). This conflict between positions embodied the kind of rhetorical debate central to Athenian democracy. As Paul Cartledge puts it, "For such average citizens, tragic theatre was an important part of their learning to be active participants in self-government by mass meeting and open debate between peers" (19). In other words, the conflicts within tragedy reflected the processes of rhetorical exchange and civic debate at the heart of democratic Athens. Tragedians used mythical/historical material as meaning-making tools: "performances of these plays staged the current tensions of the polis in an imaginative

\footnotetext{
${ }^{77}$ He writes that the individual "was part of a single crowd, bounded by a space that created no vertical or horizontal boundaries, and concealed no group from the rest. If all 15,000-plus tightly packed people were listening to the same words at the same time, and shared the same broad experience, the power of emotion generated would have been quite unlike that created today in a studio theatre. Communication was effected not simply via light and sound waves but via an osmosis passing through the bodies of the spectators" (qtd. in Storey and Allen 50-51).
} 
negotiation with stories of the past. As such, they often provoked a critical examination of the polis of the present" (Zarrilli et al 64). ${ }^{78}$ As when contemporary dramatists adapt Greek tragedies to respond to current cultural issues, Athenian tragedians explored, debated, and worked through the values of the polis via the medium of myth.

\section{Global Greeks?}

Greek tragedians utilized a shared stock of myths as the basis for most of their tragedies, but to what extent do these myths — and the Hellenic plays they inspired - continue to make up a cultural commonwealth for contemporary dramatists? Or, more specifically, how common a part of a global commonwealth are these Greek tragedies? This question is particularly meaningful in a postcolonial world, because following the wave of national independence movements from the 1940s to 1970s the status of the classics vis-à-vis culture and power changed significantly. During the colonial era, especially under the Victorians, the British education system spread throughout the world, and in colonies in Africa and the Caribbean, the classics were taught as evidence of the inherent superiority of European civilization. ${ }^{79}$ However, after decolonization many African intellectuals and artists continued using Greek material, even as other European arts and literature —including dramatists like Shakespeare, Ibsen, Racine, Moliere, etc.-were rejected as tools of oppression. ${ }^{80}$ Throughout newly decolonized African and Caribbean nations,

\footnotetext{
${ }^{78}$ Storey and Allan write, "To many modern critics the political content of tragedy is equally evident. In both its themes and its language, tragedy can be seen to be an extension of the political debates carried on in the law courts, assemblies, and councils of contemporary Athens, where its citizens were continually redefining themselves and their city through the enactment of new laws or the introduction of new policies that altered to a greater or lesser degree the social institutions that we identified as the subject of debate in drama. Like comedy, tragedy takes the institutions of the city as its point of reference, but these are embedded in a framework of myth" (68-69).

${ }^{79}$ Trivedi outlines three different Imperial education systems: an Indian system devoid of classics, an African system where Latin and Greek were central, and a settler colony system using some classics (288). So the British education system was not uniform, but instead adapted to different perceived needs in different colonies.

${ }^{80}$ Although many thinkers in liberated nations enthusiastically rejected Shakespeare and other European authors, this was not entirely uncontested. Osofisan laments the excision of the Bard from Anglophone African curricula, and suggests that this loss of Shakespeare as a cultural touchstone has contributed to the decline of theatre spectatorship and practice in Africa. He writes that when he was younger, "To be educated was to acquire the favour of entering into the magical splendours of his extraordinary mind and of accepting with awe his central, canonical
} 
dramatists adapted classical material for their own purposes. ${ }^{81}$ Kevin Wetmore writes, "The ancient Greeks, however, were not considered part of the European culture that was being rejected. Greek tragedy, for a variety of reasons... appealed to African playwrights and could be utilized without the taint of imperialist Europe and the national literatures of the colonial powers" (Athenian Sun 21). The irony of this exception is that the Greeks were introduced into imperial education systems as a means to demonstrate Europe's cultural superiority. ${ }^{82}$ However, the status of the classics has since changed drastically from the instrument of Imperial superiority they had been under the British. Through processes of cultural hybridity and mimicry, African dramatists have performed and adapted Greek tragedy to write back to Imperial powers, contest European cultural ownership of Greek literature, and engage contemporary African and global politics. In The Location of Culture, Homi Bhabha theorizes hybridity and mimicry as strategies colonized peoples use to resist their oppression. Bhabha argues that notions

status in the world of letters" ("Shakespeare" 10). He laments, however, that "It is doubtful if any political leader in Africa today - indeed, any academic outside the field of literary studies - would be able to quote so tellingly from Shakespeare. This is not just because the standard of education has declined generally, but rather because, for better or worse, Shakespeare no longer occupies such a central position in the acquirement of literacy, or even in the mastery of English itself" ("Shakespeare" 10). Osofisan has adapted many "European" plays, including Shakespeare's Hamlet and Chekov's The Government Inspector.

${ }^{81}$ In Chapters IV and V, I examine adaptations of Greek tragedies from Nigerian and South African authors, which is why I largely frame my discussion here in terms of British colonial Africa, though there is similar adaptive practices in Irish, Australian, Scottish, Welsh, and even English theatre, as well as adaptations of Greek tragedy outside Anglophone countries.

${ }^{82}$ Europeans, especially those looking to build empires, spent a lot of time, money, and energy establishing links between themselves and classical Greek and Roman civilization, on the premise that these (largely fictive) links would legitimize the latter day empires as the heirs of an antiquity culturally figured as the origin of civilization. Goff writes, "By acquiring this heritage [specifically the Elgin Marbles, though in a broader sense classical artifacts in general], the contemporary empire would announce its claim to be the new heart and centre of Europe, a centre which proclaimed not only its cultural identity with the ancient version of Europe but also its new ability to reach beyond itself and engage with foreign lands and other empires" (Introduction 7). Part of the project of establishing this legitimacy was the creation of education systems to export the ideology that Europe inherited a classical tradition and was, therefore, culturally superior. The impact of this classical education continues to shape contemporary postcolonial drama, art, and culture in Anglophone Africa, in part because many contemporary dramatists were either directly in British schools or in post-independence schools still largely following the older British curriculum. Gibbs points out that, "in the background to all discussion about the importation of Antigone into Ghana is a sense of the position of the Classics in the history of world drama and of the education system exported from Britain to her colonies" (58). The classics remain a deeply influential part of a standard education in many Anglophone African countries. 
of fixed or stable identities are key to the racially oriented Imperial project (66), but hybridization inherently destabilizes these ostensibly fixed cultural-ethnic identities. Hybridity and mimicry are liminal processes, transgressing and blurring the supposed boundaries between cultures and essential identities: "The borderline work of culture demands an encounter with 'newness' that is not part of the continuum of past and present. It creates a sense of the new as an insurgent act of cultural translation. Such art does not merely recall the past as social cause or aesthetic precedent; it renews the past, refiguring it as a contingent 'in-between' space, that innovates and interrupts the performance of the present" (7). In other words, through the repetition of the past (e.g., classical mythology, which becomes the basis for contemporary cultural myths) in new and unique ways, the ostensible certainty of race and identity upon which the colonial project is founded becomes unstable. ${ }^{83}$

For West and South Africans, Greek tragedy/performance presents a particularly fertile ground for hybrid adaptations, in part because of the similarities between ancient Greek and traditional Sub-Saharan African ritual and performance. Budelmann gives a compact list of connections: "choruses and the presence of some kind of public; performance spaces in the open, with spectators sitting on more than one side of the acting area, and plays often set outside buildings; the importance of music and of dance, the use of masks; and - perhaps most important - contact with the supernatural" (134) ${ }^{84}$ For most of the theatrical cultures discussed in this project—British, Irish, US, etc.- - performance norms have largely shifted away from elements that were (probably) central to $5^{\text {th }}$ century BCE Athenian performance: dance, masked

${ }^{83}$ In particular, the two plays by Femi Osofisan discussed in Chapter IV will demonstrate this hybridity and the instability it threatens for both the Imperial project and the post-independence Nigerian dictatorships that inherited the political and martial approach of the British Empire.

${ }^{84}$ Both Wetmore's Athenian Sun in an African Sky and Van Weyenberg's Politics of Adaptation similarly discuss links between Attic tragedy and African performance styles. 
performance, ritual, etc. Of the theatrical contexts this project studies, West and South African performance practices have the strongest similarities to Athenian forms. These connections are made by many who study African adaptations of Attic tragedy, but the important point here is that African adapters frequently utilize Greek tragedy as a basis for hybrid dramas/performances that open new cultural spaces.

Not all adaptations of Greek tragedy from postcolonial nations contest the canonical authority of the classics, but many utilize Greek tragedy to construct multi-faceted responses to contemporary political, social, cultural, and economic worlds ${ }^{85}$ In analyzing the political projects of African versions of Greek tragedy, Astrid Van Weyenberg identifies three levels of critical/political engagement on which adaptations work: 1) adapters respond to their current situation, whether that's a military dictatorship, civil war, poverty, or exploitation by global north corporations or governments; 2) adapters critique the ideological tradition locating the Greeks as a cultural origin of Western culture; and 3) adapters contest the cultural ownership of the Greeks by the West (xii). In other words, by adapting Greek tragedy, African and other postcolonial authors can contest the cultural politics which deployed the classics as proof of Western superiority, but these plays also respond to the authors' own politico-cultural concerns apart from relationships to the Imperial center.

In this sense, contemporary African adapters keep alive the politically engaged, worldbuilding tradition of their Greek predecessors. Wetmore writes that, "Both ancient Athenian and contemporary African playwrights use the myths of their community not only as source material for drama but also in order to call into question the very things those myths represent" (Athenian

${ }^{85}$ Sirish Rao and Gita Wolf_- both Indian authors of novels and children's books — have produced a prose edition (illustrated by Indrapramit Roy) entitled Euripides' Hippolytos for Los Angeles' J. Paul Getty Museum. The book is a transmedial adaptation of Euripides' drama into illustrated prose, but Rao and Wolf stick quite close to Euripides' storyline. This version offers little in the way of postcolonial critique or interrogation. 
Sun 27). Many of these adaptations blend Greek and African mythology, allowing the two sets of stories, deities, world views, etc. to coexist within the cultural space of the play. In other words, the fundamental gesture of repurposing culturally sanctioned material guides Attic drama, African drama, and adaption. Culturally hybrid adaptations in particular represent the interstitial nature of Greek culture, which was already influenced and shaped by the Egyptians, Persians, Phoenicians, and others. Greek culture itself was the hybrid product of cultural interaction in the eastern Mediterranean. Wetmore writes, "the classical world, remarkably similar in many ways to our own, was a world in which culture flowed freely. The Greeks in general and Athens in particular were influenced by the cultures of Egypt, Africa, and Asia, and the Greeks, conversely, influenced those cultures" (Athenian Sun 19).

Through hybrid adaptations, African dramatists — and other adapters across culturescontest narratives of cultural ownership, which I argue is fundamentally an anti-capitalist stance. As Chapter V will explain in more detail, part of the anti-capitalist potential of adaptation is that it problematizes the idea that the West/global north owns Greece as part of its exclusive cultural patrimony. Van Weyenberg argues for seeing Attic tragedy as an inherent component of Anglophone African culture because study of the classics was a major element of the British Imperial education system. She writes, "for African playwrights, Greek tragedy is part of their upbringing and their culture. This is also why I prefer the concept of 'adaptation' over 'appropriation', because etymologically the latter implies that playwrights make the texts 'their own' and thereby suggests an original ownership of these texts that is located elsewhere: namely, in the West" (xxxi). In contesting cultural ownership, adaptation has the potential to undermine ostensibly stable — though in reality, culturally conditioned — notions of property ownership. In contemporary, neoliberal capitalism, the notion of intellectual property ownership is an 
important economic principle, especially as we move further into the digital age and the products of intellectual labor become increasingly virtual rather than physical. But adaptation as a process, by troubling notions of originality, complicates questions of intellectual property ownership, which suggests larger questions about ownership in general.

\section{The Political Economy of Adaptation}

Much of this project's critical work will be literary and performance analysis concerned with political economy, and adaptation has its own distinct economics. I assert that adaptation threatens notions of cultural ownership rooted simultaneously in capitalism and assumptions of global north superiority. The question of how much adaptation is capable of resisting, critiquing, contesting, or providing alternatives to neoliberalism rests in large part on one's attitude toward trends like cosmopolitanism. Chapter V explores the idea of a cosmopolitan cultural commonwealth in more depth, but this last section of Chapter I will provide a preliminary look at the relationship between political economy and adaptation. Sanders claims that scholars working on adaptations must inherently deal with the question of ownership, and decide in favor of a shared, collective approach to textual ownership: "Studies of adaptation and appropriation invariably conjure up questions of ownership and the attendant legal discourses of copyright and property law. Following on from Barthes's destabilization of fixed textual meaning, however, as both procedure and process, adaptation and appropriation are celebratory of the cooperative and collaborative model" (4). Theatre also embraces cooperative and collaborative modes of production, bringing together a variety of practitioners - actors, directors, tech people, house staff, etc.- and audiences to create a shared artistic experience. Even the most profit driven theatre is encoded to a certain extent with a communal ethos (often disavowed by the capitalist economic structure), which could be highlighted to critique the interpolation of theatre and 
performance within late capitalism. Adaptation theory complicates or challenges two different models of ownership: copyright, and cultural patrimony. The process of adapting and performing material — especially when a hypotext is blended with other texts and cultures to create a hybrid — can contest both forms of ownership.

The question of copyright is closely tied to the capitalist desire to commodify and make money from cultural texts, artifacts, and processes ${ }^{86}$ Adaptation can be a fraught cultural process because it troubles the question of ownership, but is also quite profitable for industries - film, television, video games, McTheatre, etc.- - seeking vast profits. As Hutcheon puts it, "Adaptations are not only spawned by the capitalist desire for gain; they are also controlled by the same in law, for they constitute a threat to the ownership of cultural and intellectual property" (89, original emphasis). Adaptations can be potentially lucrative for several reasons, chief among them that the adapted text already carries cultural capital and may draw built-in audiences. ${ }^{87}$ Hutcheon identifies cultural capital as a key attraction of adaptation for capitalists trying specifically to produce profitable new texts. As she explains, "one way to gain respectability or increase cultural capital is for an adaptation to be upwardly mobile," which explains the prevalence of cinematic adaptations of Shakespeare, as well as the popularity of period piece adaptations of novels by Austen, Dickens, the Bronte sisters, etc. (91). ${ }^{88}$

${ }^{86}$ In Commonwealth, Hardt and Negri advocate undermining intellectual property protections in the name of a global common. They write, "an open infrastructure of information and culture would have to be constructed to develop fully and put into practice the multitude's abilities to think and cooperate with others. Such an infrastructure must include an open physical layer (including access to wired and wireless communications networks), an open logical layer (for instance, open code and protocols), and an open content layer (such as cultural, intellectual, and scientific works). Such a common infrastructure would counter the mechanisms of privatization, including patents, copyrights, and other forms of immaterial property, which prevent people from engaging the reserves of existing ideas, images, and codes to use them to produce new ones" (308).

${ }^{87}$ Bourdieu explains cultural capital as the degree of legitimacy of a particular text within the struggle for power and recognition in its own field. He conceptualizes aesthetics as two interconnected fields - "a field of positions and a field of position-takings" - and argues that to understand a text we must see its position relative to the other texts in its fields (34).

${ }^{88}$ If, for instance, a new film version of Hamlet or Oliver Twist is released, the film-makers can be relatively sure of a good financial return because the play and the novel are beloved by millions, and so a good 
Of course, adaptations — particularly in the theatre, which is often more politically engaged than mainstream cinema - can contest the role of capitalism in structuring society and the role of the arts. Matthew Maguire's Phaedra takes a directly anti-capitalist stance, linking destabilizing neoliberal economic policies with Faye's (Phaedra's) psychological deterioration and sexual perversion, which bears many of the hallmarks of affluenza. Rather than control of a kingdom, Maguire's 1995 update of the play involves control of a corporation. Thomas —a Theseus for the 90s — acquired his rival's (Aricia's father's) company and stripped it of all assets. The corporate re-envisioning from Racine stages the twin neoliberal impulses of high risk behavior and callous selfishness:

WILLIAM. But he [Thomas] destroyed your family. ${ }^{89}$

ARICIA. No. My father's arrogance did that. He left the company vulnerable by expanding too fast and acquiring too much debt. He swore no one would ever dare a take over.

WILLIAM. But my father left him nothing, no face saving merger, no golden parachute, he deliberately crushed him.

ARICIA. I saw it coming three months before. Your father has people on his team that hate him. I had three calls giving me inside information. I begged my father to protect our position. He wouldn't listen to his daughter. He thought he was a tightrope walker. (24).

As we shall see in Chapter II, risk-taking, economic ruthlessness, and the reduction of people's

worth to their economic status are endemic parts of late capitalism. The politics of ownership and the greed-is-good capitalism of the 90s here produce distorted sexuality, tied to incest and dreams of bestiality (in Faye's case), and domination (in Thomas' and Aricia's cases). Ultimately, this world, understanding itself entirely through economics, leads to the tragic

turnout at the box office and sales of DVDs, blue rays, and digital copies are likely. Further, because Hamlet and Oliver Twist have been already been much adapted-both in straight/serious adaptations and through more satirical approaches - even potential audience members who have not read/seen these hypotexts will likely be familiar with them from a cultural zeitgeist saturated with Shakespeare and Dickens. This familiarity and the cultural capital that goes with it is a major reason why "the film industry, and Hollywood in particular, take advantage of recycling wellknown material as a marketing strategy" (Bruhn et al 2).

${ }^{89}$ William is Maguire's version of Hippolytos. 
destruction that ends the Phaedra plot. Capitalism and the ethics of ownership become tools of mutually destructive oppression.

The second type of ownership contested by adaptation — cultural patrimony — may equally represent a form of destructive oppression, but here the waters are much murkier. The continuum between cultural ownership and a global commonwealth is fraught with concerns about cultural appropriation and imperialism. ${ }^{90}$ Daryl Chin explains the risks: "The idea of interculturalism as simply a way of joining disparate cultural artifacts together has a hidden agenda of imperialism. When is interculturalism a valid expression of the postmodern crisis in information overload, and when is it merely a fashion statement of the ability to buy and sell anything from any culture?" (87).${ }^{91}$ He therefore urges that intercultural performers-that is, performers/artists who seek to combine different cultural or national traditions in hybrid performances - use the utmost diplomacy in adopting the cultural or performative norms of others (94). The reason for this caution is the imbalance of power between the global north and the global south, a power imbalance tied to histories of imperial dominance. ${ }^{92}$ One of the ways this imbalance manifests is in the presumption of universalism for European/American texts, and the relegation to local or regional of non-Western cultural performances and texts (Fischer-

${ }^{90}$ Fischer-Lichte points out that the notion of cultural ownership has several problematic premises. One major problem, she explains, is "assuming that a play written by an author of a particular nation belongs to and is in that sense 'owned' by its citizens. Another equally questionable idea goes hand in hand with this assumption: that the people of that country are more competent to interpret and understand these texts, making them the only ones with access to the true meanings of the play" ("Interweaving" 7). In other words, the notion that, say, Shakespeare's plays are an inherent property of the English (or British) merely because Shakespeare happened to have been born and written his plays in England is not necessarily logical. Further, the much more problematic idea is the presumption that because Shakespeare was English, English people have greater access to inherent meanings or truths of his work than people from other cultural backgrounds.

${ }^{91}$ One limitation of Chin's argument is the assumption that intercultural performance principally involves global north authors taking from the global south. He is less clear about the ethical implications of global south authors adapting from the global north.

${ }^{92}$ Leitch argues that this kind of power imbalance orients even the most equitable collaborative work: "collaboration is never innocent because collaborators are never wholly equal. Adaptation always involves a power struggle for the same reason that any authorial collaboration involves a power struggle: because try as the collaborators may, it always involves a power differential from contract to contract or sentence to sentence" (12). 
Lichte, "Interweaving" 8). This assumed disparity allows global north directors to freely appropriate performance styles and texts from the global south without either respecting the cultural position of those styles/texts in their original context, or without seeking permission from the original culture (though cultural ownership is, again, a problematic assumption). Fischer-Lichte illustrates this point: "When Richard Schechner, for example, used the adoption ritual of the Asmat people of New Guinea in his Dionysus in 69, he evidently did not even feel the need to ask for permission. He justified the transferral by his particular artistic intentions, ignoring the fact that in this case the aesthetic was inextricably tied to the ethical" ("Interweaving" 8). In other words, Schechner appropriated and de/re-contextualized a specific cultural ritual without concern for the ethical implications of utilizing that ritual without permission from the Asmat people. ${ }^{93}$ In this sense, intercultural or cosmopolitan performance risks repeating the gesture of imperial dominance.

However, intercultural or cosmopolitan performances and hybrid texts also contest the ostensible boundaries dividing cultures and underpinning notions of cultural ownership. Although far from a universally accepted distinction, my argument differentiates globalization and cosmopolitanism, following the definitions put forward by Dan Rebellato. Rebellato explains globalization in economic terms: "globalization is the rise of global capitalism operating under neoliberal policy terms" (12, original emphasis). By contrast, cosmopolitanism

\footnotetext{
${ }^{93}$ Of course, one problem with cultural patrimony as a model of ownership is that it isn't clear from whom Schechner should/could have sought permission. If the ritual is owned by the Asmat people as such, would any entity be authorized to give Schechner permission? Even if he got permission from a ruler/chief, would that be sufficient to justify Schechner's repurposing, when the ritual is the patrimony of the entire culture, including both the current generation's ancestors and their descendants? Who could possibly authorize Schechner to use a ritual so thoroughly owned by the living, the dead, and the yet unborn? Or, could Schechner have legitimately used a ritual from "his own" culture, like communion, without incorporating the entirety of its original ethical and cultural context? Additionally, we might ask whether an Asmat artist could legitimately use the ritual outside of its "authorized" context, or whether that use of the ritual would be similarly (or differently) illegitimate? If cultural patrimony is to function as an exclusionary form of ownership, then it is contradicted and undermined by its own inherently collective nature.
} 
is an ethical openness to alterity and communalism: "Cosmopolitanism is a belief that all human beings, regardless of their differences, are members of a single community and all worthy of equal moral regard. Cosmopolitanism also entails a commitment to enriching and deepening that global ethical community" (60). As we will see in Chapter V, cosmopolitanism as an ethical alternative to imperialist and racist neoliberal capitalism is a contested position. However, there is substantial evidence supporting the premise that inter- or transcultural performance, texts, and arts can provide an ethically grounded counterpoint to the neoliberal ethics of ownership.

In terms of adaptation and intercultural aesthetics, fluid models of cultural/textual transmission are one foundation of cosmopolitan theory. These models promote liminality and cultural openness by advocating non-linear, non-ownership based models. Fischer-Lichte proposes using the term interwoven as opposed to intercultural. ${ }^{94}$ The model of cultural interconnection Fischer-Lichte advocates embraces liminal instability as a positive good, advancing a shared cultural common no longer reliant on notions of cultural/intellectual ownership and the questions of authenticity that go with them. In this model, culture is free and open to be used. Similarly, Diana Taylor proposes a model in which culture circulates as a way of resisting domination and oppression. She says, "the hope might be that by engaging the many, previously marginalized others, these cultures may be able to decenter (not replace) the hegemonic" ("Transculturation" 71, original emphasis). Ultimately, for Taylor, Fischer-Lichte, and Rebellato, the goal of cosmopolitan — or interwoven, or circulating - cultural models is to performatively liberate cultures from patterns of ownership and exclusivity, while simultaneously promoting ethically grounded and conscious methods of performing a multi-

\footnotetext{
${ }^{94}$ She explains, "By interweaving performance cultures without negating or homogenizing differences but permanently de/stabilizing and thus invalidating their authoritative claims to authenticity, performances, as sites of in-betweenness, are able to constitute fundamentally other, unprecedented realities - realities of the future, where the state of being in-between describes the 'normal' experience of the citizens of this world" ("Interweaving" 12).
} 
culture. It is in this sense that I argue adaptation ultimately provides an alternative to the neoliberal model of late capitalism.

This first chapter has begun theorizing the nature of adaptation as a process and a product, and teasing out some of the ethical quandaries surrounding adaptation and performance. Working from a basic definition of adaptation — a text that substantially, directly, and purposefully reworks a prior text (or texts)—we have explored and complicated some concerns raised and discussed in adaptation studies. However, we have tried to move beyond questions discussed widely and ad nauseam by adaptation theorists. This chapter has laid the groundwork for theorizing adaptation's liberatory potential. In particular, the theory of faithful infidelity proposes that the adaptations discussed in this project will recreate the world making tradition of Attic tragedy—a premise developed in more detail in Chapter $\mathrm{V}$ - and that the repurposing of cultural forms and narratives through an open, cosmopolitan cultural framework can provide an ethical model of resistance to late capitalism.

However, the ideological edifice of neoliberalism is vast and complex. It fundamentally reshapes human subjectivity through ideals like radical individualism, the unfettered free market, and a globalized economy. Unfortunately, these ideological goals are often turned to the service of rebuilding economic class power and exploiting and oppressing the global poor and working classes. The next three chapters explore some of the problems of neoliberalism and trace ways in which contemporary British and Anglophone dramatists respond to and resist some major cultural challenges of neoliberalism. 


\section{Chapter II}

\section{Homo Oeconomicus: Marketized People and Culture}

One of the most important ideological revolutions of late capitalism is the centralization of market values and economics as a way of understanding the self and cultural institutions. Since the 1980s especially, the Western cultural imperative is to conceptualize oneself through one's engagement with finance, to see oneself as a marketable commodity. As Randy Martin contends, "Finance is not only the question of what to do with the money one has worked for, but a way of working that money over, and ultimately, a way of working over oneself" (16-17). Under the dictates of homo oeconomicus — the economic human — the subject's value and importance is reduced to a monetary calculation, determined by various markets, which allow the subject to build or lose value through exchange. The cultural hegemony of late capitalism erodes other potential subjective modes—homo politicus, homo familias, etc. - by foregrounding a marketized mindset. Among the larger implications of this marketization is the commodification of public spaces and cultural spheres, which are themselves reduced to economic zones under a logic of financialization and commodity exchange.

The two plays analyzed in this chapter draw attention to these issues of the marketized individual and the expanding economic realm under late capitalism. Christine Evans' play Trojan Barbie adapts Euripides' Trojan Women, while Colin Teevan's Alcmaeon in Corinth adapts/reimagines the now lost Euripides' play of that title. ${ }^{95}$ Trojan Barbie premiered in 2009 at the American Repertory Theater in Cambridge, MA. Teevan's play premiered under the title Cock of the North at the Live Theatre in Newcastle upon Tyne, in 2004. Each play deals with the reduction of human life, and the transformation of the spaces of public life and enjoyment into

\footnotetext{
${ }^{95}$ I refer to Teevan's play with the published title Alcmaeon in Corinth, rather than the title it premiered under, which was The Cock of the North.
} 
monetarized spaces. Evans' adaptation picks up on the theme of the concentration camp, already inherent in the Euripides source text, and filters it through twentieth and twenty-first century concerns about bare life and the camp as the nomos of modernity, theories developed largely by Giorgio Agamben in Homo Sacer. The other major theme Evans develops is a postmodern concern with mechanical reproduction and the elevation of the commodity to a sphere of high art. By implicitly and explicitly identifying the defeated Trojan women with the broken bodies of Barbie dolls, Evans works through concerns about the reduction of the human to the mass produced commodity. Teevan uses a different lens in his reconstruction of Alcmaeon in Corinth, focusing on contemporary concerns about the monetarization of spheres long thought to be inappropriate for an economic worldview, specifically sexuality, religion, and the family. Through Teevan's examination of the increasing space of the market, we see the emergence of a new psychological mode under neoliberalism, namely pathological narcissism, which becomes the dominant way of experiencing desire under the imperatives of consumer capitalism.

Western philosophy has a long tradition of rejecting commerce or trade as inherently unethical or unnatural. We find this opinion in Aristotle's Politics, when he writes in book one that exchange is not the natural purpose of goods-i.e., the purpose for which the goods were created. Aristotle says, "Every piece of property has two uses [its practical use and use for exchange]. Both of these are uses of it as such, but they are not the same uses of it as such: one is proper to the thing and the other is not" $\left(1257^{\mathrm{a}} 5-7\right)$. This line of reasoning leads directly to Marx's theory of the commodity fetish, in which the object becomes understood not through its use value but through its exchange value - the monetary value at which a commodity can be exchanged becomes the inherent value of the object, not the degree to which it is usable as a 
product. Thus, money becomes the alternative to use, or the alternative to individual skills, powers, abilities, etc. and becomes the foundation for structuring zones of power. As Marx writes, "money is thus the object of eminent possession. The universality of its property is the omnipotence of its being... But that which mediates my life for me, also mediates the existence of other people for me" (Economic and Philosophic Manuscripts 136, original emphasis). In other words, under the logic of capitalism the commodity reshapes both our understanding of value and how we relate to others.

However, this is old school Marxist theory, and the crucial question today becomes how neoliberalism changes the ground of the commodity and its role within society. On perhaps a basic level, neoliberalism simply removes some of the blocks preventing capitalism from reaching its full potential. When the market becomes the ideological ideal, it surpasses or replaces the political, social, aesthetic, and cultural spheres, or reconfigures them within its own logic. In promoting market capitalism as a political model, Milton Friedman argues, "The kind of economic organization that provides economic freedom directly, namely, competitive capitalism, also promotes political freedom because it separates economic power from political power and in this way enables the one to offset the other" (9). Friedman's goal, and the goal of neoliberal theorists more generally, is to diminish the power of government in favor of the power of free markets, which they conceptualize as a natural and independently functioning system of checks and balances. This ostensible uncoupling of economic and political power in practice has meant the reduction of regulations on business and trade, which have allowed multinational corporations to expand both their economic and political power through globalized financial networks - the brakes upon nineteenth and especially mid-twentieth century capitalism have 
been reduced (and in some places removed altogether) allowing capitalism to follow its naturally accumulative and exploitative impulses.

The more radical and foundational change of neoliberalism is the rewriting of the terms through which we understand ourselves as subjects and the models of selfhood which remain culturally viable. As we saw in the Introduction, this means reducing the possibilities for human subjectivity to homo oeconomicus, which requires a fundamental reshaping of the public mind. The construction of consent as a means of social control is an idea developed by Noam Chomsky throughout his career. Long a critic of ideological apparatuses, Chomsky analyzes ideological and discursive methods utilized by late capitalism to reshape the human. For Chomsky the primary tool in this campaign is a massive public relations industry centered in the US and the UK (45). He says that "The importance of 'controlling the public mind' has been recognized with increasing clarity as popular struggles succeeded in extending the modalities of democracy, thus giving rise to what liberal elites call 'the crisis of democracy' as when normally passive and apathetic populations become organized and seek to enter the political arena to pursue their interests and demands" (53). This contestation over the space of political action and the right to a voice is precisely what Jacques Rancière terms politics, which he contrasts with the police. For Rancière, politics is the conflict created when a disenfranchised, disempowered, and silenced segment of society asserts their right to political voice and action, thereby creating a gap in the sensible — disturbing the ostensibly normal distribution of power and hegemony within a society. He terms this conflict over the sensible dissensus, over against consensus which is enforced by a police mentality establishing clear divisions and separations. ${ }^{96}$ According to Chomsky, the tool

\footnotetext{
${ }^{96}$ For Rancière, "The essence of politics is dissensus. Dissensus is not a confrontation between interests or opinions. It is the demonstration (manifestation) of a gap in the sensible itself. Political demonstration makes visible that which had no reason to be seen" ("Ten Theses" 38, original emphasis). In other words, dissensus is politics in
} 
through which police consensus is enforced is a public relations industry functioning through mass media. And this ideological apparatus reshapes the human into conforming economic subjects/consumers rather than political subjects.

The position of theatre (and adaptations in theatre) is a complex one within this network of ideological apparatuses and state power. On the one hand, theatre — or the arts more broadlyoften contest politico-economic power structures, but often remain governed by those same power structures. Ngũgĩ wa Thiong'o asserts this fundamental conflict: "the artist and the state became not only rivals in articulating the laws, moral or formal, that regulate life in society, but also rivals in determining the manner and circumstances of their delivery" (434). As much as many theatre artists - particularly those like Boal, Brecht, or Artaud - seek to turn theatre away from capitalist economics, however, theatre remains entrenched within economic structures. Most theatre (at least Western commercial theatre) runs on a fundamentally corporate model wherein "directors are understood, at least by their boards and backers, to deliver theatrical productions as 'products' for the consumption of audiences who are understood to be the consumers of the theatre industry" (Knowles 25). Because very few theatres receive full public funding and necessarily need to supplement their finances to a greater or lesser extent at the box office - the most visible means of capitalist ideology at work in the theatre - virtually every show, no matter how revolutionary its content, is inscribed within capitalist/corporatist modes of production. According to Jen Harvie, the Arts Council England (ACE) actively supported this view of theatre in Supporting Growth in the Arts Economy, published in 2011. The British government, through ACE, "aggressively and explicitly advises arts practitioners to behave in more business-like ways" (Harvie 72). Harvie argues that this shift toward an increasingly 
pervasive business approach to the arts compromises artistic integrity, potential for artistic collaboration, and ethical human interaction (72-73). In other words, the very nature of theatrical/artistic labor is ideologically revised.

Under the neoliberal regime as much labor as possible becomes contingent, part-time, stripped of benefits, and individually isolated. But probably the biggest shift from labor under industrial capitalism is the emphasis on flexibility for laborers. Rather than providing long-term, stable contracts for workers, the contemporary, post-Fordist model of employment prefers shortterm, contract based work. This shift represents a major disadvantage for workers because it cuts benefits, stable work schedules, job security, and in many cases pay rates. Contemporary theatrical labor is characterized by comparable instability and demands for flexibility, both in material working conditions and in actor training. ${ }^{97}$ Harvie describes actors' labor in nearly industrial terms, arguing that actors "are usually subject to both alienation, performing notoriously repetitive labour, and job insecurity, often working for short contracts, moving from company to company, literally and repeatedly taking on new roles even if they continue to perform the same task (acting), working with new colleagues in each casting, and often temporarily being unemployed or underemployed" (49). This sounds like the ideal labor force under post-Fordist capitalism: a labor force composed of individuals (as opposed to a working class), without job security, without long term contracts, and willing/able to move quickly from job to job taking on whatever role the new position requires. In his book on the material theatre, Ric Knowles argues that this kind of labor flexibility and instability is reinforced by contemporary actor training methods, which he argues "construct the body of the actor ahistorically as a free and empty space" (35). In other words, actor training systems teach actors

\footnotetext{
${ }^{97}$ I can't say whether or not this reflects an historical shift in the nature of theatrical labor, though my sense is that working in theatre or the arts more broadly has long been characterized by instability and insecurity.
} 
to conceptualize themselves as infinitely malleable blank slates upon which can be written whatever is needed for a particular show. This approach to training molds a labor force open to the influences of the dominant (i.e., neoliberal) ideological system, both in theatrical labor specifically and in the larger social context. These labor norms and training methods instill neoliberal values, seeing the worker as a kind of business unto him or herself. Under industrial capitalism it was sufficient for workers to obey, but neoliberalism rewrites the very nature of labor and subjectivity. As we shall see, however, these methods of rewriting subjectivity are heavily contested by those seeking alternative, non-neoliberal social possibilities.

\section{Rebuilding Barbie: Bare Life and Modern Art after Troy}

More than most adaptations, Christine Evans' 2009 play Trojan Barbie makes explicit the fundamentally repetitive motion of adaptation, the notion of folding time together to reexperience an aspect of the past in a new way. ${ }^{98}$ This is, of course, a major divergence from Euripides' Trojan Women, which is set entirely in the Greek heroic age. Evans collapses time upon itself, bringing the Trojan War into the modern world, through a postmodern layering of time and by evoking specific connections to the contemporary Iraq and Afghanistan conflicts. Lotte, who runs a London doll hospital, is taking a holiday to the modern city of Troy; while Hecuba, Poly X, Cassandra, and the other Trojan women are simultaneously the women of Euripides' play (set during the age of Greek mythology) and the prisoner-refugees of modern military conflicts. Trojan Barbie directly layers history into the present. This notion of reexperiencing past events is a fundamental gesture of adaptation. In a concise definition, Linda

\footnotetext{
${ }^{98}$ Evans, who is Australian, lives and works in the US, and Trojan Barbie premiered at the American Repertory Theatre in Cambridge, MA. It may seem like a strange choice that I begin this study, which fundamentally examines British and non-US Anglophone drama, with a US-Australian play. However, Trojan Barbie evokes the role of classical culture in Australia's self-definition as a settler-colony, as well as directly confronting neoliberalism and military adventurism in the US in the context of the Iraq and Afghan wars. Another direct example of the importance of classical culture in Australia can be found in Nowra's The Golden Age, which opens and closes with evocative metatheatrical performances of Iphigenia in Tauris.
} 
Hutcheon claims that "Adaptation is repetition, but repetition without replication" (7). What Hutcheon means by this is that adaptation takes a source text and re-enacts it, or re-performs it, but makes critical changes to distance the new work from the adapted work. These changes may intend homage or critique, but in order to be an adaptation, the new work repeats a hypotext.

The Trojan War was one of the most important stories of the Greek Classical period, including the fifth century BCE when Aiskhulos, Sophokles, and Euripides wrote. The tale is presented in its most well-known form by the $9^{\text {th }}$ century BCE poet Homer, in his epic poem The Illiad. As Homer recounts it, Helen is the most beautiful woman in the world. She marries Menelaus, king of Sparta, but is seduced/raped/eloped with Paris, a Trojan prince. To avenge the loss of his wife, Menelaus calls upon all of the Greek princes, who had sworn an oath to aid him if anyone interfered in his marriage, to sail with him to Asia Minor and conquer the city of Troy. After overcoming some initial setbacks, the Hellenic fleet sets sail, headed by Menelaus, his brother Agamemnon, Odysseus, and the great hero Akhilles. When the Greek forces arrive at the city of Troy they find the stout battlements of Illium closed against them and the Trojans prepared for a bitter siege. The conflict drags on for a decade, during which time both sides lose men, including heroes like Akhilles, Ajax, and Hektor. Finally the Greeks adopt a plan by the cunning Odysseus to build a gigantic hollow wooden horse as a sign of their defeat — but unbeknownst to the Trojans, a force of Hellenic fighters hide inside the horse, ready to open the gates of the city from inside when night falls. This plan opens the city to the Greek forces who slaughter the Trojan warriors, including old men and young boys, and sell the women as slaves in various Greek city-states.

In 415 BCE, Euripides presented The Trojan Women, which deals with the immediate aftermath of the sack of Troy - specifically the enslavement of the women of Troy and their 
dispersal as slaves to the leaders of the victorious Hellenic army. The central figure of the playwhich largely takes the form of a lamentation —is Hekabe, the widow of the Trojan king Priamos and mother of Paris, Hektor, Kassandra, and Polyxena (along with many others). Much of the play involves the Trojan women in a prison camp discussing their various troubles- dead children and husbands, the ruined city—and fearing for their futures as slaves to the Greek conquerors. As she looks on the burning towers of Illium, Hekabe laments for the last time the callousness of a fate that has destroyed her city and her family. She addresses an apostrophe to her city:

O Troy, great city, once breath of grandeur on the barbarian scene, how fast your glory is extinct!

They burn you down, and we, we are being herded off as slaves.

$\mathrm{O}$ you gods...

but why bother to invoke the gods?

In the past they never heard my prayers.

So, hurry, hurry into the flames.

Let my glory be

to die in the bonfire of my home. (510)

In beautiful, moving verse Euripides gives us the lament of a woman from whom everything has been taken - a woman who has lost her city, her husband, and most of her children, all for the cause of Helen, who betrayed her husband. Hekabe recounts all that she has lost in Helen's cause: her noble sons killed by the Greeks, her husband the king killed in their home, the city sacked, her daughters raped and sacrificed, and her own enslavement in old age.

But for all that she suffers, and even as she wishes for death, Hekabe retains her dignity. Though she is beaten, Hekabe is a noble figure. As she says, "I was a queen and married a king; / became mother of princely sons" (478). Although she despairs and bewails her fate, Euripides' Hekabe retains an inner strength and nobility that contrasts sharply with the fallen and defeated 
position in which she finds herself. Even her attempted suicide - trying to run into the burning ruins of Troy near the end of the play—-bespeaks a defiant and undefeated spirit, which would have been seen by the Greek audience as a sign of her admirable superiority.

Evans' play shares certain thematic similarities with Euripides' Trojan Women, but the plot is very different. Trojan Barbie follows three major characters: Hecuba, Polly X, and Lotte, while Euripides focuses principally on Hekabe. Evans' Hecuba is more or less the woman of Euripides' play, a dignified matriarch brought to slavery through the Greek conquest. She alternates between great dignity and deep despair. Polly X is one of Hecuba's daughters. She is mentioned in the Euripides version, but does not appear. In Evans' adaptation, Polly X becomes a central figure pursuing modern sculpture out of "the need in her / to make something matter" after the fall of Troy (54). Whereas Hecuba — as in Euripides - spends much of her time bewailing her fate, Polly $\mathrm{X}$ is taken by soldiers to a dilapidated zoo, where they get her drunk and sexually assault her before delivering her for execution at Achilles' tomb. The third major figure of the play is Lotte — who has no place at all in Euripides' cosmology — a London doll repair expert who takes a vacation to $20^{\text {th }}$ century Troy only to find herself caught between time periods. While vacationing, Lotte meets Hecuba's daughter-in-law Andromache before being captured by Greek soldiers and brought to the Trojan prison, despite her protests about being a British citizen.

The play's narrative structure relies on a series of loops, apostrophes, and scenes imagined to take place outside the main space of the action. This temporal play structurally evokes the repetitive relations between an adaptation and an adapted text, including a sense of continual return, rebuilding, and re-understanding. Lotte, in planning her vacation to a modern Troy, reads a brochure which informs her that, "The city has been razed and rebuilt nine times, 
each time resurrecting itself over the buried bones of its previous lives and deaths" (9). There is a kind of horrific inevitability of Troy (and of re-experiencing Euripides' Trojan Women via Evans' Trojan Barbie) — the city that is utterly destroyed and its inhabitants scattered to live as slaves of their conquerors. Even Mica, the official spokesperson for the occupying Hellenic army acknowledges, "somehow you always end up in Troy" (16). This sense of inevitability inheres in the re-enactment of the Trojan War and Euripides' play. The form of adaptation, as a type of reenactment, lends itself to this sense of inevitable return. In her book Performing Remains, Rebecca Schneider argues for the meaning making potential of re-enactment, looking at how reperforming an event preserves and adds to the store of knowledge about that history. In a sentence that could have been written directly about the postmodern temporal layering in Trojan Barbie, Schneider describes the queasy action of re-enactment. She writes, "Touching time against itself, by bringing time again and again out of joint into theatrical, even anamorphic, relief presents the real, the actual, the raw and the true as, precisely, the zigzagging, diagonal, and crookedly imprecise returns of time" (16, original emphasis). In other words, through the performative repetition of history or historical events, we collapse the distance between the present and the past, exposing the limitations of linear teleology and opening up possibilities for new pasts as well as new presents and futures.

In the Author's Note in the Samuel French edition of the play, Evans emphasizes the importance of transitory staging to represent the temporal flux of the play. She begins by pointing out that "The Trojan women's camp is a barren space that suggests both ancient and modern war zones," and further suggests that "Since the layers of time collapse into one another in this play, it's best served by a flexible and evocative design, where discrete spaces can form and bleed into one another, rather than being 'realistically' rendered." In the production photos 
available on the American Repertory Theatre's website (http://americanrepertorytheater.org/events/show/trojan-barbie) the original Cambridge run utilized the general viscera of modern refugee camps — corrugated tin, plastic tarp walls, rubble and cinder blocks - to convey the collapse of time and space into one locale. With multiple levels and performance areas divided off by piles of rubble, the stage provided distinct areas for simultaneous action. Even when those actions were divided by temporality or geography, they visually occurred against the same (semi-)temporary background of rubble, tin walls, and plastic sheets. Constance Gorfinkle, reviewing for the Massachusetts Patriot Ledger, noted "The episodic structure of the work, which intersperses an ancient story with a contemporary sensibility" and how this structure destabilizes an illusory linear time, as "the scenes go back and forth, between Euripides' Troy and the Troy Lotte has found herself in 2,000 years or so later, where the world's endless war is still being fought."

Apart from the continuity of war throughout human history, Evans' choice to collapse time in an adapted/repurposed prisoner-of-war camp carries with it significant implications for modernity. The camp is a philosophically significant space representing, on the one hand, the reduction of the human from citizenship to bare life, and on the other hand, the structure of modern global capitalism as a means of controlling and delimiting populations. Both of these concepts are united in Foucault's concept of biopolitics, or politics that attempts to establish control over life itself - a politics which moves beyond traditional legislative issues like taxation, national defense, judicial law, etc. Biopolitics becomes the guiding force of the modern state, where power is the ability to put citizens beyond the control of the law-unlike feudal or agrarian cultures in which the goal of a regime was to exert law (however arbitrary and 
uncodified) over subjects. Instead, modern late capitalist regimes attempt to politicize life through the state of exception - the space and subjects held outside both human and divine law.

Giorgio Agamben develops this argument in detail in Homo Sacer, where he argues that the nomos of the modern is the camp because the camp represents the state's sovereign power to determine which subjects shall reside permanently outside the law. Agamben writes, "the sovereign exception is the fundamental localization (Ortung), which does not limit itself to distinguishing what is inside from what is outside but instead traces a threshold (the state of exception) between the two" (19). What Agamben means by this is that sovereignty is the power to reduce some people from proper subject-citizens to what he terms bare life or homo sacer, people without rights whom it is permissible to kill without being guilty of homicide, but who cannot be sanctified through ritual sacrifice. Bare life is, then, a subject outside both the law of human civilization and outside divine law, a being totally unprotected. Agamben argues that this version of sovereignty has moved throughout modernity beyond just the realm of politics, into virtually every aspect of daily life. ${ }^{99}$ The ultimate embodiment of this biopolitical regime- the state of exception in everyday life-manifests itself in the space of the camp.

This space of continual exception is precisely how Christine Evans re-imagines the prison camp of Euripides' Trojan Women-Evans' women are, and understand themselves to be, in a space permanently outside the rule of law and the rights of citizenship. In scene eight Clea and Esme, two of Hecuba's imprisoned retinue, underscore this liminal existence. Clea tells the story of "this Iranian guy, he'd been living in Charles de Gaulle airport for fourteen years. Got his papers cleared to escape to Paris, but then they wouldn't grant him asylum. So he's allowed to

\footnotetext{
${ }^{99}$ Agamben writes, "This line is now in motion and gradually moving into areas other than that of political life, areas in which the sovereign is entering into an ever more intimate symbiosis not only with the jurist but also with the doctor, the scientist, the expert, and the priest" (122).
} 
land, see, but not to leave. Can't go forwards and he can't go back" (37). ${ }^{100}$ This narrative of the threshold that becomes a prison resonates with the women in the camp, who find themselves in the same kind of space. They are neither citizens of Troy—which has been destroyed—nor properly subjects of Greek city-states since they haven't been processed and dispersed to their new positions as slaves. Agamben writes, "In the camp, the state of exception, which was essentially a temporary suspension of the rule of law on the basis of a factual state of danger, is now given a permanent spatial arrangement, which as such nevertheless remains outside the normal order" (169). In the camp — the nomos of the modern — we see the detachment of the refugee, extraordinary prisoner, or detainee from both order and identity. This detachment is physically represented on Evans' stage through a set consisting of ostensibly temporary shelters - the corrugated tin, plastic sheets, and cinder blocks emblematic of refugee campswhich become increasingly identifiable as permanent dwellings (e.g., in occupied Palestine or Soweto) as the camp expands as the norm throughout contemporary culture. ${ }^{101}$

However, the nomos of the camp is not limited to the geographic space of the camp itself, it does not end at the fence, but rather the state of exception extends throughout the modern world. We learn from Agamben that "the camp was also the most absolute biopolitical space

100 This story is a variation on the experience of Mehran Karmini Nasseri, who escaped Iran and lived in Charles de Gaulle Airport from 1988 until he was hospitalized in 2006, after losing his paperwork to gain refugee status in the UK. Although the general contours of Clea's account match Nasseri's story, the unidentified Iranian in her story killed himself in a bathroom. As of this writing, in June 2016, Nasseri is alive and in Paris, but no longer living in the airport.

${ }^{101}$ The camp as a political space is also a profoundly economic space under neoliberalism, in part because neoliberal politics and economics are always keenly intertwined. The exercise of sovereignty to deny rights to populations increasingly occurs along socio-economic lines, with the physical structures of the camp being used to police the movements of the disenfranchised. In The Shock Doctrine, Klein identifies a shift in the nature of the camp under neoliberalism - from spaces controlling disenfranchised labor forces to spaces controlling people not seen as necessary to the global economy. She identifies the origin of this model in Israel's militarized Gaza and West Bank occupation zones. Klein contrasts apartheid South Africa's Bantustan work camps keeping black or colored laborers from escaping against the Israeli system. She writes, "What Israel has constructed is a system designed to do the opposite: to keep workers from working, a network of open holding pens for millions of people who have been categorized as surplus humanity" (559). This practice of holding surplus humanity in camps extends around the world, everywhere neoliberalism has taken root, though most visibly in the global south. 
ever to have been realized, in which power confronts nothing but pure life, without any

mediation. This is why the camp is the very paradigm of political space at the point at which politics becomes biopolitics and homo sacer is virtually confused with the citizen" (171). The women in Evans' prisoner of war camp recognize the expansion of the state of exception from the limits of the fence to the entirety of modern life, acknowledging their situation as the nature of life under a biopolitical regime:

ESME. it's like someone tore up a map and that map was my body.

CLEA. There's a country without borders growing like an oil spill.

A space where you can't live -

ESME. - but you can't, strictly speaking, die.

CLEA AND ESME. That's our new home.

Charles de Gaulle airport all over the world.

CLEA. We don't belong anywhere.

ESME. Not since our city burned - (37).

Part of the reason biopolitics extends throughout modern life is because the state of exception is tied to the politico-cultural power of global capitalism, which reduces subjects from citizens endowed with rights and protections to commodities/capital within a system of exploitation. ${ }^{102}$ However, the potentiality for a generalized state of exception is also tied to the depthlessness and playfulness of postmodernism, which blurs lines Modernists saw as distinct.

According to some theorists, these two phenomena-the emergence of late capitalism and of postmodernism — are intricately connected, and their two forms of cultural production are inextricably linked. While some postmodern theorists downplay the relationship between postmodern culture and late capitalism, Frederick Jameson identifies the two trends as mutually

${ }^{102}$ Under neoliberal capitalism, citizens who are not capital producers (e.g., the poor, small scale farmers, fishing people, etc.) lose their rights in favor of corporate interests. Chapter IV will discuss the processes of disaster capitalism and economic shock therapy which allow this deprivation to work on a massive scale. 
constitutive. ${ }^{103}$ Building on traditions of Marxist cultural analysis, Jameson writes, "late or multinational or consumer capitalism, far from being inconsistent with Marx's great nineteenthcentury analysis, constitutes, on the contrary, the purest form of capital yet to have emerged, a prodigious expansion of capital into hitherto uncommodified areas" (36). This expanded scope of economics is fundamentally tied to postmodern aesthetics and culture, because "aesthetic production today has become integrated into commodity production generally" (4). Within Evans' Trojan Barbie the aesthetics of postmodernism are particularly evident, as the play collapses the distance between high and consumer culture, and disorients through the overlap and intersections of time. As we've already seen, Trojan Barbie layers time - the modern and the ancient—in ways that are not immediately intuitive, as events occur simultaneously across millennia. This is the nature of postmodernism's complex engagement with the past, an engagement which is, according to Jameson, always an engagement with our own imagination of the past. Jameson cites "the disappearance of the historical referent," explaining that in postmodernism "we are condemned to seek History by way of our own pop images and simulacra of that history" (25). Theatrical adaptation has a complex relationship with historical referents, because on the one hand adaptation-as-product builds on an historical text (i.e., the hypotext), but on the other hand, the adaptation-as-process eliminates much of the original context to rework material in a contemporary framework. What this means for Trojan Barbie is that the history of the prisoners in Euripides' Trojan Women is reconceptualized through the contemporary lenses of the camp (a symbolic space of modern biopolitics) and Barbie dolls (saleable commodities whose broken bodies take the place of the Trojan dead).

\footnotetext{
${ }^{103}$ For instance, Lyotard's The Postmodern Condition focuses more on narrative/meaning-making strategies and the materiality of language in postmodern culture. I feel that Jameson's neo-Marxist analysis sometimes overstates the interconnectedness between postmodernism and late capitalism, seeing them as causally linked when they may in fact be parallel phenomena.
} 
The commodified human being is probably the most important guiding image in Trojan Barbie. The title of the play speaks directly to the reduction from the properly human to the mass produced doll. The commodified and broken bodies of dolls stand in for the dead bodies of Trojan soldiers and the enslaved bodies of the surviving Trojan women. In the opening stage direction Evans even describes "a series of these older dolls sitting in a row, looking a little like the bodies from war photographs" (9) Throughout the play we are continually reminded of the identification between the broken dolls on stage and the broken human bodies of the Trojan War dead. In scene two, Hecuba dreams of searching among the casualties while Lotte simultaneously (but also centuries apart) sorts through the spare doll parts in her repair shop. Hecuba begins the sentence, “this time there aren't even bodies, just limbs hopelessly mixed up / An old man's ear, a girl's left hand" and Lotte finishes the line with her: "Hair, heads, legs, fingers" (14). The Trojan dead become identity-less body parts, just like the doll parts in Lotte's London shop. The indistinct mass of body parts- whether we take them as dolls, as war dead, or as both simultaneously_indicates a cultural shift from Modernist alienation to postmodern fragmentation. ${ }^{104}$ The image of jumbled body parts performs postmodern fragmentation, as even the portions of the human body become separated and lose their connection to a unified self. In other words, the piles of indistinguishable body parts visually represent postmodern psychological fragmentation through the continuous physical representation of that fragmentation on stage.

Near the play's end, in scene fourteen, Hecuba and Lotte again conflate the dolls with corpses, this time with the very specific body of Asthyanax, Hecuba's grandson murdered by the occupying Greeks so he could not grow up and avenge Troy. Asthyanax is played by a doll on

\footnotetext{
${ }^{104}$ As Jameson writes, "the dynamics of cultural pathology can be characterized as one in which the alienation of the subject is displaced by the latter's fragmentation" (14).
} 
stage and in Lotte's reality, but in Hecuba and the Trojans' reality he is/was a living child. As Hecuba grieves, Lotte sets to work repairing the doll, which has been executed by having its skull crushed with a tank. The way Lotte talks about this doll blurs seemingly stable lines between the inanimate porcelain body the audience sees and the dead flesh of a human child being prepared for burial. Her repair work tries to bring Hecuba and the women consolation, as Lotte says, “At least his Mama's going to recognize him now, that's something” (62). Even before his death, Asthyanax blurs the line between human and commodity, being treated by the Greeks as a (formerly) living child, while for Lotte and the audience he is clearly a doll. However, the question is not limited to whether Asthyanax is human or a doll, but whether any character is human or commodity. At the beginning of scene eleven Andromache refers to "My boy and I, damaged war loot" (53). Andromache identifies herself and her son as commodities (and by extension, so are the other Trojan survivors), as things to be carried off by the Greek army. This mutual commodification capitalizes on a Brechtian alienation generated by performing with the doll Asthyanax, producing misrecognitions (despite Lotte's optimistic prognosis of her repair work) of the commodity status of both the doll and the actors.

Recognition is central to how Lotte understands her work in the doll hospital, which is set up to give the impression of providing genuine medical care. Although Lotte explains that her goal is to comfort children who think of their dolls as living companions, she reflects that "once you've spent thirty hours on a doll, you do come to feel that she's alive, or - not exactly alive, but - latent, do you know what I mean? Sort of potentially alive, because they always might become somebody" (28). The irony of these lines is that Lotte speaks them to Andromache, who sees the doll-version of Asthyanax as her actual flesh-and-blood child (a child who, incidentally, is executed by the Greek army to prevent him from becoming somebody). On one level, the play 
conflates the human and the doll, so that the human and the doll occupy the same space and bear within them the same potentiality to become somebody. But at the same time the play acknowledges a biopolitical reduction of the human from rights bearing subject to commodityfrom homo politicus to homo oeconomicus. It is, of course, absurd to think of Barbies and other dolls as rights bearing subjects which deserve legal and political protection. But this absurdity becomes increasingly uncomfortable the more the bodies of the dolls and the bodies of the Trojan women and Trojan dead become one and the same on stage. One further layer at play in Lotte's speech is metatheatrical, as the notion of latent lives, potential lives applies to actors as well. As laborers, actors are tasked with filling out the positive content of a character's potential life, and this metatheatrical reference strengthens the identification between actors-as-laborers and the dolls-as-commodities displayed on stage.

Linking the dead and the conquered with commodities plays a major part in Evans' critique, which takes issue with neoliberal economic imperialism. This play debuted in 2009, which was, of course, a period with heightened opposition to the US wars in Iraq and Afghanistan, which had been going on for six and eight years respectively. ${ }^{105}$ Many critics of the wars saw them (especially the conflict in Iraq) as imperialist schemes for western multinational corporations to gain access to Middle Eastern resources. ${ }^{106}$ In Trojan Barbie, economic

1052009 was also (debatably) the lowest point in the international recession, driven principally by the 2008 US housing market collapse.

${ }^{106}$ Harvey explains that Paul Bremer's plan to economically rebuild Iraq seemed more interested in providing easy access for international capital than in providing safety, stability, and prosperity for the Iraqi people: "What the US evidently sought to impose by main force on Iraq was a state apparatus whose fundamental mission was to facilitate conditions for profitable capital accumulation on the part of both domestic and foreign capital" (Neoliberalism 7). In the case of the Iraq War, international financial institutions recognized an opportunity (whether incidentally or purposefully created for them) to rebuild an economy and restructure it for maximum profit. This was an example of what social critics call accumulation by dispossession (Harvey) or disaster capitalism (Klein). Under this brand of economic imperialism, "Nations driven by capitalism (or neo-colonial ambitions), corporations and International Financial Institutions all have tendencies to wreck places, lives, ways of life, to help create natural or man-made disasters, or to move quickly in after them. In the wreckage, they manipulate, create and solidify opportunities to accumulate profit through development or re-development" (Wickstrom 12). Under Bremer's 
(neo)colonial ambitions play a subtle role in Greek policy vis-à-vis the captured city of Troy. The official spokesperson for the occupation, Mica, parodies the language used by real world military officials, dignitaries, and corporations in explaining plans to rebuild the economy of an area wracked by war or natural disaster. He announces, "What is the strategic plan for Troy? - You may well ask. To think of 'Troy' as a failed state, mired in civil war and ancient hatreds, is to take an unnecessarily negative view. We must look to the future. We must imagine Troy rebuilding itself over the bones and rubble of the past! Pulling itself back up by the crutches. I mean, by the bootstraps" (15). This rhetoric_- 'failed state,' 'mired in civil war,' and so onshould sound familiar from any discussion of late $20^{\text {th }}$ and $21^{\text {st }}$ century attempts to rebuild national economies in the Middle East, Africa, Latin America, or elsewhere in the Global South. And, just as in real world discourse, Mica's repetition of these buzz terms serves the exact opposite purpose of transcending them, it in fact reinforces these images of Troy (read, Iraq) as a failed state unable to get past ancient grievances and enter the ostensibly benevolent world of modern corporate capitalism.

But perhaps this is unfair to Mica. He may not have been talking about restructuring Troy along neoliberal capitalist lines. He does, after all, claim that Troy should pull itself up by its own crutches. I mean, by its own bootstraps. But this sets the stage for the dominance of neoliberal ideology, which fundamentally requires the individual to assume responsibility. ${ }^{107}$ What I mean by this is that Troy becomes responsible for its own reconstruction, but it is a reconstruction assumed to take place along liberal capitalist lines. Again, we are meant to see

reconstruction plan, the US attempted to restructure the Iraqi economy in such a way that it opened the country to private ownership at the expense of the Iraqi people.

${ }^{107}$ In Chapter IV, we will see a similar rhetorical move made by Theseus in Buffini's Welcome to Thebes. 
parallels here with Iraq, which was maneuvered into adopting US imposed laws. ${ }^{108}$ The reference to bootstraps at the end of Mica's official statement locates this occupation of Troy squarely within a tradition of American capitalism, with its ethos of Ragged-Dick-style self-reliance and imagined socio-economic possibilities. We get another reference to the ostensible benevolence of capitalism when Talthybius - the liaison between the Greeks and the Trojan women—lies to Hecuba about Polly X's fate. Instead of revealing that she is to be executed as a sacrifice to the spirit of Achilles, he claims that "Her problems are over; she's - she'll be an attendant. / In the Achilles museum gift shop" (20). Talthybius interpolates Polly X within a capitalist structurethe museum gift shop — as the condition which solves all of her problems. In other words, he implies that the economic opportunity of working as a shop attendant is adequate compensation for the destruction of her city, the conquest of her people, the slaughter of several family members, and the enslavement of her remaining female relatives. This imagined economic opportunity reflects on the micro scale the macro-scale economic "opportunities" offered for Troy to rebuild itself. The model for this rebuilding is actually given earlier in the play, when Lotte is reading her travel brochure (9). Troy will rebuild itself as a tourist attraction, drawing affluent visitors from the global north-like Lotte - to come and spend money on the experience of Troy.

The final scene of Trojan Barbie is one of the most powerful critiques of imperialist capitalism in the play, locating resistance to imperialism in the conflation of the dead with commodified dolls. The closing image is the culmination of Polly X's attempt to both come to terms with and resist life in the camp through aesthetics. After seeing a display of sculpture,

\footnotetext{
108 The Bremer reforms in Iraq circumvented Geneva Convention laws prohibiting an occupying power from imposing a constitution because the US appointed a "sovereign" interim government, which had no authority to make new laws or challenge those imposed under the US occupation. This "sovereign" Iraqi government was only allowed to adopt those laws the US had already specified (Harvey, Neoliberalism 7).
} 
Polly X decides to construct a modern art of the camp, built from the debris of the Trojan detention center, which consists mostly of broken Barbies and beer bottle caps. She envisions a project she will title Trojan Barbie, consisting of a giant pink cardboard heart covered in bits of broken dolls. Polly X envisions this artwork as a catalyst for resistance against the Greek occupation, imagining that she and her sister will lead an uprising after the statue is constructed. As she says, "when it's done, me and Cassandra will rain down revenge on our enemies! We'll smash them like dolls!" (11). Tying aesthetics/performance with resistance is common amongst refugee or detained populations. Maurya Wickstrom studies how Palestinians imprisoned in camps by the Israeli government use theatre to protest and re-appropriate space, movement, freedom, and equality. Wickstrom writes that through resistance to their forced existence in the camps, Palestinians "on stage and watching the stage, may in this context be thought of as joining a body, a subjectivating body in a new present. On stage, equality is" $(34$, original emphasis). In other words, through the aesthetics of theatre, Palestinians - particularly the children's theatre on which Wickstrom focuses_-perform a space of equality, liberation, and national return, and these performances begin to reshape the terrain of the sensible. Palestinians (or Trojans like Polly X in Evans' play) begin to enact their liberation by performing it. Polly $\mathrm{X}$ 's modern art is the artwork of her people's destruction and through the creation of the statue Polly X immortalizes the loss, allowing the Trojans to live forever through the aesthetic.

We should not ignore the symbolic dimension of Polly X's choice of medium - the decision to use broken Barbies as the decorations for the cardboard heart is linked to the continuing identification throughout the play of dolls with the bodies of the Trojan dead. In other words, on one level Polly X's art consists of the corpses created by militaristic imperialism recontextualized as a protest against the occupation. Unfortunately, to be true to this refugee art, 
Polly X must herself become part of the sculpture, part of the artwork of destruction. In the powerful final scene of Trojan Barbie, Polly X stands framed by the heart covered in broken dolls, and in a stylized ritual, two soldiers pull a red ribbon tight around her throat, symbolizing Polly X's throat being sacrificially cut. Her body remains framed by the heart, her own being the final body needed to complete the masterpiece.

To think of Polly X's statue as a masterpiece (whether her masterpiece or Evans'), requires a discussion of the multi-layered question of corporeality as medium. On the one hand, the use of broken Barbies is emblematic of postmodernism's attitude toward kitsch and low/consumer culture, which Jameson explains are "materials they no longer simply 'quote,' as a Joyce or a Mahler might have done, but incorporate into their very substance" (3). By putting her own body into the Trojan Barbie statue, Polly X incorporates herself visually and performatively in the aesthetic realm, identifying her body as one amongst the other Trojan dead. However, we may also read this in the opposite direction, whereby when Polly X becomes a part of the Trojan Barbie statue alongside the broken dolls/Trojan dead, she performatively elevates the dolls to the level of (formerly) living human subjects. Yet another layer of complexity here is the actor-doll dichotomy: the actor playing Polly X identifies her performing body as commodity alongside the bodies of the dolls in the statue, while at the same time elevating the dolls to the status of actor. As Gorfinkle notes in her review, "dolls, in different stages of broken, cracked and twisted, lie around the rehearsal studio, because, although a very human cast of 12 performs 'Trojan Barbie,' the dolls are cast members, too." Polly X's ritual execution—a dual purposed ritual, as she is sacrificed by the Greeks to Achilles and by herself to her art—marks a liminal movement from one state to another. On stage she performs the ritual, completing the play's performative attempts to synthesize the human bodies of the actors with the plastic and porcelain bodies of the 
dolls. Thinking about the possibilities offered by bodies in the theatre expands the terms of the postmodern which Jameson sets out, because performance opens up bodily avenues of transformation capable of engaging and changing the experience of the aesthetic.

Ultimately, it is not merely that Polly $\mathrm{X}$ becomes one body among other bodies, or that the Barbies are elevated to properly human status. What matters about the final scene of Trojan Barbie is that it opens up spaces for performance to transform the world in which we find ourselves. In Performance Theory, Richard Schechner identifies transformation as the essence of drama. He writes, “[Victor] Turner locates the essential drama in conflict and conflict resolution. I locate it in transformation - in how people use theatre as a way to experiment with, act out, and ratify change" (191, original emphasis). He locates this transformative potential at three different levels: 1) within the dramatic narrative, 2) in the performers who embody a character, and 3) in the audience. This change (which we might tentatively identify with Aristotle's katharsis) functions because it is performed by live bodies. In Trojan Barbie this transformative ability relies on a confusion or alienation meant to teach the audience a moral lesson. For Brecht the goal of theatre was not ultimately to entertain, but to transform through instruction and social commentary, and he argued that performance should create distance through the Verfremdungseffekt, or alienation effect. ${ }^{109}$ Trojan Barbie achieves a Brechtian alienation because Evans layers different temporal settings (simultaneously ancient Greek and modern British/Turkish) and conflates/confuses dolls and living human actors, thereby opening viewers to the transformative effects of a theatrical production critiquing late capitalist practices of commodification, biopolitics, and militant imperialism.

${ }^{109}$ In explaining the alienation effect, Brecht writes, "A representation that alienates is one which allows us to recognize its subject, but at the same time makes it seem unfamiliar" (192). 


\section{Korinthiazomai: Colin Teevan's Alcmaeon in Corinth, the Commodification of Social Processes, and Jouissance}

Because of the limited information available about the Euripides hypotext (if we can still call four fragments, a dozen contested fragments, and a paragraph long plot description a proper hypotext), Colin Teevan has produced an essentially new version of Alcmaeon in Corinth from a $21^{\text {st }}$ century standpoint. ${ }^{110}$ Of course, the very nature of adaptation implies a temporal difference between the adapted text and the adaptation itself, but in most cases adaptations exist alongside their predecessors and are marked by the echoes of those hypotexts. When we read Trojan Barbie our understanding of Evans' nuance and political project is enhanced by familiarity with Euripides' Trojan Women. But in this case, that echoing or haunting of the new play is entirely absent (even if there are a few classicists in the audience who might know the Alkmaeon story, no one today has read the Euripides text). This original absence raises questions about whether Teevan's Alcmaeon in Corinth is even properly an adaptation. Certainly Teevan's play is hypertextual, establishing itself as an outgrowth of the earlier Euripides hypotext, but this unusual situation raises an interesting question about whether an adaptation must necessarily be haunted by the adapted text. ${ }^{111}$ If an adaptation falls in the forest and no one is around to recognize its hypotext...

The fragments we have and the broad contours of the story preserved in Apollodorus' Library of Greek Mythology allow us to generally reconstruct Alkmaeon's story and the basic

110 There is disagreement about how many fragments of the original play remain. Christopher Collard and Martin Cropp positively identify four fragments as belonging to Alkmaeon in Korinth (Euripides, "Fragments" 9093) and twelve that belong either to Korinth or to another play entitled Alkmaeon in Psophis (94-99). On the other hand, in her introduction to Teevan's play, Edith Hall writes that, "Approximately 23 fragments - perhaps forty lines - have been incorporated into Alcmaeon in Corinth" (Introduction 11).

${ }^{111}$ Genette defines hypertextuality as "any relationship uniting a text B (which I shall call the hypertext) to an earlier text A (I shall, of course, call it the hypotext), upon which it is grafted in a manner that is not that of commentary" (5, original emphasis). So Teevan's play is certainly hypertextual, but whether it is an adaptation depends on whether or not we demand that an adapted text be recognizable. 
events of Euripides' play. ${ }^{112}$ Apollodorus recounts that Alkmaeon was the son of Amphiaraus, one of the defeated Argive captains of the Seven against Thebes conflict. Ten years after the defeat, the Argives raised a new army headed by the sons of those who had fallen, called the Epigoni, and this new army conquered Kadmus' city, sending some of the plunder in tribute to Apollo's temple at Delphi, which had prophesied their victory. Alkmaeon afterward discovered that his mother had betrayed his cause, and so "when Apollo gave him oracular sanction to do so, he murdered her" (Apollodorus III.86) after which "he was pursued by the Erinys of the matricide, and in a state of madness went first to Oicles in Arcadia, and from there to Phegeus in Psophis" (III.87). In attempting to cure his madness, Alkmaeon married first Arsinoe, daughter of Phegeus, then later Kallirrhoe, daughter of a river god. Upon their marriage Alkmaeon had presented Arsinoe with the famed necklace and robe of Harmonia, but after a time Kallirrhoe grew jealous of this gift and demanded the cursed trinkets for herself. Under the pretense of taking the necklace and robe as offerings to Delphi, Alkmaeon asked for the return of the items, which Phegeus granted him. However, "when a servant disclosed that Alcmaeon was really taking the articles to Callirrhoe, he [Phegeus] had his sons ambush Alcmaeon and murder him" (III.90). After Alkmaeon's murder, Kallirrhoe asked Zeus that her children could be immediately grown to avenge their father.

Euripides' Alkmaeon in Korinth relates events during the time of Alkmaeon's madness, when he was driven by the Furies across Hellas in search of relief. Before his marriage to Arsinoe, Alkmaeon had two children with Manto_-daughter of the Theban seer Tiresias_-before sending her as part of the war loot to Apollo Mantikos' Delphic shrine. As the prophetic god says

112 The attribution of the Library to Apollodorus is unreliable at best, and there is considerable evidence that the collection was written after his death. However, Apollodorus is conventionally credited with authorship and so I defer to that tradition in identifying him as the writer. 
in fragment 73a, "And I myself was childless by her; but the unmarried girl bore Alcmaeon two children," named Amphilokhus and Tisiphone (Euripides, Fragments 91). Alkmaeon left his children in Korinth to be raised by king Kreon and his wife, Merope. However, as Tisiphone grew to womanhood and became more beautiful, Merope sold her into slavery to prevent her infatuated husband from marrying the young woman. Collard and Cropp write that "Alcmaeon bought her in ignorance; when he returned to Corinth to recover his children, she accompanied him. A typical Euripidean recognition and reunion would have followed" revealing Alcmaeon's relationship to the young slave girl and reuniting them both with Amphilokhus (87). Beyond these basic outlines, Apollodorus provides no more details of Euripides' plot, and the fragments provide little enough to go on when trying to reconstruct the story line. All in all, one is left largely in the dark when trying to work out Euripides' Alkmaeon in Korinth.

Teevan's 2004 play is thoroughly grounded in the cultural and ideological concerns of the early $21^{\text {st }}$ century, including concerns about the transformation of the individual and society under late capitalism. The plot, however, largely follows the story line of Euripides' play as recorded by Apollodorus. The play opens with a prologue by the goddess Hera, combining fragments of the ancient manuscript and commanding "let us weave these words, / The last stray and fraying threads" (19). This metatheatrical opening hearkens back to the lost play as Hera reads several fragments - which is probably the only referent most audience members will have for the historical play. Hera finishes her speech and the Chorus enters in the parados - the opening march—as women of Corinth. ${ }^{113}$ The Corinthian women introduce Alcmaeon's story and meet him at the docks, but he insists upon going to see the king, or more accurately the queen because he has been commanded by Apollo's oracle to deliver the necklace of Harmonia

\footnotetext{
113 The Chorus is particularly interesting in Alcmaeon in Corinth because they play several different roles, including Corinthian women, temple prostitutes, and the Furies. This will be discussed further below.
} 
to his new wife as the only way to lift his madness. Meanwhile, Creon — the king — is painfully in love with Tisiphone, whom he thinks is his daughter but is, in fact, Alcmaeon's child. Creon's wife Cruesa is aware of her husband's affections and Apollo's prophecy that the first man Tisiphone sleeps with will be her father. Jealous of her own position as queen, Cruesa schemes to have Tisiphone and her brother Amphilocus sold to Nikarete, temple priestess of Aphrodite. When Alcmaeon comes looking for his children and the necklace Tisiphone had, Cruesa convinces him that the children died but the necklace might be recovered. Meanwhile Creon takes Alcmaeon to Aphrodite's temple where they hire hetaria - holy prostitutes. Little does Alcmaeon know that the new prostitute he hires is his long lost daughter Tisiphone. The mistake is revealed (pre-incestuous sex) by Amphilocus, who tries to kill Alcmaeon before discovering that the famous man is their father. Together the father and son return to the palace to denounce Cruesa, whereupon (in good tragic fashion) she kills herself offstage. Hera wraps up the action by returning to predict the future, and require that Tisiphone marry Creon.

Much of Teevan's interest in the play focuses on the consequences of neoliberalism expanding the realm of market logic across the entire sphere of society. The predominance of neoliberal hegemony is arguably the greatest shift in global culture since the end of World War II because it has refigured the foundations upon which not only Western society but every culture touched by the globalized economy understands itself. ${ }^{114}$ Alcmaeon particularly exemplifies the

\footnotetext{
${ }^{114}$ Both Teevan's home nation of Ireland and the United Kingdom where this play premiered (in Newcastle) were key players in this expansion of neoliberal ideology. Within Britain, neoliberalism introduced a profound culture shift as "Thatcher forged consent through the cultivation of a middle class that relished the joys of home ownership, private property, individualism, and the liberation of entrepreneurial opportunities" (Harvey, Neoliberalism 61). This cultural shift "allowed a consumer culture to flourish, and the proliferation of financial institutions brought more and more of a debt culture into the centre of a formerly staid British life" (Neoliberalism 62). Although Tony Blair and New Labour gave a face lift to Britain's economic policies in 1997, the core of Blair's Third Way remained neoliberal, focusing on monetary policy and inflation rather than employment (Arestis and Sawyer 205). Similarly, by 2004 Ireland had entered what Donovan and Murphy identify as the second phase of the Celtic Tiger economic boom, where the focus shifted from production of electronics and pharmaceuticals for export to production of luxury goods for domestic consumption. They claim that by the early 2000 s, "Instead of
} 
risk-fueled consumer culture of early $21^{\text {st }}$ century neoliberal capitalism, because Alcmaeon himself is driven by desire, violence, and madness - all of which have their literal or metaphorical counterparts in late capitalism. Alcmaeon is a legendary lover-a kind of ancient Greek Lothario - pursued by the Erinyes from one woman's bed to another across Hellas in punishment for his matricide. ${ }^{115}$ Toward the end of the play the Chorus (playing the Furies at that point) haunts Alcmaeon with the refrain, "Run, crazy head, / Run from bed to bed, / Hide yourself beneath the sheets / Of every little girl you meet" $(75,76)$. Although Alcmaeon's madness is well known as the cause of his expansive sexual experience, women still flock to sleep with him. Upon his return to Corinth, Alcmaeon is immediately inundated with women longing to share his bed. When he is reticent, insisting that he has business and not pleasure to attend to, the Chorus of Corinthian women pleads, "One of us! Choose one of us, Alcmaeon! / Which woman of Corinth do you choose?" (24).

While this reads like the ultimate male fantasy, it fits with the larger Corinthian setting Teevan constructs. Corinth is presented almost as a pleasure city (at least for the wealthy, powerful, and famous), where every aspect of life revolves around sex and business. The Corinthian women's Chorus address the city in the parados - the Chorus' entry song — evoking "the nightly ecstasies / Of flesh on silky flesh, / The dark mysteries of desire, / Korinthiazomai, / To copulate in the ancient tongue" (Teevan 20,21-22). The very essence of the city is sexuality, with the name Corinth derived from the word for fornication. This parados sets the stage for a

maintaining momentum based on competitive exports, people became seduced by the idea of building more and more houses, hotels, apartments, leisure centres, and other amenities for each other" (60). This shift was fueled by both Irish and international banks that, "With an appetite for quick profit-making...started to cast caution to the winds and climbed eagerly aboard the property bandwagon" (60). In other words, both Britain and Ireland experienced economic shifts that made consumerism, spending, debt, and economic risk major elements of their national cultures and psychologies.

${ }^{115}$ Interestingly, sex addiction and feelings of emptiness are pathologies James identifies with affluenza, which he characterizes as psychological distress caused by interpolation within a market ideology (15). 
lascivious culture of sensuality and sexuality, a culture driven by desire. This is a major element of late capitalist culture, with the shift from a society of prohibition to one of enjoyment. ${ }^{116}$ With the pervasiveness of consumer capitalism in contemporary society, the principal societal imperatives become enjoyment and consumption. These processes restructure the subject as homo oeconomicus, because even consumption becomes refigured by the society of enjoyment as self-investment. ${ }^{117}$ And Alcmaeon—as much as his promiscuity is driven by the Erinyes—is an ultimate figure of consumption, he is a figure understood by the Chorus of Corinthian women, Creon, Cruesa, and others in the play as having special access to enjoyment through his expansive sexuality. As we shall see, however, this expansive access to sex objects actually cuts off Alcmaeon's access to enjoyment, replicating the paradox of consumer culture.

In its depiction of a society driven by enjoyment/consumption, Teevan represents a growing aspect of British culture via the lens of an ancient Greek city-state. In his review for The Journal, Paul Rhys writes that "Teevan sees Corinth as ancient-day Newcastle, as the party capital of Greece." Under Martin Wylde's direction, the premiere performance of Teevan's play performatively evoked both the contemporary Geordie party scene and a sexually rapacious image of ancient Corinth. Rhys acknowledges that while the costumes and setting suggest the verisimilitude, "what really drives the play is the Chorus. From funky breakbeat to melancholic harmony, the women of the Chorus fuel the tale with sex, desire and despair." Throughout the play the chorus serves several roles - Corinthian women, temple prostitutes, Erinyes—and

\footnotetext{
${ }^{116}$ McGowan argues that this shift is inherent to neoliberalism. He writes, "The 'commodification of everyday life' - the sine qua non of late capitalism — has the effect of, at once, undermining figures of authority and stressing the importance of enjoying oneself...one cannot exist for long in late capitalist society without being confronted by signs of or inducements to great enjoyment" (End of Dissatisfaction 30-31).

${ }^{117}$ Wendy Brown claims that for homo oeconomicus, "Whether he is selling, making, or consuming, he is investing in himself and producing his own satisfaction" (80). In other words, even enjoyment becomes financialized through pervading notions of self-investment and the commodification of enjoyment/satisfaction governed by the maternal superego.
} 
through the range of their performances (and the music accompanying those performances)

emphasize the central role of sexuality in organizing a society of consumption.

It should not be surprising that the women of the Chorus perform many roles in

Alcmaeon in Corinth, and that the threads of desire and commerce are woven through each of

these roles. We have in the Chorus another performative embodiment of the late capitalist push

for labor flexibility, discussed earlier. In performing multiple roles, the Chorus demonstrates this required flexibility within the sphere of theatrical labor by playing a variety of parts within a single show. The logic of late capitalism is totalizing. ${ }^{118}$ Teevan's most direct representations of labor in its flexible new organization are in the chorus, whose multiple roles collectively demonstrate the centrality of flexibility in contemporary labor forces, but particularly in the Choral role of hetaria, or temple prostitutes. As we shall see in more detail below, the holy prostitutes in the temple of Aphrodite are responsible for marketing themselves - their bodies as sexual commodities for customers' enjoyment. This is the most immediate example of the new status of labor as commodity-capital under neoliberalism, that is, as the commodity responsible for selling itself in a cultural sphere always dominated by market logic. ${ }^{119}$

${ }^{118}$ This totalization of the market form results largely from the change in how labor is conceptualized from classical economics (especially in the work of Marx and Engels) to the neoliberal emphasis on human capital. Neoliberalism doesn't, properly speaking, have a theory of labor. What neoliberalism has is an ideological world system into which its proponents suppose labor to fit. The problem is that within this market system - which must, to retain any semblance of ideological coherence, ignore all Marxist critiques of the alienation and exploitation of workers - labor is imagined as simultaneously commodity and capital. To the extent that workers must sell their labor in an ostensibly free market, labor is a commodity. As neoliberalism reconfigures homo oeconomicus not as a partner in exchange (as the concept figured in the classical economics of Smith and others), but as an entrepreneur of the self, labor moves from commodity to capital. As Foucault points out, neoliberal discourse refigures labor as capital and a wage as a return on that capital investment (224). In this schema, labor is neither fish nor fowl, neither pure commodity nor pure capital. Polanyi argued that labor (along with land and money) was fundamentally not a commodity, and that one of the major inconsistencies in viewing labor as a commodity is, "It is not for the commodity to decide where it should be offered for sale, to what purpose it should be used, at what price it should be allowed to change hands, and in what manner it should be consumed or destroyed" (185). What distinguishes neoliberal labor from other commodities is that labor is responsible for improving and marketing itself, whereas other commodities remain exclusively objects acted upon by labor and capital. On the other hand, labor's transformation to a form of capital is imperfect because labor remains tied to its status as commodity.

119 This, again, marks a major break with Liberal economics because Liberals did not posit homo oeconomicus as the only legitimate subjectivity. However, under neoliberalism "in contrast with classical economic 
In Alcmaeon in Corinth, market ideology has in fact become pervasive through

Corinthian society, reflecting in family life, religion, and sexuality. Late capitalism shifts the notion of family relations to sets of economic investments and returns. ${ }^{120}$ Foucault traces this logic in mother-child relations, explaining that neoliberals see child-care as "a human capital, the child's human capital, which will produce an income" (244). This income will consist in both the salary earned by the child when he or she becomes a worker, and in the psychic return (selfesteem, pride, social status as a mother, etc.) garnered by the mother. However, when the family is economized it becomes incumbent on the child to provide a return on the parent's investment. Failure to repay an investment is precisely the logic Cruesa uses when she sells Tisiphone and Amphilocus to Nikarete, the priestess of Aphrodite's temple. Although Cruesa is really motivated by her jealousy of Tisiphone's beauty and her fear of Creon's (quasi-)incestuous lust for their adopted daughter, her stated rationale is economic. Cruesa tells Nikarete:

We gave the best to these slave children, ${ }^{121}$

But rather than their gratitude, we've earned

Their resentment. Whatever we might give them

Is never quite enough, they mooch, they moan,

And when they are at home, they do nothing

But lounge around like well fed cats.

In fact, I fear they've begun to steal from us. (34-35, my emphasis)

liberalism, we are everywhere homo oeconomicus and only homo oeconomicus" (W. Brown 33). Classical liberals like Smith or Ricardo understood economics as one component of a comprehensive culture, and economic subjectivity as one among many types of subjectivity. As Wendy Brown puts it, "Adam Smith, Nassau Senior, JeanBaptiste Say, David Ricardo, and James Steuart devoted a great deal of attention to the relationship of economic and political life without ever reducing the latter to the former or imagining that economics could remake other fields of existence in and through its own terms and metrics" (33). This is precisely the step taken by the neoliberals: to conflate market freedom with freedom. For thinkers like Hayek and Friedman, the liberalization, deregulation, and privatization of markets represents the surest path to individual freedom from a coercive government and (perhaps paradoxically) from market exploitation.

${ }^{120}$ In the discussion of Marina Carr's By the Bog of Cats in the next chapter, the economics of family life will be further developed.

${ }^{121}$ Cruesa misrepresents the children as slaves instead of as her adopted children. 
This description invokes the same rhetoric used by contemporary politicians to demonize what used to be called 'welfare queens,' people imagined to be leeching off the hard work of decent, tax-paying citizens without contributing their fair share to the good of society. In characterizing Tisiphone and Amphilocus, Cruesa establishes an immediately economic relationship revolving around what she and Creon have earned from the children and the economic and material investment made in the two young people. As Foucault explains, for neoliberals family consists of a series of investments and returns built on a market model, and when members of the family becomes economic liabilities - mooching, moaning, lounging, or stealing — that person or people lose the legitimacy of their place in the familial structure.

Because Tisiphone (and by extension Amphilocus) threatens to usurp Cruesa's place in the family structure — which is the truth behind Cruesa's fears that the children are 'stealing' from her-she must be exiled from the house. This expulsion takes the form of an economic transaction as Cruesa entrusts Nikarete to sell the twins into slavery. Nikarete sells Amphilocus to the priest of Apollo, but keeps Tisiphone in the temple of Aphrodite. ${ }^{122}$ In the Corinth of the play, religion is entwined with both business and sexual desire, as Aphrodite's temple is a holy brothel, and the priestesses are sacred prostitutes. ${ }^{123}$ The first indications we get of the link between commerce and religion are near the beginning of the play when Nikarete comes to pay Creon "Last quarter's leisure levy / From the Temple of Aphrodite" (28) and Cruesa remarks that "Your Temple does business with all sections / Of our Corinthian society" (34, my emphasis).

\footnotetext{
${ }^{122}$ Although we never see the Temple of Apollo, we do find out that sexuality pervades that holy space as well. When Amphilocus escapes and returns to rescue Tisiphone, he recounts that the high priest "told me he admired my pretty face, / And found my lips pleasingly feminine, / Then he took his penis out / And tried to put it in my mouth" (67).

${ }^{123}$ Korinth was particularly known for sacred prostitution, though it happened throughout much of the ancient world. Strabo's Geographika recounts that in Korinth "the temple of Aphrodite was so rich that it owned more than a thousand temple slaves, courtesans, whom both men and women had dedicated to the goddess. And therefore it was also on account of these women that the city was crowded with people and grew rich" (VIII.vi.20).
} 
But it is only later in the play, after Tisiphone has been brought to the Temple, that we discover the extent of the link between religion, sexuality, and commerce. As Nikarete brings Tisiphone to Aphrodite's Temple, the Chorus says they shall go see "The golden statue of Aphrodite...Paid for by the priestess Polyarchis / Who made her fortune / From the splendor of her body" (51). As Tisiphone is shown inside, the other hetairas and pornais take a rather wicked delight in taunting Tisiphone with her new position and the sexual responsibilities that come with it. Despite working in the Temple and being consecrate to the goddess, Tisiphone's new companions are entirely commercially minded. As they describe for her how to please men's sexual appetites and suggest her own distinct niche - that of the teasing virgin - the Chorus (now playing Temple prostitutes) makes sure to emphasize "we haven't got all day, / Our clients pay by the hour" (58). Any distinction modern Western viewers might expect between the realm of religion and the realm of sexual consumption — because of course, prostitution is not simply sex, it is commercialized sex—is collapsed, as both religion and women's bodies become commodified. The other element collapsed within this Temple economy is family itself. Nikarete tells Tisiphone, "We are now your family. / And we've got a family business to run" (56). She repeatedly refers to the hetarias as her daughters $(53,54,57,61,62,66)$. In conceptualizing the Temple of Aphrodite as a family business, Nikarete picks up in a different (perhaps more honest) key Cruesa's earlier theme of family as an economic unit in which each member must contribute in order to earn their keep. Each of the sacred prostitutes must particularly be available that night because of Alcmaeon's presence in Corinth. Essentially, each daughter must be prepared to sell herself using the full range of her talents in order to profit the family. As Nikarete says, "Alcmaeon's in town, / We need to be ready if he calls round...think of the publicity / His patronage will bring. So, ladies / We need to be offering a full selection" (56). Once again, the 
neoliberal idea of the economic family shapes the rhetoric of this scene. Not only are the women reduced to sexual objects, they also figure as human capital — that is, as commodities required to sell themselves. Their 'family business' depends on an economy of desire, enjoyment, and excess. In other words, the late capitalist economy of enjoyment.

Late capitalism requires a culture of consumption, a culture in which products are continually bought in order to sustain the action of markets. According to McGowan, the result of this structural reliance of consumption is a shift in the cultural laws structuring (Western) society. McGowan argues that neoliberalism has catalyzed "the transformation from a society founded on the prohibition of enjoyment (and thus the dissatisfaction of its subjects) to a society that commands enjoyment or jouissance (in which there seems to be no requisite dissatisfaction)" (End of Dissatisfaction 2). This is the world of Teevan's Corinth-a cultural economy running on excessive consumption and the commodification of everything: women, religion, family, monarchy, friendship, etc. In other words, this is a society in which everything can be paid for, from family life to the gods' favor, and this market-value schema eclipses all other standards of value. The psychic economy of late capitalism—which takes the form of pathological narcissism-develops when the maternal superego subsumes the Law of the Father. ${ }^{124}$ The “"maternal' superego...does not prohibit enjoyment but, on the contrary, imposes it and punishes 'social failure"' (Žižek, Looking Awry 103). When the father is absent, and therefore the Law of the Father is replaced by the maternal superego, the path to normal sexual relationships is blocked (Looking Awry 99). In Alcmaeon in Corinth the father as agent is doubly absent, first in

\footnotetext{
${ }^{124}$ Freud recounts the origin of the superego — psychological prohibition — as a primal aggressive impulse against the father. He explains, "it gave that agency [the superego] the father's power, as though as a punishment for the deed of aggression they had carried out against him, and it created the restrictions which were intended to prevent a repetition of the deed" (Civilization 95).
} 
Alcmaeon who abandoned his children and second in Creon who wavers between prohibition and obscene enjoyment.

Alcmaeon left the children he fathered with Manto in the home of his friend Creon and former lover Cruesa. Although his sexual promiscuity results from his madness, the real punishment he encounters is precisely the trap of enjoyment, namely that the command to enjoy cuts off the possibility of enjoyment. Early in the play Alcmaeon reminds himself not to be seduced by any beautiful woman, because "Behind the pretty faces hide the Erinyes" (26). But, the society of enjoyment rejects the possibility of abstention or moderation. In this case, Creon brings Alcmaeon to Aphrodite's temple to spend an evening with the prostitutes (neither of them know Tisiphone is there). Initially Alcmaeon tries to resist, but alongside Creon and Nikarete's urging, the Furies - an embodiment of the maternal superego-urge Alcmaeon to lust. He says, "What harm sing those 'kind ones' in my head? / What harm in one more woman in my bed? / You've had so many, how can one more hurt?" (62). From three sides-Creon, Nikarete, and the Erinyes in his mind-Alcmaeon is bombarded with the demand that he enjoy, that he give in to his jouissance, even though he knows it is part of his punishment for matricide. And indeed, when Alcmaeon has chosen the veiled Tisiphone and brought her to a room, his access to enjoyment is curtailed. In Tisiphone's face he begins to see his own mother, her (unbeknownst to either of them) grandmother. Alcmaeon laments, "I must be mad when every girl I meet / Begins to resemble my own mother" (73). Despite the imperative to jouissance, Alcmaeon here runs into both an ironically applicable incest taboo and his own guilt as a matricide, which drive him further into madness. His pleasure becomes the source of his suffering.

Comparably complex and tortured by enjoyment is Creon. He stands in as surrogate father, but only Cruesa knows he is not actually Tisiphone and Amphilocus' father. Creon 
becomes obsessed with Tisiphone, physically suffering from his sexual desire for her. His

struggle is, therefore, directly against the incest taboo as an obstacle to his jouissance. Initially he resists the incestuous desire for Tisiphone, appealing to the laws of prohibition foundational to society: "We are civilized, we have our rules, / And a man must put his family first" (27).

However, as king of Corinth, Creon reigns in a society which has-like neoliberal capitalismtransformed from a culture of prohibition to a culture of enjoyment, and he therefore metaphorically locates himself as the Other to whom all enjoyment is open:

Does Zeus care

For the proximity of relationship

To the object of his rapacity?

He married his own sister Hera.

And, as Zeus rules Olympus, I rule here, I am Creon, king of Corinth

I'll desire whomseoever I want to desire. (27)

When Creon understands himself to exist on an equal plane to the gods, especially to Zeus, he grants himself access to the obscene jouissance normally prohibited by the Law of the Father (which, of course, as Tisiphone's father it is Creon's subjective role to enforce). His declaration that he will desire whomsoever he wants signals Creon's acceptance of the maternal superego's obscene injunction to enjoy and the abandonment of the paternal prohibition.

On a visual/performative level, this shift from paternal prohibition to jouissance is marked by the emergence of the anamorphic stain, a symbol repeated throughout the play. ${ }^{125}$

${ }^{125}$ In Lacanian psychoanalysis the anamorphic stain signals the eruption of the Real within the symbolic order, an eruption which is visually meaningless or formless. The stain appears at first simply as a distortion: "the element that, when viewed straightforwardly, remains a meaningless stain, but which, as soon as we look at the picture from a precisely determined lateral perspective, all of a sudden acquires well-known contours" (Žižek, Looking Awry 90). The stain represents a duality: on the one hand, it is a meaningless accidental stain-wine or blood - but when we shift our gaze to see it in the context of taboos, it becomes a visual marker of the Real. The stains are distortions in the fabric of reality which signal a moment of collapse that threatens to undermine the entire edifice of the symbolic order. The anamorphic stain is a physical/visual embodiment of the Real. As Žižek explains, "the Real is an anamorphic stain which pops up all of a sudden in the midst of reality...it indicates a process of the ontological disintegration of reality itself" (For They Know Not lxxxix). 
Visually the stain is created by spilled wine, and wine is tied explicitly to sexual desire. In Creon's speech, the transition between his acceptance of the incest taboo and his embrace of jouissance is marked by the servant Isthmias overfilling his wine glass. Creon admonishes her, "You've overfilled it! The wine's run over, / It's stained, it's stained me" (27, my emphasis). At the moment he resolves to abandon the incest prohibition, Creon is marked with a stain. This staining is repeated twice more in the play, both at times when a taboo is about to be violated. After Alcmaeon unknowingly hires his daughter in Aphrodite's Temple, she spills wine over her dress as she tries to seduce him (70). Then, when Amphilocus is about to murder Alcmaeon to prevent him possibly raping Tisiphone's unconscious body, Alcmaeon warns his son, "the sheets of this bed are now stained, / Not with your sister's, but with your father's blood" (79, my emphasis). This imagery of the anamorphic stain recurs around the violation of taboos: the first two times wine signals the abandonment of the incest prohibition, and with Amphilocus the blood stain marks the taboo of patricide.

Wine is used throughout Teevan's play as a marker of sexual desire. Creon drinks excessively as he struggles with his sexual desire for Tisiphone, and Cruesa (the voice of his prohibition, in asserting her own obscene enjoyment) challenges him: "Creon, have you not had sufficient wine - ?" (29), which is, of course, her coded demand that he be sexually satisfied with her (and the Temple prostitutes) and renounce the sexual enjoyment of their daughter. But the wine-sexuality imagery coincides more directly in the Temple itself, where the Chorus of hetarias utilize an extended metaphor to 'train' Tisiphone to tease and satisfy men. They begin by explaining, "Making love is like drinking wine" (58) and elaborate on the techniques for oral sex and faking an orgasm to stoke a client's ego (58-59). The metaphor establishes the clear connection between wine and sexuality, both linked to consumption and enjoyment in the 
economy of the brothel. But the wine functions not only as a signal for sexual desire, but as an anamorphic stain indicating the erosion of the social order. The repeated use of the stain motif in Alcmaeon in Corinth is a visual marker for thresholds where the prohibitions upholding social order threaten to collapse, and where, therefore, social order is jeopardized by jouissance.

The irony of Alcmaeon in Corinth culminates in the deus ex machina ending, in which the goddess Hera resolves the conflicts of the plot. Hera's entrance embeds the play metatheatrically within an obscene jouissance. First, Creon gets his wish that a deity will arrive to resolve the plot. Tisiphone refuses to marry Creon (understandably so), and he demands:

CREON. What? That is no way to end a story. TISIPHONE. Is real life not like that? Unsatisfactory?

CREON. Real life? I am the king and I have all these feelings I demand a god come crashing through the ceiling. (92)

At which point Hera appears. Tisiphone posits the reality of renunciation and the fundamental assumption of the society of prohibition, against which Creon asserts the necessity of his own enjoyment. The conclusion of the play is that Creon's desire is fulfilled, first in the intercession of Hera at his command, and then in her resolution of the plot problems. Hera comes to reassert the law, but the law is mangled beyond recognition as it blends obedience to the Other with a violation of the incest taboo and retroactively validates Creon's obscene desire. In pursuance of Apollo's oracle that Tisiphone would lose her virginity to her father (32), Hera proclaims, “Creon, you shall marry Tisiphone. / Apollo's oracle said she must lie with her father, / And though I'd rather not do this to you, child, / Oracles must in some way come true" (94). The conundrum of this pronouncement is precisely that it upholds the Law of Apollo's oracle through the violation of the incest taboo. The Law is refigured as demanding enjoyment. This is the destructive excess of jouissance, in which enjoyment destroys rather than brings pleasure or contentment. And of course, this is the foundation of neoliberal late capitalism, when the social 
imperative to renounce one's desire is abandoned and the maternal superego commands enjoyment, which then becomes impossible.

This chapter has begun to trace some of the complex interplay between theatre and political economics, and the plays examined here have critiqued the reduction of human subjectivity to merely homo oeconomicus. Both Trojan Barbie and Alcmaeon in Corinth highlight limiting aspects of neoliberal hegemony. Evans' play presents an overt picture of life in a refugee camp, which has increasingly become the permanent homes/holding pens for massive numbers of "surplus humanity," particularly in the global south. Teevan, on the other hand, explores the threat posed to subjectivity within a monetized culture of enjoyment, where everything and everyone is conceptualized in financial terms. While the specific details of these two plays — and the positions they depict within a neoliberal world — are quite different, fundamentally both plays show how a culture built on a market mentality constricts the potential ways in which human beings can find and measure meaning in life.

However, experiencing a work of art encourages us to seek out new ways of making meaning for ourselves, new ways of encountering and engaging with the world. As with Polly X's statue, art responds to a situation in the hope of change. The appreciation and viewing of art - including theatre - can offer a way to resist neoliberalism by evoking a common, cosmopolitan culture built on community and valuing human beings and social activities beyond economic terms. And with the collaborative nature of performance-the combined efforts of actors, directors, tech people, playwrights, audiences, and communities - theatre is an excellent medium for resisting neoliberalism's reduction of the human to merely economic value. As we shall see in the next chapter, communal identification and the empathy for others it helps build 
are key to resisting the neoliberal erosion of democratic and communal spaces and cultural structures. 


\section{Chapter III}

\section{Polis No More: Atomized Consumers and the Dissolution of Common Modes of Being}

In the first book of Aristotle's Politics he tells us that human beings are political animals and that the community of the polis is the natural space for the human $\left(1253^{\mathrm{a}} \cdot 7-18\right)$. These premises have long shaped philosophical understandings of the nature and role of society, but the turn to neoliberalism erodes these fundamental premises - rather than conceptualizing human beings as political and social (or more properly, complex and multi-faceted) subjects, neoliberalism, with its overwhelming emphasis on homo oeconomicus, encourages us to understand our subjectivity in purely monetary terms. As we have seen in the previous chapter, the impulse to commodify is a fundamental drive in neoliberal ideology, economizing vast swathes of the social, political, and personal previously regarded as inappropriate for the logic of commerce. Among the results of this impulse to economize daily life are the erosion of interpersonal connections, which get reduced merely to transactions, and the reduction of individual humans to consumers and human capital. This atomization of the individual as buyer and seller erodes possibilities for collective action and democracy because each individual is pitted against all other individuals.

This chapter examines two adaptations which critique and offer hope in the face of declining possibilities for communities and publics. David Greig's 2000 play Oedipus the Visionary and Marina Carr's 1998 play By the Bog of Cats both take up Greek story linesSophokles' Oedipus the King and Euripides' Medea, respectively—-transporting them into the present to dramatize the problems of privatized public spheres, declining democratic potential, and the economization of the family. Greig directly confronts the isolating power of a marketbased society in his adaptation, which sets the Oedipus story in contemporary South Africa. 
Evoking Greek and South African performance traditions for a Scottish audience, Greig imagines rebuilding civic unity by rejecting late capitalist market ideology and renouncing individual enjoyment for the benefit of society as a whole. Carr's bleak Medea adaptation provides less room for optimism, but is equally pointed in its critique of market forces as a means of controlling populations, especially women and nomads. In her play, set in the contemporary Irish midlands, Carr draws attention to the plight of the Irish Travellers, nomads who live uneasily in sedentary neoliberal Ireland, and the ways in which neoliberal discourses commodifying the family increase the economic burden of unpaid domestic labor for women. Both plays identify neoliberalism's market ethos and push for individual economic isolation as culturally destructive violences committed against those least able to resist or to conform to the requirements of the new hegemony.

Greek tragedies are fitting hypotexts for authors critiquing the erosion of democratic possibilities, because Greek theatre was itself rooted in a democratic Athenian public, and served as a cultural apparatus for the polis to define itself to itself and to the larger Hellenic world. As we saw in the first chapter, the festivals honoring Dionysus, where drama was principally performed, were massive civic events "used by the city of Athens as a polis to promote Athenian identity, political unity, and shared ideals about citizenship" (Storey and Allan 66). The most prominent drama festival, the City Dionysia, allowed Athens not only to display its wealth and power, but to produce plays engaging in a public discussion of norms, laws, justice, free public speech, and other elements that were fundamental to democracy in the city-state. And they could display and performatively work through these values before both citizens and foreigners, establishing Athenian and democratic values for both Athenians themselves and for the wider 
public of Hellas. In utilizing these ancient plays to advocate for expanding contemporary public spheres, civic collectivity, and democratic structures, these adaptations retain a kind of fidelity to the democratic spirit many critics argue shapes Athenian tragedy.

Neoliberal cultural politics eliminate public spaces for collective democratic discourse as traditionally public spaces become increasingly privatized. One reason for the difficulty in forming community under neoliberal late capitalism is that this political economic ideology elevates competition from an unfortunate by-product of capitalism to a moral good. Whereas many traditional political economists_-particularly Marx and Engels—identify competition as a destructive force inherent to property ownership, neoliberal ideologues valorize competition without acknowledging the socially and psychologically destructive forces exerted in unequal markets. To be engaged in the capitalist system is fundamentally to be an individual, alone and isolated in endless struggle against all other individuals. ${ }^{126}$ When neoliberalism elevates competition from a necessary evil to a social good the effects of this atomization are redoubled. ${ }^{127}$ Whereas society used to support non-economic spaces to withdraw to, today every facet of life (including family life) is increasingly dominated by a commercial mindset making it harder to escape one's role as homo oeconomicus. ${ }^{128}$ In other words, neoliberal ideology and

\footnotetext{
${ }^{126}$ Of course, we must remember that this is the logic of neoliberalism - we may think back to Friedman's idealization of Robinson Crusoe as an economic model, quoted in the introduction. While most people continue to maintain interpersonal relationships, late capitalist logic seeks to commodify all social processes.

${ }^{127}$ In Financialization of Daily Life, Martin argues that contemporary political economic ideology creates a world in which competition, risk, and instability are the only options because the human always figures as capital and must therefore always invest and re-invest in the self. He characterizes this world view as schizophrenic, writing that, "A hypercompetitive world such as this requires constant attention to opportunity and vigilance as to potential threats. There is nowhere to hide, and no moment of respite from the exertions of financial activity" (36).

${ }^{128}$ Of course, in neoliberal political economic theory competition does not figure as a destructive isolating force, but is in fact the source of political and economic liberty. Friedman makes this argument in Capitalism and Freedom: "The kind of economic organization that provides economic freedom directly, namely, competitive capitalism, also promotes political freedom because it separates economic power from political power and in this way enables the one to offset the other" (9). In other words, economic competition without government interference - the central goal of neoliberal political economics - intends to increase individual freedom by creating market spaces of free exchange absent the coercive power of a central government enforcing decisions. Friedman characterizes this economic protection of freedom thus: "So long as effective freedom of exchange is maintained,
} 
practice are opposed to the kind of collective civic unity (at least ostensibly) represented by the Athenian polis as a democratic space.

The two plays this chapter examines - Greig's Oedipus the Visionary and Carr's By the Bog of Cats — criticize the erosion of a shared public sphere through late capitalist emphasis on individualism. This erosion takes two main forms: declining potential for collective, democratic action and the loss of communal identities grounding the human subject. Robert W. McChesney explains the importance of non-marketized public spheres, writing, "democracy requires that people feel a connection to their fellow citizens, and that this connection manifests itself through a variety of nonmarket organizations and institutions" (11). In McChesney's account, the spaces of public life are a crucial prerequisite for a vibrant and democratic society in which citizens can participate in communal life, political life, social life, etc. ${ }^{129}$ McChesney is certainly not alone in identifying the importance of public institutions for democracy. In The Structural Transformation of the Public Sphere, Jürgen Habermas closely ties the emergence of a rational critical public sphere in $17^{\text {th }}$ century Northern Europe to the emergence of public spaces in which citizens could (ostensibly) engage in discussion about issues of common concern to society, while enjoying "a certain parity of the educated" (32). ${ }^{130}$ While Habermas is more interested in the abstract public sphere (i.e., modes of rational discourse), such a sphere requires public spaces

the central feature of the market organization of economic activity is that it prevents one person from interfering with another in respect of most of his activities" (14).

${ }^{129} \mathrm{McChesney}$ writes further, "A vibrant political culture needs community groups, libraries, public schools, neighborhood organizations, cooperatives, public meeting places, voluntary associations, and trade unions to provide ways for citizens to meet, communicate, and interact with their fellow citizens. Neoliberal democracy, with its notion of the market über alles, takes dead aim at this sector. Instead of citizens, it produces consumers. Instead of communities, it produces shopping malls. The net result is an atomized society of disengaged individuals who feel demoralized and socially powerless" (11).

${ }^{130}$ Habermas acknowledges that this parity was more theoretical than practical, but his understanding of the public sphere as a shared space for mutual communication between citizens continues to function as a prerequisite for a vibrant and engaged democratic populace. Habermas' critics often accept this theoretical premise, even as they increasingly identify real world limitations and restrictions of the bourgeois public sphere model. 
in which to occur, whether those spaces be physical like the coffeehouses and salons Habermas discusses, or digital in the $21^{\text {st }}$ century.

This, again, is where Greek drama becomes a useful medium for resisting neoliberalism's ideological tenets. In its original Athenian performance context, drama encapsulated the multitude of the polis - the collection of singularities existing in contact with one another. As Ian Storey and Arlene Allan put it, "The theater was also a large communal space. There were at least ten thousand spectators crowded into a restricted space... The experience of attending the Greek theater was not one of individuals responding as individuals to the performance set before them, but of a community of spectators reacting en masse to the horror or the humor played out for them" (50). Each audience member had their own reaction to a performance, but the sheer scale of the audience gave a collective power to shared emotional experience. One common analogy is that seeing Greek drama was like going to a modern football game, both in the sense of being surrounded by thousands of other spectators and in the emotional impact of other spectators on individual reactions. ${ }^{131}$ While virtually no modern theatres draw the size crowds (or allow for the kind of shared emotional reaction) scholars estimate attended Greek theatres, performing, adapting, and viewing Greek drama in live performance can perhaps establish smaller scale multitudes in modern theatres, and perhaps larger ideological multitudes with the vast numbers of people who have seen and experienced the same productions we see today.

\section{The Communal Crisis as Crisis of Individualism in David Greig's Oedipus the Visionary}

In the published introduction to his 2000 play Oedipus the Visionary, David Greig writes that he composed the adaptation as an exploration of power and economics (4). During a trip to

${ }^{131}$ Barsade writes, "emotional contagion does occur in groups and inasmuch as emotional contagion changes people's moods and serves as affective information, people are 'walking mood inductors,' continuously influencing the moods and then the judgments and behaviors of others" (667). 
the Republic of South Africa, Greig was affected by the ubiquitous presence of townships segregating the wealthy from the poor, and reflected that, "Perhaps, if our township existed as blatantly as it does in South Africa we would find it intolerable. But, like so much else in Scotland, the architecture of power is rather elegantly executed and so the ugly realities are kept out of sight" (5). One of Greig's great talents as a playwright is utilizing location to explore the pervasive cultural impact of late capitalism across national boundaries; as Marilena Zaroulia writes, "by using these small, unknown locations as the stage of the characters' stories, he indicates how the flow of global capital and its consequences can penetrate people's everyday lives in locations across the world" (178). When Greig wrote Oedipus the Visionary for the Glasgow-based Theatre Babel, he transculturally adapted Sophokles' play to a rural community in the mountains of South Africa - though the play is only partially grounded in South Africa's specific cultural or political situation. Using the RSA setting, Greig's play speaks to contemporary Scottish concerns about postcolonial politics, democracy, and national selfdetermination in the wake of the 1997 Scottish devolution referendum. ${ }^{132}$

The story of Oedipus, King of Thebes, is a fitting tale to adapt into a critique of neoliberal social isolation. Oedipus is doomed by his individualism. As a young man, he does not live peacefully, as Apollo's oracle at Delphi warns that he will kill his father and marry his mother. While attempting to escape this gruesome fate, Oedipus kills an older gentleman and several of his attendants in a dispute at a crossroads. Continuing his travels, Oedipus arrives at the city of Thebes, unbeknownst to him the city-state of his birth. Thebes is besieged by the Sphinx, and only wise Oedipus can answer the deathly riddle, freeing the city from the beast's

\footnotetext{
${ }^{132}$ To be clear, Greig's critique is not limited to either Scotland or South Africa, but takes on problems he feels are shared between the two societies (as well as by others structured through neoliberal ideology). Both the African setting and the Greek hypotext contribute to the play's Brechtian alienation, helping viewers/readers to reflect on the message but not identify in such a way that forestalls critical distance.
} 
tyranny. As a reward, Oedipus is made king and marries the queen, Jokasta, who had given birth to him - a relationship still unknown because Oedipus believes himself to be a son of Korinth. After many years and four children together, the happy time of Oedipus and Jokasta's reign come to an end as a great plague descends upon the long-suffering city-state of Thebes.

It is here that Sophokles picks up the tale in his 429 BCE play Oedipus the King. Oedipus' brother-in-law, Creon, brings word from Apollo's oracle that the only way to lift the plague is kill or banish the murderer of Laius, the previous king (Sophocles 218). Oedipus pledges himself to this cause, and it is here that his stubborn individualism becomes apparent, as the closer Oedipus gets to the horrible truth the more he is entreated to desist. When she begins to suspect the truth, Jocasta begs her husband to stop his quest, telling him to "Forget it all. It's not worth knowing," to which Oedipus replies indignantly, "Forget it all? I can’t stop now" (248). Oedipus rushes blindly into the arms of fate. And when the horrid truth of Apollo's oracle is revealed - that the man killed at the crossroads was none other than his father Laius, and Oedipus' wife and queen the mother who bore him—-Jocasta slaughters herself and Oedipus stabs out his eyes. Oedipus is the consummate individual, a flawed ruler who puts his own personal interests above those of his city-state and position. Though warned that it would bring destruction, Oedipus sought the truth for his own selfish reasons, and ended up, as he describes himself, a "pariah self-damned and self-arraigned" (258), exiled from his native Thebes at his own command. And so Oedipus again wanders Greece, the solitary exiled figure.

Greig's play re-imagines the Theban plague as the AIDS crisis currently facing southern Africa, and critiques global capitalism and continuing structures of economic apartheid for ignoring the plight of many poor Africans. For much of the adaptation, Greig remains true to the earlier Sophokles hypotext, despite the transhistorical shift from the Hellenic Heroic Age to the 
contemporary RSA. ${ }^{133}$ Greig's Oedipus is a landowner (possibly white, though Greig neither specifies nor precludes this possibility) who rules a small rural community—an analogue for Thebes, and possibly echoing Scotland — effectively maintaining apartheid-style economic relations without the legal apparatus of a racist state. As in the Sophokles, Oedipus pursues the truth about his and the community's history in an attempt to lift the curse of a plague. However, Greig ends his play quite differently than Sophokles, with the community breaking out of the cycle of the sacrificial crisis rather than expelling Oedipus.

Greig's play, originally performed just as Oedipus, debuted as part of the Glasgow-based Theatre Babel's Greeks trilogy, which included Liz Lochhead's Medea and Tom McGrath's Electra. The Greeks trilogy was the brainchild of Graham McLaren, Theatre Babel's artistic director, who sought to bring the timeless Attic tragedies to a turn of the millennium Scottish audience. The project was conceived because McLaren believed "by using writers that people know from today, and by doing these kinds of plays in Scots, you help open them up both by making them seem closer to home, and at the same time reintroducing that element of surprise" (Wilson). ${ }^{134}$ The playwriting and the performances sought to blend contemporary Scotland (and in Greig's case, contemporary South Africa) with classical Greece, straddling cultural and theatrical lines. However, in her review for The Scotsman, Joyce McMillan describes the miseen-scène as a failure: "Graham McLaren's staging - all oatmeal-coloured robes, stilted bodylanguage, cold-eyed cockney chorus and a single barren tree - somehow looks like nothing more than a string of cliches drawn from some textbook of classic productions." Despite some

${ }^{133}$ Interestingly, one way in which Greig remains true to the Sophokles plot is that the plague, or in this case the AIDS crisis, is the backdrop of the play but isn't a direct subject of inquiry. While the crisis sets events in motion, Greig - like Sophokles - is relatively uninterested in the concrete details of the plague.

${ }^{134}$ Greig's play is the least linguistically Scottish of the three plays. Lochhead and McGrath rely much more heavily on the Scots language. 
problems in attempting to update/represent Greek performance practices, Greig's play successfully blends the ancient with the modern in ways that shed new light on contemporary late capitalist globalization. My reading of the play focuses specifically on how Greig presents the socially corrosive effects of neoliberal free market ideology and the society of enjoyment as eroding communal unities by positioning every individual as a consumer in a competitive market place. This isolation of the individual threatens traditions of collective action among South Africans which helped undermine and eventually destroy legal apartheid, and which might model possibilities for Scottish self-government apart from the London based UK government. Greig, I argue, uses the sacrificial crisis structure of the Oedipus plot to promote collective action as a possible model for strengthening communities threatened by neoliberal attacks on public institutions.

Neoliberal ideology combines the ethics of ownership with the individualism already present in Sophokles' play to shape Greig's Oedipus. Benefiting from a racist legacy of land appropriation and economic inequality, Oedipus claims individual ownership of the land: "I came here, I live and farm this land. / It's mine as if it were the land that bore me" (28, my emphasis). Similarly, Jocasta tells him, "This is your land now. / Rule it. / Make it like it was before" (13, my emphasis). As in Sophokles, Greig's Oedipus is strongly individualistic and justifies his rule based on his own deeds—-saving the people from tribulations in the past and his promise to do so again. He establishes his arkhê— his right to rule—by claiming, "God didn't build the dam, or road or drive away your / persecutors it was a man, men. A person. Me. / If there's a reason for this plague. / I will find and cure it" (16). In identifying his right to rule based on his deeds, Oedipus conveniently ignores the history of apartheid inequality which dispossessed the lands of indigenous Africans. He ignores as well the continuing economic 
inequalities that maintain a functional apartheid in neoliberal South Africa. As Geoffrey

Schneider writes, "Although apartheid-era laws limiting black mobility and black voting rights

have been removed, 'economic' apartheid is being perpetuated in part through neoliberal

economic policies. The ideology of apartheid, which kept the races separate and unequal, is

being replaced by the ideology of the market, which is helping to preserve that inequality" (24)..$^{135}$

The contemporary dominance of a global capitalist free market has had a detrimental effect on South Africa, eroding communal ties that might otherwise have helped create a more economically just Rainbow Nation. ${ }^{136}$ Under neoliberal policies imposed by the IMF and World Bank, there have been few African success stories to mirror the Asian Tigers or the Celtic Tiger, partly because capitalists generally avoid Africa, fearing national instability, or because "When capital has come to Africa in recent years, it has been overwhelmingly in the area of mineralresource extraction" (Ferguson 35, original emphasis). ${ }^{137}$ According to Sagie Narsiah, pressure

${ }^{135}$ One bizarre aspect of neoliberalism in the South African context is the neoliberal assertion that a free market system will actually break down racism. According to Geoffrey Schneider, the English neoliberal economist and apartheid opponent William H. Hutt's "faith in the redistributive powers of the free market led him to conclude that no redistribution of any kind was necessary in South Africa: all that was necessary was the elimination of apartheid restrictions and the free market would tend to equalize incomes" (26). The basis of the neoliberal argument that free markets create equality is the assumption that all economic players operate rationally and on entirely economic principles, but the theory fails to acknowledge the centrality of prejudice and the roles played by ideology and irrationality in decision making.

${ }^{136}$ Markets have played a complex role in South African history and culture, a role that tends generally toward social instability rather than the equality and stability that neoliberals promise. My argument here relies on linking local African markets with The Market of global capitalism, though I recognize that these two types of markets are nowhere near the same economic entity, and I will distinguish them as much as possible. However, I am willing to make this somewhat uncritical conflation because, as we shall see, Greig collapses the distinction and stages a local market to stand in for the infrastructure of global late capitalism.

${ }^{137}$ In other words, capital (as opposed to international aid money or NGOs) tends to focus on extracting resources from African nations, as opposed to investment in infrastructure and industry. In 2016 the World Economic Forum compiled a list of the top 16 reasons corporations are reluctant to do business in RSA, despite a strong banking industry. The list includes problems like 1. inefficient government bureaucracy, 4. policy instability, 5. corruption, 6. crime and theft, 8 inadequate supply of infrastructure, 13. government instability, and 16 insufficient capacity to innovate ("16 Things Businesses Hate"). Apart from the question of whether these concerns represent real problems in South Africa, the wide spread belief that African nations are unstable, corrupt, and underdeveloped continues to deter global north businesses and capitalists from investing heavily in the continent. 
on South Africa and the ANC from the IMF and World Bank played a significant role in shifting the ANC's policies from a socialist focus on economic justice to a neoliberal faith in free markets. Under pressure from the IFOs, "South Africa was formally subsumed into a neoliberal, free-market paradigm in 1996 - with the adoption of the Growth Employment and Redistribution (GEAR) program. Particular policy positions were adopted as a consequence, promoting fiscal austerity, export oriented development and privatisation" (Narsiah 31). The economic policies Narsiah identifies in South Africa since 1996 largely conform to neoliberal orthodoxy, using free markets and private property to preserve an exploitative social order. ${ }^{138}$

Greig takes inspiration for his critique of globalization from both South African resistance to apartheid and $20^{\text {th }}$ century Scottish theatre's tradition of left leaning resistance to right wing London governments, especially under Thatcher. ${ }^{139}$ Beginning in the 1970 s, Scotland began to conceptualize itself less as a partner nation of the UK, and more as a small nation with historical ties to Europe. John Corbett links the emergence of Scots language adaptation to this shifting mindset: "The shift in the nature of the 'classical' adaptations of drama into Scots in the years following Scottish devolution is consonant with a repositioning of Scotland, from an internally colonized nation on the periphery of European civilization, to a reinstated nation, once more in control of its own, but still troubled destiny" (99). ${ }^{140}$ Such a national redefinition

${ }^{138}$ For instance, unemployment remains a massive problem, even as the national economy has boomed since the end of apartheid. In 2010, The Economist reported that RSA has a $25 \%$ unemployment rate, but factoring in unreported numbers and "those too discouraged to look for work" the number may be as high as 40\% ("Jobless Growth"). And the pattern of unemployment is racially divided: "30\% of blacks are officially unemployed, compared with just 6\% of whites." Although The Economist speaks approvingly of the ANC government's "prudent fiscal and monetary policies," many critics (including Narsiah) argue that the South African government has betrayed the ANC's socialist ideals and accepted neoliberal policies that preserve racial inequality.

${ }^{139}$ Reid writes, "Thatcher's brand of neo-liberal conservativism proved a political philosophy profoundly at odds with the values of Scottish civic society...during the 1980s Scottishness as a marker of identity became increasingly synonymous with hostility to Thatcher's free-market neo-nationalism" (63).

${ }^{140}$ While Greig's Oedipus the Visionary is not written in Scots, it is part of a wide trend of translation and adaptation in contemporary Scotland. Lochhead's Medea, which premiered alongside Greig's play as part of the Greeks trilogy, has heavy Scots influences. And Edwin Morgan's Phaedra: A Tragedy, mentioned in the first chapter, is an example of a classical play adapted into Scots. 
certainly resonates with post-Apartheid South Africa. Greig is deeply engaged in Scottish

politics, having been shaped by the politically engaged theatre of the 1970 s and 80 s. He has been

a vocal advocate for Scottish separation from the UK, particularly leading up to the 2014

Independence Referendum. In particular, Greig critiqued the concentration of power in

London — as both national and economic center — which he feels fails to respond to the wider

needs of people in Britain. ${ }^{141}$ Greig advocates a decentralized and locally democratic union as

the basis for supporting Scottish independence: "If you start flipping your thinking...our

government is far too top down; I think that the British state is far too centralized. London is

essentially an entirely different economy, an entirely different society...In principle, power

should be decentralized down" (qtd. in Carrell). Along with many other advocates of Scottish

independence, Greig supports localized democratic government which could better represent the

political leanings of their citizens and be less imbedded in a globalized economic order. ${ }^{142}$

Oedipus the Visionary depicts the individualizing action of the market, and the desire to

consume that neoliberalism promotes, as socially corrosive. René Girard argues that (at least in

literature) desire is socially conditioned, that we identify desirable objects by recognizing that

others desire those objects. This mimetic desire creates rivalries, which orient self-destructive

${ }^{141}$ Greig told The Guardian, "When the City of London wields such astonishing power, it entirely dictates the terms of how we view each other as human beings. We've lost the idea that an economy exists to make sure we're fed and happy. It's as if we exist to feed the economy" (qtd. in Carrell).

${ }^{142}$ One major problem is that neoliberal free market ideology — which the ANC made central to South African economics under pressure from the IMF and World Bank (Narsiah 30) and Thatcher put at the heart of UK politics - atomizes individual consumers, focusing principally on individual rights and enjoyment rather than social justice or economic equality. Neoliberals like Friedman identify individual freedom as the primary social good: "the intellectual movement that went under the name of liberalism emphasized freedom as the ultimate goal and the individual as the ultimate entity in the society" (Friedman 5). This focus on the individual as the most important socio-economic unit underpins neoliberalism's suspicion of any sort of collectivist culture. As Harvey notes, this freedom contains a paradox: "While individuals are supposedly free to choose, they are not supposed to choose to construct strong collective institutions (such as trade unions)... They most certainly should not choose to associate to create political parties with the aim of forcing the state to intervene in or eliminate the market" (Neoliberalism 69). This suspicion of collective culture has been extremely effective in eroding social links - especially in the global north-leaving contemporary subjects increasingly isolated through lifestyles focused on consumption and the paranoid suspicion that everyone poses a threat to their property/enjoyment. 
violence within the community. Girard explains that this desire is rooted in the subject's perceived lack:

The reason is that he desires being, something he himself lacks and which some other person seems to possess. The subject thus looks to that other person to inform him of what he should desire in order to acquire that being. If the model, who is apparently already endowed with superior being, desires some object, that object must surely be capable of conferring an even greater plentitude of being. (146, original emphasis)

Clearly neoliberal capitalism did not invent desire, but in the society of late capitalism we are plunged into a world continually marked by the promise of enjoyment, and the implication that others/the big Other always has greater enjoyment than we do. Therefore, the marketization of all social processes under neoliberalism puts desire and competition at the center of much contemporary culture.

The erosion of community as a valued organizing principle precipitates the sacrificial crisis, which Girard argues underpins the movement of tragedy. In a society in crisis, forces like anxiety, tension, dissent, and violence build to potentially explosive or revolutionary levels if not vented. Girard theorizes that a crisis becomes 'sacrificial' when the community selects a surrogate victim who can become a kind of lightning rod attracting all the violence that would otherwise destroy the community itself. As he puts it, "The sacrifice serves to protect the entire community from its own violence. . The elements of dissention scattered throughout the community are drawn to the person of the sacrificial victim and eliminated, at least temporarily, by its sacrifice" ( 8 , original emphasis). Girard identifies this as the fundamental narrative structure of Greek tragedies, and Greig maintains the sacrificial crisis structure into Oedipus the Visionary by transplanting the early portion of the plot structure from the Sophokles hypotext. However, whereas Sophokles showed the mimetic and violent relationships between Oedipus, 
Kreon, and Tiresias (Girard 69-72), Greig physicalizes these destructive desires in the marketplace.

Greig's exploration of subjective desire conflates the individual market of Oedipus' village with the economic Market of global capitalism. Scene five is set in the town market, where individual members of the chorus imagine what they'll do with the money if they can manage to sell their few personal possessions. In traditional Greek tragedy (as well as in most of Greig's play) the chorus is a communal voice, or a voice with which the audience is collectively supposed to identify, so for Greig to split these chorus members up as individuals within this market sphere is significant. Greig himself points this out, writing in the "Note on the Chorus" that 'At certain points they [the chorus] are individuated as 'Man 1' or 'Woman 1'. This individuation should be respected" (8). The market itself is a dismal place, a space of sad dreams, sickness, and despair. Each chorus member has his or her own reason for wanting money. Man 1 wants to go to Harvard business school so he can get a good job, Man 2 wants a Happy Meal, Woman 2 wants to hear music and see movies (22-24). The goals these chorus members identify — their objet petit $a$-mask the real object of lack, which is expressed unconsciously through the form of desire. ${ }^{143}$

The guiding force of desire in scene five is what Freud calls the death drive or death instinct, which is a primordial desire to return to an inorganic state. Freud describes the death drive as "an urge inherent in organic life to restore an earlier state of things which the living entity has been obliged to abandon under the pressure of external disturbing forces" (Beyond 30,

\footnotetext{
${ }^{143}$ As Lacan explains, the objet petit $a$ is "a privileged object, which has emerged from some primal separation, from some self-mutilation induced by the very approach of the real" (83). Or as McGowan puts it, "It is the object that holds out the promise of the ultimate jouissance for the subject. And yet, at the same time, it is an impossible object: it remains always just out of reach" (End of Dissatisfaction 77). In other words, the objet petit a substitutes for the actual desire, which is the lost (or imagined) experience of subjective wholeness. The problem of course is that no object obtainable within the symbolic order can actually replace the lost phallus, so the search is always in vain.
} 
original emphasis). Trauma can bring the death drive most obviously to the surface by disrupting the balance between the pleasure principle - the desire to seek happiness and avoid unhappiness — and the reality principle — which acknowledges the need for delayed gratification. Amidst the traumas of poverty and the AIDS crisis/Theban plague, the characters in the market seek escape, release, sleep, and even death. For example, Man 2 wants to consume a McDonalds Happy Meal, which is, of course, a perfect representative of objet petit a because the very name 'Happy Meal' declares the food's privileged connection to enjoyment. And this connection to enjoyment is exactly what Man 2 ostensibly seeks, claiming he wants to "know that I have done what I wanted, only once" (23). However, the objet petit a simultaneously obscures and reveals the real object of desire, which is the death drive, the desire to escape the cycle of capitalism that constitutes the entirety of life under neoliberalism. As Man 2 speaks three times, the interaction with the Happy Meal moves from a refined consumer experience to excrement. In his opening line, Man 2 says specifically that he wants to buy a Happy Meal. He does not initially say he wants to eat a Happy Meal, centering this interaction in the space of the commercial, the space of the commodity (22). The next time Man 2 speaks the interaction is more visceral. He claims he wants to "feel the warm burger meat fill my stomach," moving from the realm of the impersonal commodity to the mechanics of digestion (23). Finally, in his last bit of dialogue in this scene, Man 2 wants to know "what it's like to shit burger meat onto the dry earth by the roadside" (24). This final change is the most revelatory. In the shifting focus of desire from the consumer purchase of the commodity/objet petit a to leaving excrement by the roadside we see the truth of Man 2's desire, which is to escape the consumer cycle so reliant on an economy of enjoyment (i.e., buying the Happy Meal) and return to a non-conscious, or perhaps pre-symbolic, condition (represented by shit or waste, by that which capitalism is ill-able to commodify). 
The culmination and most direct representative of the despairing voices in this market is Man 6, the presentation of whom is an almost heavy-handed evocation of the death drive. Man 6 intends to buy alcohol and drink himself into oblivion, then "when I'm no longer conscious of anything. / I'll smash one of the bottles on a rock. / And cut my throat with the glass" (24). More explicitly than any of the other chorus members, Man 6 seeks death in both the figurative and literal senses. The Freudian death drive is not simply or directly about wanting to die, but about achieving "an initial state from which the living entity has at one time or other departed and to which it is striving to return by the circuitous paths along which its development leads" (Freud, Beyond 32). So both in a simple sense of seeking death directly, and in the more properly Freudian sense of seeking an inorganic oblivion through extreme drunkenness, the object of Man 6's desire correlates with the instinctual dictates of the death drive. Cultural erosion and selfdestructive violence builds in scene five, culminating in the suicidal dream of Man 6. Although it may seem counter-intuitive, Man 6's desire is, in fact, a mimetic desire for enjoyment. His pursuit of the death drive is conditioned by those around him, who also seek escape from a monetarized subjectivity, and in the fulfillment of the drive he seeks a kind of obscene enjoyment, more properly termed jouissance, or destructive enjoyment. The longing for oblivion and death signifies a larger cycle of violence as the community breaks down, replacing the harmonious dream of the Rainbow Nation with individuals competing in an indifferent free market sphere.

This scene embodies the action of the neoliberal market, and the paradoxical destructiveness of desire within the society of enjoyment. This condition is tied to neoliberal political economics because "Global capitalism functions by submitting all cultural life to the process of commodification, and this process can only be sustained if everyone is engaged in the 
endless pursuit of enjoyment” (McGowan, End of Dissatisfaction 50). The pathological

narcissist — the psychological subject shaped by global capitalism—has no interest in or

responsibility to a community, but is entirely geared toward seeking his or her own enjoyment in

compliance with the Law of the Other. Within the psychological structure of neoliberal

capitalism, each individual is pitted against one another, competing with rivals over mimetically

desired objects. Greig's presentation of the market condemns neoliberal capitalism for atomizing

individuals, each of whom is ostensibly responsible only for his or her own desires, with no

space for civic or social unity. ${ }^{144}$

However, African markets also offer a model for strengthening communities through

shared public spaces. ${ }^{145}$ Traditionally, African markets were centers in which to meet people,

hear and discuss news, and so on. Paul Bohannan and Philip Curtain write that markets "could be

used for many purposes other than buying and selling — to meet your girlfriend, settle a legal

dispute, get the latest news, or pay your respects to important elders or chiefs. Market places in

Africa are almost as important politically and socially as they are economically" (103). Kevin

Wetmore, Jr. links African markets to the Athenian agora, writing, "the marketplace of Athens

was in many ways the cultural, social, economic, political, and geographic center of the city.

Similarly, the marketplace in any African village is the center of everyday life" (Athenian Sun

${ }^{144}$ Of course, many South African communities were deeply undercut by apartheid, which limited workers' movements throughout the country at the same time that South Africa's economy increasingly became centered in cities. Many people moved from rural areas to townships surrounding major cities, thereby limiting or losing contact with their families and ancestral communities in the countryside. However, at the same time, a distinct and vibrant township culture began forming, though because of the fluid nature of township populations these communities were more subject to change than more conservative rural areas.

${ }^{145}$ In West Africa traditional markets functioned somewhat like the bourgeois public sphere described by Habermas. The openness and equality that were the ideals of the European bourgeois public sphere also characterize West African markets. However, markets are not an indigenous part of South African culture; "In many parts of Subsaharan Africa, then, markets post-date European control; are frequently strictly European-introduced phenomena; and in some cases are operated by largely non-indigenous peoples" (Hodder 101). Nevertheless, markets have become an important facet of contemporary South African culture. 
41). ${ }^{146}$ Although African markets are traditionally controlled by a local chief or king, their daily functioning is fairly democratic. In this sense, the market makes up a kind of commonwealth, or a space of common ownership inhabited by the multitude, from which collective action could arise.

Indeed, Oedipus the Visionary advocates collective action at the culmination of the sacrificial crisis. Girard emphasizes the collaborative (though unconscious) nature of selecting a sacrificial victim, writing, "Each member's hostility, caused by clashing against others, becomes converted from an individual feeling to a communal force unanimously directed against a single individual" (79). In Oedipus the Visionary, Oedipus comes to stand in for all the evils of colonialism, apartheid, continuing economic apartheid, and the global north's indifference to the AIDS crisis (in other words Oedipus becomes a new shared objet petit $a$, the object standing for desire). He must therefore be expelled from the community in an attempt to make it symbolically whole again. ${ }^{147}$ As in Sophokles, Greig's Oedipus largely drives his own self-sacrifice, telling the people, "Inside my skin is all the agony the world can make. / I hold it in me. / My skin protects you. / Outside my skin the world is good" (83). In his pain and shame Oedipus tries to

146 To understand the cultural role that Bohannan and Curtain, and Wetmore ascribe to markets in African and Hellenic cultures, we might think about the difference Turner describes between liminal and liminoid rituals. For Turner, liminal rituals shape an entire society and are compulsory, while liminoid rituals have some of the characteristics of liminality but are smaller scale and optional. So, when I go to the grocery store in the US today, I enter a public (though usually corporately owned) market space where I see people and interact (often minimally) with other members of the community. However, the market is not a major public space which orients collective social life - we might think of cafés is 1890s Paris or the mall in 1990s US culture as better analogs. The very fact that markets today are often privately/corporately owned may exclude sociality from most markets-ubiquitous security cameras and "No Loitering" signs reminding us that we enter as guests into privately owned public space.

${ }^{147}$ Ironically, the search for a scapegoat to serve as a sacrificial victim utilizes the same modes of mimetic and collective decision making that created the rivalries from which the communal violence sprung: "A single victim can be substituted for all the potential victims, for all the enemy brothers that each member is striving to banish from the community; he can be substituted, in fact, for each and every member of the community. Each member's hostility, caused by clashing against others, becomes converted from an individual feeling to a communal force unanimously directed against a single individual. The slightest hint, the most groundless accusation, can circulate with vertiginous speed and is transformed into irrefutable proof. The corporate sense of conviction snowballs, each member taking confidence from his neighbor by a rapid process of mimesis. The firm conviction of the group is based in no other evidence than the unshakable unanimity of its own illogic" (Girard 79). 
retain his individuality — the atomized selfhood which neoliberalism envisions as the human condition. Rather than seeing himself in a context, Oedipus retains his earlier attitude of total ownership, both of his ill-gotten possessions and of his deeds.

This is where Greig really diverges from the Sophokles hypotext. In Sophokles' Oedipus the King the titular character is expelled from the community. Through the cyclical movement of the sacrificial crisis, the Theban community embraces the obscene enjoyment of its violent impulses. It is also clear in Sophokles that, while they may find an object lesson in his tragedy, the chorus members do not identify themselves with Oedipus. At the end of Oedipus the King the chorus reflects, "Look on this Oedipus, the mighty and once masterful: / Elucidator of the riddle, / Envied on his pedestal of fame. / You saw him fall. You saw him swept away" (263). In these final lines of the play the chorus discusses Oedipus as an individual, as an isolated person who can be disconnected from the Theban polis and exiled to his fate. ${ }^{148}$

By contrast, even in his self-sacrifice Greig's Oedipus can never truly be expelled from the community - he remains an integral part of the larger identity of the multitude. In the face of Oedipus' individual suffering, the community experiences a melting of identities into a commonwealth of universal experience. During the play's climax in scene sixteen, the priest tells the people:

His mind and body dissolved.

He became nothing.

He became all time.

Nature shatters all humanity.

$W e$ are Oedipus.

We are nothing. (76, my emphasis)

Oedipus is brought into the fold, into a shared experience of the world marked by suffering, and therefore into the commonwealth of humanity. When Oedipus dissolves, he does not dissolve

\footnotetext{
${ }^{148}$ Indeed, in Oedipus at Kolonus the wandering Oedipus largely continues to figure as lone individual.
} 
into non-being, his individual self blends into the collective identity of the community—evident in the pronoun shift from he to we. This prayer incorporates Oedipus into the multitude. This prayer contrasts the first scene of the play, which offers a foil to highlight the eventual renunciation of sacrificial violence. In scene one, the chorus watches a man dying of thirst drag himself along seeking water. Instead of helping this man, the chorus prays—establishing a parallel between the religious ritual of prayer in scene one and in scene sixteen - that God will "kill the pity in us" as they helplessly watch the man die (10). The prayer envisions a god of opulence and enjoyment, this is the god/Other imagined as having total access to jouissance in ways denied to subjects within the society of enjoyment. The chorus' prayer addresses:

Dear fat god.

Dear drunken god.

God on your throne of battered gold leaf.

In your rooms of red velvet.

With your naked, laughing whores sat on your lap.

Your mouth stained red with wine.

Make us like you.

Give us the power of your hate.

The power of a God to see pain and feel nothing. (10-11)

In this vision of hedonistic enjoyment—of food, wine, sex, texture, color, and indifference—the chorus addresses the Big Other of neoliberal capitalism, which commands enjoyment and simultaneously punishes the subject for never being able to enjoy enough. To this god, the god of enjoyment, the chorus prays for the power of hate, to eliminate the displeasure of seeing disease and suffering destroying the community. But this prayer from scene one is replaced in scene sixteen with the prayer to bring Oedipus into a renewed community, a prayer which renounces the enjoyment promised by violence in the sacrificial crisis. Unlike Sophokles' Oedipus the King, here the community foregoes the sacrifice of the surrogate victim, refusing the 
violence/enjoyment, preferring instead to pass through the liminal space of ritual that erases Oedipus' atomized individualism and incorporates him within a communal body.

This image of connection characterizes much African ritual and drama, as well as Greek theatre, which can serve to strengthen communities. Wetmore argues that communal affect is central to ritual and sacrifice throughout Africa, noting, "in a group context sacrifice forms a communal bond that joins the participants into a community" (Athenian Sun 61). While Greig is not an African dramatist, Oedipus the Visionary reflects a similar kind of communal ethos, a communal connection allowing intersubjectivity to replace isolation. Clare Wallace traces this connectivity in many of Greig's plays as a counterpoint to the erosive force of global capitalism: "If postmodern globalization is often seen to offer a plethora of potentially detrimental or dislocating effects, Greig turns to the ethical resources of human communication and contingent communities as a means of suggesting, however partially, utopian possibilities of transcending those negative conditions" (107). ${ }^{149}$ Steve Cramer writes that Greig utilizes setting to engage questions about communality, questions he feels are fundamentally human rather than specific to one particular culture: "Context is everything to Greig, and the precision with which he outlines his characters' circumstances reflects a recurrent thesis throughout his oeuvre about the ways humans are diverted from their organic sociality" (173). In other words, Greig utilizes particular spaces - in this case the geophysical space of South Africa and the cultural space of Oedipus the King - in order to establish connections with viewers, to find common ground to create

\footnotetext{
${ }^{149}$ Oedipus the Visionary was not the first play in which Greig used a non-Scottish setting to critique neoliberalism's impact on Scotland and the globe as a whole. Cramer writes that in Greig's 1995 play Europe, "there seems to be a subtext too about another small nation asserting its independence. Scotland's rate of unemployment amidst the ongoing free market economic experiment remained high, with vast tracts of local industry obliterated" (174). In the mid-1990s Greig found inspiration for Europe in the neoliberal experiment that crippled the Russian economy, and in Oedipus the Visionary he turned to on-going economic apartheid in South Africa. Both of these provided comparable models for contemporary Scottish politics and resistance to the centralized neoliberal government in London.
} 
liberatory socio-political aspirations. In Athenian democracy, theatre also had socio-political implications. As public performances at the heart of a major religious and civic festival, Attic tragedy modeled democratic engagement through publicly performing rhetorical conflict, collective citizenship, and by being enacted in a shared, public space. Graham McLaren's production for Theatre Babel tried to bring the Greek tragedies to a contemporary Scottish audience. Evoking Greek culture builds connections between modern audiences and ancient Athenians, links shared by theatre-goers the world over: the collective experience of theatre as a public art form. The experience of theatre is a deeply human one, which has the power to connect audiences across time, space, and culture, producing a commonwealth of theatre spectators. ${ }^{150}$ In Greig's play, Oedipus' pain and shame become part of a shared human experience, and through the collective recognition and embrace of this common cultural experience it becomes possible to break the cycle of violence constituting the sacrificial crisis.

This recognition of common culture and renunciation of sacrificial violence gestures toward an end to global capitalism and the society of enjoyment. Greig does not offer a simple or transcendental strategy for moving beyond the current political economic mode, but through recognition of our place within the organizing structures of neoliberal capitalism it is possible to remake the world by working against the forces of social isolation. The problem created by neoliberalism is that "the absence of the idea of a neutral public world leaves us trapped within the shell of the ego, intent on safeguarding our private enjoyment. We become isolated monads" (McGowan, End of Dissatisfaction 175). However, recognizing ourselves as singularities already existing in the multitude, and therefore already imbedded in the common, can work against the forces of neoliberalism that seek to destroy communities. In the choice not to expel Oedipus

\footnotetext{
${ }^{150}$ As we shall see in Chapter V and the Conclusion, these connections produce a cosmopolitan empathy that I argue is crucial to adaptation's cultural politics.
} 
from the community — contra Sophokles—Greig's imagined South African community

renounces the enjoyment promised by violence, the enjoyment promised by the structure of the sacrificial crisis. Instead of pursuing the objet petit a by killing or expelling Oedipus, the community elects to accept its own partial enjoyment, thereby leaving the cycle of (consumercompelled) desire. Similarly, coming together in the shared space of the theatre to enjoy and reflect collectively creates civic spaces to resist the cultural imperative to enjoy individually.

\section{Marina Carr's By the Bog of Cats and the Politics of Space and Family in Neoliberal}

\section{Ireland}

Loss of communal ties under an individualistic free market ethos particularly affects people already disempowered within societies, especially women and ethnic minorities. As we began to see in the previous discussion of Teevan's Alcmaeon in Corinth, by the time of the Celtic Tiger in the mid-1990s, the Republic of Ireland had become a distinctly neoliberal society. ${ }^{151}$ However, neoliberal ideological developments were not entirely welcome. Irish neoliberalism included the politicization of space and mobility, which significantly affected Eire's oldest minority—-the Travellers. Like the Roma, Travellers are nomadic and insular, often working short term labor jobs. Marina Carr's 1998 play By the Bog of Cats adapts the Medea story to critique the social isolation and damage caused by policing space and forcing Travellers to settle as unwelcome outsiders in (or on the fringes of) sedentary Irish communities. ${ }^{152}$ While this reading of the play is not unique, I argue for situating Carr's play in a larger context: that she

${ }^{151}$ In the mid-1990s Ireland's economy expanded rapidly due to an influx of investment from abroad, largely by digital technology companies. In 1998, when By The Bog of Cats premiered, the Irish economy had seen several years of massive growth - as much as 10\% per year between 1995 and 2004 ("Luck of the Irish") —and for the first time in modern history Ireland was flush with cash. However, in the early 2000s domestic investors turned increasingly to construction, which created a property bubble that collapsed dramatically shortly before the Great Recession of 2008, which plunged Ireland back into economic crisis. For more on the Celtic Tiger see Ó Riain or Donovan and Murphy.

${ }^{152}$ Robbie McVeigh theorizes sedentarism as a mode of existence in contrast to nomadism. This theory will be explained in more depth below. 
critiques neoliberalism's emphasis on private property as a precondition for subjectivity and citizenship, and the social erosion that results from conceptualizing people as atomized consumers and families as economic units. Much of Carr's drama explores the experiences of women and constructions of family networks, and in adapting Medea Carr intensifies Euripides' original interest in Jason and Medea's family structure. But Carr filters this thematic interest through a contemporary move to marketize the family, an ideological shift akin to the processes of neoliberal commodification explored in the previous chapter. ${ }^{153}$ It bears repeating here that neoliberalism does not necessarily innovate, it does not necessarily create new modes of interpersonal/social relationships, rather neoliberal cultural politics forecloses subjectivities other than homo oeconomicus, and this foreclosure precludes non-market based relationships even within families. In other words, while family has always included economic relationships, neoliberalism seeks to limit family to exclusively economics.

Medea's long history is marked by bloodshed and strife. Raised in Kolkhis (in modern day Georgia), she meets Jason when he and the Argonauts venture across the Black Sea to seek the Golden Fleece possessed by King Æetes, Medea’s father. The king demands an impossible trial before he will surrender the Fleece, and Medea provides Jason with a magic potion that helps him succeed in the task. Medea lulls the serpent guarding the Fleece to sleep so that the Greeks can take their prize. Making their escape with Medea, who is now Jason's affianced bride, the Argonauts sail for home pursued by Medea's brother Apsyrtus, whom they lure aboard the ship where she and Jason kill him. After this adventure the Greeks return home and Jason

\footnotetext{
${ }^{153}$ As feminist critics have well established, families and especially women have long had a commodity value in Western culture. However, as we learned in the Introduction and shall see in more detail below, neoliberalism intensifies the imperative to see family as merely or principally a set of economic transactions, rather than seeing family as a complex and multifaceted set of social relationships.
} 
brings Medea to Korinth, where they have two children together and Jason becomes an important leader in the city-state.

Euripides picks up Medea's story in his 431 BCE play. After several years living happily in Korinth, Jason decides to leave Medea and marry Glauke, daughter of Kreon, the king. This is a political marriage to improve Jason's standing, but Glauke is also much younger than the middle-aged Medea. Medea is justifiably outraged at Jason's desertion, which increases her sense of isolation not only in a foreign city-state but as a non-Greek living in Greece-Medea is an outsider, betrayed by the man who brought her out of her homeland and abandoned in a foreign nation. When Kreon orders her to leave the city, it is the last straw. Medea determines to have her bloody revenge. She sends a poisoned wedding gown and tiara to her rival, who dies taking Kreon with her when he tries to rescue his daughter. After these covert murders, Medea decides to slaughter her children to prevent Jason from raising them, which she does just before he arrives to save the boys and take his vengeance. As Jason curses her, Medea escapes to safety in Athens in a chariot pulled by magical dragons.

Medea is a challenging plays for modern critics; those who want to see Medea as a symbol of female resistance to a patriarchal authority and sexual violence or domination have to find a way of reckoning with Medea's decision to murder her children. Indeed, this is a decision Euripides, as skillful as he generally is at interpreting human motivation, seems to struggle to explain. Edith Hamilton claims that Medea kills her sons because "There was no protection for her children, no help for them anywhere. A slave's life might be theirs, nothing more" (180). But this is a contentious point because the play gives evidence Jason wants to keep the children alive and raise them as his sons. Jason is the betrayer at the beginning of the play, but it becomes 
increasingly difficult to see Medea as a suffering victim when she slays Glauke—who is after all probably only marrying Jason to firm up a political alliance — and her own children.

Carr transculturally adapts the basic plot of Euripides' Medea, shifting it from the heroic age of Greek mythology to the contemporary Irish midlands. Hester Swane, a Traveller settled on the edge of the Bog of Cats, has been abandoned by Carthage Kilbride who intends to marry Caroline Cassidy. Carr further develops the issue of maternity, already present in the Euripides source text, by exploring not only Hester's relationship with her daughter Josie, but her longing for her own mother who left during Hester's childhood with promises to return. As we will see, familial relationships in Carr's adaptation are refracted through the lens of neoliberism's complex family politics. Like Medea, Hester kills her daughter at the end of the play, but unlike Medea who is rescued by a divine dragon, Hester also dies at the play's conclusion. By the Bog of Cats premiered at Dublin's Abbey Theatre in 1998, as part of the Dublin Theatre Festival, and was recently revived at the Abbey in 2015. Both productions demonstrated Carr's ability to combine the mythic and the real in a characteristically Irish way, as well as a characteristically Greek way. The sets, both designed by Monica Frawley, evoke the destitution of Medea's abandonment through a sparse, almost Beckettian, frozen Irish landscape. David Nowlan wrote that the 1998 production was "Set majestically and bleakly by Monica Frawley on a snowcovered terraced turf bog in Offaly" and the staging evoked connections with the Euripides source text. In her review of the 2015 revival, Helen Meany writes, "the snow-covered landscape forms a gleaming amphitheatre, beautifully evoking Euripides' Medea, which is the inspiration for this play. The vast white ridge helps create the dreamlike mood." Unlike the Babel production of Greig's Oedipus the Visionary, which utilized a clichéd Greek aesthetic, the Abbey 
production's mise-en-scène was distinctly Irish and they let the play itself establish its

connections to its Athenian forerunner.

Like Medea, transplanted from Kolkhis to Korinth, Hester is an outsider. Because of her

Traveller heritage, Hester is regarded by the community with fear, disdain, and suspicions of black magic, even though she is native Irish and lived her entire life by the Bog of Cats. As she says, "I was born on the Bog of Cats, same as all of yees, though ya'd never think it the way yees shun me" (314). Hester speaks extensively about being an outsider, about feeling ill at ease in her settled life, and about the distrust and hostility she encounters as a child of Travellers. This marginality is a common experience of Irish Travellers who, like European Gypsies, have historically been seen as dangerous fringe elements living by magic, crime, and violence. ${ }^{154}$ Hardt and Negri argue that mobile populations, like nomads or refugees, exemplify a cosmopolitan way of being in common that challenges neoliberal capitalism. They argue that, "Migrants demonstrate (and help construct) the general commonality of the multitude by crossing and thus partially undermining every geographical barrier" (Multitude 134). ${ }^{155}$ In attempting to preserve the existing social order, nomads living within predominantly settled cultures become negative social examples, reinforcing their already marginal positions. ${ }^{156}$

${ }^{154}$ Richardson describes the role of Travellers or Gypsies as folk devils—groups that folk wisdom identifies as a threat to mainstream society. Richardson claims that "The government, for instance, uses the role of Gypsy as folk devil from a functionalist perspective in order to tell the rest of society how not to live" (112).

155 At the same time, Hardt and Negri also argue that in the era of postmodern biopolitical production migrants provide a model for neoliberal exploitation of labor: "In the contemporary economy, however, and with the labor relations of post-Fordism, mobility increasingly defines the labor market as a whole, and all categories of labor are tending toward the condition of mobility and cultural mixture common to the migrant" (Multitude 133). In other words, even as work becomes increasingly flexible and unstable, these changes may bring workers into greater contact with others than they had in the relatively stationary scheme of industrial capital.

${ }^{156}$ In a brief social history of the Irish Travellers, Hayes notes that, "Prejudice against Travellers is entrenched in Irish society. They have a pariah status and live in 'caste-like' isolation" (134). He argues that the main roots of this distrust are suspicions of sexual openness or immorality, and a fear of self-contained cultures existing within a mainstream culture. In other words, because Travellers have their own language, customs, religious dogma, and socio-familial organization, they represent an unknowable Other which exists as a potential threat to the ostensible unity and coherence of Irish culture. 
The predominance of sedentarism provides a strong ideological imperative to isolate and control the movements of nomads. Robbie McVeigh defines sedentarism as "that system of ideas and practices that serves to normalise and reproduce sedentary modes of existence and pathologise and repress nomadic modes of existence" (9). Or as Wickstrom explains it, sedentarism is "a deeply formative attachment to place, to staying in one place, and to a, however unconscious, belief that being itself can only begin, cohere and persist through being in place. To maintain oneself in place is, of course, dependent upon how one acquires the place in which one is to stay. Hence sedentarism is joined to ownership, of the land, of the house" (134). Western civilization is heavily invested in sedentarism as a mode of existence, and therefore unsettled or nomadic peoples pose an existential threat to societies conceptualized through geographic location. Historically, sedentary cultures have invested significant resources in monitoring the locations and activities of groups perceived as having non-geographic identities-Travellers, Gypsies, Jews, refugees, and so on.

Policing space and regulating movement has become significantly more important in the era of increasing globalization. ${ }^{157}$ Neoliberal Ireland (both in the Republic and Northern Ireland) has promoted or imposed sedentarism, passing laws that severely restrict Travelling. Wickstrom documents spatial regulation as a means of disciplining potentially dissident populations in Palestine and the Republic of Ireland. She notes that Irish "attempts to end traveling have come

\footnotetext{
${ }^{157}$ While in theory neoliberalism advocates coupling individual choice with personal responsibility, in practice neoliberal states - including the Republic of Ireland, the UK, and the US - have coupled a procorporate/pro-financial climate with law-and-order policies enforced through ideological state apparatuses and increasingly militarized police. Travellers have a long and fraught relationship with law enforcement. It is not just stereotypes of violence and criminality that cause trouble between (particularly neoliberal) law enforcement and Travellers, it is the very condition of nomadism. In an article about policing space and Traveller culture, Mulcahy writes, "Travellers remain elusive to many of the information demands that mobilize police activities and measure organizational behavior. . .in more prosaic terms, the need to check names, addresses and other spatially relevant information - is directly undermined by nomadism" (316). Modern police work relies on being able to gather and use information to keep track of people - a system presupposing sedentary populations. It is much harder to keep track of nomads because at any time they are capable of changing location.
} 
to almost total fruition since the Housing (Traveller Accommodation) Act of $2002^{158}$ (also

known as the Trespass Law) that effectively criminalized it. The Act mandated that any parking

or camping on private or public property (including the sides of roads) was illegal" (135).

Additionally, the Housing (Miscellaneous Persons) Act, 2002, and the Unauthorized

Encampments (Northern Ireland) Order, 2005, provide broad powers for the Gardai (Republic of

Ireland Police) and the PSNI (Police Service of Northern Ireland) respectively in moving

Travellers out of illegal encampments, even when there is no legal space for Travellers to camp,

despite laws in both the Republic and NI requiring government provision of housing or camp

sites for Travellers (Drummond 38-39, 40). ${ }^{159}$ The almost unavoidable conclusion is that the

nomadic mobility that made Traveller culture unique in Ireland has been legally targeted across

the island. ${ }^{160}$

Hester Swane's ambivalent attitude toward her settled life by the Bog of Cats reflects the complex positioning of Travellers in neoliberal Ireland - outsiders seen as a moral and economic

158 The Housing (Traveller Accommodation) Act was actually passed in the Republic in 1998 (Oireachtas, "Traveller"). Wickstrom here conflates it with the Housing (Miscellaneous Provisions) Act of 2002 (Oireachtas, "Miscellaneous"), which revised some of the provisions of the 1998 HTAA.

${ }^{159}$ Drummond also notes that the Republic's "Failure to recognize Irish Travellers as a distinct ethnic minority is out of sync with policies in Northern Ireland and elsewhere in the UK" (48-49), which complicates questions about Travellers' human rights on the island of Ireland. Differences in laws between NI and the Republic create some legal uncertainty about the ethnic status of Travellers and legal requirements to provide camp sites.

160 This criminalization is part of a larger neoliberal project of using identity politics as a means of disciplining increasingly large populations of disenfranchised (and frequently mobile) people-the poor, women, ethnic minorities, homeless, queers, etc. Duggan argues that neoliberalism utilizes the rhetorics of identity politics and nationalism to obscure the real role of political and economic power in generating inequality and oppression. She writes that neoliberalism "organizes material and political life in terms of race, gender, and sexuality as well as economic class and nationality, or ethnicity and religion. But the categories through which Liberalism (and thus also neoliberalism) classifies human activity and relationships actively obscure the connections among these organizing terms" (3, original emphasis). In other words, emphasizing identity categories de-emphasizes the role of political economy in structuring material and political life. McVeigh points out that the enforced sedentarism of Travellers constitutes oppression in terms of both identity politics and political economy, writing, "nomadism is a constituent part of the ethnicity of 'ethnic nomads' - forcibly to sedentarize them is not simply to stop them travelling, it is actively to destroy their ethnicity" (16). Simultaneously, he argues that sedentary societies police Travellers to uphold the legitimacy of property ownership against nomadic peoples who use land without a concept of legal ownership. In McVeigh's theory, nomadism inherently raises questions about the legitimacy of owning land, and draws attention to the systems of violence and inequality that undermine sedentarism as an ideology (20-21). 
threat, and subject to spatial disciplining. Hester's Traveller pride exists in tension and sometimes contradiction to her desire to remain settled in her home. She clearly and happily identifies as a Traveller, telling Carthage, "as for me tinker blood, I'm proud of it" (289). Despite this pride, however, Hester is ideologically invested in sedentarism, asserting a moral right to remain in her home against the legal claims of Carthage Kilbride and Xavier Cassidy. She establishes this tie to the geography of the Bog of Cats in the first scene of the play, telling her friend 'I'm goin' nowhere. This here is my house and my garden and my stretch of the bog and no wan's runnin' me out of here" (268). Hester is caught between the almost biological imperative of her "tinker blood" - a phrase she repeats twice $(268,289)$ —and an ideological imperative tying subjecthood to being in place. This self-division derives from an enforced sedentarism; enforced in part by Carthage Kilbride, who moved Hester from her caravan to a house. Hester's internal conflict mirrors the play's capitalist dilemma over property ownership. The ambivalence in Hester's attitude reflects a struggle over ideological models of property and family, pitting nomadic culture against capitalist property ownership. Near the play's end, Hester tells him, "Ya built that house for me. Ya wanted me to see how normal people lived. And I went along with ya again' my better judgment" (333, my emphasis). Hester's identification of normalcy with sedentarism reinforces the notion of Travellers as exotic Other—distinct and deviant from the Irish norm, and therefore subject to reformation.

In By the Bog of Cats, this reformation operates primarily on an individual level, with Mrs. Kilbride —Carthage's mother—-trying to destroy her granddaughter's Traveller identity. Mrs. Kilbride, herself the descendent of Travellers, is the most viciously anti-Traveller voice in the play. She states directly and unapologetically that she intends to destroy Josie's Traveller identity and reform her as a sedentary Irish subject, in spite of Hester's continued identification 
with her familial heritage. Mrs. Kilbride tells the child, 'I'll break your spirit yet and then glue ya back the way I want ya" (279). She envisions the process of raising Josie as literally smashing her identity — an identity infused with her mother's 'tinker blood' — and reforming it as a settled Irish identity. One of the key debates between Josie and Mrs. Kilbride is whether the girl is a Kilbride — as Josie claims — or a Swane — as her grandmother asserts. This is not merely a dispute over a name or the legality of marriage, because Travellers identify principally by family. Being nomadic and doing seasonal or irregular work means Travellers have limited or no access to the identity categories used by sedentary society_identifying by occupation, neighborhood, or address, for instance. Instead Travellers organize through kinship networks. In her study Irish Travellers: Racism and the Politics of Culture, Jane Hellenier writes that Traveller families often co-reside "among the husband's 'people' - his parents, brothers, cousins, uncles, and/or grandparents" (178). This means, of course, that family relationships and family identity play a major role in the self-identification of Travellers. For Josie to disavow her identity as a Swane complicates her links to a potential Traveller identity. On the one hand, Josie identifies with her patronym, the name of her father's family, which is appropriate for the patriarchal structures of Traveller culture. However, she is simultaneously denying the family name that represents her Traveller heritage - Swane — in favor of a sedentary (and economized) family identity.

Travellers' familial unity results partially from economic cooperation, a version of the primitive communism characteristic of many nomadic societies. ${ }^{161}$ In contrast to the neoliberal family where each individual is weighed in terms of costs and benefits, under primitive communism the family works communally to produce and enjoy the products of that labor.

${ }^{161}$ Engels explains primitive communism: "At all earlier stages of society, production was essentially collective, just as consumption proceeded by direct distribution of the products within larger or smaller communistic communities. This collective production was very limited; but inherent in it was the producers' control over their process of production and their product" (233). 
Traveller families have a great degree of control over their own labor. Because they are mobile and typically have a variety of skills with a wide market —including things like construction, plumbing, electrical work, and other handicrafts - they have more labor choices than sedentary people tied by geography to a specific job market. The tenuous nature of Traveller income, however, has major implications. Primitive communism is much more group oriented than individualist capitalism, because at any given time only some family members may have income, which means that everyone depends on sharing resources. The economic unit relies on reciprocity — when I have money and food I share with you on the expectation that in the future you may have money and food to share with me. This communal reliance on an economic collective tightens the bonds between family members because each individual's survival depends on his or her family members.

Josie's denial and Hester's ambivalent sedentarism isolate them from a Traveller community that might have given them a shared identity, and instead locates the mother and daughter in a settled Irish community ideologically invested in property ownership. The problem Hester (and Josie, to a lesser extent) has is that in this sedentary world she is always seen as a foreigner (partly because Hester doesn't legally own her home). Euripides’ Medea describes similar isolation:

I am alone, without a city, wronged by a husband, uprooted from a foreign land.

I have no mother, brother, cousin; am without a haven in this storm. (345)

Similarly, Hester is without a haven in her storm, despite the fondly held belief that her mother will return to the Bog of Cats and find her again. The staging of the Abbey productions embodied this isolation, with the frozen landscape of the bog rising around the stage, with its icy 
waters and inhospitable trees. Hester could have sought her family, and likely would have been able to find her mother, father, and brother, but entering the sedentary family-world of Carthage Kilbride eroded Hester's ability to establish the long distance kinship networks typical of Traveller women (Hellenier 179). ${ }^{162}$

Instead, Hester immersed herself in the economically invested world of a sedentary neoliberal Ireland. The debates over Hester's house attest to this investment. She asserts a moral right to continue living in the house Carthage built for her, while Carthage and the Cassidys claim legal ownership. This agon — this structuring clash of ethical systems — exposes the socially isolating force of capitalism as it pits consumer against consumer for private possession of resources. Seán Ó Riain argues that one of the key factors in both the rise and fall of Ireland's Celtic Tiger was the liberal creed, which "is a set of beliefs or an ideology that supports marketisation. More importantly, it is a process through which market relations and institutions come to be seen as natural by members of the society" (20). Both Carthage and Xavier find it natural to think of Hester as merely an economic or financial problem to be solved; both think it is possible to pay her off with money. For Xavier this is business as usual, as he's fully embedded in a neoliberal world view; though Carthage (who is not fully integrated into neoliberalism) struggles when confronted with Hester's emotional and familial loyalty to him and their relationship:

CARTHAGE. And here. (producing envelope) There's your blood money. It's all there down to the last penny. HESTER. No! I don't want it!

\footnotetext{
${ }^{162}$ We can assume that Hester could have found Big Josie based on the scarce pieces of geographical evidence the play provides and on the fact that Hester's brother Joseph found her comparatively easily after his father sent him looking (321). Hester and Carthage take Joseph out on Bergit's Lake, which must be somewhere near the Bog of Cats (given how close Hester stays to the bog), and she reflects that Big Josie's home is visible across the lake. (333). So, from the lake where Joseph was murdered Hester can see Big Josie's (former) house.
} 
CARTHAGE. (throws it is the snow) Neither do I. I never should've took it in the first place. I owe ya nothin' now, Hester Swane. Nothin'. Ya've no hold over me now. (Goes to exit.)

HESTER. Carthage - ya can't just walk away like this. (290-291)

In these lines we see the competing ethics of Carthage's burgeoning neoliberal belief in money and Hester's emotional and personal investment in their relationship. Carthage asserts that the only debt he has to pay is the money used to buy his farm. Given his consistent attempts to find an arrangement that will suit Hester, Carthage may protest too much here, apparently trying to convince himself that their relationship was only financial. For Hester the debt is not monetary, it consists of Carthage's responsibility to her built up over a fourteen-year life together, now abandoned for the greater economic prospect of Cassidy's property. Hester's emotional devotion to the relationship with Carthage demonstrates the importance of family in Traveller culture. When conceptualized as a communal network, family has a troubling and troubled position in neoliberal ideology. ${ }^{163}$

If individuals are to be free from constraint and coercion in their economic dealings, the individual cannot be tied to a family to and for which they are responsible; contrariwise, if the family is the point around which freedom and an economized society coalesce, then the individual is displaced from its position of importance. ${ }^{164}$ However, because of a politically

${ }^{163}$ In her brief comments about By the Bog of Cats, Wickstrom writes that, "the Traveller is used symbolically, more a means for the playwright to arrive at her own message than an investment in the Travellers themselves" (148). I don't necessarily agree that the two descriptions are mutually exclusive, but I do agree that Carr's play has larger ideological stakes than a narrow focus on Traveller issues. State sponsored criminalization of and cultural violence against Travellers is one manifestation of larger processes of individual isolation in neoliberal Ireland. The erosion of Traveller culture functions as part of a sustained ideological campaign to reformulate identity not along communal lines, but as individual consumers in a social sphere guided by a market mentality. The unity of Traveller communities, and the threat posed by nomadism to private property ownership, necessitates the destruction of Traveller identity if neoliberalism is to retain its cultural hegemony because the Travellers embody an alternative social organization, one based on familial loyalty and nomadic mobility, rather than market competition, sedentarism, and late capitalist notions of ownership.

${ }^{164}$ As Wendy Brown points out, the family introduces a fundamental uncertainty within neoliberal ideology (100). The problem is that family as a social organizing unit clashes with the freedom of the individual: "if the family is the ultimate operative unit, the site of freedom, and the perspective from which we judge social arrangements, then the individual cannot be, and vice versa" (100-101). 
necessary alliance with social conservatives in the UK and Evangelical Christian conservatives in the US (both of whom promote "family values" as a central platform), neoliberal advocates have needed to reconcile the discrepancy between the rhetoric of individualism and the rhetoric of family. The solution is the economic family, wherein the family becomes an investment for the individual, though a complex investment. Friedman makes this point when he writes:

children are at one and the same time consumer goods and potentially responsible members of society. The freedom of individuals to use their economic resources as they want includes the freedom to use them to have children - to buy, as it were, the services of children as a particular form of consumption. But once this choice is exercised, the children have a value in and of themselves and have a freedom of their own that is not simply an extension of the freedom of the parents. (33)

Identifying children as merely commodities (and proto-consumers) reduces them from human beings and eliminates the importance of homo familias by figuring all familial interactions through homo oeconomicus, sets of individuals investing in one another on the promise of economic, emotional, or psychological returns. ${ }^{165}$

In By the Bog of Cats this economized family is epitomized in Xavier Cassidy's conceptualization of his dead son and his future son-in-law. For Xavier, family is an economic prospect, not something to be valued in and of itself for providing a communal or emotional support network. Although the allegation occupies only a moment in the play, Xavier Cassidy (allegedly) murdered his son and seems to be replacing the dead boy with the more desirable Carthage Kilbride. Hester says, "You're not a farmer for nothin', somethin' about that young lad bothered ya, he wasn't tough enough for ya probably, so ya strychnined his dog, knowin’ full

\footnotetext{
${ }^{165}$ Martin finds an overt example of this impulse to financialize the family in Willard Stawski II's book Kids, Parents \& Money: Teaching Personal Finance from Piggy Bank to Prom. Martin describes how the family and the home are refigured when pervaded by financial logic: "The redefinition of the family home as an object of speculation and credit, together with the infusion of its interior design with financial tastes, displaces domestic life in a number of ways... When the family too is transparent, run like a corporate boardroom with full disclosure, authority lies in the marketplace that bisects the domestic economy into a holy writ of allowance (to teach financial literacy) and unpaid chores. The home is no longer an entertainment center, but a medium of age-appropriate financial management" (195).
} 
well the child'd be goin' lookin' for him" (329). Xavier's primary concern in the play is preserving his farm through the generations, and so family becomes principally an economic investment to maintain the integrity of his land. If his own son didn't seem capable of preserving the farm as a viable economic prospect, Xavier needed to replace him. Carthage was already running his own farm, so not only did a marriage between Carthage and Caroline represent the preservation of Xavier's farm, it involved a long term investment combining the two properties. Xavier actually acknowledges that his relationship with his daughter is not emotional and that she is a means to an end: securing the farm by establishing a (marriage) contract with Carthage. Xavier tells Hester, “I married me daughter today! Now I don't care for the whiny little rip that much, but she's all I've got, and I don't want Carthage changin' his mind" (330). Randy Martin argues that in a culture driven by a market mindset "the family home takes on the trappings of the modern state, rational governance underwritten by threat of force" (59). The goal of this rational governance is to protect, preserve, and expand property. As Xavier suggests, Carthage is a good familial investment because "He loves the land and like me he'd rather die than part with it wance he gets his greedy hands on it. With him Cassidy's farm'll be safe, the name'll be gone, but never the farm. And who's to say but maybe your little bastard and her offspring won't be farmin' my land in years to come" (328). Through the investment in family Xavier replaces his own son, who was unlikely to be strong enough to maintain the farm, for a stronger son-in-law who has already proven his ability to run a farm, and who already has a child who can further maintain familial control over the land.

On some level the murder of Hester's brother, Joseph, resembles the murder of Xavier's son, in that both were family murders motivated by money, but looking deeper into Hester's motives reveals a very different character. In an echoing of the murder of Medea's brother 
Apsyrtus, Hester's brother came and found her and they went out onto Bergit's Lake with Carthage, where Hester killed her sibling with a fishing knife. She and Carthage stole his money and dumped the body in the lake. It was this money that bought Carthage his farm and gave him his start. In this sense - murdering a family member for economic advantage-Hester's actions resemble Xavier's killing of his son. And of course, it is not unreasonable to ascribe an economic motive to Hester's actions. But what actually drove her to murder was rage at being abandoned by her mother. ${ }^{166}$ When Joseph's ghost visits her, she tells him, “If ya hadn't been such an arrogant git I may have left ya alone but ya just wouldn't shut up talkin' about her as if she wasn't my mother at all" (319). And later Carthage says, "I always thought ya killed your brother for the money," after she recounts to him "I looked across the lake to me father's house and it went through me like a spear that she had a whole other life over there" (333). Hester's rage stems from losing her mother, and Joseph comes along as a reminder of the life she's lost and the potential relationship she could have had with a mother who abandoned her. As a Traveller, Hester should derive much of her identity from family, but being abandoned has distorted that aspect of identity and cultural self-knowledge. In fact, Hester's obsessive devotion to remaining by the Bog of Cats (a geographic rootedness not found in Medea) is based on the belief that her mother will return and complete Hester's divided psychic identity.

Losing her family — first mother, then quasi-husband, and finally the immanent loss of her child ${ }^{167}$ — compromises Hester's identity because she has no other supports that help her selfdefine. She does not, as far as we can tell, have a job, meaning she functions outside the public economic sphere. Instead, the sphere from which Hester derives her identity is the domestic-

\footnotetext{
${ }^{166}$ Hester's mother is her objet petit a. The maternal relationship is the missing component of Hester's identity which she fantasmatically believes will make her a unified subject.

${ }^{167}$ I call Carthage Hester's "quasi-husband” because they were never actually married, but Hester does tell Caroline "You're takin' me husband, you're takin' me house, ya even want me daughter" (283).
} 
femina domestica rather than homo oeconomicus—in her matrilineal (sometimes imaginary) relations with her mother and her daughter. But without her family Hester's role in the cultural economy becomes superfluous. Although she refuses to consciously admit it, the encounter with Joseph and the knowledge that her mother lived across the lake for years eroded the phantasy of her mother's return, and when, near the end of the play, Carthage declares, 'I'm takin' Josie, Hester. I'm takin' her off of ya. It's plain as day to everyone 'cept yourself ya can't look after her" (335) we see the final erosion of Hester's potential familial role. While the play gives only hints about how Hester and Josie's domestic relationship works, it is clear that Hester derives much of her sense of value from her role as caregiver to her daughter, a traditional sphere of unpaid domestic labor.

The home — to the extent that it remains a non-economized space—poses a problem for neoliberal theory because domestic life coerces work, usually from women and usually without pay. In other words, domestic labor exposes the limits of a capitalist fantasy of free and equal economic relations between workers and owners. Neoliberalism bypasses the problem of the contradiction between enforced/unpaid domestic labor and economic freedom by reintroducing a kind of separate spheres dichotomy, ironically hearkening back to the Greek root of the word economic (oikos referring to the art of household management) which was originally distinct from the public sphere. Neoliberal discourse relegates unpaid domestic labor to a private sphere not governed (or minimally governed) by the freedom of economic markets. Wendy Brown writes that under neoliberalism, "gender subordination is both intensified and fundamentally altered. The intensification occurs through the shrinking, privatization, and/or dismantling of public infrastructure supporting families, children, and retirees" (105). ${ }^{168}$ The concerns and role

\footnotetext{
${ }^{168}$ In other words, by eroding the state or communally supported resources that displaced some of the labor of domestic caregivers to the public sphere, neoliberalism re-establishes gendered hierarchies that had been
} 
of women had rarely been treated on the Abbey stage before 1998, according the Victoria White:

“In Marina Carr's By The Bog of Cats...I saw women's rituals and psychological dynamics

sketched for the first time on the national stage, on such a scale that I could see them as being significant at a national level.” The visceral performance of Hester's pain, played by Olwen

Fouéré, put the voice of suffering women at the center of the Irish national stage almost for the

first time. ${ }^{169}$ Hester's experience, and the experiences of Irish women more generally, entered a highly visual and nationally influential public sphere. In the economic sphere however, the neoliberal value of responsibilization - privatization and the dismantling of public support networks - increases the burden of women's unpaid labor, in contrast to the neoliberal philosophical commitment to economic freedom of choice.

This division of labor between paid/market and unpaid/domestic returns to ancient divisions structuring Western culture and intensifies them through a newly economic (and distinctly gendered) lens. Going back to the Greeks, human life has been divided between necessity and freedom, with necessity ascribed to women, slaves, and workers, while freedom was the (male) space of politics, art, and philosophy. ${ }^{170}$ Given the social conservativism linked to

weakened under the social democratic welfare state because women are traditionally and disproportionately responsible for caring for children, the elderly, and the sick or injured, while the more public spheres of business and wage-earning remain male spheres.

${ }^{169}$ By the time Susan Lynch played Hester in the 2015 revival women's concerns and issues had gained more attention in Irish theatre, but reviews of the revival tended to emphasize the play's fatalism, the inevitability of loss and death suggesting the fated collapse of the Celtic Tiger boom. Meany writes that, Hester's "self-knowledge can't save her from her actions, which are presented as inevitable...Knowing that this was coming doesn't make it any less brutal." In an Irish Times review, Crawley links the greedy, land-grubbing Kilbride family to "the crude beginnings of the Celtic Tiger years," but he also notes the seeming inevitability of fate, writing, "Destiny and family here have an [sic] similarly oppressive pull: they hold you fast and suck you down." Looking back on the Celtic Tiger years from 2015 provides a much darker picture of Ireland's economy than many would have forecast in 1998 .

${ }^{170}$ According to Arendt, "What all Greek philosophers, no matter how opposed to polis life, took for granted is that freedom is exclusively located in the political realm, that necessity is primarily a prepolitical phenomenon, characteristic of the private household organization" (31). The Greeks knew (though they were occasionally reluctant to admit) that the existence of a public life is dependent on the coerced labor of the household, and neoliberalism recreates this dichotomy between a public (now market) sphere of freedom, and a private/household sphere of necessity and servitude. 
neoliberal politics, it should come as little surprise that this market-household dichotomy is rooted in assumptions of natural gender divisions, which helps reify neoliberal exploitation of women's unpaid labor. Brown explains, “Generally uncoerced, yet essential, this provision and responsibility [of care for those unable to care for themselves] get theoretically and ideologically tucked into what are assumed as preferences issuing naturally from sexual difference, especially from women's distinct contribution to biological reproduction" (105). In By the Bog of Cats, much of the conflict over custody of Josie hinges on the question of Hester's "fitness" as a mother, or her ability and willingness to perform the labor required to care for her daughter. Carthage claims he could easily have Josie taken from Hester: "I only have to mention your drinkin' or your night roamin' or the way ya sleep in that dirty auld caravan and lave Josie alone in the house" (290). However, earlier in the scene we get one of the most domestic exchanges of the entire play, giving us a glimpse into Hester and Josie's life. When Josie returns from Mrs. Kilbride's house, Hester makes sure she has eaten a healthy breakfast and sends the child to brush her teeth (286). While this doesn't prove Hester is a good mother, the conflict over her maternal fitness reinforces a gendered labor scheme that assigns women the unpaid work of caregiving. Ultimately this regressive formulation of labor division as a natural preference or choice rather than an enforcement of culturally constructed and hierarchized gender roles underpins neoliberalism's campaign to construct consent and establish market principles and individualism as common sense policies across the distribution of the sensible.

$$
* * *
$$

This chapter has drawn out some implications of the neoliberal commodification of subjects and social processes, an idea introduced in the Introduction and Chapter I. In particular, the plays discussed here respond to the erosion of democratic spaces and possibilities through the 
increasing atomization of individual consumers. Both Oedipus the Visionary and By the Bog of Cats explore intersections of marginalized or downtrodden communities or identities: Greig puts South Africa's continuing economic apartheid in conversation with Scottish separatism and resistance to a centralized UK government; Carr's female Traveller protagonist finds her values pitted against those of sedentary, neoliberal Ireland, exemplified by Xavier Cassidy. As we've seen, those most at risk of violence, oppression, and dispossession under late capitalism are those already on the fringes or margins of society. And as we shall see in the next chapter, this is true not only within cultures, but on a global scale as well. Neoliberalism's push for free trade, mobile capital, and liberalized international markets has established a (neo)colonial power structure re-establishing the authority of the global north over the global south.

Despite neoliberalism's individualizing power and the threat it poses to a democratic public sphere, theatre remains an important vestige of a collective culture. Although less central to contemporary civic life than it was for the ancient Athenians, theatre can still function to show us processes of democratic life and the value of common, cosmopolitan cultural forms. In particular, adaptation puts different value systems, different ways of seeing the world, different ways of performing and conceptualizing identity and ethics, and different cultures into conversation with one another. And when we experience theatre together in public, it may help rebuild some of the collective sociality and democratic civic engagement that neoliberal forces have worked so hard to undermine. 


\section{Chapter IV}

\section{Economic (Neo)Colonialism: Disaster Capitalism Makes Globalization Go Round}

Global politics have been largely shaped by a colonialism premised on military conquest and political domination. However, in the increasingly financialized world of neoliberal late capitalism, even the relations of colonial domination are changing. Since the wave of national liberations in the 1960s and 70s, with a few exceptions—-Britain's Falkland's War or US military adventurism in Afghanistan and Iraq, for instance - the global north has abjured overt military conquest, but maintained a continuous, albeit unofficial, dominance over the global south through the manipulation of international economics. While this new imperialism looks different from old $19^{\text {th }}$ century empires, global north financial interests continue to set economic, social, and trade policies for many global south nations through international financial institutions like the IMF, World Bank, and WTO. These policies are specifically crafted according to the three major policy platforms of Chicago School economics: privatization, deregulation, and free trade. David Harvey writes that, "The extraction of tribute via financial mechanisms is an old imperial practice" (Neoliberalism 74). Or, as Lisa Duggan puts it, neoliberal "policies reinvented practices of economic, political, and cultural imperialism for a supposedly postimperial world" (xiii). Because most of the money 'freed' up through enforced economic liberalization flows to global north financial centers in New York, London, Tokyo, or Frankfurt, the new globalized economy extends the imperial domination of the global north into the $21^{\text {st }}$ century.

This chapter will examine three plays critiquing contemporary practices of imperialism and the financial exploitation of the global south. First I discuss two plays by the Nigerian playwright Femi Osofisan: Tegonni: An African Antigone, first performed in 1994 at Theater Emory in Atlanta, and Women of Owu, which premiered at Oxfordshire's Chipping Norton 
Theatre in 2004. The second portion of the chapter will turn to Moira Buffini's 2010 play Welcome to Thebes, which premiered in the National Theatre, London. Both Tegonni and Welcome to Thebes are Antigone adaptations, though Osofisan's play draws heavily on Yoruba myth and culture, and Buffini's play pulls in storylines from other Greek tragedies. Women of Owu resets Euripides' Trojan Women in roughly 1821, when the West African city-state of Owu was destroyed by a coalition of its enemies. All of these plays re-situate the action of their source texts into colonial or postcolonial settings, which provides the basis for a critique of imperialism, collaboration, and the economic mechanisms underpinning contemporary (neo)colonialism.

In Capital, Volume I, Marx picks up a founding myth of capitalism from Adam Smith, namely, what Marx calls primitive accumulation. This primitive accumulation-which Smith discussed as a benign process in The Wealth of Nations (361)—ostensibly explains the historical origins of capitalism, wherein at some point a particular social group began to appropriate the means of production and to cut laborers off from the products of their labor. Or as Marx puts it, "So-called primitive accumulation, therefore, is nothing else than the historical process of divorcing the producer from the means of production" (Capital 874-875). The historical mechanism for this divorce was, not to put too fine a point on things, violent theft. ${ }^{171}$ Whether through land enclosures that made common spaces private, or through industrial capitalist structures of the factory and the workhouse, primitive accumulation involves the invention of means whereby the proto-capitalist gains the power to extort the labor of others. While Marx acknowledges colonialism as a space of inherent political economic domination, his commentary

\footnotetext{
${ }^{171}$ Marx tells us, "In actual history, it is a notorious fact that conquest, enslavement, robbery, murder, in short, force, play the greatest part" (Capital 874).
} 
on colonies focuses largely on settler colonies and the internal economic tensions between European settlers and the parent countries.

However, primitive accumulation — also called accumulation by dispossession (as Harvey terms it) or disaster capitalism (in Klein's terminology)—remains fundamental to contemporary colonialism. The generalized imposition of Chicago School economics through IMF and World Bank coercion, as well as the larger structure of the "War on Terror" have both helped ensure the dominance of the global north. International financial institutions have been among the principle tools used to re-establish colonial economic relations in post-independence global south nations. While the IMF and World Bank were conceived as humanistic institutions intended to help preserve global economic stability, the practice of allotting power based on national shares of the global economy meant that the US — with Europe and Japan as secondary powers — gained effective control of the organizations, and under Thatcher and Reagan turned the institutions into neoliberal vehicles (Klein 204). Even Joseph Stiglitz, former vice president and chief economist of the World Bank, has linked the actions of the Bank and the IMF with economic (neo)colonialism. ${ }^{172}$

The 11 Sept. 2001 attack and the "War on Terror" have significantly advanced a global neoliberal agenda of privatization and economic imperialism. Klein's The Shock Doctrine examines at length the massive amounts of public money given to contractors who often did subpar work, left contracts unfulfilled, and artificially inflated prices to get larger amounts of US taxpayer dollars - contracts running as much as \$20 billion to Halliburton for their various roles in Iraq (482). The Bush and Rumsfeld approach to the Iraq War — and government in general-

${ }^{172}$ In reflecting on a 1998 picture of Michael Camdessus (at that time head of the IMF) standing over Indonesia's president Suharto signing an enforced structural adjustment agreement, Stiglitz writes, "To those in the developing countries, the picture raised a very disturbing question: Had things really changed since the 'official' ending of colonialism a half century ago?" (41). 
involved the government doing as little as possible and contracting as much as possible to the private sector (paying, of course, with public funds). This approach massively enriched private corporate contractors from public coffers with little oversight. ${ }^{173}$ The non-teleological nature of the "War on Terror" is part of what makes it such a threatening political economic prospect; it is an endless conflict that will perpetually require public funding, meaning the government needs to continually raise revenue at public expense to pass into private hands. ${ }^{174}$

While late capitalist (neo)colonialism is rooted in the global economic system, globalization may also provide ways of resisting continued economic imperialism, and it is here that theatre and adaptation can have efficacy. Processes like cosmopolitanism and cultural hybridity help make it possible to reformulate hegemonic ideological discourses. As Homi Bhabha explains, interstitial cultural spaces or encounters provide the opportunity to redefine ourselves and our cultural attitudes. He writes, “These 'in-between' spaces provide the terrain for elaborating strategies of selfhood - singular or communal - that initiate new signs of identity, and innovative sites of collaboration, and contestation, in the act of defining the idea of society itself" (1-2). In other words, liminal spaces of contact between cultures open possibilities for establishing new identities on both an individual and on a communal level. It is precisely this kind of openness, this kind of encounter with others that characterizes both cosmopolitan theatre and the production of the common.

${ }^{173}$ According to the neoliberal logic of the Bush administration, government oversight is an unnecessary burden on businesses, especially given the neoliberal assumption that private industry always does everything more efficiently than government. However, the Bush and Rumsfeld policy of handing out contracts without competition to corporations with personal ties to the administration eliminated the process - competition - that ostensibly forces businesses to provide the best quality product for the lowest cost.

${ }^{174}$ This is a direct effect of Chicago School economics, which, Harvey argues, "was from the very beginning a project to achieve the restoration of class power" (Neoliberalism 16). This restored class power exists both vertically within nations (in the form of widening income disparities) and horizontally between nations (in the form of resource and capital extractions from the global south). 
However, the cynical deployment of performance can also undermine possibilities for genuinely felicitous encounters. Theatre critical of neoliberalism and economic (neo)colonialism risks playing into the hands of neoliberal ideology through a process of disavowal. Essentially, in psychoanalysis disavowal occurs when a subject consciously knows something to be true, but refuses to internalize that fact and behaves as though he or she does not know. Freud's example is the boy who discovers that his mother doesn't have a penis, but refuses to internalize this anatomical distinction, giving rise to castration anxiety. In terms of theatre and economic (neo)colonialism, however, this disavowal may take the form of producing critical theatre as a means of obscuring one's own position as exploiter within a global economy. For instance, by sponsoring theatre critical of economic exploitation, the British government implicitly (or perhaps explicitly) positions itself as an opponent of the very processes of disaster capitalism and accumulation by dispossession that its economic and international policies enforce. This process claims a moral high ground by turning theatre into an ideological state apparatus.

\section{Economic Anti-Colonialism: Protest in Two Femi Osofisan Plays}

Femi Osofisan's Tegonni: An African Antigone and Women of Owu were first performed almost a decade apart, and in very different contexts. The two plays share many fundamental interests and attitudes, but Osofisan's latter play shows a major change of focus from the specifically Nigerian/postcolonial interest of Tegonni to an engagement with global ethics in Women of $\mathrm{Owu}$. Both plays respond in complex ways to how international economic trends play out in Nigeria, a response that carries a multi-faceted critique of the global north, the old imperialist powers, Nigerian governments, and an international culture seeking to ignore Africa. ${ }^{175}$

\footnotetext{
${ }^{175}$ Ferguson points out the common absence of African nations and concerns in globalization discourse, identifying this as a mutation of older Imperial rhetorics (6). And he further identifies the re-emergence, in a new
} 
One big difference is that Tegonni speaks back to the global north and British colonialism almost didactically, while the equally poignant critique of global imperialism and economics is dealt with more indirectly in Women of Owu's satirical rejection of the Iraq War. These plays reflect two of the paradigms Kevin Wetmore theorizes for how Greek source material gets adapted relative to African/African American experience - the "Black Orpheus" model and the "Black Dionysus" model. ${ }^{176}$ According to Wetmore, "Black Orpheus" is the most Eurocentric method of linking Greece to Africa, in which Greece serves as a metaphor that allows Westerners to understand Africa or African diasporic cultures (Black Dionysus 14-15). The assumption underpinning "Black Orpheus" texts is that African culture is too fundamentally foreign to be comprehensible unless made accessible through the comparatively better known (at least to most Europeans and Americans) Greek culture (Black Dionysus 15). The other model at work in Osofisan's plays is the "Black Dionysus" model, which is rooted in cultural hybridity and through which Greek material is reworked genuinely in the service of African or diasporic concerns: "a creative and constructive system of complex intertextuality designed to critique the very cultures that prioritize ancient Greek culture" (Black Dionysus 15). Tegonni evokes then rejects the "Black Orpheus" paradigm in favor of the "Black Dionysus" approach, while Women of $O w u$ skips the intermediary metaphorical stage. ${ }^{177}$ Ultimately, I argue for the specific engagement of Osofisan's plays with a globalized economic system — that is, the plays do not

\footnotetext{
form, of thinking about Africa as "the Dark Continent": "not so much a continent defined by a lack of enlightenment as a place where much is unknown, hard to make out, perhaps even unknowable" (16).

${ }^{176}$ Wetmore's third scheme is the "Black Athena" model, in which adapters work from the perspective of Afrocentric classicism to reclaim Greek material as coming fundamentally from Afroasiatic cultures (Black Dionysus 15).

${ }^{177}$ Although Wetmore uses the term "Black Orpheus" to describe the first of his the paradigms, he explains that "Many of these texts are titled using 'Black' or 'African' as an adjective to be followed by a name from Greek mythology, tragedy, or epic" (Black Dionysus 15). Tegonni's subtitle - An African Antigone - is therefore particularly important because it suggests a connection to this metaphorical tradition; however, the play troubles the unidirectionality of the metaphorical relationship implied by the "Black Orpheus" model, i.e., adapting the Greeks to explain Africa to Europeans or Americans.
} 
merely have a Nigerian interest or a post-colonial interest, but in fact locate a Nigerian worldview within a global, cosmopolitan ethics resisting late capitalism.

Sophokles' Antigone is one of the most common vehicles for playwrights protesting authoritarian power because it has often been read, especially in the $20^{\text {th }}$ century, as pitting the individual against the forces of government overreach. Antigone is the youngest daughter-sister of Oedipus, and her inheritance from him colors much of her experience throughout the three Sophoklean plays in which she appears-Oedipus the King, Oedipus at Kolonus, and Antigone.

She appears as a child at the end of Oedipus the King, when her father-brother blinds himself and leaves Thebes to wander as a vagabond, but Antigone remains Oedipus' constant companion on the road until his death in Oedipus at Kolonus, after which she returns to her home city for the civil war pitting her brothers Eteokles and Polyneikes against one another for the Theban crown. Sophokles' play picks up at the end of the war, when Kreon, the new king, declares Eteokles a hero deserving of a state funeral, and names Polyneikes an outlaw whose body shall not be buried. In the Greek cosmological view, leaving a body unburied was to condemn the soul to wander eternally, never reaching the afterlife, so Kreon's edict violates a major taboo of Greek culture. In defiance of the edict and the associated death penalty, Antigone buries her brother, and when caught appeals to the eternal laws of the gods in contrast to Kreon's mortal word:

CREON. Now, tell me, Antigone, a straight yes or no:

Did you know an edict had forbidden this?

ANTIGONE. Of course I knew. Was it not publicly proclaimed?

CREON. So you chose flagrantly to disobey my law?

ANTIGONE. Naturally! Since Zeus never promulgated such a law,

Nor will you find that Justice,

Mistress of the world below, publishes such laws to mankind.

I never thought your mortal edicts had such force

they nullified the laws of heaven, which unwritten, not proclaimed, can boast a currency that everlastingly is valid, 
an origin beyond the birth of man.

And I, whom no man's frown can frighten,

Am far from risking heaven's frown by flouting these. (358)

Although what exactly Antigone stands for is the subject of major critical debate-pre-political

kinship, religious law, feminism, anarchy, individualism — she is almost universally seen as a

symbol of defiance against a political state engaged in unethical or oppressive action. ${ }^{178}$ Her

defiance asserts the centrality of an ethical code, laid out by the gods, as superior to human law.

In this sense, Antigone is an excellent choice for Osofisan to adapt for his own multi-

faceted project of speaking back to power. ${ }^{179}$ He relocates the Antigone story from the mythic

Greek past into British-controlled Yorubaland in the late Victorian era, establishing conflict not

only between competing views of the role of government, but also based in ethnic hatred and

oppression. On one level, Antigone becomes the Yoruba princess Tegonni, who expresses her

individualism by founding the first guild of women's bronze casters and by marrying Captain

Allan Jones, the white District Officer. The marriage pits her against the dictatorial British Lt.

${ }^{178}$ In Antigone's Claim, Butler questions the binary opposition between Antigone and the state, particularly critiquing readings by Hegel and Lacan which figure Antigone as representing individualism or pre-political kinship. Butler argues that Antigone in fact represents a potentially queer deformation of both kinship and political sovereignty: that her kinship with Polyneikes (inherited from Oedipus) is run through with incestuous desire that undermines kinship structures, and Antigone's masculine use of rhetoric and legal debate undermines the easy identification of Kreon with political authority by usurping that position for herself (24-25).

${ }^{179}$ Of the three plays examined in this chapter, Tegonni has the most overt engagement with Nigeria's postcolonial past by refiguring the clash between Antigone and Kreon as a clash between Tegonni and Carter-Ross. Whereas in Antigone the agon pits two competing ethical models against one another, Osofisan opposes both competing ethics and competing cultures, refiguring the Antigone story to explore the oppression of colonized Nigeria by an autocratic British Empire. However, Osofisan's political project is not as simple as it might at first seem - this is not merely a post-colonial author writing back to the global north, it is also a devastating attack on the Nigerian dictator Sani Abacha, who came to power in 1993, the year before Tegonni was staged. Van Weyenberg asserts that in using Greek tragedy as source material African dramatists engage politically on multiple, interconnected levels (xii). While Tegonni deals overtly with British colonialism, the subtext-as well as Osofisan's "Note from the Playwright/Director"- critiques the Nigeria dictator. Osofisan makes clear that his interest in Tegonni is not simply anti-colonial, but to directly confront Abacha's regime. He writes, "my concern is also to look at the problem of political freedom against the background of the present turmoil in Nigeria — my country—where various military governments have continued for decades now to thwart the people's desire for democracy, happiness, and good government" (11). The brutal figure of Carter-Ross in Osofisan's play carries multiple resonances, representing simultaneously the history of British colonial dominance and the authoritarian governments that have ruled Nigeria for much of the post-independence period. 
General Carter-Ross, who believes in iron-fisted rule based on a violent racism. Carter-Ross decrees that the body of Tegonni's brother Oyekunle—-killed while fighting the British—should be left unburied before the palace, where Tegonni encounters it during her wedding procession. As in Greek culture, leaving a body unburied is taboo for the Yoruba: as the town poet Isokun tells the soldiers, "We do not leave dead bodies unburied in the sun, it's an abomination" (48). As with her Greek predecessor, Tegonni buries the body despite Carter-Ross' warnings, though unlike the solitary Antigone, Tegonni is assisted by her friends and bridal retinue. In contrast to Antigone's suicide in the cave at the end of Sophokles' play, Tegonni survives and Carter-Ross dies. This shift in the ending of the play points to the liberatory possibility of adaptation, breaking away from the potentially tyrannical authority of tradition. As Barbara Goff writes, "Such questions, about the possibilities of different endings and of escape from theatrical tradition, can also be understood as questions about the weight of the colonial past, and so bear here a special urgency" (“Antigone's Boat” 45).

The question of theatrical agency and the weight of tradition is particularly important in Tegonni because it is a deeply metatheatrical play. One major metatheatrical influence is Antigone herself, who comes from the past of Greek myth to observe and assist Tegonni. Antigone arrives in scene three hoping that she's not late for the start of the play (25). This is not the Antigone that a Western audience might have expected; she undermines a Eurocentric tradition claiming ownership of Greek culture for white Europeans. Tegonni's friends challenge Antigone's identity:

KUNBI. The same Antigone we've heard about? ANTIGONE. There's only one Antigone. KUNBI. But that's impossible. She's from Greek mythology. ANTIGONE. And so am I. From the Greek and other mythologies. FADERERA. An impostor! Let's go. ANTIGONE. Antigone belongs to several incarnations. 
KUNBI. But you...you're black!

ANTIGONE. (Laughs). And so? What colour is mythology?

ANTIGONE'S CREW. We're metaphors. We always come in the colour and the shape of your imagination. (26-27).

The meaning making potential of the Antigone myth is divorced from a tradition linking the Greeks to whiteness/Europeanness through the physicality of the actor's body, and instead provides human meaning making potential apart from the specific limitations of skin color and ethnicity.

The emphasis of this scene shifts from Antigone as Greek mythology to Antigone as Greek mythology - in other words, a change in accent from the ethnic to the narrative. Astrid Van Weyenberg characterizes this type of adaptation as resisting the canonical weight of Greek tragedy: "by offering Greek tragedies as theirs, the playwrights indirectly yet effectively undermine eurocentric claims of ownership and authority. They counter these claims by performing, through adaptation, a cultural politics directed at the Europe or West that has traditionally considered Greece as its property and as the very foundation of its supposedly superior culture" (xii). This rejection of the claim to Greece as Europe's exclusive cultural patrimony has been challenged by scholars advocating a model of Afrocentric classicism, which asserts that the origins of Greek culture came from Egypt and the Middle East, and therefore Greek culture itself is not fundamentally European but an offshoot of African and Asian traditions. ${ }^{180}$ However, I see little evidence that Osofisan is particularly interested in the concerns

${ }^{180}$ Bernal is probably the best known proponent of Afrocentric classicism, though Cheikh Anta Diop laid much of the groundwork for Bernal and others. In his book Black Athena, Bernal advances what he calls the 'Revised Ancient Model' to explain the origins of Hellenistic culture. This model "accepts that there is a real basis to the stories of Egyptian and Phoenician colonization of Greece set out in the Ancient Model...It also agrees with the latter that Greek civilization is the result of the cultural mixtures created by these colonizations and later borrowings from across the East Mediterranean" (2). Where the Revised Ancient Model differs from the Ancient Model is that "it tentatively accepts the Aryan Model's hypothesis of invasions - or infiltrations - from the north by Indo-European speakers" (2). Essentially, Bernal's thesis is that the primary influences shaping Greek culture were the Egyptians, Phoenicians, and Persians - all African or Near Eastern civilizations - and while Caucasians might have played some role, it was certainly not a major one. In adapting Greek tragedy to an African context and 
of Afrocentric classicism; his play frees Antigone from an assumed white European identity, positing instead that myth belongs to a cultural common of shared stories.

The British commander, Carter-Ross, embodies an overt cultural hierarchy grounded in the racist denigration of everything and everyone black or African. Carter-Ross is the virulently racist opposite of Allan Jones, who welcomes the hybrid blending of his own British culture with Yoruba culture. Scenes nine and ten clearly lay out these differences. In scene nine, while preparing for his wedding to Tegonni, Allan dresses in traditional Yoruba groom's clothing and jokes with Bayo, an African American missionary, about how uncivilized the British are compared to the Yoruba (53). In the following scene, Carter-Ross arrives to take charge of the situation with Oyekunle's body and (as we find out later) to prevent Jones from marrying an African. His attitude toward both cultural hybridity and African culture are exposed when Bayo brings in a group of local women who sing a Christian hymn translated into Yoruba. CarterRoss' reaction is violent and bigoted:

Welcome me - with that! Rather audacious, isn't it! This is what they call Christianity, these liberated priests who come over to Africa! They bring the word of God to the jungle, and what happens! Satan takes over! Everything changes to voodoo! Our sacred hymns are turned to dark incantations! And I am supposed to like that! I am supposed to tolerate it as 'the expression of another culture', while the Devil crows triumphant in my ear! (64)

For him any expression of African culture, even a vernacular expression of the Christianity imposed by Western imperialism, is demonic. The very display intended to assure Carter-Ross that Western culture (via Christianity) is being embraced becomes proof to him that British

presenting Antigone's ethnicity as fluid rather than stable, Osofisan challenges a Western cultural tradition seeing ancient Greece as, first, entirely European, and second, as superior to African cultures (from which it is distinct). Bernal has been widely critiqued for overstating his case and misinterpreting or ignoring evidence. For instance, Bernal uncritically asserts that the Egyptians were black Africans, while the majority of Egyptologists now suggest that race did not have the same meanings in the ancient world that it does today. Wetmore summarizes some of the scholarly opposition to Bernal's book (Black Dionysus 37-38), as does Van Weyenberg (xxxviii-xxxix). 
domination is under existential threat. And the only way Carter-Ross imagines the threat can be dealt with is brutal force. Now that he has arrived, Carter-Ross promises, "The Empire will assert its power!" through "Fear! That's what these niggers respect! That's why Oyekunle's death will be used to teach them a lesson!" (65). Carter-Ross endorses the violent inevitability of autocratic authority, which represents not only British colonialism, but also Sani Abacha's dictatorship, and the tyrannical authority of the European Antigone plot line.

It is significant that the play anticipates Carter-Ross being performed by a black actor, and that the virulent racism and authoritarian colonialism comes from a specific physical body. ${ }^{181}$ The actor's physicality invites us to read the character in at least two major contradictory ways: simultaneously as a condemnation of Abacha, and as a mockery of authoritarian tyranny. A black actor portraying Carter-Ross directly evokes the history of African military leaders and national oppression, which often emulates British military aesthetics. On the other hand, through the playful irony of the performance - presenting a black body in the place of a racist white Englishman - Osofisan stages the kind of colonial mimicry that Bhabha argues exposes ambivalence at the heart of colonial (and perhaps postcolonial) authority. ${ }^{182}$ What this means is that playing Carter-Ross through the body of a black actor undercuts the essential component of the whiteness/difference upon which Imperialism was predicated. As whiteness (and its assumed superiority over blackness) is undermined and shown to be performative, the foundations of colonialism become increasingly unstable. And to the extent that the actor playing Carter-Ross simultaneously stands in for Abacha, dictatorial authority becomes similarly

\footnotetext{
${ }^{181}$ The note to Tegonni's Prologue states, "This prologue is suggested only when the Cast is mono-ethnic in composition, and has been written here with an all-Black cast in mind...Ideally, however, the Cast should be racially mixed, and when that happens, the Prologue should be omitted" (13). In the metatheatrical Prologue, a Director moves to start the play, and when the Actors protest that there are no white actors to play the British, they settle on several actors wearing wigs to indicate that they will play white people (14).

182 Bhabha writes, "the discourse of mimicry is constructed around an ambivalence; in order to be effective, mimicry must continually produce its slippage, its excess, its difference" (86, original emphasis).
} 
untenable_-Abacha is exposed as himself a mimic man, merely acting a British Imperial role, one which he will never be able to fully embody.

There is, however, a further remove from Antigone's Greek incarnation, as Tegonni explicitly rejects the plot of Sophokles' Antigone, denying the inevitability of death and defeat that the hypotext seeks to impose. In this sense, Osofisan's play transcends the "Black Orpheus" approach evoked by its subtitle, and embraces a "Black Dionysus" model through which it challenges the dominance of the Greek/European hypotext. Late in Osofisan's play, Antigone tries to convince Tegonni to give up the struggle, to accept the inevitability of tyranny and oppression as part of the human condition (126). As Goff suggests, the plotline of Antigone risks becoming an overbearing stand in for political oppressors, for those who seek to assert their will and deprive others of their freedom. But Tegonni rejects Antigone's advice, proclaiming, “I'll never stop believing! Freedom is an undying faith, the force which underwrites our presence here on earth, as human beings" (127). This is precisely the defiance Antigone sought to test, and precisely the defiance that allows Tegonni to resist the imposition of the Antigone plot. While Tegonni adapts a Greek precursor, it is not ruled by Sophokles' text, but instead seeks a new destiny for Nigeria, a destiny conscious of European culture but not limited to it.

Extensive metatheatrical performances of Yoruba ritual and song, and the presence of Yoruba deities in Tegonni challenge Abacha's attempts to repress Nigerian history and culture. ${ }^{183}$ Yoruba elements bolster the expansion of the Antigone myth beyond merely a European property. Antigone herself arrives on the boat of the Yoruba river goddess, Yemoja

${ }^{183}$ During his reign, Abacha attempted to run Nigeria ahistorically. Soyinka, who escaped the country and was sentenced to death in absentia, wrote that the dictator "has no IDEA of Nigeria; beyond the reality of a fiefdom that has dutifully nursed his insatiable greed and transformed him into a creature of enormous wealth, and now of power, Abacha has no NOTION of Nigeria" (239). Abacha's ahistorical conception of Nigeria seems markedly out of sync with a culture rooted in understanding the present and the future through recourse to the past. However, within the larger scope of disaster capitalism, Abacha's blindness is par for the course. 
(24), and both Antigone and Tegonni leave the play by boarding Yemoja's boat (141).

Structurally Tegonni is framed by Yemoja, who seems, despite never speaking in the play, to be a guiding force behind the action and the resistance to Carter-Ross. Yoruba song and storytelling are two of the most overt ways in which Tegonni resists interpolation within a Eurocentric paradigm - the play asserts its hybrid appropriation of the Antigone story alongside West African performance traditions. In fact, the first scene shows Yemoja's boat on the river as her attendants sing to honor the goddess (17). Visually and aurally our first experience of Tegonni is deeply imbedded in Yoruba culture, a culture likely to be unfamiliar to most of the original audience at Theatre Emory. ${ }^{184}$ The play's hybridity opens new opportunities for thinking about identity in a dynamic way, and for seeing beyond a mono-cultural horizon. Yoruba songs are sung throughout the play (scenes 2, 6, 7, 10,11, 13, 16, 18, 20, 26, and Epilogue). Additionally, scene 23 recounts the Yoruba myth of the tiger and the frog, an anti-corruption fable, the moral of which is that those who trick or bully their way to power always fall, while those who suffer shall be redeemed. The songs and story are not incidental, but locate Tegonni within a large and complex heritage of Yoruba performance culture.

While the Emory audience's unfamiliarity with Yoruba culture posed a potential problem in performance, that very unfamiliarity could become the site of productive cultural development by challenging preconceived hierarchies privileging Western cultures over African cultures. Bhabha argues, "The borderline work of culture demands an encounter with 'newness' that is not part of the continuum of past and present. It creates a sense of the new as an insurgent act of cultural translation" (7). In other words, cultural hybridity becomes possible in the face of the radically new, which challenges a sense of cultural propriety and normalcy. By incorporating

\footnotetext{
${ }^{184}$ This encounter with a foreign culture may have catalyzed the kind of cosmopolitan empathy Rebellato argues can be created by theatre.
} 
Yoruba performance and the Antigone myth alongside one another as equal cultural tools being repurposed to build a better future, Osofisan confronts the received notion that Greek culture "belongs" to the West as an origin point. ${ }^{185}$

Potential spaces of hybridity became even more crucial by the time Women of $O w u$ premiered a decade after Tegonni, as the US-led global "War on Terror" reasserted old imperialistic discourses of the clash of civilizations. Women of $O w u$ adapts Euripides' The Trojan Women, which has already been introduced in chapter II. However, Osofisan takes the Euripides tale in quite a different direction than Evans. Women of $O w u$ utilizes many of the same elements of Yoruba performance, ritual, and song that Osofisan deploys in Tegonni, but the engagement with the Greek hypotext is not as overt, and the scope of the play is not as constrained by writing back to British colonialism. In other words, Women of $O w u$ forgoes the metaphoric "Black Orpheus" stage likening Greek and African culture-which Tegonni opens with — and begins with a critically engaged "Black Dionysus" paradigm. Osofisan's Women of Owu sets the story in 1821 following the destruction of the city of Owu. Like ancient Thebes, the West African city-state was sacked by a coalition of its enemies following a lengthy siege. The play's action centers on the sufferings of Erelu Afin, wife of the defeated Oba Akinjobi, former ruler of Owu. Erelu is Women of Owu's Hecuba, a figure vacillating between despair, defiance, and dignity. She and the women of the sacked city await their fate at the hands of the coalition

\footnotetext{
${ }^{185}$ Uniting the traditions of Greek tragedy and African performance embodies a fundamental principle of Yoruba culture: "İfọgbontáayéșe is the Yorùbá concept of the unity of knowledge across disparate fields for pragmatic purposes...The interconnectedness of knowledge is fundamental to the Yorùbá world-view - homologies and analogies across fields are not coincidental but exist because all knowledge is the same knowledge" (Odom, Yorùbá Performance 4). Odom argues that Yoruba performance draws upon the past to respond to contemporary political problems through social renewal-through a sophisticated exploration of how the past is refracted into the present and sets the stage for the future, performers comment on current political situations. This principle inflects Osofisan's blending of ostensibly separate performance/theatrical traditions in the service of socio-political critique.
} 
members. The storyline features many of the same elements as Euripides' play, focusing mainly on the sufferings of the women and the callous indifference of the brutal victors.

Although Osofisan sets the play in West Africa in 1821, Women of Owu overtly responds to the "War on Terror" and the destruction of Iraq by the US-led "coalition of the willing." When the play premiered in Britain in 2004, the Iraq conflict had only recently begun, but was already unpopular with a large portion of the British public, who opposed their government's support for what many saw as imperialist adventurism more suited to Thatcher's martial nationalism than Blair's New Labour government. In the "Note on the Play's Genesis," Osofisan directly connects the sacking of Owu with the Iraq invasion, writing, "it was quite logical therefore that, as I pondered over this adaptation of Euripides' play, in the season of the Iraqi war, the memories that were awakened in me should be those of the tragic Owu War" (vii). In this connection between the destruction of Owu and the Iraq war we find again a Yoruba proclivity for seeing the past as intimately connected to the present through the structuring unity of İfọgbontáayéșe. Osofisan's knowledge of West Africa's past and Greek myth provides him with a basis for the ethical response to the Iraq War in the present.

Within the first scene it becomes clear that Women of Owu rejects the logic of the Iraq War, satirizing the rhetoric of liberation so often deployed by US and coalition politicians to justify the invasion. In the first scene the patron-god of the city, Anlugbau, returns to find Owu in ruins, and the women he meets report that the coalition, "said our Oba / Was a despot, that they came to free us / From his cruel yoke" (2). This repurposing of US liberation rhetoric runs throughout the play. The defeated women reflect, "Nowadays, / When the strong fight the weak, it's called / A Liberation War / To free the weak from oppression" (8). The sad irony, as it was in 
Iraq, is that so many innocent people were killed, displaced, tortured, and deprived of any hope or opportunity by their "liberation." As one of the women puts it:

Liars! You came, you said, To help free our people from a wicked king. Now, After your Liberation, here we are With our spirits broken and our faces swollen

Waiting to be turned into whores and housemaids. (12)

This passage is a microcosm of the three shocks Klein theorizes as underpinning disaster capitalism: the initial political shock, economic restructuring, and physical repression. The liberation itself serves as the first political shock, which disorients the populace by completely wiping out Owu's political system. The last line reflects common results of the economic privatization and capital liberalization often imposed on the global south by international financial institutions: massive expansions of menial labor and sexual slavery often follow Chicago School policies. The visceral experience of broken spirits and swollen faces suggests the physical repression used to discipline the dispossessed victims of neoliberal violence.

The costuming and stage space for Women of Owu physically represents the women's deprivation. The visual aspect conveys dispossession and locates the women in the kind of temporary housing becoming the standard in global south slums. At the opening of the play Osofisan describes the set: "Along the broken wall are the temporary tents of the old market, built of wooden and bamboo stakes, and straw roofs" (1). The materials housing the women are meant for, at best, provisional shelters, much like the plywood boards, corrugated tin, and cinder blocks characterizing the camps of the global dispossessed. ${ }^{186}$ Similarly, the women are cut off from domestic resources and comforts, like water for washing and cleaning. At the beginning of scene five, after a Yoruba dirge, the women complain, "Two days now without a wash; two days

${ }^{186}$ Again, these are the kinds of temporary building materials making up the set of Trojan Barbie. 
of waiting, / Stinking in our underwear. We have stayed like this, / In these make-shift tents, watching our city burn to ashes" (39). The physical space of the stage and the ragged, dirty costumes of the women mark a sharp contrast to the former prosperity of $\mathrm{Owu}-$ the wealthiest Yoruba city-state of its time - and visually identifies these Owu survivors with others of the world's dispossessed. In the 2014 Lagos State University revival of Women of Owu, the set, designed by Biodun Abe, followed Osofisan's lead in evoking a ruined village from early $19^{\text {th }}$ century West Africa. In a production review, Edozie Udeze wrote, "the desolate nature of the village further defined that the people were at war. The whole village was deserted and that in itself evoked profound pity." The mise-en-scéne of Osofisan's play speaks directly to the themes of loss and dispossession at the heart of Eruipides' play, which have become a reality of daily life for so many under late capitalism, including those displaced and dispossessed during the War on Terror.

The satirical undercurrent in many of the references to the War on Terror mocks the dispassionate rhetoric of liberation, which many critics of the Bush and Blair administrations argue was a humanitarian face for blatant greedy theft. Confronting both the rhetoric of humanitarian benevolence and the schema of the clash-of-civilizations, Erelu asks:

Savages! You claim to be more civilized than us But did you have to carry out all this killing and carnage

To show you are stronger than us? Did you Have to plunge all these women here into mourning Just to seize control over our famous Apomu market Known all over for its uncommon merchandise? (12)

She links the violence of Owu's destruction and her community's enslavement to the accumulative needs of international capital, just as many critics of the Iraq War linked the 
invasion to pervasive Western oil consumption. ${ }^{187}$ As Marx reminds us, the quest to secure resources through violent conquest and repression is fundamental to capitalism. Chicago School economics has relied on a pervasive rhetoric of individual freedom to cover over the economic crimes committed in the name of free market fundamentalism. ${ }^{188}$ The historical problem, of course, is that virtually everywhere neoliberal capitalism has been imposed around the globe individual freedoms and personal liberty have declined drastically, including a massive expansion of the kinds of detention/concentration/refugee camps that form the setting for Women of Owu.

As with Tegonni, however, Osofisan presents artistic and cultural production as a means of resisting capitalist and imperialist violence. While the latter play does not incorporate Yoruba songs and stories as extensively as Tegonni, they continue to be central to resisting unjust authority. The women of the camp utilize songs and dances as tools for building communal unity in the face of the allies' destruction of their city. Erulu exhorts the women, "Ah, raise your dirges again, without trembling, even if / For the last time, women!...Start the song: / For those who survive, there's always another day" (16). The Chorus Leader makes a similar plea:

All we can Is counter misfortune with our spirit, and our will. So, let us dance my friends as we wait, as Our mothers taught us to do at such moments. Dance the Dance of the Days of Woe! (17)

${ }^{187}$ Klein argues that the stakes were, in fact, much larger than control of Iraq's massive oil fields. She says that the invasion provided a wedge with which to force open largely closed Middle Eastern economies: "not just the world's third largest proven oil reserves but territory that was one of the last remaining holdouts from the drive to build a global market based on Friedman's vision of unfettered capitalism" (413). With so much wealth from petroleum in many Middle Eastern countries, Arab states historically had little need to turn to the IMF or the World Bank, which have held, since the 1970s, both the carrot and the stick of late capitalist globalization. In the strongly protected economies of the Middle East neoliberal capitalism had difficulty taking root until 2003 when the US invasion imposed a disastrous new political economic system on Iraq.

${ }^{188}$ Friedman identifies the fundamental goals of neoliberalism as freedom and individualism, and claims, "In political matters, it supported the development of representative government and of parliamentary institutions, reduction in the arbitrary power of the state, and protection of the civil freedoms of individuals" (5). 
In dancing as their mothers taught them, the women of Owu retain their identity and their heritage, even as they wait to be divided as slaves among their conquerors. Throughout the play the women perform Yoruba dirges and dances to keep their spirits up and to remind their captors that although the city-state has fallen, the spirit of Owu lives on.

The abolition of historical memory is a purposeful step undertaken as part of the shock doctrine to weaken resistance to reforms intended to concentrate wealth at the expense of the people. Klein suggests that the US and coalition invasion forces in Iraq purposefully set the stage for the extensive looting of Iraqi national treasures to weaken Iraq's collective sense of self: "The bombing badly injured Iraq, but it was the looting, unchecked by occupying troops, that did the most to erase the heart of the country that was" (425). Creating an ahistorical national space - treating a country or a people as a kind of tabula rasa — favors upward economic redistribution because without ties to their history and culture, it is more difficult for a people to orient itself and resist exploitation. In this way, the arts can play a crucial role in protecting and preserving culture, as the arts serve a valuable function in orienting people and stabilizing their identity. The same purposeful theft occurs in Women of Owu. One of the women complains to the deity Anlugbua that "The invaders have been looting our city, / Turning it into a wreck, violating / Our sacred shrines and groves" (6). Like the Iraqi national treasures stolen from the National Museum and Saddam's palaces, the stripping away of Owu's cultural heritage makes it easier for the conquerors to remold the survivors as slaves by cutting them off from the cultural identity markers that orient them in their world.

However, in his adaptations, Osofisan utilizes the tools of a shared cultural heritage to create new aesthetic markers for resisting exploitation and oppression on a global scale. ${ }^{189}$

\footnotetext{
${ }^{189}$ Rejecting the limitations of merely "African" or "postcolonial” culture, Osofisan's plays engage with multiple traditions - Greek, African, and European - in working toward a common cosmopolitan aesthetic as a
} 
Women of $\mathrm{Owu}$, and to a lesser extent Tegonni, provides an excellent example of how

contemporary dramatists from the global south adapt Classical material to draw attention to the role of political economics in creating new global economies. In the program notes to the Emory production of Tegonni, Osofisan leaves no room for doubting the links between political economy and repressive violence in Africa: within the first paragraph, he mentions "small, wellarmed cliques, sustained by foreign multinational business interests" as Africa's political reality (8). Osofisan points to the irony that democratic nations of the global north prop up repressive, anti-democratic regimes in Africa (and elsewhere in the global south) in exchange for natural resources and other economic perks under the regime of international capital. As Osofisan puts it, global north democracies "openly sell their conscience and lend support to military dictatorship, just as long as their vast economic interest in oil exploration, telecommunications, the construction industry, and so forth are protected" (10). Although links between economics and political repression is clearly in Osofisan's mind, Tegonni actually has very little discussion of economics. By 2004, with the coalition invasion of Iraq, however, the link between global economics and imperialism assumed a more central place in international discourse, as many opponents of the war argued that the main goal of the invasion was to seize control of Iraqi oil.

\footnotetext{
potential counter-point to late capitalist atomization and economic exploitation. One crucial point here is that we cannot limit our readings of these "postcolonial" plays to merely postcolonial concerns. It may be true that "in most post-colonial nations (including the West Indies and India) the nexus of power involving literature, language, and a dominant British culture has strongly resisted attempts to dismantle it" (Ashcroft et. al. 4), but postcolonial authors are not inherently limited to writing back to the Empire. Van Weyenberg points out, "To see these texts mainly in terms of resistance makes the history of colonialism their defining force and the 'West' their sole term of comparison, a perspective that ultimately threatens to reduce African literatures to mere addenda to European culture" (xlix). In other words, the desire to read African drama/literature as merely (or even primarily) postcolonial relies on an ethnocentric worldview seeing European imperialism as the defining force in formerly colonized cultures, a move which collapses the potential for unique and independent cultural development and points of view. Van Weyenberg argues that in adapting Greek tragedies, African dramatists produce multi-faceted critiques-what Wetmore would call the "Black Dionysus" paradigm — directed at the contemporary political situation in their own nations (e.g., Osofisan's critique of Abacha), at the former colonial powers (e.g., Carter-Ross' strident Britishness), and at the role of Greek literature and drama as a symbol of Western culture's ostensible superiority (Van Weyenberg xii). I would add an additional layer of critique for contemporary plays - a critique of economic globalization and (neo)colonialism.
} 
Osofisan satirizes the discrepancy between Bush and Blair's rhetoric of liberation and the baser economic motives many critics ascribe to the invasion. In scene two, the women in the refugee camp mock their oppressors' lofty words and disavowal of a profit motive. ${ }^{190}$ After Erelu accuses the coalition of sacking the city to gain control of the Apomu market, one women sarcastically reminds her, "No, Erelu, what are you saying, or / Are you forgetting? / They do not want our market at all_-" and another woman adds, "They are not interested in such petty things / As profit" (12). As with the invasion of Iraq, the destruction of Owu is accompanied with proclamations of freedom, liberation, and democracy, but in fact the invasion delivers slavery, terror, and the loss of any democratic power or public control the people of Owu might have exercised. Like Euripides' Trojan women, the women of Owu and the people of Iraq lost control of their destiny through the violent imposition of an imperialist power seeking resources (even the Greeks in The Trojan Women sought Helen and honor). However, Euripides' play does not include this bitterly ironic commentary on the disjunction between liberatory rhetorics and imperialist wars; this theme is a new addition through which Osofisan's play responds to the conditions of late capitalist globalization. ${ }^{191}$

Further, the "War on Terror"- which has been largely a privatized affair run through contractors hired by the US government at great public expense- expands the reach of

190 The function of neoliberal disavowal will be discussed more thoroughly at the end of this chapter.

${ }^{191}$ Osofisan's drama helps bring an important, though frequently ignored, West African voice to international discourses on economic globalization., considering that Africa remains largely peripheral to scholarship on and processes of global capital flow. As Ferguson notes, "The enormous recent literature on globalization so far has had remarkably little to say about Africa. Astonishingly, the entire continent is often simply ignored altogether, even in the most ambitious and ostensibly all-encompassing narratives" (25). Ferguson gives several potential reasons why Africa is such a glaring blind spot for commentators on globalization, including the failure of neoliberal policies to produce virtually any successes, however temporary (26), Africa's long standing resistance to externally imposed economic systems (27), and national/political instabilities that lead to weak property laws and protections (28).However, Ferguson's collected essays in Global Shadows demonstrate that merely because globalization theorists (generally hailing from the global north) aren't paying attention to Africa, that doesn't mean the continent has been spared the ravages of neoliberal structural adjustment. African nations have been as much subject to IMF and World Bank structural-adjustment programs as the rest of the global south, in ways maintaining a balance of power that preserves the global north's dominance. 
(neo)colonial power through both upward economic redistribution and the erosion of potential points of cosmopolitan interculturalism. The privatization or proxyization of military activity plays an interesting role in Women of $\mathrm{Owu}$, in which it becomes a mutually destructive force. In scene three Anlugbua, patron deity of Owu, confronts his mother Lawumi, who had blessed the invading army. As we learn, the entire war was set up using both the Owus and the coalition as proxies for Lawumi's own objectives, which was ultimately to punish the Owus' hubris. ${ }^{192}$ Like a vengeful Greek god, Lawumi sought revenge on the proud city-state of Owu. But the roots of the conflict are murky, murky in ways that suggest the tangled ethical origins of the "War on Terror." Anlugbua tells his mother, "It was / The Ifes who first attacked Owu, at / The market of Apomu_-" but Lawumi counters, "Because the Owus were selling / Other Yorubas into slavery!...Flagrantly at Apomu, they broke the law, and / The only way to stop them was by force!” (19). There is a verisimilitude here between the Ife attack on Apomu and the 11 Sept. attacks on the World Trade Center-in both cases financial centers came under attack which sparked a devastating conflict. Neither the Owus nor the coalition were ultimately fighting for their own ends, they were fighting Lawumi's war. We might equally venture that the Iraq War was not fought in the interests of either the American or the Iraqi people, but rather in the service of international capital, which sought to recreate Iraq as a disaster zone to strip its resources.

The further ideological threat of the "War on Terror" is that it conspires with neoliberal consumerism to isolate individuals within limited, atomized identity categories. Paul Gilroy argues that the "War on Terror" has allowed old racist and nationalist bigotries to return with

${ }^{192}$ Interestingly, hubris here is collective—Lawumi says, "Arrogance, that was their $\operatorname{sin!"~(18,~my~}$ emphasis) - whereas in Greek tragedy hubris is nearly always individual. This difference may represent the more communal ethos of West African cultures, as opposed to the individualism of Western tradition. 
new venom, dividing the globe between Us-and-Them. ${ }^{193}$ The comparative heterogeneity of contemporary global north societies has also been turned to the advantage of neoliberal political economics because fear of ethnic and religious Others provides a smoke screen for corporate attacks on public and collective culture. ${ }^{194}$ This is essentially the same system that Girard identifies as the foundation of Greek tragedy: the fomentation of a sacrificial crisis with its attendant execution of a scapegoat in order to redirect the violence building within a society itself. The "War on Terror" relies on the same kind of (semi-)controlled violence that Girard argues is at the structural heart of tragedy as a form. While it is possible to renounce the enjoyment promised by the sacrificial crisis, as we saw in Chapter III, the structure of the crisis and the process of scapegoating are premised on deeply engrained patterns of human tribalism. The exclusionary and divisive structure of the sacrificial crisis - whether within a tragic play or at work in society—closes down avenues of empathy and cosmopolitan identification, the foundations of a common culture that might challenge the hegemony of international capitalism.

${ }^{193}$ He notes that in the wake of the 11 Sept. 2001 terrorist attacks, a "clash of civilizations" rhetoric divided humanity into the same kinds of hierarchies that had underpinned colonialism. US President George Bush's rhetoric clearly demarcated the world between the camp of the good and the camp of the evil. As he put it, "Every nation, in every region, now has a decision to make. Either you are with us, or you are with the terrorists." The implications of this are, as Gilroy says, "some abject human bodies are more easily and appropriately humiliated, imprisoned, shackled, starved, and destroyed than others. These obvious distinctions effectively revived a colonial economy in which infrahumanity, measured against the benchmark of healthier imperial standards, diminished rights and deferred recognition" (10). In other words, the simplistic good-vs-evil approach taken by global north leaders like Bush and Blair re-established old colonial power structures asserting the global north's unchallengeable right to protect its own interests through the destruction, erasure, and exploitation of people in the global south.

${ }^{194}$ Gilroy argues that the strands of xenophobia and quasi-authoritarian nationalism in contemporary politics disguise a continuation of the neoliberal project: "in their flight away from socialistic principles and welfarestate inclusiveness and toward privatization and market liberalism, these beleaguered regimes have produced strangers and aliens as the populist limit against which increasingly evasive national particularity can be seen, felt, measured, and then, if need be, negatively discharged" (123). 


\section{The God of Profit: Nation Building and Global Economics in Moira Buffini's Welcome to}

\section{Thebes}

In the summer of 2010, I was in a class studying British novels and drama in London. While there we saw a performance in the premier run of Moira Buffini's Welcome to Thebes, an adaptation of the Antigone story. In a way, seeing Buffini's play was the genesis of this project, because Welcome to Thebes was perhaps the first play I encountered using adaptation to ground a contemporary political economic stance against globalized economics. Buffini's play is set in a $21^{\text {st }}$ century Thebes decimated by the civil war between Eteokles and Polyneikes, a Thebes just returned to peaceful democracy. Welcome to Thebes retains the brutality and socio-political divisions at the heart of Sophokles' Antigone, but transfers them into a contemporary context where the war has been waged with machine guns, machetes, bombs, civilian executions, rape, and all the horrors of modern guerilla warfare and shock doctrine tactics. Buffini critiques the system of late capitalist economics that allows the global north to exploit the weaker economies of global south countries and to utilize the destructive force of disaster capitalism, while still patting themselves on the back for expanding ostensible benefits like (market) freedom and personal responsibility. In making this critique, Buffini tries to expose techniques Western nations - including her home country of the UK - use to maintain their illusion of benevolence.

Although the plotline of Welcome to Thebes draws primarily on Antigone, Buffini's play ranges far afield from a single hypotext, incorporating storylines from other Greek playsnotably Hippolytus and Lysistrata — and resituating the story in contemporary West Africa. The conflict over Polyneikes' body remains, but unlike in Sophokles it is peripheral to the political conflict in Welcome to Thebes. Visually and politically, the play evokes Liberia's recent history and the struggles of its first female President, Ellen Johnson Sirleaf, whose dramatic counter-part 
is Eurydice. ${ }^{195}$ The costuming of the National Theatre production suggested the competing forces contending over Thebes' future, as well as over global south nations like Liberia. Broadly speaking the costumes fell into three categories - traditional West African garb on Eurydice and her ministers, business suits on the Athenians, and military fatigues on the soldiers. Eurydice's cabinet, in their brightly colored wrappers and head ties, are a sharp contrast to the sober and formal suits worn by Theseus and his various aides. This contrast represents more than variations in fashion, but a fundamental struggle over who will control Thebes' future. Nikki Amuka-Bird's (playing Eurydice) golden wrapper and head scarf proudly symbolize a West African heritage, representing Eurydice's deeply grounded determination that Thebes should be the master of its own destiny; in contrast, David Harewood's (Theseus) sharp blue suit and tie locate him directly in the world of global north corporate capitalism. Eurydice relies on her strong populist identity and politics to try and help Thebes back to its feet, but just like Liberia and other global south nations, international capital has represented a mixed blessing.

Sirleaf's administration faced difficulties in uniting the country after the Second Liberian Civil War, from 1999 to 2003, just as Eurydice’s newly elected government struggles to return peace, stability, and a decent standard of living after the Theban civil war. During the war, Eurydice had been the head of a women's peace campaign (Buffini 34) modeled on the Women of Liberia Mass Action for Peace movement, which protested, put themselves in combat zones, and staged a sex strike to end the Liberian Civil War. In contrast to Antigone, in which the male monarch Kreon denies Polyniekes burial, in Welcome to Thebes the female, democratically-

\footnotetext{
195 Although the National Theatre utilized West African costumes to evoke Liberia (which this chapter will discuss in more detail), the play text itself is not specific about the location or cultural aesthetic. In the published version, the setting is given as "A city named Thebes, somewhere in the twenty-first century" (2). In fact, the play could be set in any of the war ravaged world of the 1990s to 2010s - the Middle East, North Africa, the Balkans, Kashmir, Southeast Asia, China, Latin America, or even increasingly militarized urban spaces in the global north. Andrew Barnaby, who taught the class with which I saw this play, pointed this openness out after the show.
} 
elected President Eurydice denies the burial, which becomes a major rallying point for the opposition, not led by Antigone — who remains largely outside of politics, essentially abandoning the defiance of the hypotext — but by Prince Tydeus, one of the most brutal warlords of the civil war. Also present in this new adaptation is Theseus, First Citizen of Athens, who provides an extended allusion to Hippolytus through his series of mobile phone calls trying to contact his missing wife Phaedra. Theseus represents the interests of the global north in his frequently paternalistic and exploitative plans for the rebuilding of Thebes, rooted in economic (neo)colonialist policies.

In act one, Theseus arrives in the devastated city-state of Thebes. Officially the visit is to congratulate the people of Thebes on their new democratic government and to establish diplomatic relations with the new administration under President-elect Eurydice. As Theseus puts it, "I've come here in humility / I want to see first hand what we Athenians have done / We've given common people here control of their own fate / the gift of democratic government" (11). Theseus makes this statement standing amidst a ruined city with no national power grid, no political, social, or economic infrastructure, in which virtually every citizen has been directly touched by war. The National Theatre set was designed by Tim Hatley, whose "ruined presidential palace suggests both the classical world and a conflict-devastated African country" (Billington). Like the sets for Trojan Barbie and Women of Owu, the stage for Welcome to Thebes evokes the destitution and temporary housing conditions becoming increasingly permanent under the biopolitical regime of neoliberalism - piles of rubble, plastic sheets, twisted rebar sticking out of smashed concrete. This is also a space deprived of the kinds of resources Theseus naturally expects, including electricity and phone systems. When he arrives, his aide Talthybia reports that the largely destroyed palace is "basic but OK. A lot of art and artefacts; no 
electricity. There is no national grid right now" (9). The physical architecture of the space represents the living conditions of increasing numbers of people around the world, but is, of course, totally foreign to Theseus with his global north/Athenian horizon of expectations. ${ }^{196}$

Theseus has not come into this devastated city just for the nicety of congratulating Thebans on a democratically elected government—-his goal is to secure Athens' interests in a newly stable area. In his public address to the people of Thebes, Theseus declares his openly economic intentions: "I hope to see a land where business thrives, endeavor is rewarded, and stability achieved. If peace is maintained, Athens and her partners could do business here. Imagine this: a vast economic development zone, bringing investment and employment; industry that would transform your land. . Your war is over. Now improve yourselves" (35). This speech is textbook neoliberalism. Theseus emphasizes the economic over the social or communal, the cultural or artistic, or any other realm of human endeavor; instead, everything boils down to how business should be conducted. Although Theseus never directly states it, everyone in the Theban political system operates under the assumption that the new Thebes will be shaped either by Athenian policies or by Spartan policies—a Cold War style West vs. USSR rivalry. Eurydice's foreign secretary, Aglaea, warns her that the administration needs to carefully play Athens against Sparta to secure the best deal for the ruined city (15), and Prince Tydeus promises to act as an Athenian strongman. He tells Theseus, "I'd see your will was done. / I'd make sure that Thebes becomes whatever you desire" (101). Both sides of Thebes' political spectrum accept a certain amount of imposition from the Athenians - the difference is how willing each side is to conform. But for Theseus himself, the central question is one of economic control of Theban

\footnotetext{
${ }^{196}$ After being confronted by Tiresias while waiting to meet Eurydice, Theseus loses patience and demands, "I want internet, hot water. I don't care if you drag the generator up the hill yourself. I want a private line, Phaedra on the end of it" (22). Despite being in the middle of a devastated city-state, with limited resources and continuing political and economic problems, Theseus ultimately insists on his own comfort first.
} 
resources. Near the play's end, when Eurydice finally tells Theseus she is going to entertain an offer from the Spartans, he protests:

THESEUS. They feel no responsibility to improve your lot. They're here to feast upon your natural resources. You can be sure of that

AGLAEA. And Athens offers us an economic zone

THESEUS. They'll strip you bare

EURYDICE. Our people go to bed with hunger craving in their bellies every night. Right now we'll entertain any regime that gives us means to feed them. (103)

Theban needs and Athenian interests lie in entirely different political spaces: while Theseus prioritizes control of resources and Theban economic potential (rather hypocritically, as Aglaea sarcastically points out), Eurydice's government is charged with providing basic national stability and living conditions. This fundamental disparity of goals, and the destitute condition in which Thebes finds itself, contributes to Theseus' paternalistic assumption that Athens' economic power gives him an imperialistic right to control Thebes' destiny.

Eurydice's ministers, especially Aglaea, chafe under the oppressive yet detached paternalism of Theseus' vision of a new Thebes. The problem the women have with Theseus' speech is his closing phrase "Now improve yourselves" (35). This injunction lays the blame for Thebes' condition squarely on the shoulders of the Theban citizens and degrades them through its insipid paternalism. ${ }^{197}$ As Aglaea puts it, "That speech of his / It made me livid / Telling us we could improve ourselves / As if we're children learning how to spell / And offering the carrot

${ }^{197}$ Duggan links a rhetoric of personal responsibility to the neoliberal push for privatization, because, as we have seen in previous chapters, privatization disproportionately shifts the burdens of (unpaid) domestic labor to women and minorities. Duggan writes, "The overall impetus of welfare 'reform,' or the elimination of the so-called welfare 'entitlement,' was to transfer the function of providing a social safety net from public agencies to private households maintained through low-wage employment" (15). During the Reagan and Bush Sr. eras, the push for cuts to welfare tended to be couched in racist and misogynistic stereotyping, but under Clinton's New Democratic administration the welfare "reform" movement got a kinder, gentler face promising "uplift." Before the Clinton era, anti-welfare crusaders worked "through the deployment of images of sexually promiscuous, lazy welfare queens breeding for the profit of an ever-enlarging welfare check. The specific neoliberal spin on this cultural project was the removal of explicitly racist, misogynist language and images, and the substitution of the language and values of privatization and personal responsibility" (16, original emphasis). While Theseus' advice to the all-female Theban government is not overtly sexist, his not-so-subtle paternalism reflects the continuing resonances of sexism and racism in 1990s and 2000s neoliberal attacks on welfare and other social programs. 
of his economic zone" (50). The Athenian offer comes from a position of economic strength, but infantilizing the Thebans is a rhetorical technique reinforcing national and gendered hierarchies - Athens superior to Thebes, and the male Theseus superior to the all-female Theban government. Further, Theseus reduces the Thebans to animals in his condemnation of their Civil War. He tells Eurydice, "Your war was bestial" and she counters, "Our war was very human" (57). ${ }^{198}$ Theseus' discourse re-contextualizes old imperialist ideology about the childishness and animalistic nature of the ethnic and colonialized Other - an ideology equating imperial and economic power with maturity or adulthood and civilization.

One cause of resistance among the Theban administration is the inherent violence of an economic system imposed through shock doctrine methodology. ${ }^{199}$ Theseus arrives in Thebes almost immediately after the end of the elections, before the decimated city-state has time to rebuild any of its infrastructure, and begins presenting his plans for an economic development zone (35). Theseus' business oriented plans are in stark contrast to those of Eurydice's government. As soon as Theseus is introduced to the Theban ministers they launch into the business of rebuilding the state, securing finances, and asking about Athenian aid to achieve immediate goals (42-43). Even as Theseus tries to dodge these pragmatic questions about aid and assistance, the reality of economics in the global south re-asserts itself. Following standard IMF and World Bank practice, Eurydice's government inherits the debt of the previous dictatorial regime, and must undergo structural adjustments in exchange for debt relief: Euphrosyne, the

\footnotetext{
${ }^{198}$ Eurydice points to the hypocrisy of "civilized" warfare as practiced by the global north, telling the Athenian, “All war is savage, Theseus, whether it's fought close quarters with machetes or from afar with missiles and computer-guided bombs. Are you more civilized because you can't hear people scream?" (57).

${ }^{199}$ Klein explains that violent destruction and speed are the key components for successful disaster capitalism: "the process deceptively called 'reconstruction' began with finishing the job of the original disaster by erasing what was left of the public sphere and rooted communities, then quickly moving to replace them with a kind of corporate New Jerusalem - all before the victims of war or natural disaster were able to regroup and stake their claims to what was theirs" (10).
} 
Minister of Finance, tells Theseus, "I also have a cheque for you: the latest instalment of interest on the overwhelming debts we have inherited. Would you like it?" and Theseus' aide informs her, "Debt relief is down on the agenda but there are various criteria you must fulfil" (42). Although the criteria are never listed in the play, there is a clear evocation of the standard neoliberal line. Harvey explains that the global north used the IMF and World Bank to impose aid conditions designed to shift capital upwards rather than distribute it to the indebted nations: "In return for debt rescheduling, indebted countries were required to implement institutional reforms, such as cuts in welfare expenditures, more flexible labour market laws, and privatization" (Neoliberalism 29). ${ }^{200}$ Stiglitz writes that the IMF and World Bank sometimes imposed arbitrary policies merely as an exercise of power (46). Of course, to impose policies like these - that is, policies that directly attack the interests of the people in developing nationsrequires a population already disoriented and demoralized by a disaster.

From the very beginning of Welcome to Thebes the violence, destruction, and disorientation of the Theban civil war is apparent. The physical setting of the ruined Presidential palace and piles of rubble visually cue the destruction before any of the actors step on stage. Then, in the metatheatrical prologue to the play, three soldiers come out—sergeant Miletus, Megaera, and Lt. Scud, a child soldier bewildered by forced drug use. Megaera, a female soldier, tells the audience about Theban politics. She says that the only law in Thebes is a gun, and describes a gang rape by militiamen that shattered her psychologically. She recounts, "Time was not even. It was odd / It bends and it's misshapen in my mind / A day was like a month, a month

${ }^{200}$ These kinds of required reforms are one major reason "over 50 years of experience has demonstrated that, in fact, aid is more likely to serve the interests of the donor country; and that ODA [Overseas Developmental Assistance] functions as do other forms of 'resource flows' - as a mechanism of surplus transfer, a catalyst not of development, but of regression" (Veltmeyer and Petras 125). This is surely the predictable result of the Athenian plan for a Theban economic development zone based on certain unspecified debt relief conditions. 
a year" (5-6). Megaera describes regression, living in the woods unable to speak. ${ }^{201}$ She was able to recover when the sergeant "put this gun into my hand and / Made me human once again" (6). But violence doesn't offer everyone a way out of the psychological disorientation of trauma. Polykleitos, a mechanic whose son was murdered by Tydeus, finds his path out of shock by working for peace and ultimately for justice. Thalia and Haemon come and speak to Polykleitos on behalf of the Theban Truth and Reconciliation project, and he recounts the destruction of his worldview:

I thought there was an order to the universe

When I looked up at the sky at night

I'd see a pattern mathematical in its complexity

Now I see random dots

There's nothing

But

An image like a bloodstain. (25)

For Polykleitos, the murder of his son undid the orderliness and comprehensibility of a world he thought he understood. But as his aborted attempt to assassinate Tydeus demonstrates, Polykleitos cannot find his way back to a meaningful world through violence (52-53). Instead, he finds a kind of fulfillment dismantling the weapons of war, destroying the tools that caused his suffering (25), and finally through his public denunciation of Tydeus (104-106). Although he remains skeptical of the TRC process, Polykleitos takes control of his own destiny by speaking out against his son's murderer. ${ }^{202}$

Like Polykleitos and Megaera, Eurydice's government seeks to take control of Thebes' destiny, a proposition made more difficult by both Theseus' economic imperialism and Tydeus'

201 This kind of regression through disorientation and torture is a method developed by the CIA through the MKUltra project, published in detail in the Kubark manual, which combined physical torture techniques with sensory deprivation and forced drug use to break down torture victims' sense of reality and self (Klein 46-49).

${ }^{202}$ Despite Polykleitos' reservations about the TRC process, his testimony actually does destroy the political ambitions of Tydeus and Pargeis, Polynices' widow and Tydeus' principal supporter. Immediately after the testimony, Theseus distances himself from the pair, telling them, "You are untouchable; / A tyrant's wife, a warlord" (106). 
potentially violent opposition. Although Tydeus plots a coup, Eurydice's foreign secretary, Aglaea, rightly identifies Theseus as the more dangerous threat to their aspirations. While most of the ministers are initially taken in by Theseus' charm and charisma, Aglaea continually voices her distrust of the Athenian and his intentions. While all the other ministers admire Theseus and occasionally encourage Eurydice to try and seduce him, Aglaea recognizes in him the ruthlessness that underlies disaster capitalism. She cautions Eurydice, "I know he wears a splendid suit / Sewn with a democratic thread; / He's still a warlord with a warlord's heart" (16). When Eurydice protests that not all men are warriors, Aglaea responds, "He fights his wars behind a desk / But don't imagine that the beast is tame" (16). In playing Theseus, David Harewood exemplified this delicate balance between charm and destructive power. In his review for the Independent, Paul Taylor called Harewood's performance as Theseus "swaggeringly presidential," while Billington said that he "exudes cocksure charisma as the Athenian leader." Matt Williamson, in the Socialist Review, paints a more complex picture of Harewood's performance: "Harewood is a commanding presence. Effortlessly switching between charismatic public persona and petty private self, Harewood's performance shows both the dangers and charm of personality politics." Although she initially inclines to trust Theseus and his democratic promises, Eurydice is quickly put off by his unwillingness to confront immediate problems and his rather clumsy attempt to extort sex from her in exchange for aid (61-62). It becomes clear over the course of the play that Athens intends not to help Thebes but to help Athens-just as the global north extends aid to the global south with the intention that the money will return north.

However, money is not the only thing that flows north in the wake of disaster capitalism and economic exploitation in the global south. As Chicago School economics wreaks havoc around the world, both armed and peaceful resistance arises to protest and attempt to protect 
individual rights against exploitation by business and government. The Epilogue of Welcome to

Thebes reflects simultaneously the very real violence and resistance resulting from globalized exploitation, but also the global north's disproportionate fear of violence bleeding over from the acceptable battlegrounds of the global south to the comparatively much more secure enclaves of the global north. In the Epilogue sergeant Miletus and Megaera decide to go to Athens in search of work, as indeed refugees from economic hardship and political repression often seek better conditions in the global north. The pair know "They don't like Thebans there," and they will either be rejected by Athens or given menial work at best (115). But as products of a violent society, particularly a violence stemming from Athenian influence, Megaera and Miletus are prepared to respond to their exclusion. The play closes with Megaera's lines:

Miletus, man,

They give us any shit

They stand there in their marble palaces and try to keep us out We'll soak our rags in petrol And we'll burn their city down (115)

Megaera's casual willingness to bring violence and devastation to the heart of the global north represents both a political reality of the "War on Terror" and an ideological fantasy within the global north that drives increased security, militarization, and the repression of immigrants, ethnic Others, and the dispossessed. ${ }^{203}$ By deploying politically and ethnically/religiously

${ }^{203}$ Imperialism and oppression have always produced violent resistance. Fanon outlines the conflict between Imperial settlers and colonized peoples as Manicheism, a fundamental ethical conflict between two incompatible forces. Fanon writes, "At times this Manicheism goes to its logical conclusion and dehumanizes the native, or to speak plainly, it turns him into an animal" (42). However, Fanon notes, with the reassertion of the colonized subject's humanity, violence becomes inevitable (43). At the same time, however, the fantasy of Manichean forces directing their violent energy at the global north — regardless of whether or not any serious external threat actually exists - fuels a security panic that further strengthens the oppressive systems the dispossessed are seen as threatening. Gilroy writes that this need to further fortify becomes constituent of the contemporary global north. He claims, "even when armed to the teeth, its [the West's] fortified wholeness is imperiled, subject to anxiety about the prospect of its durability and tormented by the knowledge of its inevitable decline" (19). And so in the desperate attempt to prevent the repressed masses of the poor and oppressed from constituting a threat, the global north becomes more oppressive, more militarized, and more intolerant of anyone conceptualized as a threat. 
charged rhetorics, neoliberal forces seek to dismiss the humanity and the legal, moral, and ethical rights of the dispossessed and the exploited. ${ }^{204}$ One of neoliberalism's great strengths is its ability to disavow the results of its own policies and retain a rhetoric devoted to free market beneficence.

\section{Politics of Disavowal: Neoliberal Rhetoric and Results}

One of the great strengths of neoliberalism is its skill in disavowal—its ability to sell socially and economically oppressive policies using a rhetoric of freedom and opportunity. Freud explains disavowal as a kind of disconnect between conscious knowledge and a wish, in which both are granted the status of reality. He writes that disavowal consists of two mental processes, "the one which was consistent with reality stood alongside the one which accorded with a wish" ("Fetishism" 208). In the case of neoliberalism, this disavowal occurs most prominently through the disjunction between promised individual freedom and prosperity measured against the real world results of Chicago School economics - political repression, the rapid concentration of vast wealth in a few hands, and the re-emergence of global class disparities. David Harvey writes, "It has been part of the genius of neoliberal theory to provide a benevolent mask full of wonderfulsounding words like freedom, liberty, choice, and rights, to hide the grim realities of the restoration or reconstitution of naked class power" (Neoliberalism 119). We may think of this politically through the "search for rationalization which attempts to justify the violation of a principle" that Žižek attributes to Stalinist logic: "in principle it is of course so; nevertheless, in

\footnotetext{
${ }^{204}$ Roy writes about the repression of dispossessed peoples in Central and Northern India, where all protestors against government and corporate theft of land and resources are met with violence. She writes, "the government has begun to flood the forests with hundreds of thousands of security forces. All resistance, armed as well as unarmed, has been branded 'Maoist.' (In Kashmir the preferred phrase is 'jihadi element')” (61).
} 
the concrete circumstances..." (For They Know Not 243). This kind of disavowal is fundamental to neoliberal real world economics. ${ }^{205}$

The plays examined in this chapter direct attention to the cynicism and disavowal so central to neoliberal political economy by satirically mocking the violent coercion used to secure "freedom." Osofisan's Women of Owu mocks the disavowal of the profit motive at the heart of the Iraq Invasion, as the women bitterly and ironically complain about the rhetoric of their "liberators":

WOMAN. They are not interested in such petty things As profit-

WOMAN. Only in lofty, lofty ideas, like freedom-

WOMAN. Or human rights-

WOMAN. Oh the Ijebus have always disdained merchandise-

WOMAN. The Ifes are unmoved by the glitter of gold-

WOMAN. The Oyos have no concern whatsoever for silk or ivory-

WOMAN. All they care for, my dear women

All they care for, all of them, is our freedom!

WOMAN. Ah Anlugbua bless their kind hearts!

WOMAN. Bless the kindness which has rescued us From tyranny in order to plunge us into slavery! (12-13)

As with the impoverishment and political disenfranchisement of the Iraqi people after the war to "liberate" them from Saddam Hussein, the women of Owu find themselves in a materially worse position than they had been under their ostensible oppression-displaced, dispossessed, denied any social, political, or economic control over their own destiny, with their loved ones killed,

${ }^{205}$ Rationalization to justify the violation of principles makes comprehensible the disjunction between Chicago School theory and real world practice: in principle Friedman opposed political repression, but he frequently supported brutal dictators throughout his career, most notably Pinochet's repressive Chilean government which overthrew and executed democratically elected President Salvador Allende in 1973. Pinochet was one of the most repressive leaders of the late $20^{\text {th }}$ century, but because his economic policies were shaped by the Chicago Boys-a group of young Chilean economists trained by Friedman at the University of Chicago-Friedman supported the Pinochet government. Friedman's support of brutal regimes existed uneasily alongside ideological statements like, "The fundamental threat to freedom is the power to coerce, be it in the hands of a monarch, a dictator, an oligarchy, or a momentary majority" (Friedman 15). Or, if we reformulate this in Žižek's terms, Friedman's position becomes: of course in principle dictatorship and violent coercion is wrong; nevertheless, in the concrete circumstances of Allende's moderately socialist government, political repression and the circumvention of democracy become necessary to produce economic freedom. This denial, this doublethink runs throughout neoliberal political economy. 
tortured, and raped. Welcome to Thebes features comparable criticism of the disjunction between a global north rhetoric of freedom and the real world violence protecting corporate and governmental economic interests. In contrast to Theseus' proud proclamation that Athenians have "given" the people of Thebes democracy (11), Haemon notes the role Athens played in giving Thebes its war. He tells Theseus, much to Eurydice's embarrassment, “That's the irony, you see. Thebes is not a weapons-manufacturing state. Most of the arms in our conflict were Athenian" (41). ${ }^{206}$ Neoliberalism continues to utilize a beneficent rhetoric of freedom, liberation, and choice even as neoliberal forces create and support some of the world's most violent and repressive regimes and rebel groups.

In fact, one potential method of disavowal for neoliberal global north governments is through theatre/the arts themselves. This is the great irony of Buffini's play, which premiered in the Olivier auditorium of the National Theatre in London. ${ }^{207}$ London is one of the world's financial centers and a stronghold of neoliberalism. It is tempting to suggest that Buffini's play takes its critique into the lion's den, directly confronting London with its own complicity in neoliberal economic colonialism. However, this reading fails to account for neoliberal disavowal. The National Theatre is, in part, publicly funded by the British government, and funding an antineoliberal play allows the British government to paradoxically send the message that they oppose the oppressive results of the very economic policies they are complicit in enforcing. In

\footnotetext{
${ }^{206}$ Of course, the global north has long supplied arms to both oppressive governments and rebels in the global south, largely under the ideological pretense of anti-communist support. But as principle hubs of arms production, global northern nations make massive amounts of money off the international arms trade. Roy asks the question: "Do we need weapons to fight wars? Or do we need wars to create a market for weapons? After all, the economies of Europe, the United States, and Israel depend hugely on their weapons industry. It's the one thing they haven't outsourced to China" (43). It is, therefore, in the best interest of global north arms-manufacturing states to maintain a continuous level of military activity around the globe in order to justify through "market demand" the creation of weapons.

${ }^{207}$ Tegonni premiered in Atlanta, which is the home of Coca-Cola, one of the most iconic symbols of globalized economics. Although this is an interesting coincidence, it is nonetheless merely a coincidence. Women of $O w u$ premiered in Oxfordshire, which, while part of England, is not a center of British financial life.
} 
Reading the Material Theatre, Ric Knowles argues for the importance of seeing theatrical production in a larger cultural context. He writes that the material theatre "understands meaning to be produced in the theatre as a negotiation at the intersection of three shifting and mutually constitutive poles" (3, original emphasis): the performance, the conditions of production, and the conditions of reception $(3,19)$. Functioning a bit like the rhetorical triangle, Knowles' schema argues for the interconnection of the phenomenon of the play itself as a meaning making entity; the location of the theatre, the condition of the building, community, etc. as meaningful signs; and the conditions of audience reception and understanding of the performance. ${ }^{208}$ Both Knowles and Jen Harvie argue for seeing funding as one of the crucial elements in understanding theatre's role within a culture.

Particularly in nations like Britain that have public arts funding schemes, how public funding is allotted reveals much about social and aesthetic values. Harvie's book Fair Play makes an excellent case for seeing contemporary arts funding in the UK as a tool helping to promote and establish neoliberal values through aesthetics. Utilizing Bruno Latour's actornetwork theory, Harvie argues, "what might initially appear to be of only 'background' significance (such as arts funding to what is apparently the 'main event' of the art object/performance) can be seen, where appropriate, as a main actor" (18). And Knowles asserts a fundamentally conservative approach to theatrical funding, especially in theatres dependent on public money. ${ }^{209}$ In other words, the need for arts funding - especially in local or regional

${ }^{208}$ Knowles argues that partly because of tradition and partly because directors are responsible to those who provide funding, truly open, collaborative, and democratic production structures pose risks. Knowles writes, "Whatever the nature, content, or conscious theme of the production, as product, and as the record of a particular ideologically coded process, its central and essentially capitalist message is inscribed, virtually by necessity, within the system itself" (32, original emphasis). This is, of course, another form of disavowal: I know that we as theatre artists believe in democracy and free individual expression, but nevertheless as the director I impose my vision on the show.

${ }^{209} \mathrm{He}$ explains that local or regional theatres receiving public funding select plays/performances through community boards, and "the (usually unstated) responsibility of such community boards is to ensure adherence to 
theatres - plays a central role in determining what shows are selected for performance. However, with a venue like London's National Theatre the rules are slightly different.

Like the City Dionysia of ancient Athens, the National Theatre is Britain's venue to broadcast its theatrical vision of the nation, both inward to British people and outward to the world at large. The National Theatre has more freedom to pursue socio-politically and formally experimental work than smaller theatres, due to its prestige, centrality, and high profile as Britain's principle theatre. However, its principal funding sources remain a mix of public monies that must be spent "appropriately" and corporate backing. Both the British government and multinational corporations have a vested interest in promoting neoliberal values, and Harvie argues they are able to do so by reconfiguring the roles and purposes of art in the UK. Harvie notes that in the 2010-2011 season (when Welcome to Thebes premiered), approximately 28 per cent of the National Theatre's funding came from the British government via an Arts Council England grant, and its "Major corporate sponsors included Accenture, American Airlines, American Express, Aviva and Bank of American Merrill Lynch, somewhat begging the question of which nation this National Theatre serves or is perceived to serve in globalized times" (174).

Funding a play like Welcome to Thebes allows the British government to project a narrative of itself as benevolent and humanitarian, as being concerned with world economic, social, and political problems. Or, in the terms Žižek has given us: the British government and economic establishment know very well that they play a major role in globalized economic exploitation, dispossession, and violence, but in funding a play critical of these trends they act as though they do not know of their own complicity. Because Athens stands in for an economically imperialist Britain/West, the British public gets to vicariously critique neoliberal exploitation

'fiscal responsibility' and 'proper community standards' rather than to promote aesthetic or formal risk - not to mention social critique" (57). 
without having to politically confront their own socio-economic values and practices. If audience members enjoy the play (as I did when I saw it) and especially if we agree with its message, this opens the possibility that we as members of the public can disavow our own responsibility for the systems of exploitation that sustain Western lifestyles. Instead of real revolutionary action, audiences embrace an aesthetic experience, and neoliberal disavowal relies on this substitution of artistic for revolutionary action. In other words, by financially backing plays critical of its own ideology, the British government positions itself as resisting the very forms of oppression it creates, but also cynically shows itself (via an Athenian proxy) as complicit in global systems of exploitation and neocolonialism.

This theatrical disavowal is, however, a risky strategy because it may end up promoting the kind of cosmopolitanism that Rebellato argues for, and this expanded empathetic worldview may undermine confidence in neoliberalism. This kind of collective disavowal relies on repressing the exploitation of the global south, the poor, and the dispossessed, as well as keeping citizens of the global north firmly imbedded in the culture of enjoyment. From the perspective of neoliberal disavowal, producing culturally hybrid adaptations depends for its efficacy on subjects not taking seriously the critiques of late capitalism in these works, or, more precisely, allowing the critiques to exist alongside the capitalist culture of enjoyment in a kind of cognitive dissonance. The inherent risk to this strategy is that the dissonance may resolve itself, leading to a rejection of the exploitation, commodification, consumer atomization, and economic (ne)colonialism so characteristic of neoliberalism. Through their appeals to a cultural commonwealth rooted in a shared heritage of Greek culture/myth, as well as the hybridity of adaptation, theatrical adaptations of Greek tragedy may in fact promote a cosmopolitan common culture that erodes neoliberal hegemony. 


\section{Chapter V}

\section{Ubuntu: Building a Better World Together}

Perhaps the best known expression of the cosmopolitan spirit comes from Diogenes the Cynic: as recorded by Diogenes Laertius, "When asked where he was from, he said, 'I'm a citizen of the world"' (Hard, 12). ${ }^{210}$ This is the earliest known endorsement of cosmopolitanism in the history of Western philosophy. What Diogenes means when he self-identifies as kosmou politês - a world citizen — is that his loyalty and the responsibilities of citizenship transcend devotion to a particular city-state, and instead encompasses all of humanity as his polis. This was, and still is, a controversial idea. In the Hellenic world it challenged the political primacy of city-states, and in the modern world it challenges the political primacy of nation-states. However, Diogenes laid the ethical groundwork for a cosmopolitan philosophy that was maintained by the Cynics, the Stoics, early Christianity, picked up by Kant in the $18^{\text {th }}$ century, socialist internationalism in the $19^{\text {th }}$, and has re-emerged as an ethical counter-point to capitalist globalization in the late $20^{\text {th }}$ and $21^{\text {st }}$ centuries.

This final chapter argues that adaptation as a form endorses a strand of cosmopolitanism by enacting a cultural commonwealth. The primary focus of this chapter is Yael Farber's Molora (2008), which adapts Aiskhulos' Oresteia for post-TRC South Africa. In combining Aiskhulos' Attic tragedy with Xhosa songs performed by the Ngqoko Cultural Group, and the ritualized procedures of the Truth and Reconciliation Commission, Farber creates a cosmopolitan space in which these disparate cultural forms become mutually supportive material collaboratively resisting oppression. The heteroglossic intertextuality of Farber's play presents audiences/readers

210 This story is also recorded in Lucian's Philosophies for Sale as a humorous dialogue between Diogenes and a buyer (Hard 3-4). In Lucian's version, Hermes is auctioning Diogenes off and the buyer questions the philosopher about his way of life and why he doesn't mind being sold. Diogenes responds that he doesn't mind being removed from the place he had been living because he considers himself belonging to the world, rather than being tied to any particular city-state. 
with ancient Greek material, traditional South African, and modern South African performance simultaneously. In other words, audiences encounter all of these performance elements as organically intertwined, absent potential hierarchies of race, nationality, imperial power, etc. This kind of hybrid performance builds connections between different styles and traditions, weakening the ostensible boundaries between cultures. This is, I argue, theatre's potential contribution to a cosmopolitan world-view: to train audiences to find the familiar in the strange.

Especially given Chapter IV's critiques of economic globalization as a form of international exploitation, it may seem surprising and even contradictory that I advocate cosmopolitanism. What, after all, is the difference between the universal orientation of cosmopolitanism on the one hand, and the universal orientation of global capitalism on the other? The answer is in the divergent ethics of the two systems. Neoliberal globalization begins with an ethics founded on market values, an ethics for which all that glitters can be gold (or oil, or coal, or diamonds, or cheap unprotected labor). Cosmopolitanism, by contrast, takes as its starting point a shared human responsibility for all of the lives we touch, which, in a globalized world, potentially includes everyone. As Richard Falk argues, it is a crucial task for cosmopolitans today to clarify the distinction between our position and that of international capitalism. Falk writes, "A credible cosmopolitanism has to be combined with a critique of the ethically deficient globalism embodied in neoliberal modes of thought and the globalism that is being enacted in a manner that minimizes the ethical and visionary content of conceiving of the world as a whole" (57). Because of the collaborative nature of performance, theatre is uniquely suited to promote the "ethical and visionary content" of cosmopolitan ideology—theatre and adaptation produce points of connection which illuminate our moral responsibilities to others and 
promote cross-cultural understandings. This argument derives from moral cosmopolitan

philosophy, which prioritizes the responsibility human beings have to one another and openness to cultural alterity. ${ }^{211}$

Moral cosmopolitanism begins from three central presuppositions: 1) that all human beings have value regardless of identity divisions, 2) that we are each ethically responsible to others, and 3) that the primary sphere of our moral obligation should be humanity as a whole. ${ }^{212}$ Dan Rebellato explains Kantian cosmopolitanism as being premised "on absolute equality of consideration of every person in the world: in making a moral judgment we invoke the global community of all persons" (71, original emphasis). Kant's modern cosmopolitan ethics found its catalyst in the age of empire, in which European imperialism and trade brought the world into much closer contact than ever before. Kant argued that this was a global society, in which the consequences of one's actions were no longer confined to the local, but (potentially) had effects the world over. As he put it, "The growing prevalence of a (narrower or wider) community among the peoples of the earth has now reached a point at which the violation of right at any one place on the earth is felt in all places" (84, original emphasis). ${ }^{213}$ In other words, Kant believed that humanity had transcended the narrow bounds of the city-state, kingdom, or nation, and through capitalism and imperialism we reached a stage where we cannot prevent our actions

${ }^{211}$ In The Cosmopolitanism Reader, Brown and Held distinguish between moral cosmopolitanism and institutional cosmopolitanism. The former begins from the idea that every human being is an equally valuable entity entitled to ethical concern, while the latter position "focuses primarily on examining what institutional designs might best implement the normative considerations of its moral counterpart" ("Editor's Introduction" 2). In other words, moral cosmopolitanism traces an ethical argument, while institutional cosmopolitanism focuses on the practical implementation of political structures to achieve or facilitate cosmopolitan objectives.

${ }^{212}$ Ecocritics and post-humanists are now challenging anthropocentric preoccupations with the human as the most meaningful category to which we are responsible. These critiques are well founded and often make the same ethical assumptions as cosmopolitanism, just with a wider sphere.

${ }^{213}$ As Appiah writes, "the one thought that cosmopolitans share is that no local loyalty can ever justify forgetting that each human being has responsibilities to every other" (xvi). 
from affecting others. ${ }^{214}$ We must, therefore, be conscious of the consequences our actions have in a globalized economy and culture. Cosmopolitanism is a fundamentally empathetic approach to ethical action, wherein the welfare of others and the impact our actions will have on those around us is key to all decision making.

However, as both Kwame Anthony Appiah and Martha Nussbaum argue, we can only begin to determine how our actions may affect others - and by extension, whether those actions are ethical—by understanding other peoples' cultures and world views. What one person thinks of as moral and right from a particular cultural context may be an appalling taboo in another context. This is the ethical grounding of cosmopolitan empathy and openness to cultural diversity. As Appiah explains, cosmopolitans "take seriously the value not just of human life but of particular human lives, which means taking an interest in the practices and beliefs that lend them significance. People are different, the cosmopolitan knows, and there is much to learn from our differences" $(\mathrm{xv}) .{ }^{215}$ For Appiah, this is a serious challenge because differences in culture, ideology, and world view condition what people believe to be normal or beneficial, and "Much well-intentioned intervention in the past has undermined old ways of life without replacing them with better ones" (14). ${ }^{216}$ Instead of approaching other people as though they need to be saved

${ }^{214}$ For instance, if I drink a cup of coffee in the morning, I may perpetuate the cycle of international capitalism that (under)pays growers in Colombia, Turkish sailors on the ship transporting the beans, Haitian factory workers making tins to pack the coffee, and workers at my local grocery store stocking the coffee. My choice to consume that cup of coffee sustains an economic cycle affecting people around the world.

215 This, according to Appiah, avoids the oft-leveled charge that a cosmopolitan world would mean cultural conformity, producing a unified world culture in place of a vivid spectrum of cultures. Appiah actually argues that small insular communities - which localists sometimes hold up as 'culturally authentic' in contrast to cosmopolitanism's ostensible mongrelization - tend to enforce homogeneity more stringently than cosmopolitan centers (101), and that "whatever loss of difference there has been, they are constantly inventing new forms of difference: new hairstyles, new slang, even, from time to time, new religions. No one could say that the world's villages are — or are about to become - anything like the same" (103).

${ }^{216}$ With different cultural contexts, we should be especially conscious that culture is contingent - that cultural forms evolve differently to meet local needs or overcome local problems. I was recently at a conference where a speaker talked about teaching cultural awareness to anthropology students. One example she used is that, in the late $20^{\text {th }}$ century, health care workers began distributing massive numbers of mosquito nets throughout West Africa. On the one hand, rates of infant mortality from malaria dropped substantially, which was the goal. However, 
from their own 'barbarous' culture, the cosmopolitan seeks points of connection around which to begin dialogue. Through conversation, cosmopolitans find ideas, values, beliefs, and practices that we share with others. But we also discover different ways of seeing the world, new ideas, new evaluations, or new ways of solving problems. ${ }^{217}$

In positing the value of cross-cultural conversation, Appiah proposes a version of what Nussbaum calls cosmopolitan education, which would train students/people to see themselves as principally responsible to humanity rather than to a particular national group. Nussbaum asks, "should they [students in the US] be taught that they are, above all, citizens of the United States, or should they instead be taught that they are, above all, citizens of a world of human beings, and that, while they happen to be situated in the United States, they have to share this world with citizens of other countries?" (6). Obviously, Nussbaum's answer is the latter, and she presents four principles supporting cosmopolitan education. ${ }^{218}$ While we can and should continue to value our local allegiances - to family, community, nation, religion, ethnicity, etc.—Nussbaum argues that a cosmopolitan education must train students to "learn to recognize humanity wherever they encounter it, undeterred by traits that are strange to them, and be eager to understand humanity in all its strange guises" (9). This kind of recognition prompts us to value others because of - rather

birth rates did not drop and wages did not rise. Also, when the children reached adulthood their immune systems weren't as strong as those of previous generations who had survived the disease. So by changing the balance these communities had developed to account for infant mortality, the health care workers inadvertently created new sets of problems.

${ }^{217}$ Appiah writes, "the points of entry to cross-cultural conversations are things that are shared by those who are in the conversations. They do not need to be universal; all they need to be is what these particular people have in common. Once we have found enough we share, there is the further possibility that we will be able to enjoy discovering things we do not yet share. That is one of the payoffs of cosmopolitan curiosity. We can learn from one another; or we can simply be intrigued by alternative ways of thinking, feeling, and acting" (97).

${ }^{218}$ First, she argues that by comparing our own culture and values with others we learn to distinguish the local or trivial aspects of our own culture from the deeply ingrained and essential (11-12). Second, international or global problems require us to work with people of other backgrounds, which require that we know something about those people (12). Third, learning about other cultures helps us identify moral obligations that we might otherwise ignore (12-14). Lastly, in a critique of Richard Rorty's defense of nationalism, Nussbaum claims that cosmopolitanism produces ethically defensible distinctions rather than dividing people arbitrarily by national boundaries (14-15). 
than in spite of - difference, and to recognize the limitations of our own cultural presuppositions. Jeremy Waldron claims that one of the ethical imperatives of cosmopolitan philosophy is to see one's cultural norms as contingent solutions to problems which others might solve differently (174). Appiah makes a similar plea, urging people — not just students — to become familiar with other ways of living, other world views, so that we can share a planet more comfortably and responsibly: "I am urging that we should learn about people in other places, take an interest in their civilizations, their arguments, their errors, their achievements, not because that will bring us to agreement, but because it will help us get used to one another" (78).

One way of promoting this kind of cultural openness is through the arts. By experiencing theatre, literature, and art from other places and cultures, we enter into the kinds of cross-cultural conversations Appiah advocates. This is a less institutional approach than the cosmopolitan education Nussbaum advocates, but the principle remains essentially the same: through awareness of the practices, problems, and views of other cultures we become more comfortable with alterity and better able to work together to solve global problems. Appiah explains:

Conversations across boundaries of identity — whether national, religious, or something else - begin with the sort of imaginative engagement you get when you read a novel or watch a movie or attend to a work of art that speaks from some place other than your own...Conversation doesn't have to lead to consensus about anything, especially not values; it's enough that it helps people get used to one another. (85)

In pointing out some of the limitations of cosmopolitanism's demand for universal empathy and consideration, Elaine Scarry writes, "The way we act toward 'others' is shaped by the way we imagine them. Both philosophic and literary descriptions of such imagining show the difficulty of picturing other persons in their full weight and solidity. This is true even when the person is a friend or acquaintance; the problem is further magnified when the person is a stranger or 'foreigner"' (98). However, if we take Appiah's argument seriously, it is not necessary to picture 
"other persons in their full weight and solidity" - a criterion which might block any argument for empathetic action if, as Scarry suggests, we cannot even do this with our friends - but merely to become comfortable with the fact that our own customs and ideas are contingent, and that others have different customs and ideas.

This kind of awareness and comfort is central to Rebellato's argument that theatre is fundamentally cosmopolitan. Rebellato claims that theatre promotes empathetic cosmopolitanism when we engage ethically with characters, either as actors or as spectators. He writes, "Acting a character involves a level of imaginative engagement with another (fictional) person, a determination to occupy and understand that person's actions, whether that is psychologically or socially. Acting might itself be considered a valuable rehearsal for the ethical principle of universal equivalence between all people" (71). In other words, to perform is to imagine becoming someone else - to imagine what that person believes, what they think, what they want, how they see themselves in society — which is one kind of act that may underpin cosmopolitan empathy. He claims, further, that audiences' sympathetic engagement with different kinds of characters on stage primes viewers for empathetic decision making in the world - just as recent studies have found higher rates of empathy among avid readers, who are better able to imagine the views, opinions, and positions of others. ${ }^{219}$

Similarly, Hardt and Negri assert that felicitous encounters are a key to constructing the common because these encounters unify the multitude. The felicitous encounter produces a type of hybridity, similar to the liminal condition Bhabha theorizes as fundamental to resisting

${ }^{219}$ Both The Guardian and Scientific American report on findings by Emanuele Castano and David Kidd that literary fiction helps readers connect better with others (Bury; Chiaet), and Psychology Today reports on a number of studies with similar findings (Bergland). 
colonialism. ${ }^{220}$ Hardt and Negri write, "the felicitous encounter results in a new production of the common — when, for instance, people communicate their different knowledges, different capacities to form cooperatively something new. The felicitous encounter, in effect, produces a new social body that is more capable than either of the single bodies was alone" (Commonwealth 254-255). While Hardt and Negri identify these felicitous encounters principally as interpersonal interactions, there is no inherent necessity that these encounters be direct. As Appiah suggests, cosmopolitan conversations can be launched by encountering a work of art, literature, or theatre speaking from a perspective other than our own. And intercultural adaptation particularly exemplifies the possibilities for finding common ground in literary/performative conversations by staging the encounter of different theatrical, performative, and literary heritages. What is imagined here is precisely the kind of encounter Rebellato ascribes to theatre. A potentially transformative social space wherein people encounter other world views, ethical systems, cultural practices, and norms. These encounters can open up new conceptions of the world, challenging and reformulating how subjects see both themselves and their community.

\section{Making A New World: Cosmopolitan Aspirations in Yael Farber's Molora}

South Africa has its own distinct notion of cosmopolitanism, one which became internationally famous in 1996 as the ethical foundation of the Truth and Reconciliation Commission: ubuntu. Derived from a Bantu philosophy translating roughly as "human kindness/togetherness," ubuntu posits that people derive meaning and purpose from acting morally within a community of human beings. As Archbishop Desmond Tutu - chairman of the TRC — explained, "A person with ubuntu is open and available to others, affirming of others,

${ }^{220}$ In promoting cosmopolitanism and critiquing the myth of cultural purity that so often underpins nationalism and cultural exceptionalism, Waldron writes, "For human cultures, it is the rule, not the exception, that ideas and ways of doing things are propagated and transmitted, noticed and adapted" (166). 
does not feel threatened that others are able and good, for he or she has a proper self-assurance that comes from knowing that he or she belongs in a greater whole and is diminished when others are humiliated or diminished, when others are tortured or oppressed" (qtd. in Nield 10). Ubuntu shares much with Kant's notion of cosmopolitan responsibility, particularly the position that in an interconnected world the suffering of anyone reflects on everyone. But in a society as riven by racial/ethnic and socio-economic divisions as post-apartheid South Africa, achieving such human togetherness was a monumental task. The medium chosen to begin the processes of healing was story-telling through the structure of the TRC. ${ }^{221}$

In Performing South Africa's Truth Commission, Catherine Cole argues that performance fundamentally shaped how the TRC was organized and presented to South Africans and the world. $^{222}$ The role of performance, particularly story-telling, was central to the TRC and its various theatrical and artistic afterlives, in part because of story-telling's potential for establishing empathetic connections between performers and spectators. Farber's dramaturgy often works to establish these kinds of links that uplift and prompt empathetic action in the world. As Farber herself said, "The barriers we construct to differentiate ourselves from one another, collapse under the weight of the evidence that we all inevitably share these fragile 'once-upon-a times"' (Fisher and Farber 21). Tutu echoes this sentiment in his foreword to the collection Theatre as Witness, which brings together three plays Farber wrote collaboratively with people who had testified at the TRC — testimonial plays enacting the stories of those

\footnotetext{
${ }^{221}$ Cole explains that the official goals of the TRC were: "to investigate past gross human rights violations, grant conditional amnesty, give victims a place to 'relate the violations they suffered,' take measures toward restoring human dignity, report to the nation at large about its findings, and make recommendations aimed at preventing gross violations of human rights in the future" (xi).

${ }^{222}$ The TRC actually had three different commissions - the Human Rights Violations Committee, the Reparation and Rehabilitation Committee, and the Amnesty Committee. Although these committees each had different mandates and juridical structures, most people think of the HRVC when they think of the TRC. The HRVC was the committee charged with taking the statements of victims of apartheid political violence.
} 
specific individuals. The Archbishop writes, "True story-telling helps us reach beyond the damage, and into the future...to touch every human heart that longs to hear and be heard" (7). With this faith in the power of stories to prompt empathetic action and remake the world in new and better ways, Farber's choice to adapt the Oresteia makes perfect sense for the new South Africa, a nation trying to establish both justice and forgiveness. ${ }^{223}$

Aiskhulos' Oresteia dramatizes the transition from a society ruled by violence and feuding to a society (specifically, Athenian society) ordered by the rule of law. This trilogy-the only extant trilogy from ancient Greece-was first performed in $458 \mathrm{BCE}$, when it won first prize at the Dionysia. The first play, Agamemnon, shows the titular character's return from the Trojan War and his murder by his wife Klytemnestra as revenge for sacrificing their daughter Iphigenia at the beginning of the war (an event dramatized in Euripides' Iphigenia in Aulis). This is followed by The Libation Bearers, in which Orestes and Elektra, the children of Klytemnestra and Agamemnon, murder their mother and her new husband Aegisthos to avenge their father. In the final play, The Eumenides, things shift. The play begins with the Erinyes (the Furies) pursuing Orestes for matricide and Apollo protecting him, until Athena intervenes and establishes a trial by jury to determine whether Orestes was justified in spilling his mother's blood to avenge Agamemnon. ${ }^{224}$ This is the fundamental shift marked by the play: from a

${ }^{223}$ Cole writes, "If gross violations of human rights unmake the world...the advocates for the TRC wished to remake that world by restoring certain extreme experiences and unspeakable deeds to language" (17).

${ }^{224}$ Here we should be cautious, and reiterate the warning given by Laera in Reaching Athens, namely that the values of Greek democracy are very different than the values of modern democracy. The court that Athena establishes is very much a masculine sphere, and we should be conscious of the problematic gender politics in the Oresteia. For instance, Apollo argues in The Eumenides that, "The mother is not parent of her so-called child / but only nurse of the new-sown seed. / The man who puts it there is parent; / she merely cultivates the shoot- / host for a guest" (186). Apollo dismisses the humanity and the procreative role of women, reducing them to mere receptacles for men's children. Molora does reimagine Aiskhulos' trilogy with a feminist slant, though I don't say much about that here. Farber excises Apollo's argument against women's humanity, and she puts Elektra and Klytemnestra at the center of her play, while Orestes becomes more peripheral than he is in the Greek. The feminist changes in Farber's adaptation would be an interesting topic for a future project. 
'primitive' and 'barbaric' culture of bloody revenge (situated in and represented by Argos) to a

'civilized' and democratic jury trial (located both psychically and ideologically in Athens—no

one could accuse Aiskhulos of not being patriotic). ${ }^{225}$ After the trial, Athena explicitly

commands the Athenians - simultaneously the twelve serving on the play's jury and the audience

of citizens - to maintain the system of jury trials and uphold the laws (Eumenides, 187-188). She

informs the citizens, "This bench and this tribunal in the future / is perpetually set up for Aegeus'

people" (187). The play, therefore, dramatizes the (mythologized) moment that established

Athenian values: democracy, equality before the law, and justice. ${ }^{226}$

\footnotetext{
${ }^{225}$ In the introduction to his translation of the Oresteia, Roche puts it: "The blood feud can end only by total self-destruction, or by giving way to a divinely established justice which is itself evolving - evolving from primitive concepts of retribution into a higher order of compassion, enlightenment, and peace" (xiv).

226 There is also an interesting psychoanalytic reading of the Oresteia as a founding ritual. Agamemnon and The Libation Bearers together represent a variation of the oedipal fantasy, distorted by the mother's violence. If Orestes' fundamental unconscious drive is to murder his father and marry his mother - and Freud argues that the unconscious ambivalence between the desire to kill one's father and remorse for this desire is fundamental to human civilization (Civilization 95) - the target of his aggressive instinct is removed (i.e., murdered) before he could traverse the oedipal fantasy, thus short-circuiting Orestes' psychological development. Consequently, Orestes' only apparent purpose in life, prior to the events of The Libation Bearers, is to return to Argos to kill his mother and her new lover. The violent anger against Aegisthos is comprehensible because he has lived Orestes' oedipal fantasy: Aegisthos has murdered Agamemnon and married Klytenmestra, thus substituting himself in Orestes' place in the oedipal economy (murdering Aegisthos is, therefore, a symbolically suicidal act on Orestes' part, as he destroys the version of himself that has violated the patricidal and incest taboos). Further, Orestes' rage is directed at Klytemnestra because she also (or, rather, primarily) murdered Agamemnon, thus short-circuiting the oedipal cycle; Klytemnestra usurps Orestes' unconscious desire to kill his father, and so she becomes a substitute target for his rage. This rage culminates at the play's climax, when Orestes thrusts his sword through his mother's heart—clearly a phallic substitution for his repressed and distorted sexual desire for her.

This reading begs the question: what does it signify that Athena and the jury acquit Orestes-who does, after all, symbolically violate the incest taboo — at the end of The Eumenides? What kind of psychological foundation does the play then enact? What danger does the play run of normalizing the enactment of patricide and incest? The answer to these questions is, I think, two-fold. The first answer is that this trilogy is, like Sohokles' Oedipus the King, a performative repetition of the founding moment of culture - the moment which transcends force in favor of guilt as a means of social control. As Freud puts it, "We cannot get away from the assumption that man's sense of guilt springs from the Oedipus complex and was acquired at the killing of the father by the brothers banded together. On that occasion an act of aggression was not suppressed but carried out; but it was the same act of aggression whose suppression in the child is supposed to be the source of his sense of guilt" (Civilization 93). In other words, the aggression against the father becomes the genesis of conscience, which enforces proper behavior in the child. The second answer to the questions above is that acquitting Orestes re-enforces the status of women as property. The Oedipus complex is premised on seeing the mother as the father's property - a property which he keeps from the son, a unique property excluded from inheritance. By endorsing Orestes' innocence, despite having symbolically violated the incest taboo through his distorted enactment of the oedipal fantasy, the court founds Athenian democracy on tactic consent to the patriarchal power structures oriented and preserved by the oedipal fantasy. In other words, when read as a statement of gender politics, the oedipal myth establishes the foundational divide in Athenian society between the ekklesia (the public sphere of politics and democracy) and the oikos (the
} 
Farber's 2008 adaptation re-imagines the Oresteia as a hopeful message carrying forth the work of the TRC in healing post-apartheid South Africa. As with Aiskhulos' 458 BCE productions, Farber's play expresses a vision for the new South Africa: that the nation should transcend the violence and racism of apartheid and come together as a united nation to heal and find a way forward into the future. ${ }^{227}$ Molora's plot is based largely on the events of The Libation Bearers, with testimony and flashbacks drawn from Agamemnon. The opening portion of the play focuses on the conflict between the white Klytemnestra and the black Elektra: Klytemnestra has imprisoned Elektra and for seventeen years she was "forced to / serve in the Halls of my Father's house" (38). But, as in The Libation Bearers, Orestes returns from exile to wreak his revenge. However, unlike in the hypotext, the children do not kill Klytemnestra. As Farber said, "In the actual classic, Elektra and her brother kill their mother, but that isn't what happened in this country, ultimately. So in the moment that he is going to kill her, the women who are the chorus, who are just ordinary people from South Africa, stop and pray, and praise the courage of the children to overcome the impulse to avenge themselves" ("MoLoRa (Trailer)"). Rather than closing the sacrificial cycle of Aiskhulos, the chorus—-performed by the Ngqoko Cultural Group, about whom more will be said below—embrace Elektra and Orestes,

private sphere of home and economy). The structure of Greek democracy as a political system depended on this separation.

${ }^{227}$ Like the Osofisan plays discussed in the previous chapter, Molora is not exclusively focused on its South African context, but enters global political and cultural conversations, particularly surrounding the Iraq war. In the trailer for Molora, Farber says, "I wanted to do something I thought was very pertinent to South Africa, and also with the whole war going that just happened in Iraq, 9/11, and then the Bush administration response to 9/11, vengeance seems to be a thread that's running quite thickly through the world at the moment" ("MoLoRa (Trailer)"). Farber also writes in the foreword to Molora that, "Despite the praise Nelson Mandela received from 'First World' leaders for heralding great restraint through this transition in our troubled land, nothing could convince those same leaders to check their own ancient eye-for-an-eye, knee-jerk response and their resulting offensives of 'Shock and Awe' on the women and children of Baghdad" (7). 
giving them the choice not to kill, the choice to choose $u b u n t u$ rather than revenge. ${ }^{228}$ This decision to renounce violence is a moment of cataclysmic change.

The Oresteia represents a moment of social re-definition, a fundamental change in the logic governing Athenian society. In 1994, at the end of apartheid, the Republic of South Africa found itself in a similar liminal moment, and the TRC became the tool of re-definition. But because this was a foundational ritual, it is necessary to repeat the ritual to provide grounding for the new society, which is one reason Farber found the Oresteia such a useful model for theatrically repeating the foundational gesture of the new South Africa. Farber's adaptation is an act of faithful infidelity, remaining true to the world making project of Attic tragedy even as she modernizes the characters and situation. To return to a point I quoted in the first chapter:

Both these ancient and these modern plays are preoccupied by the paradox of the foundational moments that they represent: since these foundations of social institutions cannot be built on anything, because they are absolute beginnings, they must be ritually refounded so that they will cumulatively come to be founded on themselves. To be new, liminal events they must, paradoxically, be repeated. (Goff and Simpson 19)

In other words, the transformative moment must be repeated to establish a new ethical center through ritual. ${ }^{229}$ Theatre supports this re-performance, and by adapting both the Oresteia and

${ }^{228}$ Interestingly, The Eumenides — which establishes order, justice, and the rule of law for Aiskhulos-is almost entirely absent from Molora. There are two reasons for this: first, on a practical level if Orestes and Elektra don't kill Klytemnestra, there is no need for Orestes' trial. More importantly, in The Eumenides justice is enforced top-down by the deity Athena, rather than growing democratically from the people of Athens. Ubuntu emphasizes the importance of people, and so to sacrifice the democratic possibilities of post-apartheid South Africa would be, to some extent, to betray the dream of ubuntu and the TRC. Nonetheless, it is interesting to note that one of the most juridical plays in the Greek canon is missing from an adaptation that draws heavily from the Truth and Reconciliation Commission, which itself utilized (at least quasi-)legal rituals.

${ }^{229}$ Turner argues for "performances of rituals as distinct phases in the social processes whereby groups become adjusted to internal changes (whether brought about by personal or factional dissensions and conflicts of norms or by technical or organizational innovations), and adapted to their external environment (social and cultural, as well as physical and biotic). From this standpoint the ritual symbol becomes a factor in social action, a positive force in an activity field" (21-22). 
the TRC, Farber ritually repeats a set of founding gestures — simultaneously re-enacting the foundations of democratic justice in Athens and democratic reconciliation in the RSA. ${ }^{230}$

One element that makes Molora so powerful is the evocation, through the mise-en-scène, of the Truth and Reconciliation Commission, which had its own distinct visual and performative style. The stage directions explain that "The ideal venue is a bare hall or room - much like the drab, simple venues in which most of the testimonies were heard during the course of South Africa's Truth and Reconciliation Commission: Two large, old tables - each with a chair - face one another on opposite ends of the playing space... Upon each table is a microphone on a stand" (19). The close presence of the audience to the performance space recreates the experience of attending Commission hearings. Farber suggests that an amphitheater with raked seating on all sides is the ideal orientation. For this play, "Contact with the audience must be immediate and dynamic, with the audience complicit - experiencing the story as witnesses or participants in the room" (19). TRC hearings were often crowded with local people who had come to see, hear, and support those giving testimony, and making the audience intimately complicit with the play's events puts viewers in the position of TRC spectators.

As the first Truth and Reconciliation Commission ever to hold open hearings, South Africa's Commission was resolutely public, resolutely audience oriented (Cole xii). The TRC "was designed to restore voice, to give people who had often suffered in isolation an opportunity to publicly articulate their experiences through embodied, face-to-face encounters with audiences who listened, heard, and acknowledged" (63-64). ${ }^{231}$ Isolation and silencing are charges Elektra

${ }^{230}$ Odom claims, "By placing vivid moments of testimony within both a context that blurs the lines between past, present, and future, and a narrative that ends ambiguously, Molora suggests that, if reconciliation is to be achieved, it will have to be achieved repeatedly — and only partially" ("South African Truth" 53).

${ }^{231}$ In fact, audiences for the TRC testimony extended far beyond the people who crowded into halls, churches, and other buildings across South Africa. Cole writes, "Those who appeared before the commission gave testimony to ever-expanding layers of audiences, beginning with the language interpreters - the first line of transmission - and extending to the commissioners and lawyers, to the spectators in attendance, and to family 
repeatedly levels at her mother. In the first part of her testimony, Elektra says, "So I pay you back with / these words I could not utter before" (24, my emphasis). For the first time, Elektra has been given a forum to speak out and denounce her mother. Her voice has been restored by the microphone, and its implicit invitation to tell her story. This ability to speak-and specifically, to speak in public - about her oppression offers Elektra opportunities to reconnect with a community she had otherwise been isolated from. This is, of course, one of the fundamental aspirations of the TRC, to bring together South Africans and move as a nation toward a shared future. Elektra's bondage had separated her from the communities represented by both the chorus of Xhosa women and the audience (who again, stand in for TRC spectators, who in turn stood for the imagined national community of the new South Africa). As she says, "The man who sleeps in my father's bed / has forbidden any man to come near me" (38). In his fear of a male child to avenge Agamemnon, Ayesthus (presumably with Klytemnestra's consent) has deprived Elektra of her own family, thereby severing one of the potential pillars of communal support she might have drawn upon for strength. But as we shall see in more detail below, testimony and re-integration into that public from which she had been severed offer Elektra (and Orestes as well) a path away from violence.

The play's physical and ideological space is oriented to evoke the TRC, though it diverges to accommodate the agonistic structure of Greek tragedy. Unlike traditional trials—or the trial of Orestes in The Eumenides - the TRC did not have competing parties who tried to win their cases; it involved people testifying before a set of commissioners (and larger circles of audiences) to get compensation, justice, amnesty, or simply truth. In Molora, however, the

members, victims, perpetrators, community members, and journalists, among others. Beyond these audiences, we must consider the much larger anonymous audience tuning in throughout the country on their radios and television sets. For this group of witnesses, the commission was seen and/or heard, experienced not face to face but remotely, from their living rooms and bedrooms, while driving or working" (65-66). 
agonistic conflict between Elektra and Klytemnestra structures the play, which is why there are two tables and two microphones-from which they speak their competing testimonies. Glenn Odom argues that Molora's blend of reconciliation and tragedy is a structural weakness, which prevents either reconciliation or katharsis. He claims:

Tragedy and reconciliation contain contradictory impulses...Molora sanctions neither alternative: it averts the immediate tragic fate of its characters in a space at once general and specific, and it concludes without completing either the narrative of reconciliation or the telos of tragedy-leaving the audience in the theater, like the contemporary South African state, in a state of transition. ("South African Truth" 47-48)

For Odom this is a structural fault of the play, but I disagree. Instead, I would argue that the liminal position between these two forms in fact purposefully rejects closure because to complete the liminal ritual of the TRC or the liminoid ritual of the play is to define the new society, to delimit its potential. And the hopeful aspiration of Molora is to embrace continual possibilities for human and humane improvement.

This generic hybridity between tragedy and reconciliation becomes most apparent at the end of Molora, which puts ubuntu and the healing power of human togetherness at center stage. The chorus becomes the catalyst for forgiveness; the common people of South Africa not only impel Orestes and Elektra to renounce the cycle of violence, but they offer the children the support necessary not to take revenge. In scene xv, Orestes ritually kills Ayesthus by twirling Klytemnestra's pickaxe around his body and striking Ayesthus' blood filled boots. Orestes plucks the usurper's heart from the mess, only to find himself covered in blood (Farber, Molora 69). As we see in the "MoLoRa (Trailer)," Sandile Matsheni-who played Orestes in the original production — sinks to the ground and cradles his head in his bloody hands. He is in despair over what he has done. Ma Nosomething, played by one of the chorus women, chastises Orestes:

Mntwan'am! Kutheni ubulala nje?

Umntu akabulawa. 
Uyalazi ukuba igazi lomntu liya

kukumangalela?

Imbi lento uyenzayo.

Ungaze uphinde ubulale.

My child! Why do you kill?

A human being should never be murdered.

Do you know that human blood will haunt

you always?

What you have done is terrible.

Never kill again. (69-70).

After Ayesthus dies, Orestes urges his sister to renounce the demand for their mother's blood.

Deeply troubled by the experience of murder, Orestes drops the axe swearing to shed no more blood (75), but Elektra is determined to have her revenge, even if it means killing Klytemnestra herself. Orestes pleads, "There is still time, Sister. / Walk away. / Rewrite this ancient end" (7576). ${ }^{232}$ But Elektra declares herself a descendent of the House of Atreus, meaning that she must answer violence with violence.

For me, the two most powerful gestures in the play—both depicted in the "MoLoRa (Trailer)"- are when the chorus embraces Elektra as she charges at her mother, and when Orestes and Elektra lift Klytemnestra to her feet. While Orestes' desire for revenge is weakened after killing Ayesthus, these two moments perform the renunciation of violence in the play, and symbolically in South Africa. Both moments are described in the stage directions at the beginning of scene xix. Elektra is charging Klytemnestra when "The WOMEN of the CHORUS move swiftly as one. They grab ELEKTRA and overpower her. ELEKTRA screams in rage as they wrestle the axe from her hands. They restrain her and she finally breaks down and weeps for

\footnotetext{
232 Orestes' line here about rewriting "this ancient end" carries a multitude of resonances. On the one hand, it refers to the cyclical nature of violence in general, and of blood feuds in particular. A more specific context for this plea may be the cycle of Manichean violence that, according to Fanon, fundamentally structures the colonial (and apartheid) hierarchies and power structures. And in another sense, Orestes here speaks back to the tyranny of the agonistic structure or the plot of The Libation Bearers. This notion has been discussed earlier, as charactersespecially in Tegonni-metatheatrically choose to renounce or resist the imposition of the classical plotlines.
} 
all the injustices done to her, her brother, and her father" (77). This moment brings Elektra freedom from the cycle of violence inherent in both the tragic form and the Manichean logic of colonialism. This is, as I read it, a triumph of $u b u n t u$ over the sacrificial crisis, as described by René Girard. ${ }^{233}$ In this gesture, this communal embrace, the chorus of South African peoplethemselves victims of silencing and oppression ${ }^{234}$-reject their own potential violence, choosing instead the path of reconciliation. In an interview, the members of the Ngqoko Cultural Group, who played the chorus, explain their goal in agreeing to participate in the drama. Through their interpreter-none of the performers from the Cultural Group speak English—-they explain, "Elektra, she wants to kill her mother, and Orestes, he agrees. We try, the mamas, they try to stop it so it's not tooth by tooth, blood by blood. It's not good because it is a continuous cycle with no end, so we must stop killing, stop violence, stop wars. That's our, that's why we are singing" ("Interview"). The role of the chorus throughout the play—and I would say especially at the beginning of scene $x i x$ - is to protect the children from violence as much as possible, including protecting them from the desire for violent revenge.

It is this moment that Odom takes issue with as short-circuiting the possibility for either reconciliation or katharsis, because, he argues, the play denies a resolution. Odom claims, "Elektra's anger is purged, but not through her experience of witnessing or narrating the truth of the events that have occurred. It is the intervention of the community that allows Elektra to release her anger-or at least to commute the anger into sorrow. She experiences the beginning

\footnotetext{
${ }^{233}$ Chapter III discusses how the chorus in Greig's Oedipus the Visionary renounces the enjoyment inherent in the violent sacrifice. Elektra and Orestes go through a similar process here.

${ }^{234}$ The Chorus women are similarly victims of apartheid violence, both as characters and as people outside the fictional space of the play. On stage, the women perform as TRC witnesses, the vast majority of whom would have had their own stories and experiences of oppression. But here there is verisimilitude between the characters and the actors, because the women of the Ngqoko Cultural Group were themselves victims of the apartheid system. As the Group recounts in the "Interview," "they were affected by the apartheid because they were not allowed, for example, in 1957 the new Pass Laws were passed and the pass for the blacks was introduced, which was called Dompass, the pass for the stupid people, you see? Yes. So everyone in South Africa was affected."
} 
of a cathartic moment, but there is no suggestion of any future actions by which we might gauge Elektra's progress toward virtue" ("South African Truth" 57). ${ }^{235}$ What Odom ignores is the next gesture in the play, which does signal a movement toward reconciliation. ${ }^{236}$ After the Chorus releases Elektra, she and Orestes turn toward their mother. According to the stage directions, "They crawl towards her slowly. KLYTEMNESTRA - uncertain of what they will do to her draws back in terror. As they reach their mother, they slowly stand together and extend their hands to help her up. Once on her feet, she is a broken woman" (77). This is the moment that transcends. This is the moment that frees all of the characters - not only Orestes and Elektra, but Klytemnestra as well—from the spiral of brutality that had ordered their lives. ${ }^{237}$ Klytemnestra's breakdown in her children's arms parallels Elektra's breakdown in the Chorus' embrace.

Human togetherness, ubuntu, offers new hope and the promise of a new South Africa. This promise is reflected in the final speeches of Molora, which give voice to a cosmopolitan dream for the future and the imperative not to allow the old South Africa to dictate the shape of the new. After Elektra and Orestes help their mother to her feet, the diviner steps forward from the chorus and prays in Xhosa:

Ndiqulela umanyano lwabantu Abamhlophe nabantsundu Sinqulela abantwana bethu Bayeke ubundlobongela nokubulalana

${ }^{235}$ In fact, many who testified at the TRC did not experience a kathartic relief. Hutchison writes that for some victims of apartheid violence, "the initial narrating of traumatic memories at the TRC resulted in their feeling 'heard,' but it did not necessarily bring emotional relief from the trauma" (63).

${ }^{236}$ It's possible that the text of the stage directions changed between the original 2008 Oberon Modern Plays edition Odom cites and the 2012 reprinting I'm citing, as the stage directions Odom cites read slightly differently than my text. He cites a version of the passage from page 77 that I've cited above, but in Odom's text it reads: "women of the Chorus move swiftly as one and grab Elektra and overpower her. Elektra screams in rage...they cradle her like a child. She rages against them and finally breaks down, weeping for every injustice of the past" (Odom, "South African Truth" 57). He also cites this quote to page 85, but the 2012 reprint is only 79 pages. Nonetheless, the "MoLoRa (Trailer)" does show Elektra and Orestes helping their mother to her feet, suggesting that the gesture was not added merely for later reprintings.

${ }^{237}$ Indeed, Klytemnestra is also a victim of violence. As she recounts, "I met your father the day he opened up / my first husband and ripped out his guts. / He tore this - my firstborn from my / breast. Then holding the child by its new / ankles - he smashed its tiny head against / a rock. Then took me for his wife" (41). 
I pray for unity between black and white

We pray for our children

That they may stop crime and killing each other. (78)

This prayer carries ritual significance, and as we know, rituals have transformative power. In writing about Wole Soyinka's The Bacchae of Euripides, Van Weyenberg argues that the tyrant's death must be performed ritually to effectively free the community from the forces threatening it (68). In this ritual, this prayer, we have a similar sacrifice. Not, this time, of a tyrannical ruler like Pentheus or Klytemnestra, but the sacrifice of the jouissance of violence. Elektra and Orestes give up their vengeance, repressing their aggressive desires for the good of society, but this transition is only possible through the rites of passage-including the Chorus' intervention and the diviner's prayer - that ritually mark their reintegration into a reformed society, one which envisions the potential for a unified South Africa. ${ }^{238}$

The play's final speech, given by Klytemnestra, suggests the kind of cosmopolitan hybridity that I argue characterizes adaptation, and which I believe encodes a cosmopolitan and common worldview into the fabric of adaptation. Returning to the microphone from which she had initially given testimony, Klytemnestra says:

It falls softly the residue of revenge...

Like rain.

And we who made the sons and daughters of this land, servants in the halls of their forefathers...

We know.

We are still only here by grace alone. Look now - dawn is coming. Great chains on the home are falling off. This house rises up. For too long it has lain in ash on the ground. (79)

\footnotetext{
${ }^{238}$ Cole suggests, "Performances have the capacity to bring people together into common space across lines of past and present segregation" (150). And as we know from Turner's work on ritual and rites of passage as socially transformative performances, situating people in common spaces allows a reevaluation and restructuring of the norms which had underpinned hierarchies.
} 
Setting aside the political/ideological content of this speech, it models a complex cultural interplay of forces, which intertextually exemplifies a potential for co-existence. The first seven lines of the speech are Farber's own, lines she has written specifically for Klytemnestra, though the opening echoes Portia's “Quality of Mercy” speech from Shakespeare's Merchant of Venice. But the final five lines are drawn directly from The Libation Bearers, the second refrain of the third stasimon (or stationary choral song). ${ }^{239}$ What this means is that co-existing within this fairly short speech we have lines adapted from the Oresteia, echoes of Shakespeare, and Farber's unique composition. In other words, the passage enacts a kind of heteroglossic polyvocalism that borrows freely, recontextualizes, and builds meaning from textual interplay (since the echoing of Portia's speech is either incidental or accidental).

Adaptation is always collaborative because it relies on the interplay of new and old, the interweaving of voices, and the sharing of material. Thomas Leitch argues that adaptation is increasingly providing a model for rethinking the role of collaboration in writing in general: "authorship is always collaborative because every author depends on the assistance, example and provocation of innumerable predecessors and contemporaries, acknowledged or concealed, if only because every mode of communication by its nature involves the sharing of knowledge" (11-12). It is a truth post-structurally acknowledged that language, and therefore the use of language, is fundamentally social—we cannot speak or write without echoing others (and without ourselves being echoed by others). Adaptations simply mark their indebtedness to certain predecessors more strongly than other uses of language. According to Linda Hutcheon, one of the reasons audiences seek out adaptation is for the pleasure derived from recognizing

${ }^{239}$ Roche translates this refrain: "Look at the light that has come. / The pinch of the bridle has gone. / Lift up your heads, ye halls: too long / scattered over the ground" (Libation Bearers 147-148). This refrain is repeated twice in the stasimon. 
intertextual play: "adaptation appeals to the 'intellectual and aesthetic pleasure'...of understanding the interplay between works, of opening up a text's possible meanings to intertextual echoing. The adaptation and the adapted work merge in the audience's understanding of their complex interrelations" (117). What this means is that the heteroglossic co-existence of Aiskhulos, Shakespeare, and Farber in this speech is a fundamental component of adaptation. We have here a dynamic model of intertextuality, a model which can be traced throughout Molora. Farber's play intertextually organizes three major sources or performance modes: the Greeks, the TRC, and the Ngqoko Cultural Group. While Attic tragedy seems a fairly obvious source for an adaptation of the Oresteia, Farber's play is not limited to Aiskhulos, but draws feely from other Attic retellings of the Orestes myth. In "A Note on the Quotations” published with Molora, Farber lists her sources for direct quotations from the Greek: two translations of Agamemnon, one of The Libation Bearers, two versions of Sophokles' Elektra, and one version of Euripides' Elektra (16). As we know, Hellenic tragedy was already adaptive in the $5^{\text {th }}$ century BCE when originally staged, and Farber's choice to combine and draw from various translations of a range of Orestes and Elektra plays echoes those classical reworkings of a shared body of myth. Of course, in performance it would be almost impossible for audience members-even those with a sophisticated familiarity with various translations of Greek plays — to pick out the voices or influence of these different translators, but the printed script includes footnotes indicating the sources from the Greek. ${ }^{240}$ The key point here is that Farber freely plays with the culturally powerful myth structures, drawing from them as part of a cultural commonwealth, without demanding absolute fidelity to one particular version of the mythological predecessor.

\footnotetext{
${ }^{240}$ For instance, the final five lines of Klytemnestra's last speech are drawn from Ian Johnston's Libation Bearers translation, for which Farber provides publication information in the "Note on the Quotations."
} 
Molora makes meaning for post-apartheid RSA by putting these Greek sources and the agonistic conflict of the Oresteia into the structure of the Truth and Reconciliation Commission. The way Farber repurposes the performative practices of the TRC illustrates two important characteristics of adaptation as a form: re-enactment and the heteroglossic play of language. Re-enactment, or re-performance supports a world-building project by providing new ways to engage with, understand, and redefine the past and its implications for the future. Part of the reason there have been so many theatrical and artistic reproductions of the TRC is because the Commission's work remains unfinished-South Africa remains deeply riven by racial, socioeconomic, and ideological divides that preserve hierarchies of power, often along similar lines to those under apartheid. ${ }^{241}$ As Rebecca Schneider asserts, re-enactment highlights the continuing presence of the past, or our inability to get past the past. She explains, "it is the very pastness of the past that is never complete, never completely finished, but incomplete: cast into the future as a matter for ritual negotiation and as yet undecided interpretive acts of reworking. In this way, events are given to be past, or to become past, by virtue of both their ongoingness and their partialness, their incompleteness in the present" (33, original emphasis). In other words, the reason we re-enact the past — whether in ritual, theatre, adaptation, or the Civil War reenactments Schneider writes about — is because our present is shaped by continual negotiation over what past events mean and how they shape us. In her book on memory and performance in South Africa, Yvette Hutchison echoes this sentiment, explaining that the continual re-

${ }^{241}$ A partial list of theatrical or artistic endeavors that either directly or indirectly utilize testimony from the TRC includes: Yael Farner's testimonial plays A Woman in Waiting, Amajuba: Like Doves We Rise, and He Left Quietly (collected in Theatre as Witness), Antjie Krog's book Country of My Skull, Philip Miller's REwind: A Cantata for Voice, Tape, and Testimony, and Michael Lessac's Truth in Translation. Cole discusses and analyzes Krog, Miller, and Lessac's work in Performing South Africa's Truth Commission. 
performance of the TRC highlight gaps between the ideals of the new South Africa and the actual conditions of the nation. ${ }^{242}$

These re-enacted negotiations with memory produce physical knowledges capable of redefining archives through repeated lived experience, and Molora re-enacts one of the most iconic images of violence from the Truth and Reconciliation Commission. ${ }^{243}$ In scene viii, Klytemnestra demonstrates how she tortured Elektra to force her daughter to reveal Orestes' location. Elektra lays face down, and Klytemnestra puts a plastic bag over her daughter's head and pulls it tight around her throat. The performers hold this pose dangerously long to make the audience viscerally aware that they are witnessing the torture of a human being. According to the stage directions, "This form of torture should be a direct visual reference to the "Wet Bag Method' - graphically demonstrated at the Truth Commission, and used by South African Security Police to torture political activists during the Apartheid regime's rule" (44). Cole includes an image of Jeffrey Benzien re-enacting the wet bag torture of Tony Yengeni as part of his amnesty hearing, an incident which has become infamous in South Africa (104). ${ }^{244}$ "MoLoRa

${ }^{242}$ Hutchison writes, "It is clear that these restagings are not symptomatic of simple restorative nostalgia, an uncritical longing for the past, but suggest critical engagements with the gap between changes that were dreamt of and the realities facing contemporary South Africans" (182).

${ }^{243}$ Schneider says, "If the past is never over, or never completed, 'remains' might be understood not solely as object or document material, but also as the immaterial labor of bodies engaged in and with that incomplete past: bodies striking poses, making gestures, voicing calls, reading words, singing songs, or standing witness" (33). This is precisely the kind of physical encoding Diana Taylor associates with the repertoire, which she endorses as a supplemental mode of knowledge along with archives of documents, texts, and physical artifacts.

${ }^{244}$ In his 1999 application to the Amnesty Committee, Benzien described the torture technique: "The suspect is made to lie on the ground on his stomach, with his hands handcuffed behind his back. Benzien then sits on the small of his back, with his feet between the victim's arms. A bag soaked in water is then pulled over the head of the victim and twisted tightly around his neck, cutting off the air supply to the victim. The suspect is then questioned. From time to time, the bag is released to avoid the victim losing consciousness. The bag is only removed when the victim shows signs of wanting to talk" (Amnesty Committee). Benzien was granted amnesty after testifying to his role in the death of Ashley Kriel in 1987, the torture of seven prisoners, and perjury.

Van Weyenberg argues that Benzien's testimony failed to achieve the TRC's goals, and in fact replicated the power dynamics and psychological torment of apartheid. After demonstrating the torture, Benzien remarked that Yengeni had been quick to betray his comrades, thereby diverting attention to his victim's betrayal under duress. As Van Weyenberg puts it, "The episode described demonstrates that revealing does not necessarily result in healing. Benzien's testimony did not humble him, nor did it re-empower his victims" (111). 
(Trailer)" shows Klytemnestra's torture, which visually echoes Benzien's demonstration, with ominous overtones. This is not the only instance where Klytemnestra tortures her daughter-she also holds Elektra's face under a bucket of water, burns her arm and neck with a cigarette, and whips her-but the wet bag scene is especially chilling because of how infamous the image of Benzien is. Why, then, include such a violent and disturbing image in Molora? I think the answer has to do with the on-going process of social re-definition. The dream of the Rainbow Nation is unfulfilled, and re-enactment becomes a way of performatively re-negotiating the meaning of Benzien's demonstration. As Schneider tells us, the past haunts the present because it remains open, full of potentials, and re-enactment becomes a quest to foreclose those potentials by getting these pasts right.

One of the major goals of the TRC — with its commitments to social justice, human dignity, and providing a public forum for people silenced under apartheid—was to allow South Africans simultaneously to express themselves and speak to the nation as a whole. Whereas under apartheid, indigenous cultures and people had been repressed to privilege the white minority, the ideal of the Rainbow Nation was to restore dignity and value to the vast array of peoples and cultures that occupy South Africa. This notion that a collection of local cultures can co-exist and thrive together is a value cosmopolitans share. Cosmopolitanism is often accused of rejecting the local in favor of a homogenized global culture, but in fact cultural cosmopolitanism is incomprehensible without the differences between local cultures. Appiah describes the cosmopolitan commitment to pluralism: "Cosmopolitans think that there are many values worth living by and that you cannot live by all of them. So we hope and expect that different people and different societies will embody different values. (But they have to be values worth living by)" (144, original emphasis). There are two ethical goals here: the first being to conceptualize 
every individual culture as contingent, and the second being that some cultural values should be contested. Both of these premises are implicit in the mission of the TRC, which attempted to reshape South Africa's national culture to emphasize pluralism as a value while contesting the white supremacy that underpinned apartheid. The quest to value and emphasize South Africa's cultural heterogeneity is a fundamentally cosmopolitan goal, and one way the TRC began moving toward achieving this goal was by taking testimony in a witness' native language and translating it in real time into a multitude of other languages.

In a country like RSA, with eleven official languages and dozens more unofficial languages and dialects, these imperatives can seem mutually exclusive. To speak in one's own language - Zulu, for instance — may profoundly limit one's ability to communicate with speakers of other languages-Afrikaans, Xhosa, Swazi, English, etc. The TRC attempted to resolve this contradiction through translators, dozens of whom worked in real time to convert live testimony into major South African languages and local dialects used in the immediate area testimony was being taken. This process of simultaneous, live translation and broadcast created a bizarre echo chamber of language, of words falling over themselves and cascading in different tongues. Mark Sanders describes the experience:

One is given a headset, puts it on, and turns to the appropriate channel, and can hear the witnesses, and the questioner, speaking in a language not his or her own. Although one hears the echo, in the background, of the witness's actual words, the process of simultaneous translation means a radical dispropriation for each party: the witness speaks in Zulu, yet, as I hear him, he speaks in English. On another channel he might have been speaking Sotho or Afrikaans. Were I to have appeared before the commission, I could have been heard to speak several languages that I do not understand. (Qtd. in Cole 67)

This passage gives us a number of important impressions, including the multiplicity of voices or languages simultaneously at play over one another. Hearing testimony in English through the headset remains haunted by the echo of the original Zulu account - the spectator in the hall 
cannot but be aware that the words he or she understands are a mediation of other words he or she may not understand. Or, as Cole puts it, "the very first line of transmission of testimony was mediated and interpolated-not identical to itself" $(68) .^{245}$

The aural experience of hearing testimony, at least for those physically present in the halls where testimony was being given, worked like adaptation: layering texts upon one another while simultaneously drawing attention to the act of mediation. Molora sets up a similar interplay of languages. The translator — who disappears after the first major speech—highlights contemporary South African linguistic politics. Klytemnestra's opening lines come from the watchman in Agamemnon: "A great ox - / As they say - / Stands on my tongue," which the translator immediately renders in the Xhosa: "Ndise ndayinkukhw' isikw'umlomo" (22). On one level, this reproduces the experience of the TRC, which relied on simultaneous translation. At the same time, however, performing the English and the Xhosa highlights the aural absence of the Greek source - the Attic language remains an implied but ghostly presence in the background of the play. As we've already seen, Farber used several different English translations of Attic tragedies, a variety which is elided in performance. However, the announced presence of The Oresteia as a source for Molora implies that this is already a work in translation — staging the translator draws further attention to the politics of translation, both for adaptation and for South Africa in the era of the TRC.

As we've already seen, the Truth Commission dedicated itself to ensuring that witnesses could speak their own languages, while being heard and understood by as many South Africans

245 This disjunction between the language spoken by the witness and the language heard by the audience (though this language too is spoken, but it is spoken by interpreters) raises a number of interesting questions about the right to one's own language, the problematic colonial history of linguistic repression and appropriation, and the ethics of simultaneous, live translation. Cole does an admirable job raising these questions and considering the ethical concerns surrounding the TRC specifically as performance. 
as possible. In South Africa, language marked social/ethnic status, which is part of the reason the TRC's live translation was such a crucial means of empowering those whom apartheid had oppressed. Elektra and Orestes both speak Xhosa and are spoken to in Xhosa by the Chorus. Their ability to code switch between English and Xhosa signals the liminal position of these characters - belonging both to the world of Klytemnestra's palace and the world of the Chorus. When Elektra begins to give testimony, her first five lines are in Xhosa, followed by four in English, one in Xhosa, and then the remainder of her initial speech in English (24-25). Her language marks Elektra as distinctly different from Klytemnestra, who speaks only English throughout the play, and this linguistic difference mirrors their differences in social status under the racially defined regime of apartheid-Dorothy Ann Gould, who played Klytemnestra in the original run, is white, while Jabulile Tshabalala, who played Elektra, is black. However, in performing this dual language play, Farber and the cast undermine the kind of linguistic hierarchy propped up by apartheid, by simultaneously enacting Xhosa as a theatrical and poetic language to rival English (or Afrikaans), and by linking Xhosa language and culture with Greek tragedy — and with the cultural capital it carries. The linguistic and performative hybridity of Molora connects indigenous South African language and art with Greek tragedy, contesting the ostensible boundaries between Greek/European/white and African cultures.

One reason Farber chose to work with the Ngqoko Cultural Group was to incorporate indigenous performance — particularly umngqokolo, or split-tone singing, in which the Cultural Group specializes. This Xhosa folk music is the third major performance form Molora incorporates in its complex intertextual hybridity. From her work on testimonial plays, Yael Farber is keenly aware of the ethical issues around language and self-expression in South Africa. She explains, "There's a fundamental connection between the psyche of the country and the 
languages that people speak. The denigrating of indigenous language through colonialism is a psychic violence" (Fisher and Farber 25). This helps explain why in Molora so much of the dialogue and all of the songs are performed in Xhosa - the play tries to resist the colonialist tendency to repress indigenous languages, and joins with the TRC in allowing South Africans to engage publicly through their own languages. As the section "The Chorus Reinvented," published with Molora, says, "The envisioning of the Chorus as a group of 'ordinary' African women provides the context of the Truth Commission, which witnessed thousands of such 'ordinary' folk gathering in halls across South Africa” (13).

The Ngqoko Cultural Group's droning umngqokolo, their split tone singing, lends weight and power to Molora by evoking otherworldly forces. It is difficult to describe umngqokolowhich can be heard on the "MoLoRa (Trailer)" - but the rhythmic and resonant sound is reminiscent of other sacred forms like Gregorian chant or Lakota ritual singing. Farber's goal was "to find a group that could represent the weight and conscience of the community" to perform Molora's Chorus, and the Ngqoko Cultural Group does that (Molora 12). Umngqokolo punctuates the play, marking scene transitions and providing a backdrop for ritualized performances_-like when Klytemnestra washes Agamemnon's blood from her hands (27), or when Orestes kills Ayesthus (69). Unlike in the Attic tragedy of Aiskhulos, Farber does not write out the words of these choral songs, a gesture which reserves the power of the songs to the Cultural Group by leaving them in control of their artistry. ${ }^{246}$ The presence of the Ngqoko Cultural Group on stage also visually evokes both TRC audiences and a Greek Chorus. Stony faced and omnipresent, wrapped in their plaid blankets and head scarves, the women judge the violences done throughout the play. They hear Klytemnestra and Elektra's testimonies, as TRC

\footnotetext{
246 The one exception, where one sung lyric is written, is the opening song as the players take their places. A single member of the Chorus sings, "Ho laphalal'igazi," or, "Blood has been spilt here" (20).
} 
witnesses would have, and they render moral judgements, as Choruses in Attic tragedy do. But unlike Greek Choruses, which rarely intercede in agonistic conflicts (though they often support one side or the other as having the superior moral claim), the members of Molora's Chorus repeatedly involve themselves - almost always to resist violence. After Agamemnon's murder, Elektra delivers Orestes to the Chorus, which protects the infant (29); then when Klytemnestra tries to whip Elektra, the Chorus shelters her (40). These actions presage the crucial intervention, where the Chorus prevents Elektra from killing her mother and facilitates the movement toward reconciliation. The guiding ethical force of the chorus is $u b u n t u$, this cosmopolitan spirit of collective humanity that resists the cycle of violence.

One of the Chorus' major roles in Molora is to resist violence and help Elektra and Orestes resist violence. They offer the children an alternative to the Manichean violence that might have torn South Africa apart with the end of apartheid. Like Farber (and Osofisan, and many of the other playwrights in this study), the Ngqoko Cultural Group sees their artistry as participating in larger global conversations about ethical action and the need to renounce violence. Their interpreter explains, "What is happening outside in the world now, the wars, the conflict, the defenses, so if we can work together towards love then relationships build on relationships, that's what can be, so there's a place for everybody. Eh? Stopping wars? What is happening in Libya, what is happening elsewhere in the world, it's not good" ("Interview"). In other words, the Cultural Group envisions the ethical dimension of their art as engaging with global patterns of violence, with global patterns of exploitation, oppression, and dispossession. As black South African women, the members of the Ngqoko Cultural Group have grown up in a country where they experienced discrimination and dispossession continuously. And while they work to keep Xhosa traditions alive, they also envision their preservation efforts as part of a 
worldwide resistance to violence and oppression. This is not an organized/centralized resistance, but an identification with what Hardt and Negri term the multitude.

Hardt and Negri believe that the multitude stands in fundamental opposition to the systems of exploitation that support neoliberal capitalism. The multitude is, simply defined, all those whose labor is interpolated under the capitalist mode of production, which increasingly includes not only agricultural and industrial workers but those producing knowledges, codes, and immaterial products. ${ }^{247}$ The multitude is globally diverse: "an internally different, multiple social subject whose constitution and action is based not on identity or unity (or, much less, indifference) but on what it has in common" (Multitude 100). In this sense, the multitude is fundamentally cosmopolitan, in the sense that its social constitution cuts across the ostensible differences of local culture and national boundary to form a diverse collectivity. ${ }^{248}$ For Hardt and Negri, the quintessential space of the multitude is the metropolis, which is not merely the city, but a way or organizing the encounters within a shared space politically. The metropolis is, first, a space governed by the common, and second, a space of encounters with difference. They explain, "The metropolis is the site of biopolitical production because it is the space of the common, of people living together, sharing resources, communicating, exchanging goods and ideas" (Commonwealth 250), and the metropolis is the site of "the unpredictable, aleatory encounter or, rather, the encounter with alterity" (Commonwealth 252). In other words, the

247 The multitude has a paradoxical relationship with global capitalism, as capital simultaneously feeds on the multitude and is threatened by it: "When the flesh of the multitude is imprisoned and transformed into the body of global capital, it finds itself both within and against the processes of capitalist globalization. The biopolitical production of the multitude, however, tends to mobilize what it shares in common and what it produces in common against the imperial power of global capital" (Multitude 101).

${ }^{248}$ The productive power of the multitude is far greater than capital's ability to utilize and turn into financial gain, because the multitude is the only entity capable of creating true democracy: "the multitude is living flesh that rules itself...the challenge of the multitude is the challenge of democracy. The multitude is the only social subject capable of realizing democracy, that is, the rule of everyone by everyone" (Multitude 100, original emphasis). 
metropolis need not be an actual urban space, so much as it is a shared space in which singularities encounter one another, and encounter difference, to produce the common.

In this sense, both the new South Africa and the theatre can become spaces of the common, spaces of productive biopolitical encounters. In promoting ubuntu as an ethical philosophy, the TRC imagined a South Africa in which people of all ethnic groups, races, and cultures could exist in harmony, growing stronger through mutual support and by learning from one another. This is a vision that assumes, like cosmopolitanism, that individual cultures consist of contingent responses to the problems facing human beings, and that other answers may also be legitimate. Ubuntu also suggests that through cooperation, and through mutual understanding we can develop a more just and humane world. As we have already started to see-and will see in more detail in the Conclusion - theatre and performance can also open the possibility for mutual understanding and cosmopolitan interconnection. Theatre asks us to see characters with empathy, and to understand their desires, hopes, concerns. Often these characters come from different places than we as spectators do, but encountering them in the theatrical space can produce an openness to alterity that underpins cosmopolitanism and $u b u n t u$, and embeds us with the common.

Molora exemplifies the possibilities of a cosmopolitan commonwealth by blending Aiskhulos' Oresteia with Xhosa cultural songs, performances, and language. The play contests notions of cultural ownership or patrimony by situating a "Greek" hypotext alongside contemporary living cultures. Through an implicit faith that these ancient tragedies are not merely the cultural property of one people or continent, Farber models ways in which a 
cosmopolitan commonwealth already functions, and offers a hope that such a commonwealth could be extended in further resistance to capitalism.

The ubuntu ethic of Molora particularly emphasizes this moral position. Farber's play, perhaps more overtly than the others studied in this project, encourages a notion of human togetherness rooted in an ethical awareness of our responsibility to others, both to treat other people kindly and to find and celebrate points of connection with cultures other than our own. Most audience members seeing Molora would be unlikely to speak Xhosa, but that linguistic challenge does not alienate us from either the play or from the Chorus. The production gains moral and performative strength from the blending of cultures, which highlights and enacts our ability to resist oppression and exploitation through communal action. When the Ngqoko Cultural Group embraces Elektra to stop her killing Klytemnestra, it is the embodiment of umbuntu, the embodiment of the power of the multitude to counteract cycles of violence through creativity and mutual support. One of the fundamental goals of the TRC, informed by the ubuntu philosophy, was to find collective ways of making or revealing truths. Through its heteroglossic play of voices and sources, and through its thematic suggestion that cycles of violence can be broken when communities come together to provide mutual support, Molora promotes this ethic of human togetherness. However, this is not unique to Farber's play. I argue that this kind of cosmopolitan collaboration and openness to alterity is a fundamental aspect of adaptation and theatre. 


\section{Conclusion}

\section{Buying Thebes: Or, You Get What You Pay For}

This project's title is inspired by Moira Buffini's Welcome to Thebes. I have tried to explore the ways in which contemporary theatrical adaptations of Greek tragedy resist and offer an alternative to neoliberal capitalism through the enactment of cosmopolitan collaboration. I have tried to problematize the notion of buying Thebes, which here stands via synecdoche for the whole realm of Attic tragedy. And what exactly is it that neoliberalism seeks to buy? It is nothing less than the entire productive means of society—not merely, as with industrial capitalism, the means of producing, transporting, and selling goods, but the entire apparatus of producing, maintaining, and reproducing society as such. Under the neoliberal regime of immaterial labor, "the production involved here is the production of subjectivity, the creation and reproduction of new subjectivities in society. Who we are, how we view the world, how we interact with each other are all created through this social, biopolitical production" (Hardt and Negri, Multitude 66, original emphasis). On the one hand, the new subjectivities that neoliberalism attempts to impose are singular, anxious identities driven by the imperative to enjoy—-to buy, to consume, to keep up with (or ahead of) the Joneses. As Todd McGowan puts it, "The society of enjoyment works to convince subjects that they exist outside this society, in independent isolation. It thus becomes increasingly difficult to grasp oneself within the universal" (End of Dissatisfaction 193). However, the fundamental argument of this project is that, as collaborative forms, theatre and adaptation model the working of a cosmopolitan commonwealth, offering an alternative to neoliberalism.

To state the case very simply and directly: theatrical adaptation exemplifies the working of a cultural commonwealth because it taps into collaborative wisdom and undermines notions of 
cultural ownership that help construct arbitrary dividing lines between cultures; therefore, adaptation challenges notions of essential difference in favor of cosmopolitan empathy. Theatre and adaptation each help us see ways in which hybridity and communal wisdom help construct better solutions to global problems than individualist neoliberal capitalism. In his book The Wisdom of Crowds, James Surowiecki makes the case that aggregated group decisions and opinions are often more accurate, beneficial, and consistent than even the smartest individual answers. However, one of the major qualifications Surowiecki includes is that the group must incorporate a range of different opinions or it ends up with an echo chamber that negates the positive value of working as a group. He writes, "Diversity and independence are important because the best collective decisions are the product of disagreement and contest, not consensus or compromise...Paradoxically, the best way for a group to be smart is for each person in it to think and act as independently as possible" (xix-xx). If we take this argument seriously, it follows that the greater input available on solving problems facing a globalized world, the better solutions we're likely to come up with. ${ }^{249}$ In terms of a cosmopolitan common, Surowiecki's thesis implies the value of open access to information in order to fashion a knowledgeable, savvy, and sophisticated global polity. In other words, a global information commonwealth may help humanity solve some of our most troubling challenges.

${ }^{249}$ This may suggest the value of some form of democratic world government, though cosmopolitans disagree on what that should look like. Of the various plans and arguments for a world government I've read, I am most drawn to the scheme Pogge proposes. Essentially, Pogge suggests developing a flexible and democratic network of governments, each with some degree of authority to check the power of those above or below it. He explains, "the proposal is that governmental authority - or sovereignty - be widely dispersed in the vertical dimension. What we need is both centralization and decentralization - a kind of second-order decentralization away from the now dominant level of the state. Thus, persons should be citizens of, and govern themselves through, a number of political units of various sizes, without any one political unit being dominant and thus occupying the traditional role of state" (120, original emphasis). In other words, Pogge envisions a web of governmental levels, where the individual citizen's identity is as tied to a neighborhood as it is to a nation or to the world. One major concern about such a structure would be the difficulty posed by the massive bureaucracies that would likely evolve to staff these multiple levels of government, all asserting their sovereignty and exercising power with and against one another. 
In order to achieve this kind of educated global polity, Hardt and Negri advocate creating a shared information and culture infrastructure. ${ }^{250}$ The purpose of this commonwealth of knowledge would be to free the creative potentialities of the multitude_or, as Surowiecki might put it, to produce a global crowd of independent individuals each contributing to the group, which benefits from the aggregated knowledge. According to Hardt and Negri, this kind of information commonwealth would not only be antithetical to the ethos of capitalism, but would actively destroy the networks of ownership that currently underpin neoliberalism. They write:

an open infrastructure of information and culture would have to be constructed to develop fully and put into practice the multitude's abilities to think and cooperate with others... Such a common infrastructure would counter the mechanisms of privatization, including patents, copyrights, and other forms of immaterial property, which prevent people from engaging the reserves of existing ideas, images and codes to use them to produce new ones. (Commonwealth 308)

In other words, the commonwealth logic of shared access to cultural, performative, and scientific knowledge undermines notions of immaterial property ownership that currently delimit who is legally allowed to use ideas, images, and codes. Or, as Surowiecki puts it, "The assumption is that society as a whole will end up knowing more if information is diffused as widely as possible, rather than being limited to a few people" (164).

The logic of capitalism, which is fundamentally a logic grounded in property ownership, denies the organic movement and development of knowledge and culture by imposing legal or moral restrictions. Both Appiah, in his book on cosmopolitanism, and Fischer-Lichte, in her book on contemporary adaptations of The Bacchae, acknowledge how the natural fluidity and development of culture conflicts with notions of cultural ownership, or patrimony. Appiah explains, “"cultural patrimony' refers to the products of $a$ culture: the group from whose

${ }^{250}$ They explain that one element of this would be a global education system, "which provides mandatory education for all, starting with literacy and working up to advanced education in the natural and social sciences as well as the humanities" (Commonwealth 308). 
conventions the object derives its significance. Here the objects are understood to belong to a particular group, heirs to a trans-historical identity, whose patrimony they are" $(118$, original emphasis). ${ }^{251}$ Appiah argues that under the biopolitical logic and identity politics of late capitalism, cultural products, processes, and performances have increasingly become protected under the same laws that preserve individual copyright. For Appiah, the problem with this is that "protection, here, involves partition, making countless mine-and-thine distinctions. And given the inevitably mongrel, hybrid nature of living cultures, it's doubtful that such an attempt could go very far" (129). In other words, to remain vibrant and vital, cultures must be able to grow, develop, and find new solutions to new problems.

Fischer-Lichte makes the same point about contemporary adaptations of Greek tragedy. She asserts, "no culture can be conceptualized as monadic. They all have elements in common and are in principle able to incorporate new elements from each other. Cultures in a globalizing world in particular constantly engage in exchanges of all sorts" (Dionysus Resurrected 128). However, as she points out, modern Greeks are deeply invested in Athenian tragedy as a part of their cultural inheritance, forming a deeply-rooted part of Greek identity. She analyzes the response to Theodoros Terzopoulos' 1986 production of The Bacchae at Delphi. Terzopoulos was accused of reducing Euripides play to a mere ritual and of abandoning performance styles that were distinctly Greek for Japanese influence. Based on the generally negative response, Fischer-Lichte concludes, "this production's aesthetic... appeared to redefine the concept of

\footnotetext{
${ }^{251}$ This logic of cultural ownership presents any number of problems when examined critically. For instance, there is the issue of who properly belongs to a certain group. My father's family are Jewish, but since the time I was born he rarely practiced apart from attending weddings and bar or bat mitzvahs. My sister and I went to a few different Protestant churches as children, but then stopped going to any religious services by the time we reached high school (though my mother still attends a Protestant church). To what extent, then, do I have cultural ownership of Jewish customs, rituals, ideals, etc.? How much of a right do I have to Jewish culture? And the same may be asked about Christian ritual and culture. Another problem, as we will see momentarily, is that cultures and peoples change over time.
} 
Greekness in a way that critics and audiences experienced it as an insulting attack and threat to their cultural identity" (Dionysus Resurrected 123). This visceral investment in the "essential Greekness" of the ancient tragedies raises a problem and contradiction inherent in the notion of cultural patrimony, namely, that the people who experience cultural forms or artifacts today often live in significantly different contexts than their ancestors who produced ancient forms. ${ }^{252}$ Eleftheria Ioannidou argues that performing Attic tragedy, particularly in ancient theatres, becomes a way of eliding contemporary conditions of Greek culture-especially the painful memories of Ottoman occupation. ${ }^{253}$ This quest for a static image of cultural purity is antithetical to both the hybrid nature of living cultures and to theatre.

Dan Rebellato argues that one aspect of theatre making it ideally suited to conveying a cosmopolitan worldview is that it encourages us to imagine possibilities beyond any given singular performance. Theatrical performance, like other kinds of performances, are heavily loaded with potential meanings, and any individual production collapses these potentialities into a single event. However, the resonances of other possible performances continue to haunt the stage, as Marvin Carlson might say. With theatre, "the literal facts of what is happening (a few actors walking around a stage shouting) do not exhaust the meaning of the experience; everything seems additionally charged with significance, and the more artistically satisfying the theatre is, the more inexhaustible this significance feels" (Rebellato 84). Theatrical performance

${ }^{252}$ The Greeks are an excellent example of this. To take just one distinction, the overwhelming majority of modern Greeks identify with the Greek Orthodox faith, rather than the polytheism of their ancestors. It's not immediately evident how much claim Greek Christians should have to cultural ownership of plays written and performed in honor of the pagan god Dionysos, which often feature deities like Athena, Apollo, or Artemis.

${ }^{253}$ She argues that, "The illusionary conflation of ancient past and Greek present experienced during the performance in ancient theaters seems to compensate for contemporary Greek reality. Since the first modern stagings in ancient theaters, performances were expected to propagate the idealized view of modern Greece as an inheritor and successor of classical antiquity. In this respect, the heterotopia of the ancient theater strove to efface aspects of modern Greek reality which would attest to Greece's Ottoman and other non-Greek legacies" (390). What is particularly ironic about this quest to return to an imagined cultural purity is that, as Bernal argues, ancient Hellenic culture was deeply shaped by the cultures of other eastern Mediterranean civilizations. 
gestures toward realities beyond the practical limitations of the stage. Shakespeare can take us to Agincourt or to Oberon's enchanted forest, Beckett can dissolve space altogether, Churchill can put a man onstage as a little girl and a white actor as a black African. At the same time, any particular performance could have been produced differently. Laurence Olivier, Mel Gibson, and David Tennant gave three very different performances of Hamlet, but they all represented a potential encoded in the play. In this space of theatrical possibilities, Rebellato locates a deeply cosmopolitan breadth: "What we are encountering here is the universal structure of the mind in an unusually pure form: in aesthetic experience we momentarily disengage from the particular set of concepts that each of us has and we experience our common humanity" (84). Rebellato may somewhat overstate his case here, but fundamentally I agree with his assertion that theatre has the power to dissolve - if only for a short time - the differences of identity that divide us, bridging the specifics of culture and upbringing to find or create points of connection.

In fact, I would argue that theatrical adaptation shows us ways in which this cosmopolitan commonwealth already functions despite - and I would suggest in resistance toneoliberal capitalism. In his essay “Does Democracy Mean Something?” Jacques Rancière describes the protests of feminists during the French Revolution, who were denied political rights under the new constitution. However, "through their very protest, these women demonstrated a political capacity. They showed that since they could enact those rights, they actually possessed them" (57). In other words, through the enactment of the rights ostensibly denied them, the (proto-)feminist protesters generated their political rights by enacting them. By analogy, theatrical adaptations enact a cosmopolitan form of cultural commonwealth by behaving as though the commonwealth already exists. ${ }^{254}$ The plays I have discussed in this study do, I think,

\footnotetext{
${ }^{254}$ Surowiecki points out that scientific knowledge also exists - at least in many cases — in a shared and collaborative space, thereby also enacting a scientific common. He writes, "Science is collective because it depends
} 
perform many of these cosmopolitan values as though the commonwealth were already social reality. Specifically, we see in these plays collaborative elements like the blending of genres, relocating Attic tragedies into widely divergent contexts, and the renunciation of sacrificial violence. All of these gesture toward a collaborative mode of world-making.

One of the most important tendencies of contemporary adaptation is the blending of genres - tragedy, song, ritual, even the TRC — to produce generic hybridity, modeling the collaborative ethos of cosmopolitanism. Music played a major role in Attic tragedy, though Victorian classicists largely repressed the role of music and dance to create a more "dignified" impression of the Greeks. However, many modern dramatists include not only music, but a variety of culturally-influenced musical styles. Teevan's Alcmaeon in Corinth incorporates “four contrasting musical themes - the 'Cock o' the North' chant, the rhythmic, consolatory weaving song, the dissonant madness theme, and the hymn to sexual desire, whose tonality is Spanish and Moorish" (Hall, Introduction, 12). Farber's Molora and both Osofisan plays incorporate African song, dance, and rituals. From the Ngqoko Cultural Group's umngqokolo singing to the songs the Owus sing to preserve their culture, African musical traditions become deeply intertwined with the Greek source material. The important point here is that this generic interplay is not merely incidental, but represents a culturally collaborative approach to performance. Contra some critiques of intercultural performance, the production of generic blending here becomes a

on and has tried to institutionalize the free and open exchange of information. When scientists make an important new discovery or experimentally prove some hypothesis, they do not, in general, keep that information to themselves so that they alone can ponder its meaning and derive additional theories from it. Instead, they publish their results and make their data available for inspection. This makes it possible for other scientists to reconsider their data and possibly refute their conclusions. More important, though, it makes it possible for other scientists to use that data to construct new hypotheses and perform new experiments" (163-164). Two contemporary limitations on this freedom of information are the tight control maintained by many corporations on their own research and development, and the increasing cost to access scholarly and scientific periodicals and other publications. Both of these trends limit the possible spread of data, thereby hobbling the creative potential of the multitude, which is cut off from data, ideas, codes, and information that could otherwise support its creative potential. 
cosmopolitan gesture undermining notions of cultural ownership through the hybridity of living cultural texts-textual combinations of meaningful performance styles into new theatrical experiences rather than respecting notions of cultural distinction.

Conceptions of cultural patrimony become even more tenuous as adapters relocate ancient Greek tragedies to various contemporary or historical locations, undermining an easy association between the Attic plays and Greek or "Western" spaces. By the Bog of Cats shifts the action of Medea to 1990s Ireland; Farber and Grieg locate their plays in South Africa; and Osofisan in Nigeria. But perhaps more interesting are the plays that attempt— to one degree or another - to deny grounding in a specific space; plays which leave their visual aesthetic open to individual artistic decisions by directors or ensembles. For instance, Alcmaeon in Corinth was originally performed in Newcastle and the production utilized a local aesthetic, but there's nothing textually that would require a contemporary urban British feel for a show. The mise-enscène could as easily evoke Kolkata, Tokyo, or Mexico City without compromising the play's meaning and thematic concerns. Similarly, Welcome to Thebes was produced at the National Theatre with West African costuming, but the aesthetic could easily be relocated to any war-torn area. We may recall that the setting given in the published version of Buffini's play is: "A city named Thebes, somewhere in the twenty-first century" (2, my emphasis). Instead of locating the play geographically or visually, this setting reminds us of the ubiquitous nature of military conflict in the $21^{\text {st }}$ century, providing future directors with any number of options. But Trojan Barbie gives us perhaps the most direct challenge to the rooting of a play in a particular time and place. Evans' unstable, postmodern play shifts fluidly back and forth between modern London, ancient Troy, and modern Troy. Lotte leaves her London business to travel to modern Troy and gets drawn backward into the past of the (somehow partially modernized) Trojan War. She 
finally escapes back into the present, but Hecuba manages to make her way into that present as well - as the stage directions put it, "as if she had crawled into the $21^{\text {st }}$ century from the bottom of the ocean" (66). This playful instability denies any specificity of time and place by enacting kaleidoscopic shifts. According to Rebellato, this kind of "de-territorializing ambiguity" (79) evokes cosmopolitanism by collapsing the moral distances that may seem to parallel geographic distances: "What the play's cosmopolitan movement does is render the moral significance of 'far away' meaningless" (81). In other words, by shifting the terrain upon which ancient Greek tragedy plays out, these contemporary adapters de-territorialize both the Attic hypotexts and the modernized settings - the ostensible differences between spaces and places come to represent potential connections rather than boundaries demarcating rival nations and cultures.

Finally, one common — though by no means universal — aspect of these plays is the renunciation of enjoyment in one form or another. Most notably in Oedipus the Visionary and Molora characters short-circuit the normal tragic trajectory by foregoing the violence of the Greek predecessor: Oedipus is not cast from the community as he was in Sophokles, and Elektra and Orestes don't kill their mother as they do in the Aiskhulos. Along the same lines, Alcmaeon spends much of Teevan's play resisting his sexual desire for his (unknown at the time) daughter. This gesture of renunciation is an important symbolic act of resistance against neoliberalism, which, as I have tried to show throughout this project, is premised on an ideological, psychological, and monetary economy of excessive enjoyment. As McGowan reminds us, the late capitalist world is a world immersed in signs commanding enjoyment through consumption: "With the proliferation of advertisements (all promising immediate and incredible enjoyment)...one cannot exist for long in late capitalist society without being confronted by signs of or inducements to great enjoyment" (End of Dissatisfaction 30-31). However, as 
enjoyment becomes more and more the central social imperative, subjects enter a vicious cycle wherein the quest for enjoyment increases only the anxiety of desire. Žižek writes, "the realization of desire does not consist in its being 'fulfilled,' 'fully satisfied,' it coincides rather with the reproduction of desire as such, with its circular movement" (Looking Awry 7). This cycle of desire, this quest for enjoyment, undermines social cohesion by setting every individual against all others in a competition to achieve the social imperative: full enjoyment. ${ }^{255}$ Therefore, resisting the imperative to jouissance, whether through sexuality or aggression, takes a stand against the logic of neoliberalism. Instead, these characters who renounce their enjoyment behave empathetically, imagining and putting the needs of either specific others or the community as a whole before their own enjoyment. This is precisely the kind of ethical choice that moral cosmopolitanism often compels us to make - to regard every human being as endowed with rights, and to regard ourselves as always having moral obligations to others.

One major caveat to seeing these plays as evocations of a cosmopolitan commonwealth is the relatively limited access to live performance, and in some cases to printed texts of the plays. When trying to build a global common, we must be keenly aware of the problems and privileges of access, particularly in the division between global north and global south. Theatre practitioners in Africa, for instance, often face significant logistical obstacles that complicate the production of plays. Osofisan argues that, particularly with the rise of the film industry in

${ }^{255}$ McGowan ties aggressiveness to competition over (perceived) enjoyment: "If the other appears to have the objet petit $a$, the secret of enjoyment that rightfully belongs to the subject - and if the other publicly parades this objet petit $a$ - then the subject feels no duty to civility. The absence of civility in the society of enjoyment indicates the extent to which the subject in this society remains lacking. That is to say, the contemporary subject becomes uncivil because she/he continues to be haunted by her/his own lack of enjoyment. If we were really enjoying ourselves today, we would not develop aggressiveness in response to the other's enjoyment and believe that this enjoyment is rightfully ours" (End of Dissatisfaction 177-178). Of course, neither human aggressiveness nor the envy of the other's enjoyment are uniquely late capitalist phenomenon, but through a continual bombardment of advertising, as well as the increasing visibility of conspicuous consumption throughout (at least Western) society, the anxiety caused by denial of enjoyment is wider spread and more central to social life than ever before. 
Nigeria, West African interest in theatre has declined significantly. He says that in Nigeria, "live performances have almost completely disappeared, sustained only by the brave efforts of individuals such as Ogundokun and his Renegade Theatre company. But even then their efforts to overcome the situation are only spasmodic, and their impact is limited to Lagos, and to a clientele of diehard aficionados in an elite neighborhood of the city" ("Shakespeare" 8). Given that many global south nations have large impoverished and rural populations with limited access to the internet and other telecommunications - what scholars have termed the "digital divide"-live performance has been a traditional way of disseminating information and preserving or transforming culture. However, as public support for the arts declines (unevenly, but generally across the globe) under neoliberal "austerity," it becomes more and more difficult to produce theatre critical of the economic and political establishment, as commercial theatres are less likely to take on subversive or politically charged works. In the global south, where national economies have often been restructured according to neoliberal mandates from the IMF and the World Bank, the logistics of supporting theatre communities are especially imperiled.

Theatre by its lived nature involves inherent limitations on access, because it is not always possible to see an actual performance of a play. While I happened to see a performance in the initial run of Welcome to Thebes, I haven't seen live performances of any of the other adaptations discussed in this project. One obvious limitation of access is travel. If By the Bog of Cats is staged in Dublin, Tegonni is staged at Emory University, and Molora is staged in Johannesburg, it isn't practical to see all of those shows (however ideal it might be). Because theatre is staged and modern plays function under copyright and (almost always) require licensing for performances, this limits the number of people who can actually see a particular 
show. ${ }^{256}$ Along with this, the cost of shows limits the range/type of audience likely to go to some performances. The National Theatre production of Welcome to Thebes likely drew its audience principally from a somewhat affluent theatre going population, but access to the National Theatre is probably limited for many impoverished people in contemporary London. Even access to printed play texts can be limited by economic inequality. Because of limited publication runs from the printers in Nigeria, Tegonni is incredibly difficult to get a hold of (I borrowed the only copy listed in my library's interlibrary loan network, and have spent a few years waiting for a copy to come available for purchase online for my own collection). The upshot of all of this is that building a global commonwealth will require overcoming serious limitations posed by inequality and limited access to shared cultural materials.

Another major concern in enacting such a cosmopolitan commonwealth is the continuing capitalist structure of theatre, which must be considered in two important senses: the exploitation and instability of theatrical labor, and performance's status as commodity. There is substantial debate over whether or not theatre can function as a commodity. Some argue that because theatre is ephemeral and doesn't produce a lasting physical product, it cannot fall within Marx's definition of the commodity. However, Michael Shane Boyle argues that the more important valence is the social relations encoded in theatre. In Boyle's reading of Marx, an object or service acquires commodity status through the social relations between a capitalist and laborers - that is, through the process wherein a capitalist accumulates profit generated by labor's creative addition to invested capital. Boyle argues that in this sense, theatre (often) establishes two different sets of social relations, and therefore exists simultaneously as a

\footnotetext{
${ }^{256}$ Even finding materials on a particular show can be quite challenging, since some theatres or productions don't maintain substantial or accessible archives of materials. I wasn't able to find virtually any materials from Almcaeon in Corinth or Tegonni, even by querying authors and the theatres themselves.
} 
commodity and as a non-commodified service. On the one hand, there is an audience which pays to see a show. The audience's social relations to theatre laborers are guided by the use value of the show, because audiences cannot, generally speaking, resell for profit the experience of seeing a performance. On the other hand, the theatrical entrepreneur - a financial backer who puts up money to support a show in exchange for a return on that investment-experiences the performance as a commodity, in the sense that there is an initial capital investment, labor adds to the value of that investment, and the entrepreneur realizes a profit. As Boyle puts it, the entrepreneur "purchases 'temporary disposal over the labour-power' of the performer. In doing so the entrepreneur becomes a capitalist and the performer a laborer, and they relate to each other socially as capital and labor. The capitalist does not consume the commodity as a use value, but transforms it into a vendible commodity to sell 'to the audience'" (12). In other words, it is the social relations between the various parties - audience, theatrical laborers, and theatrical entrepreneur - that determine the commodity status of a theatrical performance.

In this schema, it becomes clear that theatrical laborers are laborers, that their labor is often exploited within a capitalist mode of production, even when the content of a particular performance is anti-capitalist. ${ }^{257}$ Boyle argues that when actors perform in theatres interpolated within capitalist social relations, the positive content of those performances are overshadowed by the structural exploitation of the performance as labor: "It does not matter if an actor performs the actions of a military general or a prisoner, a miner or a mother, a teacher or a politicianfrom the perspective of capital each of these activities when performed in a theatre organized along capitalist lines is a potential source of surplus value" (19). In other words, performers

\footnotetext{
${ }^{257}$ Boyle does recognize that many theatres do not rely on this capitalist set of social relations, and therefore many productions fall outside this scheme: "Although theatre can be organized along capitalist lines, counterexamples like community theatres, nonprofit theatres, student theatres, amateur theatres, and even statesubsidized theatres are obviously more the norm than the exception" (19).
} 
remain interpolated within a profit-generating capitalist structure even in shows which protest, critique, or condemn capitalism. Further, theatres often reproduce the hierarchies of capitalist society in microcosm, through divisions like the one between visible labor (i.e., actors, musicians, dancers) and invisible labor (i.e., stage hands, tech people, costumers, etc). Christin Essin argues for recovering this invisible labor and conceptualizing theatre as a communal artistic production, relying on the input of a wide range of workers. In tracing the labor of lighting technicians in the original Broadway production of A Chorus Line, Essin writes, "A production history that augments performers' experiences by recovering technicians' backstage labor, therefore, potentially lays bare the collective labor necessary to deliver a long-running production night after night" (199, original emphasis). In other words, both the social relations between capitalists and labor outside theatre, and the hierarchies of seen versus unseen labor within theatre present challenges and limitations to a genuinely egalitarian theatre.

How exactly these limitations and inequities can be overcome is beyond the scope of this project, though I think the three goals proposed by Hardt and Negri might give us a good starting point. They call upon the multitude to demand, first, a global minimum wage to support a basic standard of living with access to food, water, and shelter; second, universal access to education, including technical and social knowledges; third, the elimination of private property to free the productive capacity of the multitude (Commonwealth 380-381). This is what Hardt and Negri term "a political program against misery, meaning by misery not only the lack of wealth and resources but also and more generally the lack of power to create and innovate, to rule oneself. Misery is the condition of being separated from what one can do, from what one can become" (Commonwealth 380). This is, in other words, a political program antithetical to the logic of neoliberalism. Instead of privatizing every resource for individual/corporate ownership, this 
program would reject both private and public (in the sense of government ownership) schemes in favor of a radical accessibility of information, resources, ideas, and cultures. This kind of global political re-organization would require a massive shift in how we conceptualize the role of government, from its current status in neoliberal ideology as guarantor of contracts and protector of private property, to a truly democratic entity principally responsible for ensuring the distribution of resources throughout the multitude. The only way Hardt and Negri envision such a radically democratic society being constructed is through the living will of the multitude, which consists of all those whose labor is structured within global capitalism, producing a shared world. The forces of global capitalism will resist and repress the self-consciousness and expression of the multitude with all their power, for the very existence of capitalism itself is at stake.

However, in the true spirit of dialectic materialism, the neoliberal regime of biopolitical production sets the stage for its own usurpation by the common. As Hardt and Negri explain, the potential productive capacity of the multitude is unlimited, and it will always exceed capitalism's ability to convert that production into profit. ${ }^{258}$ More importantly, biopolitical production is a self-sustaining system, wherein the production of social codes, values, affects, images, ideas, and performances begets further production. Creation is neither ex nihilo nor an end point:

The production of ideas, images, and knowledges is not only conducted in common-no one really thinks alone, all thought is produced in collaboration with the past and present thought of others - but also each new idea and image invites and opens new collaborations. The product of languages, finally, both natural languages and artificial languages...is always collaborative and always creates new means of collaboration. (Hardt and Negri, Multitude 147)

${ }^{258}$ Hardt and Negri write, "Our innovative and creative capacities are always greater than our productive labor-productive, that is, of capital. At this point we can recognize that this biopolitical production is on the one hand immeasurable, because it cannot be quantified in fixed units of time, and, on the other hand, always excessive with respect to the value that capital can extract from it because capital can never capture all of life" (Multitude 146, original emphasis). 
In other words, the very processes late capitalism utilizes to produce the surplus of meaning, value, and immaterial products spawn continuing cycles of collaborative production, cycles which exceed (and potentially undermine) capitalist attempts at disciplinarity.

It is in this way that adaptation becomes an exemplary form of potential resistance. The creative re-imagining, re-purposing, and hybrid combination of ideas, images, performances, affects, etc. involved in adaptation simultaneously begins from and builds upon the common. In taking culturally shared texts and making them meaningful in new ways-particularly new ways that bridge distances between strangers - adaptation taps into the productive potential of the multitude. However, this ability to adapt and to combine differing performance traditions into new, hybrid plays depends on an open and shared access to cultural forms. Plays by the Greeks, Shakespeare, Ibsen, Moliere, etc. lend themselves to adaptation partially because they are established and revered texts, but also because they are not protected by copyright laws. However, works by these authors are sometimes regarded as the cultural patrimony of the nations in which those authors lived, or of Europe as a whole. These forms of immaterial ownership limit access to ideas, knowledge, codes, linguistics, etc. in ways that stunt the growth and development of a vibrant commonwealth expanded by the creative powers of the multitude. Adaptation represents the kind of creative hybrid power of the multitude, the ability to find new ways of combining cultural forms to solve problems or respond to crises with dynamic and experimental solutions. Against this openness of information, culture, and productivity, neoliberalism accelerates the capitalist tendencies of accumulation, individual ownership, economization of social processes, and institutionalized cycles of economic crisis. Neoliberal capitalism is not sustainable, but the cosmopolitan commonwealth exemplified by theatrical adaptation gestures toward one possible alternative. 
Works Cited

“16 Things Businesses Hate About South Africa.” BusinessTech, 8 Oct. 2016, https://businesstech.co.za/news/government/138875/16-things-businesses-hate-aboutsouth-africa/.

Aeschylus. The Eumenides. Orestes Plays, pp. 155-202.

- - -. The Libation Bearers. Orestes Plays, pp. 101-153.

- - -. The Orestes Plays of Aeschylus. Translated by Paul Roche, Meridian, 1996.

Agamben, Giorgio. Homo Sacer: Sovereign Power and Bare Life. Translated by Daniel HellerRoazen, Stanford UP, 1998.

American Repertory Theatre. “Trojan Barbie: Media.” 2012, http://americanrepertorytheater.org/events/show/trojan-barbie.

Amnesty Committee. "Application in Terms of Section 18 of the Promotion of National Unity and Reconciliation Act No. 34 of 1995: Jeffrey Theodore Benzien Applicant." Department of Justice and Constitutional Development, Republic of South Africa, http://www.justice.gov.za/trc/decisions/1999/99_benzien.html.

Apollodorus. The Library of Greek Mythology. Translated by Keith Aldrich. Coronado, 1975. Appiah, Kwame Anthony. Cosmopolitanism: Ethics in a World of Strangers. Norton, 2007. Arendt, Hannah. The Human Condition. $2^{\text {nd }}$ ed., U Chicago P, 1998.

Arestis, Philip and Malcolm Sawyer. "The Neoliberal Experience of the United Kingdom.” Saad-Filho and Johnston, pp. 199-207.

Aristotle. Poetics. The Rhetoric and the Poetics of Aristotle, translated by Ingram Bywater, Modern Library, 1984, pp. 219-266.

- - -. Politics. Translated by C.D.C. Reeve. Hackett, 1998. 
Ashcroft, Bill, et al. The Empire Writes Back: Theory and Practice in Post-Colonial Literatures. Routledge, 1989.

Badiou, Alain. Rhapsody for the Theatre. Edited and translated by Bruno Bosteels, Verso, 2013.

Bakhtin, Mikhail M. The Dialogic Imagination: Four Essays. Edited by Michael Holquist, translated by Caryl Emerson and Michael Holquist, U of Texas P, 1996.

Barsade, Sigal G. “The Ripple Effect: Emotional Contagion and Its Influence on Group Behavior.” Administrative Science Quarterly, vol. 47, no. 4, Dec. 2002, pp. 644-675. JSTOR, http://www.jstor.org/stable/3094912.

Bassnett, Susan. Translation Studies. $3^{\text {rd }}$ ed., Routledge, 2002.

Bergland, Christopher. "Can Reading A Fictional Story Make Your More Empathetic?" Psychology Today, 1 Dec. 2014, https://www.psychologytoday.com/blog/the-athletesway/201412/can-reading-fictional-story-make-you-more-empathetic.

Bernal, Martin. Black Athena: The Afroasiatic Roots of Classical Civilization. Vol. I: The Fabrication of Ancient Greece, 1785-1985, Rutgers UP, 1987.

Bhabha, Homi K. The Location of Culture. Routledge, 2001.

Billington, Michael. "Welcome to Thebes." The Guardian, 22 June 2010, http://www.theguardian.com/stage/2010/jun/23/welcome-to-thebes-live-review.

Boal, Augusto. Theatre of the Oppressed. Translated by Charles A. and Maria-Odilia Leal McBride, Pluto, 1993.

Bohannan, Paul and Philip Curtain. Africa \& Africans. $4^{\text {th }}$ ed, Waveland Press, 1995. Bourdieu, Pierre. "The Field of Cultural Production, or: The Economic World Reversed." The Field of Cultural Production: Essays on Art and Literature, edited by Randal Johnson, Columbia UP, 1993, pp. 29-73. 
Boyle, Michael Shane. "Performance and Value: The Work of Theater in Karl Marx's Critique of Political Economy.” Theatre Survey, vol. 58, no. 1, Jan. 2017, pp. 3-23.

Brecht, Bertolt. "A Short Organum for the Theatre.” Brecht on Theatre: The Development of an Aesthetic, edited and translated by John Willett, Hill and Wang, 1992, pp. 179-205.

Brown, Garrett Wallace and David Held. “Editor's Introduction.” Brown and Held, pp. 1-14.

Brown, Garrett Wallace and David Held, editors. The Cosmopolitanism Reader. Polity, 2014.

Brown, Ian, editor. The Edinburgh Companion to Scottish Drama. Edinburgh UP, 2011.

Brown, Wendy. Undoing the Demos: Neoliberalism's Stealth Revolution. Zone Books, 2015.

Bruhn, Jørgen. "Dialogizing Adaptation Studies: From One-Way Transport to a Dialogic TwoWay Process.” Bruhn et al, pp. 69-88.

Bruhn, Jørgen, et al, editors. Adaptation Studies: New Challenges, New Directions. Bloomsbury, 2013.

- -. “"There and Back Again': New Challenges and New Directions in Adaptation Studies.” Bruhn et al, pp. 1-16.

Bryant, John. "Textual Identity and Adaptive Revision: Editing Adaptation as a Fluid Text." Bruhn et al, pp. 47-67.

Budelmann, Felix. "Greek Tragedies in West African Adaptations.” Goff Classics and Colonialism, pp. 118-146.

Buffini, Moira. Welcome to Thebes. Faber \& Faber, 2010.

Bury, Liz. "Reading Literary Fiction Improves Empathy, Study Finds.” The Guardian, 8 Oct. 2013, http://www.theguardian.com/books/booksblog/2013/oct/08/literary-fictionimproves-empathy-study. 
Bush, George W. “Text of George Bush’s Speech.” The Guardian, 21 Sept. 2001, http://www.theguardian.com/world/2001/sep/21/september11.usa13.

Butler, Judith. Antigone's Claim: Kinship Between Life and Death. Columbia UP, 2000.

Carlson, Marvin. The Haunted Stage: The Theatre as Memory Machine. U Michigan P, 2006.

Carr, Marina. By The Bog of Cats. Marina Carr: Plays 1, Faber \& Faber, 1999, pp. 257-341.

- -. Phaedra Backwards. Marina Carr: Plays 3, Faber \& Faber, 2015, pp. 69-126.

Carrell, Severin. "Scottish Independence Yes Vote Would Drive Change in England, Says Writer." The Guardian, 3 Jan. 2014, http://www.theguardian.com/politics/2014/jan/03/scottish-independence-yes-vote-drivechange-england.

Cartledge, Paul. “'Deep Plays': Theatre as Process in Greek Civic Life.” Easterling, pp. 3-35.

Chiaet, Julianne. "Novel Finding: Reading Literary Fiction Improves Empathy.” Scientific American, 4 Oct. 2013, http://www.scientificamerican.com/article/novel-finding-readingliterary-fiction-improves-empathy/.

Chin, Daryl. "Interculturalism, Postmodernism, Pluralism.” Marranca and Dasgupta, pp. 83-95. Chomsky, Noam. Profit Over People: Neoliberalism and Global Order. Seven Stories Press, 1999.

Clark-Bekederemo, John Pepper. Song of a Goat. Collected Plays: 1964-1988, Howard UP, 1991, pp. 3-39.

Cohen, Joshua, editor. For Love of Country? Beacon Press, 2002.

Cole, Catherine. Performing South Africa's Truth Commission: Stages of Transition. Indiana UP, 2010.

Corbett, John. “Translated Drama in Scotland.” Ian Brown, pp. 95-106. 
Cramer, Steve. "The Traverse, 1985-97: Arnott, Clifford, Hannan, Harrower, Greig and Greenhorn.” Ian Brown, pp. 165-176.

Crawley, Peter. "By the Bog of Cats Review: A Warped Family Drama." Irish Times, 20 Aug. 2015, http://www.irishtimes.com/culture/stage/by-the-bog-of-cats-review-a-warpedfamily-drama-1.2323211.

Denith, Simon. Parody. Routledge, 2002.

Donovan, Donal and Antoin E. Murphy. The Fall of the Celtic Tiger: Ireland and the Euro Debt Crisis. Oxford UP, 2014.

Drummond, Tony. “Keep on Moving, Don't Stop Now: Anti-trespass Laws on the Island of Ireland." Hayes and Acton, pp. 37-52.

Duggan, Lisa. The Twilight of Equality?: Neoliberalism, Cultural Politics, and the Attack on Democracy. Beacon Press, 2003.

Easterling, P.E., editor. The Cambridge Companion to Greek Tragedy. Cambridge UP, 2001.

Eliot, TS. "Tradition and the Individual Talent." The Critical Tradition: Classic Texts and Contemporary Trends, $2^{\text {nd }}$ ed., edited by David H. Richter, Bedford/St. Martin's, 1998, pp. 498-503.

Elliott, Kamilla. "The Adaptation of Adaptation: A Dialogue between the Arts and Sciences." Adaptation and Cultural Appropriation: Literature, Film, and the Arts, edited by Pascal Nicklas and Oliver Lindner, De Gruyter, 2012, pp. 145-161.

- - - "Theorizing Adaptations/Adapting Theories." Bruhn et al, pp. 19-45.

Engels, Frederick. The Origin of the Family, Private Property and the State. International Publishers, 1985. 
Essin, Christin. "Unseen Labor and Backstage Choreographies: A Materialist Production History of A Chorus Line." Theatre Journal, vol. 67, no. 2, May 2015, pp. 197-212. Project Muse, doi: 10.1353/tj.2015.0048.

Euripides. Euripides: Ten Plays. Translated by Paul Roche, Signet Classic, 1998.

- - -. Fragments: Aegeus-Meleager. Edited and translated by Christopher Collard and Martin Cropp, Harvard UP, 2008.

- -. Medea. Euripides: Ten Plays, pp. 333-390.

- -. Hippolytus. Euripides: Ten Plays, pp. 45-99.

- - . The Trojan Women. Euripides: Ten Plays, pp. 457-512.

Evans, Christine. Trojan Barbie. Samuel French, 2010.

Falk, Richard. "Revisioning Cosmopolitanism.” Cohen, pp. 53-60.

Fanon, Frantz. The Wretched of the Earth. Translated by Constance Farrington, Grove Press, 1963.

Farber, Yael. Molora. Oberon, 2012.

- - -. Theatre as Witness: Three Testimonial Plays from South Africa. Oberon, 2008.

Ferguson, James. Global Shadows: Africa in the Neoliberal World Order. Duke UP, 2006.

Fischer-Lichte, Erika. Dionysus Resurrected: Performances of Euripides' The Bacchae in a Globalizing World. Wiley-Blackwell, 2014.

- - -. "Introduction: Interweaving Performance Cultures-Rethinking 'Intercultural Theatre': Toward an Experience and Theory of Performance beyond Postcolonialism.” The Politics of Interweaving Performance Cultures: Beyond Postcolonialism, edited by Erika FischerLichte et al., Routledge, 2014, pp. 1-21.

Fisher, Amanda Stuart and Yael Farber. "Interview." Farber, Theatre as Witness, pp. 19-28. 
Fischlin, Daniel and Mark Fortier. "General Introduction.” Adaptations of Shakespeare: A Critical Anthology of Plays From the Seventeenth Century to the Present, edited by Daniel Fischlin and Mark Fortier, Routledge, 2010, pp. 1-22.

Foley, Helene P. Reimagining Greek Tragedy on the American Stage. U California P, 2012. Foucault, Michel. The Birth of Biopolitics: Lectures at the Collège De France, 1978-1979. Edited by Michel Senellart, translated by Graham Burchell, Palgrave MacMillan, 2008. Freud, Sigmund. Beyond the Pleasure Principle. Translated by James Strachey. Norton, 1961. - - -. Civilization and Its Discontents. Translated by James Strachey. Norton, 1989.

- - -. "Fetishism." Sexuality and the Psychology of Love, edited by Philip Reiff, translated by Joan Riviere, Touchstone, 1997, pp. 204-209.

Friedman, Milton. Capitalism and Freedom. U Chicago P, 2002.

Genette, Gérard. Palimpsests: Literature in the Second Degree. Translated by Channa Newman and Claude Doubinsky, U Nebraska P, 1997.

Gerould, Daniel, editor. Theatre/Theory/Theatre: The Major Critical Texts from Aristotle and Zeami to Soyinka and Havel. Applause Theatre and Cinema Books, 2000.

Gibbs, James. "Antigone and her African Sisters: West African Versions of a Greek Original." Hardwick and Gillespie, pp. 54-71.

Gilroy, Paul. Postcolonial Melancholia. Columbia UP, 2005.

Girard, René. Violence and the Sacred. Translated by Patrick Gregory, Johns Hopkins UP, 1992. Goff, Barbara. “Antigone's Boat: the Colonial and the Postcolonial in Tegonni: An African Antigone by Femi Osofisan." Hardwick and Gillespie, pp. 40-53.

- -. Introduction. Goff Classics and Colonialism, pp. 1-24.

Goff, Barbara, editor. Classics and Colonialism. Duckworth, 2005. 
Goff, Barbara and Michael Simpson. Crossroads in the Black Aegean: Oedipus, Antigone, and Dramas of the African Diaspora. Oxford UP, 2007.

Goldhill, Simon. “The Audience of Athenian Tragedy.” Easterling, pp. 54-68.

Gorfinkle, Constance. “Theatre Preview.” The Patriot Ledger [Quincy, MA], 26 Mar. 2009. LexisNexis Academic, www.lexisnexis.com/hottopics/lnacademic.

“Greece’s Austerity Measures.” BBC Business News, 5 May 2010. http://www.bbc.com/news/10099143.

Greig, David. Oedipus the Visionary. Capercaillie, 2005.

Habermas, Jürgen. The Structural Transformation of the Public Sphere: An Inquiry into a Category of Bourgeois Society. Translated by Thomas Burger, MIT Press, 1991.

Hall, Edith. Introduction. Alcmaeon in Corinth, by Colin Teevan, Oberon, 2004, pp. 9-15. - - -. "The Sociology of Athenian Tragedy.” Easterling, pp. 93-126.

Hamilton, Edith. Mythology: Timeless Tales of Gods and Heroes. Grand Central, 2011.

Hard, Robin, translator and editor. Diogenes the Cynic: Sayings and Anecdotes, with Other Popular Moralists. Oxford UP, 2012.

Hardt, Michael and Antonio Negri. Commonwealth. Harvard UP, 2009.

- - -. Multitude: War and Democracy in the Age of Empire. Penguin, 2004.

Hardwick, Lorna. Reception Studies. Oxford UP, 2003.

Hardwick, Lorna and Carol Gillespie, editors. Classics in Post-Colonial Worlds. Oxford UP, 2010.

Harrison, Tony. Phaedra Brittanica. Tony Harrison: Plays 2, Faber and Faber, 2002, pp. 111207.

Harvey, David. A Brief History of Neoliberalism. Oxford UP, 2007. 
- - -. “The 'New' Imperialism: Accumulation by Dispossession.” Socialist Register, vol. 40, 2004, pp. 63-87, http://socialistregister.com/index.php/srv/article/view/5811/2707.

Harvie, Jen. Fair Play: Art, Performance, and Neoliberalism. Palgrave Macmillan, 2013.

Hayek, Friedrich A. The Road to Serfdom: Text and Documents: The Definitive Edition. Edited by Bruce Caldwell, U Chicago P, 2007.

Hayes, Micheál. "Indigenous Otherness: Some Aspects of Irish Traveller Social History.” ÉireIreland, vol. 41, no. 3\&4. Fall/Winter 2006, pp. 133-161. Project Muse, doi: 10.1353/eir.2007.006.

Hayes, Michael and Thomas Acton, editors. Travellers, Gypsies, Roma: The Demonisation of Difference. Cambridge Scholars Publishing, 2007.

H.D. Hippolytus Temporizes. Hippolytus Temporizes and Ion: Adaptations of Two Plays by Euripides, New Directions, 2003, pp. 1-138.

Hegel, Georg Wilhelm Friedrich. "The Philosophy of Fine Art.” Gerould, translated by F.P.B. Osmaston, pp. 316-326.

Hellenier, Jane. Irish Travellers: Racism and the Politics of Culture. U Toronto P, 2000.

Hodder, B.W. "Some Comments on the Origins of Traditional Markets in Africa South of the Sahara." Transactions of the Institute of British Geographers, vol. 36, June 1965, pp. 97 105. JSTOR, http://www.jstor.org/stable/621456.

Homer. The Illiad. Translated by Samuel Butler, Internet Classics Archive, http://classics.mit.edu/Homer/iliad.html.

Horace. The Art of Poetry. Gerould, translated by John Conington, pp. 70-83.

Hughes, Ted, translator. Phèdre. By Jean Racine, Farrar, Straus and Girous, 1998.

Hutcheon, Linda. A Theory of Adaptation. $2^{\text {nd }}$ ed., Routledge, 2013. 
Hutchison, Yvette. South African Performance and Archives of Memory. Manchester UP, 2013.

"Interview with the Ngqoko Cultural Group." Youtube, uploaded by Culture Project, 18 July 2011, https://www.youtube.com/watch?v=1NpMYIokaB4\&index=1\&list=FLoCvo2d5OJFF0N $\underline{\text { S_rqejCgg. }}$.

Ioannidou, Eleftheria. "Toward a National Heterotopia: Ancient Theaters and the Cultural Politics of Performing Ancient Drama in Modern Greece." Comparative Drama, vol. 44/45, no. 4/1, winter 2010/spring 2011, pp. 385-403. Project Muse, DOI:

10.1353/cdr.2010.0023.

James, Oliver. Affluenza: How to Be Successful and Stay Sane. Vermillion, 2007.

Jameson, Frederic. “The Cultural Logic of Late Capitalism.” Postmodernism, or, The Cultural Logic of Late Capitalism, Duke UP, 1992, pp. 1-54.

“Jobless Growth.” The Economist, 3 June 2010, http://www.economist.com/node/16248641.

Kane, Sarah. Phaedra's Love. Methuen, 2002.

Kant, Immanuel. Toward Perpetual Peace: and Other Writings on Politics, Peace, and History. Edited by Pauline Kleingeld, translated by David L. Colclasure, Yale UP, 2006.

Keynes, John Maynard. The General Theory of Employment, Interest, and Money. CreateSpace, 2014.

Klein, Naomi. The Shock Doctrine: The Rise of Disaster Capitalism. Picador, 2007.

Knowles, Ric. Reading the Material Theatre. Cambridge UP, 2004.

Lacan, Jacques. The Four Fundamental Concepts of Psycho-Analysis. Translated by Alan Sheridan, Norton, 1981. 
Laera, Margherita. Introduction: Return, Rewrite, Repeat: The Theatricality of Adaptation.

Theatre and Adaptation: Return, Rewrite, Repeat. Bloomsbury, 2014, pp. 1-17.

- - -. Reaching Athens: Community, Democracy and Other Mythologies in Adaptations of Greek Tragedy. Peter Lang, 2010.

Leitch, Thomas. "Vampire Adaptation." Journal of Adaptation in Film \& Performance, vol. 4, no. 1, May 2011, pp. 5-16. Academic Search Complete, DOI: 10.1386/jafp.4.1.5_1.

Ley, Graham. "Cultural Adaptation." Journal of Adaptation in Film \& Performance, vol. 8, no. 1, Mar. 2015, pp. 23-38. Academic Search Complete, DOI: 10.1386/jafp.8.1.23_1.

- - -. “Discursive Embodiment': The Theatre as Adaptation.” Journal of Adaptation in Film \& Performance, vol. 2, no. 3, Dec. 2009, pp. 201-209. Academic Search Complete, DOI: 10.1386/jafp.2.3.201/1.

“The Luck of the Irish.” The Economist, 14 Oct. 2014, http://www.economist.com/node/3261071.

Lyotard, Jean-François. The Postmodern Condition: A Report on Knowledge. Translated by Geoff Bennington and Brian Massumi, U Minnesota P, 1997.

Maguire, Matthew. Phaedra. Sun and Moon Press, 1995.

Marranca, Bonnie and Gautam Dasgupta, editors. Interculturalism and Performance: Writings from PAJ. PAJ Publications, 1991.

Martin, Randy. Financialization of Daily Life. Temple UP, 2002.

Marx, Karl. Capital: A Critique of Political Economy, Volume I. Translated by Ben Fowkes, Penguin, 1990. 
- -. Economic and Philosophic Manuscripts of 1844. Economic and Philosophic Manuscripts of 1844 and the Communist Manifesto, by Karl Marx and Friedrich Engels, translated by Martin Milligan, Prometheus, 1988, pp. 13-168.

McChesney, Robert W. Introduction. Profit Over People: Neoliberalism and Global Order, by Noam Chomsky, Seven Stories Press, 1999, pp. 7-16.

McDermott, Emily A. “Euripides' Second Thoughts.” Transactions of the American Philological Association, vol. 130, 2000, pp. 239-259. JSTOR, http://www.jstor.org/stable/284311.

McGowan, Todd. Capitalism and Desire: The Psychic Cost of Free Markets. Columbia UP, 2016.

- - -. The End of Dissatisfaction?: Jacques Lacan and the Emerging Society of Enjoyment. State University of New York P, 2004.

McMillan, Joyce. “Greek Drama Passes the Test of Time in a Scottish Makeover: Ancient Tragedies with a Modern Malaise.” The Scotsman, 20 Mar. 2000: 14. Lexis Nexis Academic, www.lexisnexis.com/hottopics/lnacademic.

McVeigh, Robbie. "Theorizing Sedentarism: The Roots of Anti-Nomadism." Gypsy Politics and Traveller Identity, edited by Thomas Acton, U Hertfordshire P, 1997, pp. 7-25.

Meany, Helen. "By the Bog of Cats Review - Spirit of Medea Haunts the Irish Wilds." The Guardian, 23 Aug. 2015, http://www.theguardian.com/stage/2015/aug/23/by-the-bog-ofcats-review-spirit-of-medea-haunts-the-irish-wilds.

“MoLoRa (Trailer).” Youtube, uploaded by Culture Project, 11 Apr. 2011, https://www.youtube.com/watch?v=F5_ctpzap8w\&index=3\&list=FLoCvo2d5OJFF0NS rqejCgg.

Morgan, Edwin, translator. Phaedra. By Jean Racine, Carcanet, 2000. 
Mulcahy, Aogán. ““Alright in Their Own Place': Policing and the Spatial Regulation of Irish Travellers." Criminology and Criminal Justice, vol. 12, no. 3 Jan. 2011, pp. 307-327. Sage, doi: $10.1177 / 1748895811431849$.

Narsiah, Sagie. "Neoliberalism and Privitisation in South Africa." GeoJournal, vol. 57, no. 1/2, 2002, pp. 29-38. JSTOR, http://www.jstor.org/stable/41147695.

Ngũgĩ wa Thiong'o. "Enactments of Power: The Politics of Performance Space.” Modern African Drama, edited by Biodun Jeyifo, Norton, 2002, pp. 434-456.

Nield, Sophie. "The Power of Speech.” Farber, Molora, pp. 9-11.

Nowlan, David. "Rich Mixture, Bleak Texture: By the Bog of Cats, Abbey Theatre.” The Irish Times 8 Oct. 1998: city ed., 14. Lexis Nexis Academic, www.lexisnexis.com/hottopics/lnacademic.

Nowra, Louis. The Golden Age. The Norton Anthology of Drama, vol. 2 The Nineteenth Century to the Present, edited by J. Ellen Gainor et al, 2009, pp. 1297-1351.

Nussbaum, Martha C. "Patriotism and Cosmopolitanism." Cohen, pp. 3-17.

Ó Riain, Seán. The Rise and Fall of Ireland's Celtic Tiger: Liberalism, Boom and Bust. Cambridge UP, 2014.

Odom, Glenn. "South African Truth and Tragedy: Yael Farber's Molora and Reconciliation Aesthetics." Comparative Literature, vol. 63, no. 1, 2011, pp. 47-63.

- - -. Yorùbá Performance, Theatre and Politics: Staging Resistance. Palgrave Macmillan, 2015. Oireachtas. "Housing (Miscellaneous Provisions) Act, 2002." Irish Statute Book, Office of the Attorney General, http://www.irishstatutebook.ie/eli/2002/act/9/enacted/en/html.

Oireachtas. "Housing (Traveller Accommodation) Act, 1998." Irish Statute Book, Office of the Attorney General, http://www.irishstatutebook.ie/eli/1998/act/33/enacted/en/html. 
O’Neill, Eugene. Desire Under the Elms. Three Plays, Vintage, 1995, pp. 1-64.

Osofisan, Femi. "Shakespeare, Africa, \& the Globe Olympiad." Shakespeare In \& Out of Africa, edited by Jane Plastow, James Curry, 2013, pp. 1-12. African Theatre 12.

- -. Tegonni: An African Antigone. Recent Outings: Two Plays, Comprising Tegonni: An African Antigone, and Many Colours Make the Thunder-King, Opon Ifa Readers, 1999, pp. 5-141.

- - -. Women of Owu. University Press PLC [Ibadan], 2006.

Plato. Republic. Translated by G.M.A. Grube, Hackett, 1992.

Pogge, Thomas. "Cosmopolitanism and Sovereignty.” Brown and Held, pp. 114-133.

Polanyi, Karl. The Great Transformation: The Political and Economic Origins of Our Time.

Beacon Press, 2001.

Putnam, Robert D. Bowling Alone: The Collapse and Revival of American Community. Simon \& Schuster, 2000.

Racine, Jean. Phèdre. Translated by Margaret Rawlings, Penguin, 1991.

Rancière, Jacques. Dissensus: On Politics and Aesthetics. Edited and translated by Steven Corcoran, Continuum, 2010.

- - -. "Does Democracy Mean Something?” Dissensus, pp. 45-61.

- - -. “Ten Theses on Politics.” Dissensus, pp. 27-44.

Rao, Sirish and Gita Wolf. Euripides' Hippolytos. Illustrated by Indrapramit Roy, Tara Publishing, 2006.

Raw, Laurence and Tony Gurr. "Bridging the Translation/Adaptation Divide: A Pedagogical View." Translation and Adaptation in Theatre and Film, edited by Katja Krebs, Routledge, 2014, pp. 162-177. 
Rebellato, Dan. Theatre \& Globalization. Palgrave Macmillan, 2009.

Reid, Trish. Theatre and Scotland. Palgrave Macmillan, 2013.

Rhys, Paul. “Greek Drama with North-East Feel.” The Journal, 21 Sept. 2004, ed. 1, pp. 2. Lexis Nexis Academic, www.lexisnexis.com/hottopics/lnacademic.

Richardson, Joanna. "Policing Gypsies and Travellers." Hayes and Acton, pp 104-115.

Roche, Paul. Introduction. Orestes Plays, pp. xiii-xxii.

Roy, Arundhati. Capitalism: A Ghost Story. Haymarket Books, 2014.

Saad-Filho, Alfredo and Deborah Johnston, editors. Neoliberalism: A Critical Reader. Pluto, 2005.

Sanders, Julie. Adaptation and Appropriation. Routledge, 2010.

Scarry, Elaine. "The Difficulty of Imagining Other People." Cohen, pp. 98-110.

Schechner, Richard. Performance Theory. Routledge, 2003.

Schneider, Geoffrey E. "Neoliberalism and Economic Justice in South Africa: Revisiting the Debate on Economic Apartheid." Review of Social Economy, vol. 61, no.1, Mar. 2003, pp. 23-50. JSTOR, http://www.jstor.org/stable/29770190.

Schneider, Rebecca. Performing Remains: Art and War in Times of Theatrical Reenactment. Routledge, 2011.

Seneca. Phaedra. Phaedra and Other Plays, translated by R. Scott Smith, Penguin, 2011, pp. 103-148.

Settis, Salvatore. The Future of the 'Classical'. Translated by Allan Cameron, Polity, 2006.

Smith, Adam. The Wealth of Nations. Elecbook Classics, 2001.

Sophocles. Antigone. Sophocles: The Complete Plays, pp. 339-387.

- -. Oedipus the King. Sophocles: The Complete Plays, pp. 209-263. 
- - -. Sophocles: The Complete Plays. Translated by Paul Roche, Signet Classics, 2001.

Soyinka, Wole. "The Last Despot and the End of Nigerian History?" An Embarrassment of Tyrannies: Twenty-Five Years of Index on Censorship, edited by W.L. Webb and Rose Bell, George Braziller, 1998, pp. 232-240.

Stiglitz, Joseph E. Globalization and Its Discontents. Norton, 2002.

Storey, Ian C. and Arlene Allan. A Guide to Ancient Greek Drama. Blackwell, 2005.

Strabo. Geographika. Vol. IV, translated by H.L. Jones, Harvard UP, 1927. Bill Thayer's Web Site, University of Chicago, http://penelope.uchicago.edu/Thayer/E/Roman/Texts/Strabo/home.html.

Surowiecki, James. The Wisdom of Crowds: Why the Many Are Smarter Than the Few. Abacus, 2006.

Taylor, Diana. The Archive and the Repertoire: Performing Cultural Memory in the Americas. Duke UP, 2003.

- - - "Transculturating Transculturation.” Marranca and Dasgupta, pp. 60-74.

Taylor, Paul. "Welcome to Thebes, National Theatre, London.” Independent, 23 June 2010, http://www.independent.co.uk/arts-entertainment/theatre-dance/reviews/welcome-tothebes-national-theatre-london-2008687.html.

Teevan, Colin. Alcmaeon in Corinth. Oberon, 2004.

Trivedi, Harish. "Western Classics, Indian Classics: Postcolonial Contestations." Hardwick and Gillespie, pp. 286-304.

Turner, Victor. From Ritual to Theatre: The Human Seriousness of Play. PAJ Publications, 1982.

Tutu, Desmond. Foreword. Farber, Theatre as Witness, pp. 7-8. 
Udeze, Edozie. "Endless Agonies of Women of Owu.” The Nation [Lagos], 26 Oct. 2014, http://thenationonlineng.net/endless-agonies-of-women-of-owu/.

Van Weyenberg, Astrid. The Politics of Adaptation: Contemporary African Drama and Greek Tragedy. Rodopi, 2013.

Venuti, Lawrence. The Translator's Invisibility: A History of Translation. Routledge, 1995.

Veltmeyer, Henry and James Petras. "Foreign Aid, Neoliberalism and US Imperialism." SaadFilho and Johnston, pp. 120-126.

Waldron, Jeremy. "What is Cosmopolitan?" Brown and Held, pp. 163-175.

Wallace, Clare. The Theatre of David Greig. Bloomsbury, 2013.

Walton, J. Michael. The Greek Sense of Theatre: Tragedy and Comedy Reviewed. $3^{\text {rd }}$ edition, Routledge, 2015.

Warner, Michael. Publics and Counterpublics. Zone, 2002.

Wertenbaker, Timberlake, translator. Hippolytus. By Euripides, Faber and Faber, 2009.

Wetmore, Kevin J., Jr. The Athenian Sun in an African Sky: Modern African Adaptations of Classical Greek Tragedy. McFarland, 2002.

- -. Black Dionysus: Greek Tragedy and African American Theatre. MacFarland, 2003.

White, Victoria. “Women Writers Finally Take Center Stage.” The Irish Times, 15 Oct. 1998, city ed., pp. 16. Lexis Nexis Academic, www.lexisnexis.com/hottopics/lnacademic.

Wickstrom, Maurya. Performance in the Blockades of Neoliberalism: Thinking the Political Anew. Palgrave Macmillan, 2012.

Williamson, Matt. "Welcome to Thebes." Socialist Review, vol. 349, July/Aug. 2010, http://socialistreview.org.uk/349/welcome-thebes. 
Wilson, Sue. "Edinburgh Festival 2000: Some Like It Scots." The Independent, 9 Aug. 2000. Lexis Nexis Academic, www.lexisnexis.com/hottopics/lnacademic.

Zaroulia, Marilena. “'Geographies of the Imagination' in David Greig's Theatre: Mobility, Globalization and European Identities.” Wallace, pp. 178-193.

Zarrilli, Phillip B. et al. Theatre Histories: An Introduction. $2^{\text {nd }}$ ed., Routledge, 2010.

Žižek, Slavoj. For They Know Not What They Do: Enjoyment as a Political Factor. Verso, 2008.

- - -. Looking Awry: An Introduction to Jacques Lacan through Popular Culture. MIT Press, 1993. 